JOÃO LUIZ BOCCIA BRANDÃO

\title{
MODELO PARA OPERAÇÃO DE SISTEMAS DE RESERVATÓRIOS COM USOS MÚLTIPLOS
}

Tese apresentada à Escola

Politécnica da Universidade de São Paulo para a obtenção do Título de Doutor em Engenharia. 
JOÃO LUIZ BOCCIA BRANDÃO

\title{
MODELO PARA OPERAÇÃO DE SISTEMAS DE RESERVATÓRIOS COM USOS MÚLTIPLOS
}

\author{
Tese apresentada à Escola \\ Politécnica da Universidade de São \\ Paulo para a obtenção do Título de \\ Doutor em Engenharia.
}

Área de concentração: Engenharia Hidráulica

Orientador:

Prof. Doutor Mario Thadeu Leme de Barros 


\section{Brandão, João Luiz Boccia}

Modelo para operação de sistemas de reservatórios com usos múltiplos / J.L.B. Brandão. -- São Paulo, 2004. $160 p$.

Tese (Doutorado) - Escola Politécnica da Universidade de São Paulo. Departamento de Engenharia Hidráulica e Sanitária.

1.Recursos hídricos 2.Sistema de reservatórios (Operação; Otimização) I.Universidade de São Paulo. Escola Politécnica. Departamento de Engenharia Hidráulica e Sanitária II.t. 
À minha esposa, Dóra, pelo seu entusiasmo, incentivo e apoio em todos os momentos. 


\section{AGRADECIMENTOS}

Aos meus pais, Agostinho e Dora, por tudo que eles representam para mim e pelo seu esforço, dedicação e incentivo ao longo da minha formação como ser humano e cidadão.

Ao amigo e orientador Prof. Dr. Mario Thadeu Leme de Barros pela condução firme e segura destes estudos e pela sua valiosa contribuição nos temas de maior relevância.

Aos professores Kokei Uehara e Rubem La Laina Porto pelo seu estímulo e apoio na iniciação das artes da Hidráulica e da Hidrologia.

Aos amigos e engenheiros João Eduardo Gonçalves Lopes e José Carlos Francisco Palos pelo companheirismo e pelos constantes e profícuos debates técnicos.

Aos colegas do DAEE, EMPLASA e THEMAG pela convivência e troca de idéias ao longo da vida profissional.

Ao CNPq (Conselho Nacional de Desenvolvimento Científico e Tecnológico) pela concessão de Bolsa de Estudos para elaboração do presente trabalho de pesquisa.

A todos aqueles que, direta ou indiretamente, contribuíram para a elaboração deste estudo. 


\section{RESUMO}

Este trabalho trata do desempenho dos sistemas de reservatórios segundo a ótica dos usos múltiplos da água. Dado que em muitos sistemas há uma competição pela água entre os diversos setores usuários, esse tipo de enfoque leva inevitavelmente à determinação de regras para partilha da água. O trabalho de pesquisa é fundamentado no uso de modelos de otimização de Programação Não-Linear criados com a ferramenta GAMS e resolvidos com o pacote de otimização MINOS, que resultou no modelo SFPLUS. O estudo de caso refere-se ao sistema de reservatórios da bacia do rio São Francisco. Numa primeira fase, o estudo enfoca a otimização do sistema segundo dois métodos para análise de usos múltiplos: o método das restrições e o método das ponderações. Na seqüência, faz-se uma exploração sobre as alternativas para tratamento dos aspectos estocásticos do problema. Os principais resultados indicam que o método as restrições é mais fácil e direto de ser aplicado. Explicita claramente os trade-offs entre os usos competitivos. Porém, permite a análise de no máximo três usos. Por outro lado, o método das ponderações permite avaliar um número maior de usos. Contudo, é necessário estabelecer a priori os coeficientes de ponderação entre os usos competitivos. Quanto à questão estocástica, para o caso estudado, verifica-se que o número de séries sintéticas geradas não influi significativamente na forma das distribuições de probabilidades das variáveis geradas pelo modelo. Contudo, essas distribuições são sensíveis ao fato de se usar séries históricas ou séries sintéticas, principalmente nos seus extremos. Além disso, o uso de séries sintéticas afeta os resultados da análise de usos múltiplos quando comparados com os resultados obtidos a partir de dados históricos. Espera-se que os resultados produzidos e as análises decorrentes venham a contribuir para aumentar o grau de entendimento sobre o tema nos meios técnicos e acadêmicos e, dessa forma, permitir que futuros desenvolvimentos nessa área possam incluir os aspectos aqui tratados. 


\begin{abstract}
This thesis deals with multiple purpose reservoir systems operation and performance. The main aspects are related to trade-off analysis by using nonlinear programming optimization models. Therefore, the SFPLUS model were developed with the GAMS software and solved by the MINOS package. The case study refers to the São Francisco river basin reservoir system. Initially, some research is done on two methods of formulating the objective function: the restriction method and the weighting method. Secondly, an alternative analysis on the stochastic aspects involving the problem is presented. According to the main results, the restriction method is an easy and direct approach, by which is possible to express the trade-offs very clearly. However, it is not possible to analyze more than three uses. On the other hand, the main advantage of the weighting method is to allow the analysis of greater number of uses. The problem with the weighting method is concerned with the weighting coefficients, which have to be defined previously. Referring to the stochastic aspects, case study results show that the number of inflow series generated synthetically does not affect significantly the probability distributions of the system performance variables calculated by optimization models. However, the shape of those distributions is sensible to the fact of using historical data or synthetic series, mainly for extreme values. Moreover, the use of synthetic series affects multiple-use results when compared to the results generated with historical data. The overall results of this research are meant to improve the knowledge and induce further discussions about the subject among the technical and academical circles.
\end{abstract}




\section{SUMÁRIO}

\section{LISTA DE FIGURAS \\ LISTA DE TABELAS \\ LISTA DE ABREVIATURAS E SIGLAS \\ LISTA DE SÍMBOLOS}

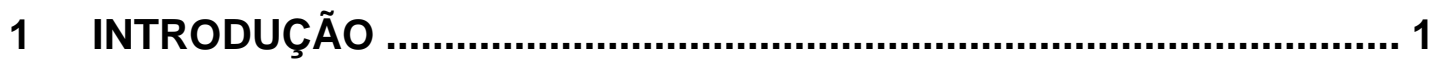

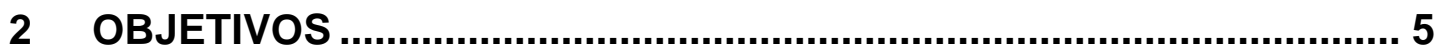

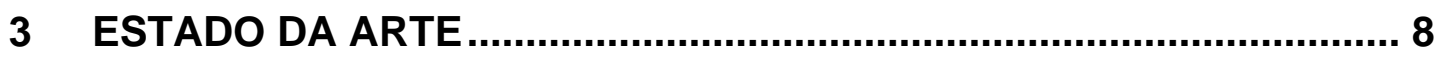

4 METODOLOGIA

4.1 Modelagem de Sistemas de Reservatórios ....................................................... 17

4.1.1 Função-Objetivo e Objetivos Múltiplos ............................................................ 18

4.1.2 Período de Análise e Passo de Cálculo dos Modelos de Operação...................... 20

4.1.3 Formulação Geral do Problema ………...................................................... 21

4.1.4 Enfoque do Problema Visando os Usos Múltiplos da Água ................................. 24

4.1.5 A Questão da Geração de Hidroeletricidade .......................................................... 31

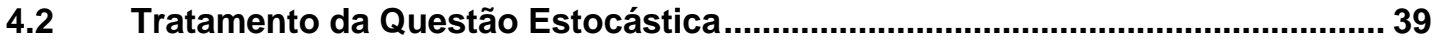

4.2.1 Modelos para Geração de Séries Sintéticas ......................................................... 40

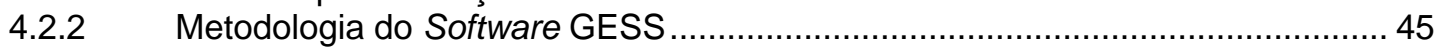

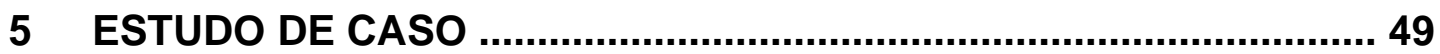

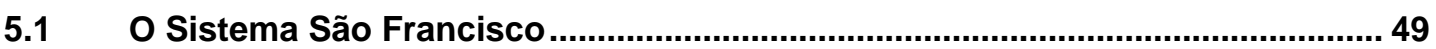

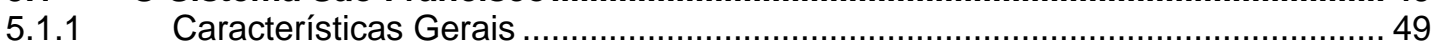

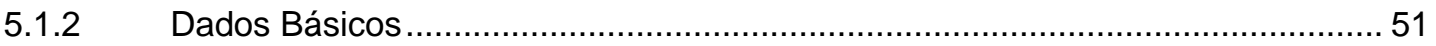

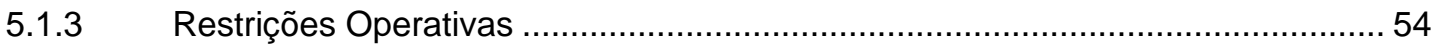

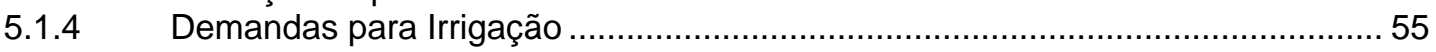

5.2 Desenvolvimento do Modelo SFPLUS …...................................................... 57

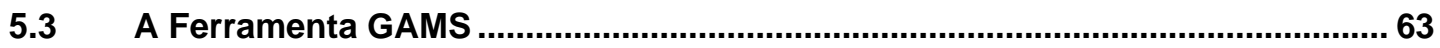

5.4 Metodologia para Solução de PNL: MINOS.....................................................66

5.4.1 Solução Ótima Global ou Local .................................................................. 67

6 ANÁLISE DA OPERAÇÃO PARA USOS MÚLTIPLOS ...................... 70

6.1 Seleção de Cenários Hidrológicos.............................................................. 70 
6.3 Análise de Usos Múltiplos: Método das Restrições............................................75

6.3.1 Análise da Influência da Transposição para o Nordeste Setentrional .................. 78

6.3.2 Análise dos Armazenamentos dos Reservatórios.............................................. 81

6.4 Análise de Usos Múltiplos: Método das Ponderações ...................................... 83

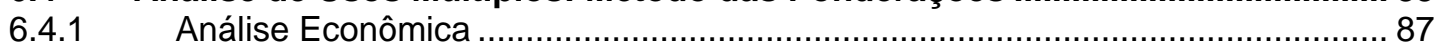

7 ANÁLISE ESTOCÁSTICA DA OPERAÇÃO DE RESERVATÓRIOS.. 90

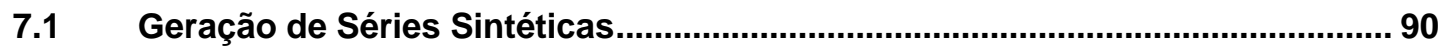

7.1.1 Resultados dos Testes de Hipótese sobre as Séries Históricas .......................... 91

7.1.2 Funções de Autocorrelação das Séries Históricas............................................... 93

7.1.3 Parâmetros dos Modelos Estocásticos ………................................................ 98

7.1.4 Análise da Correlação Espacial Anual ............................................................ 99

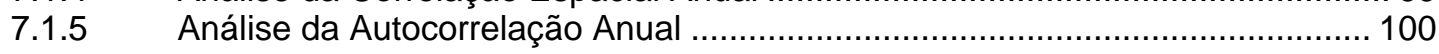

7.2 Resultados da Análise Estocástica............................................................... 101

7.2.1 Comparação com Resultados Obtidos a Partir de Séries Históricas................... 104

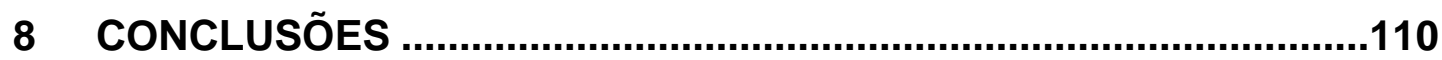

ANEXO A - SÉRIES DE VAZÕES MÉDIAS MENSAIS...........................118

ANEXO B - CÓDIGOS DE PROGRAMAÇÃO DO MODELO SFPLUS .....129

ANEXO C - RELATÓRIO DE SAÍDA DO MODELO SFPLUS ...................146

REFERÊNCIAS BIBLIOGRÁFICAS ..................................................155 


\section{LISTA DE FIGURAS}

Figura 4.1 - Representação Esquemática de um Reservatório.................... 22

Figura 4.2 - Curva de Troca entre Dois Usos Conflitantes .......................... 29

Figura 4.3 - Esquema de uma Usina Hidrelétrica..................................... 32

Figura 5.1 - Bacia do Rio São Francisco ............................................... 50

Figura 5.2 - Esquema Topológico do São Francisco ………………......... 51

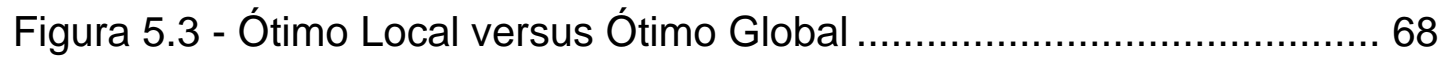

Figura 6.1 - Vazões Médias Mês a Mês no Período 1931 a 2001................ 71

Figura 6.2 - Vazões Médias Anuais no Período 1931 a 2000 - Ano

Hidrológico Out/Set........................................................ 72

Figura 6.3 - Distribuição Conjunta das Médias Móveis de 6 Anos de Vazões

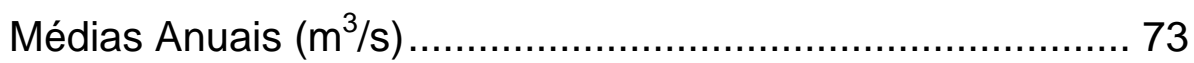

Figura 6.4 - Relação de Troca entre Usos da Água no Sistema São

Francisco - IrrigaçãoxEnergia - Curvas de Pareto 78

Figura 6.5 - Relação de Troca entre Usos da Água no Sistema São

Francisco - IrrigaçãoxEnergia - Curvas de Pareto - com

Transposição .............................................................. 80

Figura 6.6 - Trajetória de Armazenamentos - Cenário Seco ...................... 81

Figura 6.7 - Trajetória de Armazenamentos - Cenário Mediano................. 82

Figura 6.8 - Trajetória de Armazenamentos - Cenário Úmido ..................... 82

Figura 6.9 - Relação de Troca entre Usos da Água no Sistema São

Francisco - Método das Ponderações - Cenário Seco

Figura 6.10 - Relação de Troca entre Usos da Água no Sistema São

Francisco - Método das Ponderações - Cenário Mediano .... 85

Figura 6.11 - Relação de Troca entre Usos da Água no Sistema São

Francisco - Método das Ponderações - Cenário Úmido......... 85

Figura 7.1 - Função de Autocorrelação da Série Contínua - Três Marias .. 94

Figura 7.2 - Funções de Autocorrelação Periódicas - Três Marias............. 94

Figura 7.3 - Função de Autocorrelação Parcial da Série Contínua - Três

Marias

Figura 7.4 - Funções de Autocorrelação Parcial Periódicas - Três Marias. 95 
Figura 7.5 - Função de Autocorrelação da Série Contínua - Sobradinho ... 96

Figura 7.6 - Funções de Autocorrelação Periódicas - Sobradinho 96

Figura 7.7 - Função de Autocorrelação Parcial da Série Contínua Sobradinho 97

Figura 7.8 - Funções de Autocorrelação Parcial Periódicas - Sobradinho 97 Figura 7.9 - Curvas de Probabilidades Acumuladas de Energia Obtidas com Séries Sintéticas 101

Figura 7.10 - Curvas de Pareto com Séries Sintéticas. .104

Figura 7.11 - Curvas de Pareto - Comparação entre Séries Sintéticas e Série Histórica - Cenário Seco .105

Figura 7.12 - Curvas de Pareto - Comparação entre Séries Sintéticas e Série Histórica - Cenário Mediano .106

Figura 7.13 - Curvas de Pareto - Comparação entre Séries Sintéticas e Série Histórica - Cenário Úmido 106

Figura 7.14 - Curvas de Probabilidades Acumuladas de Energia Obtidas com Séries Sintéticas e Série Histórica 


\section{LISTA DE TABELAS}

Tabela 5.1 - Reservatórios/Usinas no Rio São Francisco .......................... 50

Tabela 5.2 - Dados Físicos das Usinas.................................................. 52

Tabela 5.3 - Evaporação Líquida Mensal $(\mathrm{mm})$..................................... 52

Tabela 5.4 - Polinômios Característicos das Usinas .............................. 53

Tabela 5.5- Restrições Operativas no Sistema São Francisco ................... 54

Tabela 5.6 - Volumes de Espera no Rio São Francisco - Ciclo 2002/2003 55

Tabela 5.7 - Estimativas para Área Irrigada na Bacia do Rio São Francisco (ha) 56

Tabela 5.8 - Estimativa da Vazão Média Anual Retirada para Irrigação na Bacia do Rio São Francisco $\left(\mathrm{m}^{3} / \mathrm{s}\right)$

Tabela 5.9 - Fator de Sazonalidade Médio para as Demandas na Bacia do Rio São Francisco

Tabela 6.1 - Relação de Troca entre Usos da Água no Sistema São Francisco - IrrigaçãoxEnergia 77

Tabela 6.2 - Avaliação da Redução Energética com a Transposição do São Francisco 79

Tabela 6.3 - Resultados da Análise Econômica. 88

Tabela 7.1 - Modelos PAR(p) Identificados e Parâmetros Estimados. 99

Tabela 7.2 - Correlações Espaciais Anuais das Séries Históricas e Sintéticas 100

Tabela 7.3 - Coeficientes de Autocorrelação Serial Anual (lag 1). .100

Tabela 7.4 - Teste de Kolmogorov-Smirnov para as Distribuições de Probabilidades de Energia Obtidas com Séries Sintéticas ....102

Tabela 7.5 - Probabilidades de Ocorrência de Vazões Mínimas a jusante dos Reservatórios. 103

Tabela 7.6 - Teste de Kolmogorov-Smirnov para as Distribuições de Probabilidades de Energia Obtidas com Séries Sintéticas e Série Histórica 109 


\section{LISTA DE ABREVIATURAS E SIGLAS}

ABRH - Associação Brasileira de Recursos Hídricos

ANA - Agência Nacional de Águas

AR - Autoregressivo

ARMA - Autoregressivo e de médias móveis

ARIMA - Autoregressivo e de médias móveis integrado

CEPEL - Centro de Pesquisas de Energia Elétrica

CHESF - Companhia Hidro Elétrica do São Francisco

CODEVASF - Companhia de Desenvolvimento dos Vales do São Francisco

e do Parnaíba

CT-HIDRO - Fundo Setorial de Recursos Hídricos

D. Padrão - Desvio padrão

EPUSP - Escola Politécnica da Universidade de São Paulo

EUA - Estados Unidos da América

F.O. - Função-objetivo

ITP - Itaparica

MA - Médias móveis

Máx. - máximo

Méd. - médio

Mín. - mínimo 
ONS - Operador Nacional do Sistema Elétrico

PAM - Complexo Paulo Afonso - Moxotó

PAR - Autoregressivo periódico

PARMA - Autoregressivo e de médias móveis periódico

PD - Programação dinâmica

PDDE - Programação dinâmica dual estocástica

PDE - Programação dinâmica estocástica

PL - Programação linear

PLS - Programação linear sucessiva

PNL - Programação não-linear

SIN - Sistema Interligado Nacional

SOB - Sobradinho

TMA - Três Marias

TVA - Tennessee Valley Authority

UHE - Usina hidrelétrica

UNICAMP - Universidade Estadual de Campinas

USP - Universidade de São Paulo

XIN - Xingó 


\title{
LISTA DE SÍMBOLOS
}

\author{
m: $\quad$ número de reservatórios do sistema \\ n: número de intervalos de tempo do período de análise \\ $i$ : $\quad$ índice para reservatórios $(1,2, \ldots \mathrm{m})$ \\ $t: \quad \quad$ índice para intervalos de tempo $(1,2, \ldots \mathrm{n})$ \\ $R_{i, t}: \quad \quad$ retorno ou receita do reservatório $i$ no intervalo $t$ \\ $Q D_{i, t}$ : $\quad$ vazão defluente do reservatório $i$ ao longo do intervalo de \\ tempo $t$ em $\mathrm{m}^{3} / \mathrm{s}$ \\ $Q C_{i, t}: \quad$ vazão de uso consuntivo do reservatório $i$ ao longo do intervalo \\ de tempo $t$ em $\mathrm{m}^{3} / \mathrm{s}$ \\ $Q A_{i, t}$ : $\quad$ vazão afluente ao reservatório $i$ ao longo do intervalo de tempo \\ $t$ em $\mathrm{m}^{3} / \mathrm{s}$ \\ K: $\quad$ constante para transformação das vazões em volumes \\ $V F_{i, t}: \quad$ volume do reservatório $i$ no fim do intervalo $t$ em $\mathrm{m}^{3}$ \\ $E V_{i, t}$ volume evaporado a partir do reservatório $i$ durante o intervalo $t$ \\ em $\mathrm{m}^{3}$ \\ $A m_{i, t}$ : área média da superfície do reservatório $i$ ao longo do intervalo \\ $t$ em $\mathrm{Km}^{2}$ \\ $T E_{i}$ : taxa de evaporação líquida a partir da superfície do \\ reservatório $i$ em $\mathrm{mm}$ \\ $E_{i, t}: \quad$ energia gerada pelo reservatório $i$ no intervalo $t$ em MW-médios
}


$\eta_{\mathrm{g}}, \eta_{\mathrm{t}}$ e $\eta_{\mathrm{h}}$ : rendimentos médios do gerador, turbina e circuito hidráulico, respectivamente

$H B_{i, t}$ queda bruta média mensal do reservatório $i$ no intervalo de tempo $t$ em metros

$Q T_{i, t}$ : vazão turbinada pela usina do reservatório $i$ no intervalo de tempo $t$ em $\mathrm{m}^{3} / \mathrm{s}$.

$Q V_{i, t}: \quad$ vazão vertida pelo reservatório $i$ no intervalo de tempo $t$ em $\mathrm{m}^{3} / \mathrm{s}$

$Q A B_{t}: \quad$ vazão fornecida pelo sistema para abastecimento no intervalo de tempo $t$ em $\mathrm{m}^{3} / \mathrm{s}$

$D A B_{t}: \quad$ demanda de água para abastecimento no intervalo de tempo $t$ em $\mathrm{m}^{3} / \mathrm{s}$

$N A_{i, t}$ : nível d'água do reservatório $i$ no intervalo de tempo $t$ em metros

$N M_{i, t}: \quad$ nível meta do reservatório $i$ no intervalo de tempo $t$ em metros

$Q C C_{i}: \quad \quad$ vazão para controle de cheias a jusante do reservatório $i$ em $\mathrm{m}^{3} / \mathrm{s}$

$Q I_{i, t}$ : $\quad$ vazão para irrigação fornecida pelo reservatório $i$ no intervalo de tempo $t$ em $\mathrm{m}^{3} / \mathrm{s}$

$D I_{i, t}$ : demanda para irrigação a ser atendida pelo reservatório $i$ no intervalo de tempo $t$ em $\mathrm{m}^{3} / \mathrm{s}$

$\alpha$ e $\beta$ : parâmetros de ponderação para energia e irrigação, respectivamente

$P R T_{i, t}: \quad$ produtibilidade da usina $i$ no mês $t$ em $\mathrm{MW} / \mathrm{m}^{3} / \mathrm{s}$

$P I_{i:} \quad$ potência instalada da usina $i$ em MW. 
$I D_{i}$ : $\quad$ índice de disponibilidade de máquinas da usina $i$

$N J_{i, t}$ : nível d'água a jusante do reservatório $i$ ao longo do intervalo $t$ em metros

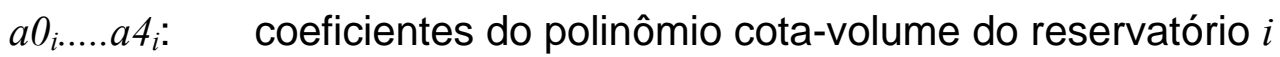

$b 0_{i} \ldots . . . b 4_{i}$ : $\quad$ coeficientes do polinômio cota-vazão defluente do reservatório $i$

$c t_{i}$ e $c v_{i}$ : respectivamente, coeficientes de ponderação para a vazão turbinada e a vazão vertida para o reservatório $i$

$T_{i, t}: \quad$ volume-meta para o reservatório $i$ ao final do intervalo $t$ em $\mathrm{m}^{3}$

DET: $\quad$ demanda total de energia elétrica em MW-médios

$P E_{t}$ : $\quad$ preço da energia elétrica no intervalo $t$

EF: $\quad$ energia firme do sistema em MW-médios

$p_{x}$ e $p_{y}$ : $\quad$ valores unitários do $\mathrm{m}^{3} / \mathrm{s}$ da água usada na irrigação $(X)$ e do MW-hora de energia $(Y)$, respectivamente

x: $\quad$ variáveis não-lineares (programa MINOS)

y: $\quad$ variáveis lineares (programa MINOS)

$c, d, b_{1}, b_{2}, l, u$ : vetores (programa MINOS)

$A_{1}, A_{2}$, e $A_{3}: \quad$ matrizes (programa MINOS)

$F(x): \quad$ função escalar contínua (programa MINOS)

$f(x): \quad$ vetor de funções contínuas (programa MINOS)

$y_{t}: \quad$ variável aleatória dos modelos estocásticos

$\mu: \quad$ valor esperado de $y_{t}$

p: $\quad$ "lag" ou ordem modelo estocástico 

$\varepsilon_{t}: \quad \quad$ variável aleatória normalmente distribuída com média zero
$\sigma_{\varepsilon}: \quad$ desvio padrão de $\varepsilon_{t}$
$\phi_{1}, \phi_{2}, \ldots, \phi_{\mathrm{p}}$ : parâmetros dos termos autoregressivos dos modelos estocásticos

$\theta_{1}, \theta_{2} \ldots, \theta_{\mathrm{q}}$ : parâmetros dos termos de médias móveis dos modelos estocásticos

M: $\quad$ indica um dado mês do ano: janeiro, fevereiro, março, etc.

$z_{M}: \quad$ variável aleatória padronizada sazonal;

$y_{M}: \quad$ vazões no mês $M$;

$\overline{y_{M}}: \quad$ média das vazões no mês $M$;

$s_{M}: \quad$ desvio padrão das vazões no mês $M$;

$P$ : $\quad$ probabilidade (teorema de Kolmogorov)

F: $\quad$ função acumulada de probabilidades populacional (teorema de Kolmogorov)

$\hat{F}$ : função acumulada de probabilidades amostral (teorema de Kolmogorov)

$F(x)$ : função acumulada de probabilidades da variável aleatória $x$ calculada a partir de uma amostra de tamanho $m$ (teste de Kolmogorov-Smirnov)

$G(x)$ : função acumulada de probabilidades da variável aleatória $x$ calculada a partir de uma amostra de tamanho $n$ (teste de Kolmogorov-Smirnov)

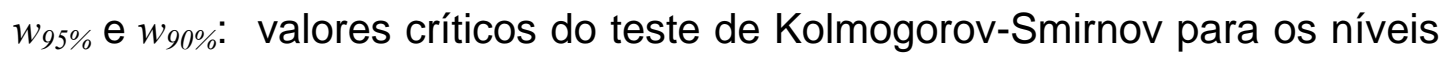
de significância de 95\% e 90\%, respectivamente 
D: estatística do teste de Kolmogorov-Smirnov

$a_{t}: \quad$ variável aleatória (ruído) independente do tempo (programa GESS)

$\sigma_{a}^{2}: \quad$ variância de $a_{t}$ (programa GESS)

$\Psi_{t}: \quad \quad$ limite inferior da distribuição de $a_{t}$ (programa GESS)

$\varphi(1), \varphi(2), \ldots \ldots . ., \varphi(6)$ : variâncias residuais (programa GESS)

$V_{t}=\left[V_{t}(1), \quad V_{t}(2), \ldots, V_{t}(k)\right]:$ conjunto de ruídos serialmente independentes (programa GESS)

$1,2, \ldots \ldots, k$ : índices dos locais onde são geradas séries sintéticas (programa GESS)

$W_{t}$ : vetor com $k$ componentes, distribuídos normalmente e independentes entre si (programa GESS)

$\operatorname{Cov}\left(V_{t}\right): \quad$ matriz de covariância de $V_{t}$ (programa GESS)

A: $\quad$ matriz definida a partir de $\operatorname{Cov}\left(V_{t}\right)($ programa GESS)

$A^{t}: \quad$ matriz transposta de $A$ (programa GESS)

C0...C4: coeficientes dos polinômios referentes a curvas-chave, curvas cota-área e curvas cota-volume

Tr: $\quad$ período de retorno em anos

\%VU: $\quad$ porcentagem do volume útil 


\section{Símbolos adotados no modelo SFPLUS:}

$u: \quad$ índice de usina hidrelétrica

$t: \quad$ índice de tempo

$t t: \quad$ índice auxiliar de tempo

em: energia média do sistema ao longo do período de análise

afl $(t, u)$ : $\quad$ vazão natural afluente ao reservatório da usina $u$ no intervalo de tempo $t$

$\operatorname{incr}(t, u)$ : $\quad$ vazão incremental natural ao reservatório da usina $u$ no intervalo de tempo $t$

qtur $(t t, u): \quad$ vazão turbinada pela usina $u$ no intervalo de tempo $t t$

qver(tt,u): $\quad$ vazão vertida pela usina $u$ no intervalo de tempo $t t$

$q d f l(t t, u): \quad$ vazão defluente total da usina $u$ no intervalo de tempo $t t$

qmon $(t t, u)$ : vazão defluente da usina imediatamente a montante da usina $u$ no intervalo de tempo $t t$

quso(tt,u): $\quad$ vazão do uso consuntivo extraída do reservatório da usina $u$ no intervalo de tempo $t t$

$v f i m(t t, u)$ : volume do reservatório da usina $u$ no final do intervalo de tempo $t t$

named(tt,u): nível d'água médio do reservatório da usina $u$ ao longo do intervalo de tempo $t t$

amed(tt,u): área média do reservatório da usina $u$ ao longo do intervalo de tempo $t t$ 
naj(t,u): $\quad$ nível d'água no canal de fuga da usina $u$ ao longo do intervalo de tempo $t$

$a 0(u) \ldots a 4(u)$ parâmetros da curva cota-volume da usina $u$

$s 0(u), s 1(u)$ parâmetros da curva área-volume da usina $u$

$b 0(u) \ldots b 4(u)$ parâmetros da curva-chave do canal de fuga da usina $u$

$h(t, u): \quad$ queda bruta da usina $u$ no intervalo de tempo $t$

$k(u): \quad \quad \quad \quad$ produtibilidade específica da usina $u$

ener $(t, u)$ : energia gerada pela usina $u$ no intervalo de tempo $t$

enertot $(t)$ : energia total gerada pelo sistema no intervalo de tempo $t$

evapo $(t t, u)$ : evaporação líquida do reservatório da usina $u$ no intervalo de tempo $t t$

$d t(t t): \quad$ número de segundos do intervalo de tempo $t t$

pi(u): $\quad$ potência instalada da usina $u$

fr $(u)$ : fator de reserva ou índice de disponibilidade de máquinas da usina $u$

c0(u), cl(u): parâmetros da equação da vazão turbinada máxima em função da queda da usina $u$

vmaxesp $(t, u)$ : volume máximo do reservatório da usina $u$ no final do intervalo de tempo $t$, considerando volumes de espera

$v \min (u)$ : $\quad$ volume mínimo do reservatório da usina $u$

v0(u): $\quad$ volume de inicial do reservatório da usina $u$

qir(tt,u): $\quad$ vazão extraída para irrigação do reservatório da usina $u$ no intervalo de tempo $t t$ 
qirtot(tt): vazão total extraída do sistema para irrigação no intervalo de tempo $t t$

um: $\quad$ vazão média extraída do sistema para irrigação ao longo do período de análise 


\section{INTRODUÇÃO}

As teorias e práticas de análise de sistemas e pesquisa operacional têm sido aplicadas à área de Recursos Hídricos a partir do término da Segunda Guerra Mundial em 1945.

Os desenvolvimentos tecnológicos decorrentes da Segunda Guerra já são bastante conhecidos, e entre eles se destacam o computador digital e as técnicas de pesquisa operacional, tais como, a programação matemática, desenvolvida para auxiliar os processos de logística militar.

Os anos do pós-guerra trouxeram uma fase de grande desenvolvimento sócio-econômico, verificado principalmente nos EUA e na Europa Ocidental, em função da necessidade de reconstrução do continente europeu. Os países que se mantiveram sob a esfera de influência dos EUA receberam grandes quantidades de recursos financeiros para serem aplicados em obras de infra-estrutura e reconstrução. Esse esforço ficou conhecido como Plano Marshal, e foi uma das formas da nação norte-americana fazer frente à expansão da então União Soviética.

De alguma forma, esses acontecimentos estão na gênese do processo de aceleração do desenvolvimento sócio-econômico que parte do mundo experimentou na segunda metade do século passado.

Como em todo processo de desenvolvimento, houve um crescimento das demandas por recursos básicos. Com a intensificação das atividades humanas e econômicas, e com o aumento das populações, o uso da água também foi sendo intensificado.

No início da década de 1960, pesquisadores da Universidade de Harvard passaram a incorporar as técnicas de análise de sistemas ao planejamento de recursos hídricos. Pode-se dizer que o chamado "Grupo de Harvard" foi pioneiro em trazer para essa área técnicas e teorias de planejamento mais 
arrojadas, cujos princípios são utilizados até hoje. Uma das obras mais importantes desse grupo foi produzida por Maass et al. (1962).

Nessa época, os EUA já contavam com uma experiência pioneira na implantação de um sistema exploração de recursos hídricos com múltiplos usos. Conhecido como TVA (Tennessee Valley Authority), esse projeto, cujas bases foram lançadas no início da década de 1930, foi uma ação do governo norte-americano no sentido de induzir o desenvolvimento regional e, assim, amenizar os efeitos deletérios da Grande Depressão que assolou o país após a crise de 1929.

Esses fatos mostram que a água, além de ser um elemento essencial à vida humana, é um fator de vital importância nos processos de desenvolvimento sócio-econômico.

No Brasil, a partir da década de 1950, também sob a influência das condições do pós-guerra, iniciou-se um processo de aceleração da industrialização. Para tanto, havia necessidade da expansão do parque gerador de energia elétrica. A opção pelo desenvolvimento da hidroeletricidade foi uma conseqüência da alta disponibilidade de potencial hidráulico próximo aos grandes centros de consumo. Foi a partir dessa época que se iniciou a construção de várias usinas de grande porte e a sua interligação, dando origem ao que se conhece hoje como Sistema Interligado Nacional (SIN).

Ao longo das décadas de 1970 e 1980, o Sistema Interligado já contava com um número expressivo de usinas hidrelétricas, o que veio a exigir um esforço do setor elétrico no sentido de desenvolver ferramentas e técnicas de modelagem de operação de reservatórios, de geração de séries sintéticas de vazões, de previsões de afluências, etc.

Com o crescimento das cidades, as demandas por água, tanto para consumo humano, como para a industria e outras atividades, aumentaram significativamente. Na década de 1970, tornou-se necessário a implantação 
de sistemas de reservatórios para captação de água para suprimento das demandas das grandes cidades. É nessa época que começa a ser construído o Sistema Cantareira para abastecimento da Grande São Paulo. Mais tarde, no início da década de 1990, é implantado o Sistema Alto Tietê com a mesma finalidade.

Dessa forma, é notório e evidente que a água vem se tornando cada vez mais um elemento de preocupação para os desafios deste milênio que se inicia. E, conseqüentemente, o equacionamento adequado da expansão e da operação dos sistemas de reservatórios de acumulação ainda deve ser alvo de pesquisas e estudos acadêmicos, que irão subsidiar as atividades de gerenciamento e planejamento dos recursos hídricos.

Atualmente, prevalece o enfoque do aproveitamento múltiplo das águas, ou seja, sistemas de exploração e controle de recursos hídricos voltados para a satisfação das necessidades humanas e das demandas vinculadas às atividades econômicas e sociais. Estas incluem o fornecimento de água para as cidades e indústrias, a irrigação, a geração de energia elétrica, a navegação, os usos relacionados com o lazer e a recreação das populações, o controle de cheias e o controle da poluição hídrica.

Nos processos de expansão e operação dos sistemas de reservatórios, que são os elementos comumente utilizados para acumulação e controle da água, é necessário que se leve em conta todos os usos concorrentes que serão beneficiados pelo sistema em questão.

Muitas vezes há conflitos, uma vez que o recurso disponível não é suficiente para atender às demandas de todos os usuários de um determinado sistema. Nesse sentido, é fundamental avaliar objetivamente a potencialidade do sistema e a sua melhor forma de operação.

É nessa função que a Economia, a análise de sistemas e a pesquisa operacional, em paralelo com o advento da "Era da Informática", têm contribuído muito para o desenvolvimento de metodologias e ferramentas 
que têm sido aplicadas aos modelos de análise de sistemas de reservatórios, dentre as quais, deve-se destacar:

- As técnicas de análise benefício-custo.

- Os modelos de simulação digital.

- Os modelos de otimização com programação matemática: linear, nãolinear, quadrática, inteira, mista (inteira-linear), etc.

- Os modelos de rede de fluxo.

- Os modelos de otimização com programação dinâmica.

- As técnicas de modelagem de bancos de dados, etc.

Algumas técnicas e metodologias obtiveram mais sucesso que outras, em função de diversos fatores, como facilidade de aplicação, adequação aos problemas, flexibilidade, abrangência, dificuldades computacionais, representatividade dos resultados, etc.

Fundamentalmente, este trabalho procura focalizar a modelagem da operação de reservatórios com usos múltiplos, buscando solucionar questões chave que contribuam para o aprimoramento dessas ferramentas de análise. 


\section{OBJETIVOS}

Atualmente, o Brasil conta com um expressivo parque gerador de hidroeletricidade formado por cerca de 100 usinas hidrelétricas. Parte dessas usinas (cerca de 60\%) conta com reservatórios de regularização de vazões intra ou pluri-anual. A operação desses reservatórios tem sido feita até o momento privilegiando o uso da água para geração da energia elétrica e em alguns casos, permitindo o uso dos reservatórios para controle de cheias. Não há ainda uma abordagem operacional desse sistema voltada para o uso múltiplo das águas.

O ONS (Operador Nacional do Sistema Elétrico) utiliza uma cadeia de modelos, dos quais se destacam o NEWAVE (CEPEL, 2002a) e o DECOMP (CEPEL, 2002b), para gerenciar a operação desses reservatórios. O objetivo dessa operação é minimizar o custo da geração térmica, atendendo à demanda de energia elétrica com uma certa garantia. Esse enfoque não leva em conta a otimização conjunta de outros usos da água como a irrigação, a navegação, o controle de cheias, as atividades de lazer e turismo e a preservação do meio ambiente. Os modelos do ONS consideram os outros usos da água na forma de restrições operativas e demandas consuntivas.

Segundo a Política Nacional de Recursos Hídricos instituída pela Lei Federal no 9.433, de 8 de Janeiro de 1997 (DAEE, 2000), o uso múltiplo das águas faz parte dos fundamentos dessa lei e está explicitado no seu artigo $1^{\circ} \mathrm{da}$ seguinte forma: .... gestão dos recursos hídricos deve sempre proporcionar o uso múltiplo das águas.

Com base nessas considerações, a proposta deste trabalho é desenvolver e explorar alternativas de modelagem de sistemas de reservatórios considerando os usos múltiplos da água. Com isso espera-se contribuir para o aprimoramento de técnicas e ferramentas que auxiliem os processos de tomada de decisão, segundo uma abordagem de gestão integrada dos recursos hídricos. 
A modelagem baseada nos aspectos da otimização econômica, vinculada à exploração sustentável dos recursos hídricos, tem como objetivo maximizar os benefícios para o conjunto de usuários da água. Nem sempre, as disponibilidades hídricas permitem a satisfação integral das demandas. Nesses casos, deve-se buscar uma solução de compromisso entre os usuários, a partir de critérios e condições que reflitam uma repartição equânime e apropriada dos recursos disponíveis.

Fundamentalmente, o que se propõe é analisar técnicas de pesquisa operacional aplicada à operação de sistemas de reservatórios com usos múltiplos, tais como a programação não-linear, e avaliar o seu desempenho na solução dos problemas propostos. Especificamente, os objetivos deste trabalho podem ser resumidos como segue:

- Avaliar o desempenho de um sistema de reservatórios e o seu comportamento quando: a) a função-objetivo inclui as variáveis de decisão correspondentes aos principais usos da água (método da ponderação) e b) a função-objetivo inclui apenas as varáveis de decisão referentes a um uso preponderante, sendo os demais usos tratados como restrições (método das restrições). Serão também analisadas as dificuldades e limitações decorrentes da aplicação de cada um dos métodos.

- Avaliar formas de tratamento das questões estocásticas relacionadas às vazões afluentes aos reservatórios e seus efeitos nos resultados da modelagem. Neste caso, será utilizado o esquema implícito, a partir da geração de um número significativo de séries sintéticas de vazões com base em modelos multivariados. A partir da aplicação das séries sintéticas ao modelo de otimização, serão calculadas estatísticas relevantes para caracterização do desempenho do sistema. Esses resultados serão também comparados aos obtidos a partir do uso das séries históricas de vazões. Dessa forma, pretende- 
se avaliar as vantagens e desvantagens quando se opta por um ou outro tipo de abordagem.

A maior parte das análises e avaliações propostas serão feitas a partir de estudo de caso, tendo por base o sistema de reservatórios existentes na bacia do rio São Francisco. Essa bacia representa um exemplo bastante peculiar para a aplicação de uma modelagem com usos múltiplos, pois ali se localizam grandes reservatórios para geração de energia elétrica, cujas usinas estão integradas ao Sistema Interligado Nacional (SIN) e, portanto, suas regras operativas são definidas pelo ONS.

Nessa bacia, já existem conflitos pelo uso da água desses reservatórios, devido ao crescimento das demandas da água para irrigação e pela possível transposição das águas do São Francisco para a região semi-árida do Nordeste setentrional. Além disso, há problemas devido à poluição das águas em certos trechos desse rio e problemas de preservação do meioambiente. 


\section{ESTADO DA ARTE}

Os estudos envolvendo a pesquisa operacional aplicada à operação de reservatórios têm freqüentado a literatura técnica especializada ao longo das últimas três décadas.

Uma importante revisão do estado da arte sobre o assunto é apresentada por Yeh (1985), onde o autor aborda vários tipos de modelagem para sistemas de reservatórios, porém o maior destaque é dado aos modelos de otimização como a Programação Linear (PL) e a Programação Dinâmica (PD) e suas variações (PD estocástica, PD incremental com aproximações sucessivas, PD com restrições probabilísticas e otimalidade progressiva). Segundo as conclusões do autor, as vantagens da PL são: a) permite resolver problemas de grande dimensão; b) existem pacotes computacionais consagrados no mercado, como por exemplo, o Simplex; c) atinge o ponto ótimo global.

Ainda segundo Yeh, a Programação Dinâmica (PD) é mais adaptável a problemas não lineares, ao caráter de tomada de decisão seqüencial e aos aspectos estocásticos, característicos da operação de reservatórios. Contudo, os problemas de dimensionalidade, ou seja, quando o número de variáveis de estado cresce de forma excepcional com o número de reservatórios, resultam em grandes dificuldades para aplicação da PD para sistemas de grande porte. Nestes casos, podem ser utilizadas técnicas como a de aproximações sucessivas, PD incremental e diferencial e outras.

Contudo, naquela época (1985) Yeh apontava problemas com modelos de Programação Não-Linear (PNL) que atualmente já estão praticamente superados. Esses problemas se referiam basicamente à reduzida capacidade de memória e baixa velocidade de processamento dos computadores de então. 
Ao longo das últimas décadas, tem-se verificado o desenvolvimento de algoritmos matemáticos eficientes para a solução dos problemas de otimização linear e não-linear. O desenvolvimento da tecnologia de rotinas eficientes de otimização, em paralelo com o desenvolvimento vertiginoso da informática, colocando no mercado computadores portáteis de elevada capacidade de processamento e de armazenamento de dados, permitiu que fossem desenvolvidos modelos mais eficientes e mais fáceis de serem processados.

Um programa que incorpora tais algoritmos é o pacote MINOS desenvolvido pelo Laboratório de Otimização de Sistemas da Universidade de Stanford, Califórnia (MURTAGH et SAUNDERS,1995). Uma importante aplicação desse programa é relatada por Tejada-Guilbert et al. (1990), que utilizaram o MINOS para Programação Não-Linear (PNL) buscando a otimização da operação do California Central Valley Project. O pacote foi utilizado para maximizar o valor econômico da energia gerada a cada mês. Esse trabalho apresenta uma discussão muito interessante a respeito da otimização de sistemas não lineares e da aplicabilidade do MINOS. Peng et Buras (2000) apresentam outra aplicação do MINOS na otimização da operação de reservatórios, enfatizando que a evolução dos computadores e dos algoritmos de pesquisa operacional têm ampliado o campo de utilização dos pacotes para solução de problemas de PL e PNL de grande porte. Os autores desenvolveram uma modelagem para sistemas de reservatórios com objetivos múltiplos, utilizando o método implícito para consideração da natureza estocástica das afluências.

Na linha da PD estocástica, Barros (1989) analisa o problema operacional de reservatórios com enfoque estocástico implícito, onde a aleatoriedade do processo é considerada a partir da geração de séries sintéticas, com base no método de Monte Carlo.

Em artigo de autoria de Kelman et al. (1990) é apresentada a técnica da programação dinâmica estocástica amostral (sampling stochastic dynamic programing) que busca modelar a complexa estrutura de correlação espacial 
e temporal das vazões afluentes aos reservatórios por meio de um número elevado de amostras de séries temporais de vazão.

Braga et al. (1991) apresenta uma aplicação da Programação Dinâmica estocástica com enfoque explícito, utilizando-se da técnica one-at-time, similar ao artifício de aproximações sucessivas, para se atenuar o "mal da dimensionalidade".

Ainda no campo da Programação Dinâmica, Reis et Chaudhry (1991) fazem uma aplicação da PD Dual Estocástica (PDDE) ao sistema de reservatórios para geração de energia elétrica do vale do rio Tietê. A formulação do problema de otimização buscou a minimização do importe de energia no horizonte de planejamento.

Outra revisão sobre a modelagem de sistemas de reservatórios é de autoria de Wurbs (1993). Nesse artigo, o autor apresenta uma análise sobre os vários tipos de modelos e suas características. Os modelos analisados são os de simulação, de otimização e os de rede de fluxo. O autor enfoca alguns aspectos que devem ser levados em conta para seleção do tipo de modelo, tais como: ambiente computacional de desenvolvimento e/ou aplicação, disponibilidade e operacionalidade de modelos generalizados, interpretação e comunicação dos resultados, propósitos dos reservatórios, série de vazões, representação do sistema, medidas de desempenho do sistema, orientação prospectiva versus orientação descritiva e algoritmos computacionais.

Em outro trabalho, Labadie (1993) descreve uma aplicação combinada entre modelos de simulação e otimização, para resolver o problema de operação de um sistema com usos conflitantes. Para tanto, o autor faz uso do software CSUDP, que é uma tentativa de se generalizar um aplicativo de Programação Dinâmica, e do modelo de rede de fluxo MODSIM.

Uma análise interessante sobre a operação de reservatórios com usos conflitantes é relatada por Martin (1995), onde o autor procura, através de 
técnicas de otimização combinadas com simulação, maximizar a produção energética ao longo do inverno, para um sistema de reservatórios no baixo rio Colorado, no Texas, sem impactar o propósito de abastecimento público.

Uma aplicação comparando otimização determinística e estocástica, é apresentada por Lund et Ferreira (1996). A metodologia é aplicada a um sistema de seis reservatórios no rio Missouri (EUA). Os resultados abordam as questões da aplicabilidade e das limitações na utilização da otimização determinística para sistemas de grande porte.

Além dos problemas relacionados com sistemas de reservatórios, mas ainda dentro da área de sistemas de recursos hídricos, tem aumentado o uso de técnicas de otimização para operação de sistemas de irrigação. Uma dessas aplicações é relatada por Dandy et Hassanli (1996), onde um modelo nãolinear é utilizado no projeto e operação de um sistema de irrigação, procurando a melhor solução para o dimensionamento dos equipamentos e a melhor forma para definição dos turnos de rega.

Outro trabalho na área de irrigação é relatado por Vedula et Kumar (1996). Os autores desenvolveram um modelo para otimização de regras operativas de um reservatório utilizado para irrigação, composto por dois módulos integrados. O módulo 1 baseado em Programação Linear tem por objetivo maximizar a produção agrícola para um dado estado do sistema. O modulo 2 é um modelo de alocação, que busca definir a política de operação do reservatório usando a Programação Dinâmica Estocástica. A metodologia foi aplicada ao reservatório de Malaprabha na Índia, cujo único propósito é fornecer água para irrigação.

Ainda com relação à operação de sistemas com usos conflitantes, Ponnambalam et Adams (1996) fazem uso da otimização estocástica, para definir curvas-guia para um sistema de reservatórios voltados para produção energética e irrigação, na Índia. Segundo os autores, os resultados obtidos, a partir da aplicação das regras operativas otimizadas a um modelo de 
simulação, indicaram um ganho no desempenho do sistema, comparando-se com dados operativos reais.

Em dois artigos, Georgakakos et al. (1997a e1997b) apresentam um modelo para otimização de sistemas hidrotérmicos de geração, combinando dois modelos de controle de processos. O primeiro, baseado em Programação Dinâmica, busca a alocação ótima de geração entre os vários grupos turbogeradores da usina. O segundo procura otimizar a operação do conjunto reservatório/usina ao longo do tempo, e é fundamentado no método de Extensão Gaussiano Linear-Quadrático. A metodologia foi aplicada a um sistema de reservatórios situados no Sul dos EUA e os resultados obtidos indicaram um ganho na avaliação dos benefícios energéticos, quando comparados com resultados produzidos por modelos de simulação.

Ainda dentro do problema de definição de regras operativas de sistemas de reservatórios, Oliveira et Loucks (1997), utilizando-se de algoritmos de busca genética, apresentam uma metodologia que procura gerar um conjunto de políticas operativas que são testadas num modelo de simulação. As políticas de melhor desempenho são selecionadas e utilizadas para se definir novas políticas, que são novamente testadas. O processo evolui até que a melhoria de desempenho cesse. O algoritmo foi aplicado a um sistema voltado à produção de energia e abastecimento público, com resultados promissores.

Francato et Barbosa (1997) analisam alguns fatores que podem influenciar os resultados de modelos de otimização de sistemas hidrelétricos. Nesse estudo, foram enfocados aspectos relacionados ao tipo da função-objetivo e à topologia do sistema. As análises foram feitas com base na modelagem dos reservatórios de Emborcação e Itumbiara localizados no rio Paranaíba.

Um pacote computacional que tem sido bastante utilizado ultimamente na área de otimização é o PCx (CZYZYK et al., 1997). Esse programa resolve problemas de PL baseado no Método do Ponto Interior, apresentado por Hillier et Lieberman (1995). Está disponível gratuitamente, e pode ser obtido através da Internet. Comparativamente ao Simplex, é um algoritmo de 
processamento mais rápido. Isso e mais o fato de ser gratuito têm encorajado a sua aplicação.

Labadie (1998) também faz uma revisão crítica sobre os principais modelos de otimização dando ênfase à otimização estocástica implícita e explícita, para tratamento da aleatoriedade dos processos vinculados à operação de reservatórios. É importante ressaltar a preocupação do autor em colocar o problema operacional como parte de um sistema de suporte à tomada de decisão, de forma a garantir a eficaz implantação das políticas oriundas dos núcleos de pesquisa e desenvolvimento. Labadie também discorre sobre o modelo de rede de fluxo MODSIM que permite incorporar aspectos otimizantes dentro de um modelo de simulação. Um dos problemas desse tipo de modelo é que ele não considera a otimização global do sistema ao longo de todos os intervalos de tempo. O modelo procura uma forma de operação otimizada dentro de cada intervalo de tempo, de forma independente.

Uma referência que relata a integração dos modelos de PL e PD à operação de sistemas de reservatórios é apresentada por Braga et al. (1998). Os autores desenvolveram o modelo SISCOM com o objetivo de otimizar a operação do sistema hidroenergético brasileiro.

Pereira et al. (1998) e Campodónico (2002) propõem o emprego da Programação Dinâmica Dual Estocástica para planejamento operacional de sistemas hidrotérmicos: o modelo PDDE. Essa metodologia é a base do modelo NEWAVE (CEPEL, 2002) utilizado pelo ONS (Operador Nacional do Sistema Elétrico) para formular o planejamento da operação do sistema de geração de energia elétrica nacional.

Philbrick Jr. et Kitanidis (1999) também analisam o problema da operação de reservatórios, comparando resultados produzidos pela otimização determinística e pela otimização estocástica, chegando à conclusão que o enfoque determinístico tende a produzir resultados pseudo-ótimos, que podem subestimar os benefícios associados aos sistemas. 
Em outro trabalho, Lund et Guzman (1999) analisam as principais características das regras operativas de sistemas de reservatórios em série e em paralelo, em função do tipo de propósito. Os autores apresentam um resumo de regras operativas conceituais para cada tipo de topologia, tendo em vista subsidiar procedimentos operacionais em tempo-real.

Uma aplicação do método do Ponto Interior à operação de reservatórios é apresentada por Seifi e Hipel (2001) que desenvolveram uma modelagem para o sistema composto pelos Grandes Lagos, na fronteira entre os EUA e o Canadá. Nesse modelo, os aspectos estocásticos são tratados através de múltiplos cenários e o problema é tratado linearmente por meio de um programa, utilizando o Método do Ponto Interior, desenvolvido pelos próprios autores. Segundo as conclusões do trabalho, o tempo de processamento do modelo cresce muito pouco com o aumento do número de reservatórios.

Lopes (2001) apresenta aplicações de PNL à operação de sistemas de usinas hidrelétricas, obtendo regras de operação conforme a topologia do sistema. Para configurações em paralelo, o autor sugere que os reservatórios com menor perda de queda por unidade de volume (fator de redução de queda) devam ser esvaziados primeiro. Para sistemas em série, os reservatórios devem ser esvaziados numa seqüência de montante para jusante, exceto quando as diferenças entre os fatores de redução de queda indicarem o contrário. Esse trabalho também enfatiza a necessidade de se considerar o tratamento não-linear quando os reservatórios são utilizados para geração de hidroeletricidade, para se obter valores corretos da produtibilidade (grandeza expressa em $\mathrm{MW} / \mathrm{m}^{3} / \mathrm{s}$ ) em função da queda.

Ros (2002) aplica o modelo SISOPT à cascata de reservatórios do rio Paranapanema, analisando os resultados obtidos a partir da otimização de várias funções-objetivo.

Barros et al. (2003) apresentam o modelo SISOPT que utiliza os pacotes MINOS e PCx (combinado com à técnica da PLS), para otimizar a operação de sistemas de geração de energia elétrica de grande porte. Esse modelo 
permite ao usuário definir várias funções-objetivo, como a minimização de vertimentos e a minimização dos desvios quadráticos em relação a uma curva-guia, entre outras.

Finalmente, o balanço que se faz dos trabalhos mais recentes, na área de otimização da operação de sistemas de reservatórios, é que grande parte das pesquisas e aplicações tem utilizado pacotes que resolvem problemas de Programação Linear e Não Linear. Esse fato está associado ao desenvolvimento dos programas e computadores que permitem soluções cada vez mais rápidas para problemas cada vez mais complexos. Além disso, muitos desses pacotes podem ser empregados em conjunto com interfaces gráficas que possibilitam um alto grau de generalização dos problemas a serem tratados e sua utilização para modelagem de diversos sistemas.

Um aspecto importante que deve ser ressaltado, é que a maioria dos trabalhos analisados enfoca a questão da operação de sistemas de reservatórios sem considerar os uso múltiplo das águas. Esse é um fator que demonstra a relevância do tema em estudo. 


\section{METODOLOGIA}

Neste item são apresentados os aspectos teóricos sobre a modelagem de sistemas de reservatórios e análise de séries temporais, voltada para a geração de séries sintéticas de vazões, que fazem parte do arcabouço metodológico para a solução de problemas de operação de sistemas de aproveitamento de recursos hídricos com usos múltiplos. A metodologia é geral, uma vez que pode ser aplicada a qualquer tipo de sistema de reservatórios de recursos hídricos.

Os grandes sistemas de reservatórios existentes no Brasil têm sido implantados primordialmente para a geração de energia elétrica. Apesar da geração de hidroeletricidade não se configurar como uso consuntivo, em alguns casos já se verificam disputas pelo uso da água desses reservatórios, ou das vazões afluentes que os alimentam. Um dos conflitos que vêm se intensificando em algumas bacias está relacionado com a retirada da água desses sistemas para irrigação de lavouras. Antigamente, essas demandas poderiam ser classificadas como marginais, uma vez que representavam uma parcela muito pequena das disponibilidades hídricas, sobretudo nas grandes bacias hidrográficas. Contudo, com a expansão da agricultura irrigada, principalmente na região Nordeste, onde as disponibilidades hídricas naturais são limitadas, as demandas por irrigação têm aumentado significativamente.

Portanto, a metodologia a ser enfocada neste trabalho pretende contribuir para o aprimoramento da modelagem de sistemas de reservatórios com usos múltiplos, explorando formas alternativas de equacionamento do problema. Atualmente, a modelagem desses sistemas utilizada pelo ONS (Operador Nacional do Sistema Elétrico) considera os demais usos da água como restrições a serem atendidas (LOPES et al., 2002). Outro aspecto que se pretende explorar é a questão do risco hidrológico associado às vazões naturais afluentes aos reservatórios. A partir da análise de cenários de 
disponibilidade hídrica, fixados com base nas séries históricas ou a partir da geração de séries sintéticas, é possível estabelecer níveis de risco para atendimento dos diversos usos da água.

\subsection{Modelagem de Sistemas de Reservatórios}

A modelagem matemática da operação de sistemas de reservatórios pode ser feita com base em modelos de simulação e/ou em modelos de otimização.

Nos modelos de simulação, os reservatórios seguem regras de operação pré-estabelecidas pelo usuário e os processos físicos são representados pelas respectivas equações que os regem. Por exemplo, o balanço hídrico nos reservatórios e as transferências entre eles são simulados pela equação da continuidade. As regras operativas, que produzem o melhor desempenho do sistema, devem ser obtidas a partir de um processo de tentativa e erro. Isso exige um grande esforço de processamento e análise de diversas alternativas, o que geralmente torna esse trabalho bastante exaustivo. Os modelos de simulação têm a vantagem de poder representar de forma mais fiel os aspectos físicos e operacionais que envolvem o problema.

Por outro lado, os modelos de otimização procuram a solução do problema de forma a atender aos objetivos estabelecidos para a operação do sistema. Isso se dá a partir da definição de uma dada função-objetivo, que é uma representação matemática dos objetivos a serem obtidos pela operação do sistema em análise. Dessa forma, os modelos de otimização buscam a maximização ou minimização da função-objetivo, cujas variáveis básicas são as chamadas variáveis de decisão. Uma vez resolvido o problema, o conjunto das variáveis de decisão obtido é a solução ótima para a operação do sistema. Todos os processos físicos e condições de contorno do problema formam o conjunto das equações de restrição, como por exemplo, os limites para as capacidades dos reservatórios, os limites para as vazões defluentes, o respeito ao balanço de massa, etc. As dificuldades associadas 
aos modelos de otimização estão relacionadas com o porte do problema, com a forma e as características das funções-objetivo e equações de restrição e com a precisão requerida para solução do problema.

\subsubsection{Função-Objetivo e Objetivos Múltiplos}

A função-objetivo é uma forma matemática de explicitar numericamente o grau de atendimento dos objetivos do sistema em análise. Esses objetivos não precisam ser expressos nas mesmas unidades e não necessariamente devem ser medidos em termos econômicos.

A modelagem para sistemas de reservatórios com usos múltiplos, via de regra, utiliza funções-objetivo relacionadas com os desempenho operativo do sistema e os benefícios gerados pela sua operação, tais como:

- Maximizacãa dos benefícios do sistema: utilizada quando a quantificação desses benefícios é direta e existem dados e informações confiáveis sobre eles. Em geral, é o caso dos usos associados aos suprimentos urbano e industrial, à irrigação, à geração de energia, ao controle de cheias e à navegação. O benefício não precisa necessariamente ser expresso em termos monetários, pode ser expresso em $\mathrm{m}^{3} / \mathrm{s}$ de água extraída do sistema ou em MWhora produzido. No caso de haver mais de um uso na função-objetivo, em geral, se adotada um critério de ponderação entre eles.

- Minimização dos desvios quadráticos em relação a uma curva guia de operação: utilizada em estudos de programação da operação ou operação em tempo-real. Serve para estabelecer diretrizes de operação de médio e curto prazos. Os usos principais associados podem ser o controle de cheias, a navegação, o controle de qualidade, recreação e lazer, etc. 
- Minimização dos desvios quadráticos em relação a uma curva de demanda: utilizada quando uma determinada demanda é conhecida a priori e o sistema é operado de forma a minimizar os desvios em relação a esse valor. Podem ser valores fixos no tempo ou sazonais. Geralmente associada aos usos vinculados à regularização de vazões como a irrigação, consumo urbano e industrial, etc.

- Minimização de vertimentos: utilizada quando há usos que necessitam armazenar água de um período chuvoso para ser utilizada num período seco. Em geral, associada à geração de energia e à regularização de vazões.

Os objetivos que envolvem com mais freqüência os processos de gestão e planejamento de sistemas de recursos hídricos são os benefícios econômicos produzidos por esses sistemas. Esses benefícios, denominados tangíveis, podem ser quantificados em nível nacional, regional ou local.

Os benefícios diretos vinculados aos principais usos da água podem ser quantificados economicamente da seguinte forma:

- Suprimento de água:

o irrigação: através do valor produção da cultura irrigada;

o industrial: através do valor agregado da água no produto final;

o urbano: pelo desenvolvimento econômico local.

- Energia elétrica: através do valor do MW-hora gerado.

- Navegação: através do frete dos produtos transportados.

- Controle de cheias: através do prejuízo evitado com o controle de cheias.

- Recreação e lazer: através da renda produzida por essas atividades. 
Do ponto de vista regional e nacional, a operação de um sistema pode gerar benefícios indiretos, tais como, o aumento do produto nacional bruto, a geração de empregos, o aumento da renda da população e a sua distribuição, etc.

A modelagem de sistemas de reservatórios com usos múltiplos ou com apenas um único uso pode ser feita com base numa formulação que inclui na função-objetivo apenas objetivos econômicos, como a maximização dos benefícios do sistema. Além desses objetivos, a análise pode incorporar objetivos de natureza ambiental ou social, como é o caso da preservação de vidas humanas, melhoria da qualidade de vida, aspectos de segurança nacional, preservação de habitats, preservação de elementos paisagísticos, etc. Nesses casos, é possível estabelecer critérios numéricos para se tentar levar em conta tais objetivos, como por exemplo, a adoção de funçõesobjetivo relacionadas a penalidades, escalas de valores, etc. Esse tipo de análise pode envolver múltiplos critérios para avaliação do desempenho do sistema, que muitas vezes são baseados em aspectos subjetivos, porém, obedecendo a uma determinada metodologia específica para solução do problema. A análise para otimização com objetivos múltiplos é abordada por diversos autores, tais como, Cohon (1978), Haimes e Allee (1982), Bogardi e Nachtnebel (1994).

\subsubsection{Período de Análise e Passo de Cálculo dos Modelos de Operação}

Segundo Wurbs (1996) a seleção do período de análise e do intervalo de tempo de cálculo dos modelos de operação de reservatórios depende de uma série de fatores, tais como, as características e os objetivos da modelagem em questão, a disponibilidade de dados de vazão e sua variabilidade temporal, as características das demandas de águas, etc.

Resumidamente, pode-se admitir que para estudos de controle de cheias é necessário adotar passo de cálculo horário ou diário e o período de análise refere-se a eventos de duração limitada (horas, dias ou semanas). No caso 
de estudos de planejamento, que envolvem usos como irrigação, geração hidrelétrica e outros usos associados ao armazenamento da água, o período de análise adotado pode ser de várias décadas ou horizontes com duração de alguns anos. Nesse caso, o passo de cálculo geralmente adotado é o mensal. Em alguns casos, passos de cálculo incluindo alguns meses, que representem períodos secos e úmidos, podem ser adequados.

O setor elétrico brasileiro adota, para o planejamento da operação, modelos que compreendem um período de análise de cinco anos com passo de cálculo mensal e modelos com horizonte de um ano, chegando a discretização semanal para o primeiro mês. O horizonte de cinco anos é adotado em função da extensão do período crítico verificado nas principais bacias hidrográficas do país que ocorreu na primeira metade da década de 1950.

Os modelos para orientar os procedimentos de operação em tempo-real, em geral, são desenvolvidos tendo em vista períodos de análise diário ou semidiário, com passo de cálculo horário ou semi-horário.

Dado que a modelagem desenvolvida neste estudo tem por objetivo abordar questões referentes ao planejamento da operação de sistemas de reservatórios, foi adotado um período de análise de seis anos e passo de cálculo mensal. Esse horizonte corresponde aproximadamente ao padrão para os estudos de planejamento da operação do setor elétrico.

\subsubsection{Formulação Geral do Problema}

A Figura 4.1 mostra de forma esquemática os elementos tratados no problema de operação de reservatórios. Nessa figura, o volume útil (diferença entre os volumes máximo e mínimo) é responsável pela regularização de vazões. 


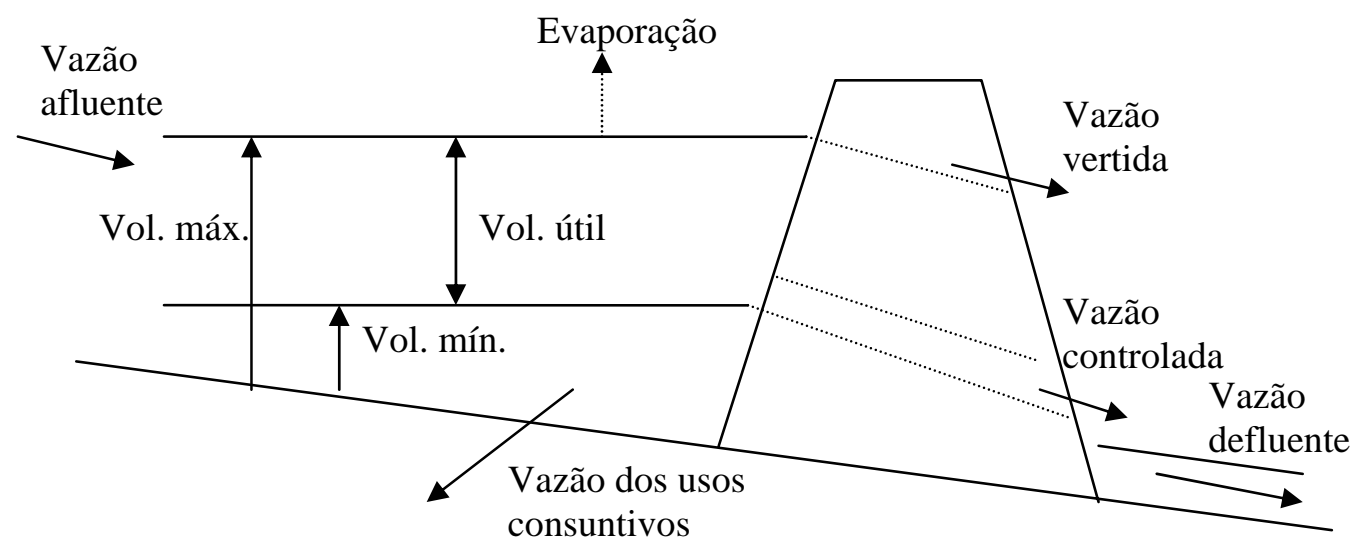

Figura 4.1 - Representação Esquemática de um Reservatório

O problema de otimização da operação de um sistema de reservatórios para usos múltiplos pode ser formulado da seguinte maneira:

Maximizar ou Minimizar: F.O. $=\sum_{i=1}^{m} \sum_{t=1}^{n} R_{i, t}$

onde

F.O.: é a função-objetivo, cujas variáveis estão associadas às decisões tomadas para a operação do sistema. Essas variáveis são chamadas de variáveis de decisão.

$R_{i, t}$ : é uma função que mede o retorno e/ou desempenho associado ao reservatório $i$ no intervalo $t$, conforme os objetivos definidos para esse reservatório.

$i=1,2, \ldots \mathrm{m}$ ( $\mathrm{m}=$ número de reservatórios do sistema)

$t=1,2, \ldots \mathrm{n}(\mathrm{n}=$ número de intervalos de tempo) 
Sujeito a:

Continuidade

$V F_{i, t}=V F_{i, t-1}+\left[Q A_{i, t}-Q D_{i, t}-Q C_{i, t}\right] . K-E V_{i, t}$

Limites de armazenamento

$V \min _{i} \leq V F_{i, t} \leq \operatorname{Vmax}_{i, m e s}$

Obs.: mês é um índice associado a cada mês do ano. Os limites máximos de armazenamento útil podem variar ao longo do ano, pois muitos reservatórios são utilizados para alocação de volumes de espera para controle de cheias.

\section{Limites de defluências}

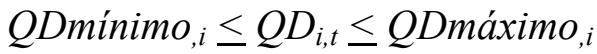

Limites para usos consuntivos

QCmínimo,$~_{i} \leq Q C_{i, t} \leq Q$ Cmáximo,$i$

$\underline{\text { Vazões não negativas }}$

$Q D_{i, t} \geq 0$

onde

$Q D_{i, t}=$ vazão defluente do reservatório $i$ ao longo do intervalo de tempo $t$ (variável de decisão) em $\mathrm{m}^{3} / \mathrm{s}$. A defluência é composta por duas parcelas: uma constituída pela vazão controlada (descargas de fundo e/ou vazões turbinadas por usinas hidrelétricas) e outra referente às vazões vertidas pelos órgãos extravasores;

$Q C_{i, t}=$ vazão do uso consuntivo do reservatório $i$ ao longo do intervalo de tempo $t$ (pode ser variável de decisão ou apenas uma restrição, depende do tipo de função-objetivo) em $\mathrm{m}^{3} / \mathrm{s}$. Vazões que não retornam ao sistema; 
$Q A_{i, t}=$ vazão afluente ao reservatório $i$ ao longo do intervalo de tempo $t$ (inclui a vazão da área de drenagem intermediária entre o reservatório $i$ e os reservatórios imediatamente a montante, mais a somatória das defluências desses reservatórios) em $\mathrm{m}^{3} / \mathrm{s}$;

$K=$ é uma constante para transformação das vazões que estão $\mathrm{em}^{3} / \mathrm{s}$ para volumes mensais em $\mathrm{m}^{3}$, ou múltiplos dessa unidade;

$V F_{i, t}=$ volume do reservatório $i$ no fim do intervalo $t$ (variável de estado) em $\mathrm{m}^{3}$, ou múltiplos dessa unidade;

$E V_{i, t}=$ volume evaporado a partir do reservatório $i$ durante o intervalo $t$ em $\mathrm{m}^{3}$, ou múltiplos dessa unidade, que é dado por:

$E V_{i, t}=A m_{i, t} * T E_{i} * c t e$.

onde

$A m_{i, t}=$ área média da superfície do reservatório $i$ ao longo do intervalo $t$, dada por: $\left[A_{i, t-1}+A_{i, t}\right] / 2$; onde $A_{i, t}$ é função do volume do reservatório $V F_{i, t}$;

$T E_{i}$ = taxa de evaporação líquida a partir da superfície do reservatório $i$ em $\mathrm{mm}$. Geralmente, adota-se um valor médio para cada mês do ano;

cte. $=$ constante de transformação de unidades.

\subsubsection{Enfoque do Problema Visando os Usos Múltiplos da Água}

Existem diversas formas de se considerar os usos múltiplos da água no problema de operação de reservatórios. Em geral, esses usos estão associados a variáveis de decisão, de estado ou a restrições. As variáveis de decisão estão incluídas direta ou indiretamente na função-objetivo. As restrições, via de regra, estão associadas a limitações impostas às variáveis de decisão ou de estado do sistema. 
A seguir são descritas as relações entre alguns dos principais usos da água e o problema de operação de reservatórios.

- Suprimento de áqua para abastecimento das cidades e indústrias e para irrigação: neste caso, o uso está associado à variável de decisão correspondente à vazão a ser extraída do sistema, para atendimento de uma dada demanda. Pode ser também um valor fixo, ou seja, uma restrição, caso outros usos sejam alvo de otimização. Um tipo de função-objetivo normalmente empregada nestes casos é a minimização dos desvios quadráticos em relação a uma curva de demanda, que pode ser expressa da seguinte forma:

$$
\operatorname{Min} \sum_{t=1}^{n}\left(Q A B_{t}-D A B_{t}\right)^{2}
$$

onde

$Q A B_{t}=$ vazão fornecida pelo sistema para abastecimento no intervalo de tempo $t$;

$D A B_{t}=$ demanda necessária de água para abastecimento no intervalo de tempo $t$.

- Geração de hidroeletricidade: está associada a duas variáveis de decisão que são a vazão turbinada e a vazão vertida. O tratamento detalhado deste uso é mostrado em 4.1.5.

- Navegação: um sistema de reservatórios onde há navegação deve ser operado de forma que os níveis d'água mínimos dos lagos e dos trechos fluviais garantam o calado para passagem das embarcações. Isso, em geral, é considerado na forma de restrições, como o valor mínimo a ser atribuído ao nível d'água e/ou à vazão mínima defluente dos reservatórios. Pode também ser necessário considerar os volumes de água que deixam os reservatórios durante os procedimentos de operação das eclusas (eclusagens). Uma forma de 
se considerar esse tipo de uso na função-objetivo é através da minimização dos desvios quadráticos em relação a uma curva-guia de operação, como segue:

$\operatorname{Min} \sum_{i=1}^{m} \sum_{t=1}^{n}\left(N A_{i, t}-N M_{i, t}\right)^{2}$

onde

$N A_{i, t}=$ nível d'água do reservatório $i$ no intervalo de tempo $t$;

$N M_{i, t}=$ nível meta do reservatório $i$ no intervalo de tempo $t$.

- Controle de cheias: via de regra, é considerado nos estudos de operação de reservatórios através da alocação de volumes de espera sazonais para acomodarem cheias de determinada magnitude e, assim, poder limitar as descargas a jusante. Na modelagem, é levado em conta através da variação sazonal dos níveis máximos de armazenamento dos reservatórios. Outra maneira de considerar esse uso nos modelos de operação é através da imposição de restrições que limitem superiormente as vazões defluentes dos reservatórios. Para ser incluído na função-objetivo, é também possível minimizar os desvios quadráticos da vazão defluente em relação a um valor limite a partir do qual começam a ocorrer problemas de inundação. Essa função-objetivo pode ser expressa da seguinte forma:

$\operatorname{Min} \sum_{i=1}^{m} \sum_{t=1}^{n}\left(Q D_{i, t}-Q C C_{i}\right)^{2}$ quando $Q D_{i, t}>Q C C_{i}$

onde

$Q D_{i, t}=$ vazão defluente do reservatório $i$ no intervalo de tempo $t$; $Q C C_{i}=$ vazão para controle de cheias a jusante do reservatório $i$. 
- Qualidade da áqua e preservação ambiental: no caso dos trechos fluviais a jusante dos reservatórios, está associada à manutenção de vazões mínimas para garantia de diluição de poluentes, níveis aceitáveis de oxigênio dissolvido, etc. No caso dos lagos, podem ser impostas restrições à variação brusca dos níveis d'água, restrições quanto a níveis d'água muito baixos, de forma a evitar áreas com baixa profundidade, restrições quanto a níveis d'água muito elevados, de forma a evitar prejuízos aos ecossistemas ribeirinhos, etc. Também devem ser evitadas situações em que seja necessário captar água em profundidades muito elevadas, onde há pouco oxigênio dissolvido. Nesse caso, para se levar em conta este uso na função-objetivo, pode-se adotar uma equação análoga à indicada na eq.(9), que busca minimizar os desvios em relação a uma curva-guia de operação. Pode-se também utilizar uma equação análoga à eq.(10), procurando minimizar os desvios quadráticos em relação a uma vazão mínima pré-estabelecida, quando a vazão defluente é inferior a essa restrição.

- Recreação e lazer: este uso está relacionado com a imposição de restrições aos níveis d'água máximos e mínimos dos reservatórios. Além disso, esses níveis não devem sofrer oscilações bruscas e/ou acentuadas. Da mesma forma que no uso anterior, pode-se adotar uma função-objetivo do tipo da eq.(9).

Uma vez que os recursos hídricos de uma dada região são limitados, o seu uso por diversos setores está, em geral, sujeito a regras de partilha. Quando as demandas de usos competitivos, como por exemplo, a produção de energia hidrelétrica e irrigação, superam as disponibilidades hídricas da região, é necessário estabelecer algumas regras para definir o montante a ser alocado a cada setor usuário. Nesses casos, a solução encontrada por um determinado modelo de otimização é uma solução de compromisso entre os dois usos, ou seja, só é possível aumentar o nível de atendimento de um uso reduzindo-se o nível de atendimento de outro uso. 
Do ponto de vista econômico, a água de um reservatório é utilizada para produzir um determinado bem ao qual pode ser associado um determinado valor monetário. Assim, a cada $\mathrm{m}^{3} / \mathrm{s}$ usado na irrigação pode-se associar um determinado valor que reflete, de certa forma, o valor da produção agrícola. O mesmo se passa com o MW-hora de energia produzida a partir de uma certa vazão turbinada e de uma dada queda.

Esses parâmetros servem de base para se estabelecer os princípios das relações de troca entre os setores usuários da água. De qualquer forma, numa situação de recursos hídricos limitados, o aumento do uso da água por um dado setor usuário irá implicar na diminuição da disponibilidade hídrica para os demais, que poderá acarretar em redução das suas receitas.

Segundo Loucks et al. (1981), a competição entre usos conflitantes, como a geração de energia e a irrigação, pode ser ilustrada pelo gráfico da Figura

\section{2.}

Nesse gráfico, é mostrada a região viável das possíveis combinações das variáveis de decisão X (vazão para irrigação) e $Y$ (produção de energia). Os limites dessa região indicam as fronteiras de possíveis alocações das variáveis $\mathrm{X}$ e $\mathrm{Y}$. A curva traçada representa o limite do recurso hídrico disponível.

A receita total obtida pelos dois setores usuários é dada por:

$R=p_{x} \cdot X+p_{y} \cdot Y$

Onde $p_{x}$ e $p_{y}$ são, respectivamente, os valores unitários da água para irrigação e do MW-hora de energia produzida.

Uma vez conhecidos os valores desses preços unitários, pode-se calcular a receita para uma determinada combinação de demandas. As retas traçadas na Figura 4.2 representam pontos onde a receita $R$ é constante. Nesse exemplo, $R_{1}<R_{2}<R_{3}$, ou seja, quanto mais as retas se aproximam da curva de 
fronteira, maior é a receita. O ponto de tangência da reta $R_{3}$, que representa a máxima receita possível, é o ponto de alocação de máximo retorno.

Para um dado sistema, é possível traçar gráficos análogos ao apresentado neste exemplo, que são as chamadas curvas de Pareto, ou curvas de soluções não-dominadas, por meio dos modelos de otimização e/ou simulação (LOUCKS et al., 1981). A partir daí podem ser avaliadas as relações de troca entre os usos e, caso se disponha de avaliações dos preços unitários do retorno de cada usuário, pode-se determinar o ponto de retorno máximo do sistema. Essa é uma solução de compromisso entre os dois usos conflitantes.

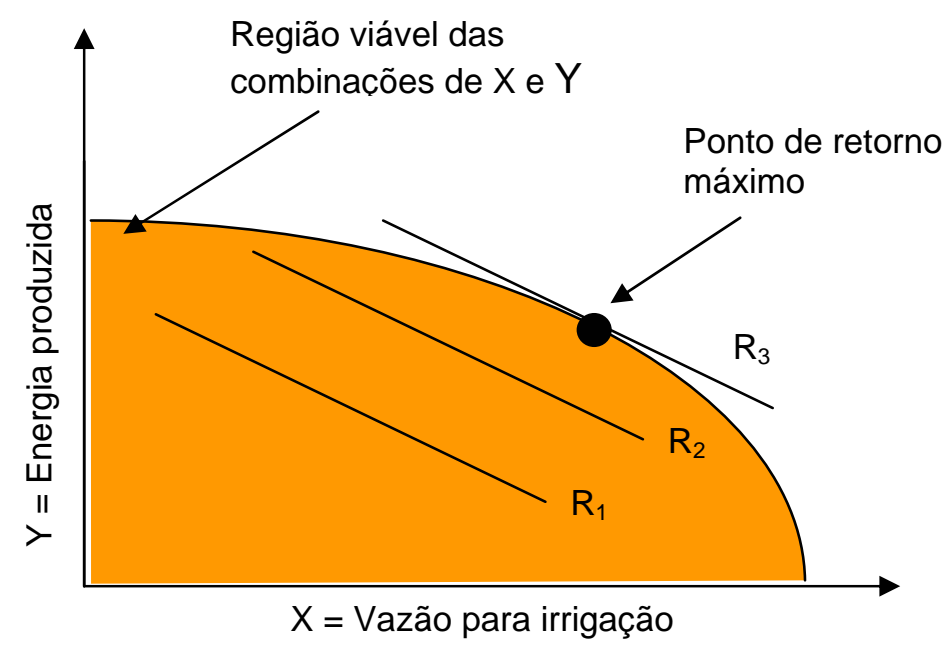

Fonte: Loucks et al.(1981)

\section{Figura 4.2 - Curva de Troca entre Dois Usos Conflitantes}

Contudo, geralmente é difícil estabelecer preços unitários adequados que expressem os valores para os usos da água. Os preços de mercado refletem o valor do benefício apenas para a população diretamente beneficiada. Os reflexos dos sistemas de recursos hídricos atingem uma população muito maior do que aquela beneficiada diretamente pelo projeto, quer pelas suas repercussões a nível local, regional e até mesmo nacional, quer pela indução de outras atividades econômicas e sociais, quer pelos aspectos estratégicos que possam estar envolvidos. 
Numa tentativa de formalizar e racionalizar a solução do problema de otimização com múltiplos usos, com base nas abordagens devidas a Loucks et al. (1981) e Lopes et al.(2002), pode-se definir dois métodos:

- Método das Ponderações: inclui na função-objetivo diversas variáveis de decisão diretas ou indiretas, como por exemplo: vazão para geração de energia, vazão para irrigação, vazão para outros usos consuntivos, níveis mínimos e máximos para navegação, recreação, conservação, etc. Neste caso, as equações de restrição consideradas são as de características físicas e de balanço hídrico. Nesse método, a função-objetivo é do tipo ponderada, onde os pesos de cada objetivo são definidos pelo decisor. Em geral, é muito difícil definir os pesos de cada objetivo em relação ao outro, uma vez que eles variam bastante de acordo com o perfil do decisor.

- Método das Restrições: inclui na função-objetivo um único uso, como por exemplo, a geração de energia e considera os outros usos nas equações de restrição. Pode-se, então, determinar as relações de troca entre os usos (curvas de Pareto), variando-se os limites de atendimento de cada objetivo em relação a outro.

Tomando-se o exemplo já apresentado para a questão da irrigação e da geração de energia, apresenta-se, a seguir, o equacionamento dos dois métodos propostos. Neste caso, busca-se a maximização da energia média e da vazão média para irrigação ao longo do período de análise.

\section{Função-objetivo segundo o método das ponderações:}

$\operatorname{Max} \cdots \alpha \cdot \sum_{i=1}^{m} \frac{\sum_{t=1}^{n} E_{i, t}}{n}+\beta \cdot \sum_{i=1}^{m} \frac{\sum_{t=1}^{n} Q I_{i, t}}{n}$ 
Função-objetivo segundo o método das restrições:

$\operatorname{Max} \cdots \sum_{i=1}^{m} \frac{\sum_{t=1}^{n} E_{i, t}}{n} \quad \operatorname{com} Q I_{i, t}=D I_{i, t}$

onde

$Q I_{i, t}=$ vazão para irrigação fornecida pelo reservatório $i$ no intervalo de tempo $t$;

$D I_{i, t}=$ demanda para irrigação a ser atendida pelo reservatório $i$ no intervalo de tempo $t$;

$E_{i, t}=$ energia gerada pela usina do reservatório $i$ no intervalo de tempo $t$;

$\alpha$ e $\beta$ são os parâmetros de ponderação para cada uso.

Os parâmetros $\alpha$ e $\beta$ são valores que expressem a importância relativa de cada um dos usos. De certa forma, indicam uma ordem de preferência de um uso sobre outro, ou seja, uma ordem hierárquica. Esses parâmetros expressam a importância relativa de cada uso considerado e são atribuídos pelos decisores e/ou gestores de forma subjetiva. Neste estudo, esses parâmetros foram alvo de análise de sensibilidade.

\subsubsection{A Questão da Geração de Hidroeletricidade}

Quando um dos usos de um dado sistema é a geração de energia elétrica, o problema de operação de reservatórios deve ser complementado pelas funções que regem a produção energética, como segue:

$E_{i, t}=9,81 \cdot 10^{-3} \cdot \eta_{\mathrm{g}} \cdot \eta_{\mathrm{t}} \cdot \eta_{\mathrm{h}} \cdot H B_{i, t \cdot} Q T_{i, t}$

onde

$9,81=$ aceleração da gravidade em $\mathrm{m} / \mathrm{s}^{2}$; 
$10^{-3}=$ peso específico da água em $\mathrm{kg} / \mathrm{cm}^{3}$;

$E_{i, t}=$ a geração média do reservatório $i$ no intervalo $t$ em MW-médios, que é a energia correspondente à potência média gerada ao longo de um mês ou de um certo número de meses;

$\eta_{\mathrm{g}}, \eta_{\mathrm{t}}$ e $\eta_{\mathrm{h}}=$ respectivamente, os rendimentos médios do gerador, turbina e circuito hidráulico (adução e restituição). Esses rendimentos, especialmente os da turbina e o do circuito hidráulico, variam com a vazão turbinada e a queda, contudo para passo de cálculo mensal podem ser considerados constantes;

$H B_{i, t}=$ queda bruta média mensal do reservatório $i$ no intervalo $t$ em metros. Diferença entre os níveis d'água do reservatório e do canal de fuga da usina; $Q T_{i, t}=$ vazão turbinada pela usina correspondente ao reservatório $i$ no intervalo $t$ em $\mathrm{m}^{3} / \mathrm{s}$.

A representação esquemática de uma usina hidrelétrica é mostrada na Figura 4.3.

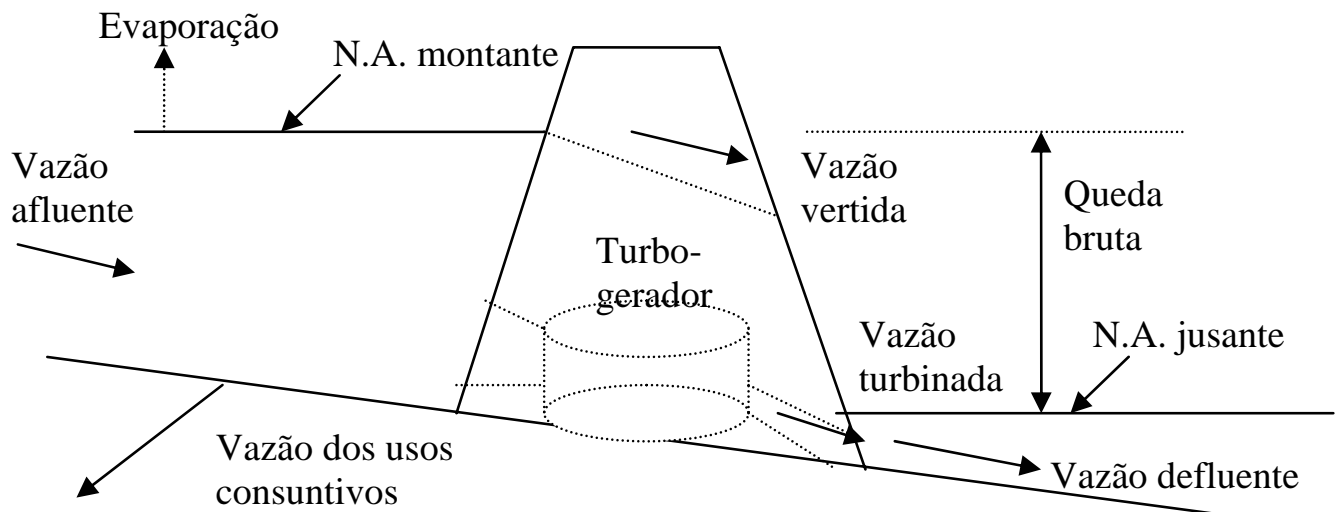

Figura 4.3 - Esquema de uma Usina Hidrelétrica 
A geração de uma usina está limitada à sua capacidade máxima de geração que é função da sua potência instalada e da disponibilidade de máquinas. Essa disponibilidade pode ser representada por um fator de redução da sua potência instalada denominado índice de disponibilidade, que engloba as paradas programadas para manutenção, as paradas forçadas e as reservas girantes, que se constituem em operações da turbina em vazio para efeito de contingências no sistema.

A vazão turbinada é limitada pelas características da turbina e pela capacidade do gerador. Para cada tipo de turbina há uma geração mínima a ser respeitada, abaixo da qual não é recomendável operá-la. Além disso, quando a queda atinge um determinado valor mínimo, a turbina não consegue produzir sua potência máxima, havendo, portanto, uma limitação superior para a vazão turbinada em função da queda. Por fim, caso haja disponibilidade suficiente de queda, há a limitação de geração imposta pela capacidade do gerador, que também se configura com um limite superior para a vazão turbinada.

Outro tipo de defluência que ocorre nas usinas hidrelétricas são os vertimentos pelo órgão extravasor do reservatório. Esses vertimentos são também variáveis de decisão, uma vez que a vazão defluente total, que é a soma das vazões turbinada e vertida, afeta a queda, em virtude da flutuação do nível d'água do canal de fuga da usina. Além disso, algumas políticas de operação podem indicar o esvaziamento prévio de determinados reservatórios, de forma a abrir espaço para afluências futuras e, dessa forma, otimizar a operação do sistema ao longo do horizonte de estudo. Assim, a vazão defluente total será dada por:

$Q D_{i, t}=Q T_{i, t}+Q V_{i, t}$

onde

$Q V_{i, t}=$ vazão vertida pela usina correspondente ao reservatório $i$ no intervalo $t$ em $\mathrm{m}^{3} / \mathrm{s}$. 
A relação entre a vazão defluente e o nível d'água do canal de fuga (nível d'água de jusante) é dada pela curva-chave da usina.

Outro aspecto que deve ser ressaltado refere-se às usinas a fio d'água. Os reservatórios dessas usinas não são operados visando regularizações intra ou plurianuais. Dessa forma, para efeito de otimizações e/ou simulações em nível mensal, não há variação volumétrica desses reservatórios. Portanto, não há variáveis de decisão associadas a essas usinas. As vazões defluentes nessas usinas são conseqüência de decisões tomadas para a operação das usinas de acumulação.

Geralmente, as funções cota-volume, cota-área e as curvas-chave, que envolvem o problema proposto, são não-lineares. No caso das funções em questão, muitas vezes, elas atendem às condições de monotonicidade, concavidade e convexidade exigidas pelos diversos algoritmos de PNL. Por exemplo, o MINOS exige que essas condições sejam satisfeitas para que tais funções sejam deriváveis dentro do seu intervalo de utilização.

Uma vez que a PD, apesar de tratar adequadamente com funções não lineares, exibe o "mal da dimensionalidade" para sistemas com vários reservatórios, ou seja, o elevado número de combinações das variáveis de estado praticamente inviabiliza a solução do problema em termos de tempo de processamento, os algoritmos de PNL são uma alternativa bastante atraente para a otimização da operação de reservatórios quando há geração hidrelétrica. Neste trabalho, optou-se pela utilização do algoritmo de PNL do pacote computacional MINOS.

Na seqüência, apresenta-se o equacionamento do problema de operação de um sistema de reservatórios voltados para a geração de energia elétrica partindo-se do equacionamento proposto em 4.1.3. Neste caso, utiliza-se uma função-objetivo que busca a maximização da energia média do sistema ao longo do período de análise. 
$\operatorname{Max} \cdots \sum_{i=1}^{m} \frac{\sum_{t=1}^{n} P R T_{i, t} \cdot Q T_{i, t}}{n}$

com

$P R T_{i, t}=9,81 \cdot 10^{-3} \cdot \eta_{\mathrm{g}} \cdot \eta_{\mathrm{t}} \cdot \eta_{\mathrm{h}} \cdot H B_{i, t}$.

onde

$P R T_{i, t}=$ produtibilidade da usina $i$ no mês $t$ em MW/m³ $/ \mathrm{s}$.

Sujeito a:

$\underline{\text { Continuidade }}$

$V F_{i, t}=V F_{i, t-1}+\left[Q A_{i, t}-Q T_{i, t}-Q V_{i, t}-Q C_{i, t}\right] \cdot K-E V_{i, t}$

Limites de armazenamento

$V \min _{i} \leq V F_{i, t} \leq V \max _{i, m e s}$

Capacidade das usinas

$P R T_{i, t} \cdot Q T_{i, t} \leq P I_{i \cdot} I D_{i}$

Limites para vazões turbinadas

QTmínimo,$i \leq Q T_{i, t} \leq$ QTmáximo $_{, i}$.

Limites para usos consuntivos

QCmínimo $_{i} \leq Q C_{i, t} \leq$ QCmáximo,$i$

Vazões não negativas

$Q T_{i, t} e Q V_{i, t} \geq 0$

onde 
$P I_{i}=$ potência instalada da usina $i$ em MW;

$I D_{i}=$ índice de disponibilidade de máquinas da usina $i$, que define a potência média disponível ao longo do tempo, descontadas as horas paradas para manutenção, programada ou forçada, e demais reservas.

As demais grandezas presentes nas eqs.(16) a (23) já foram descritas ao longo do texto.

A função-objetivo representada na eq.(16) é não-linear, pois $P R T_{i, t}$ é uma função não-linear do volume do reservatório e da vazão defluente. Para se obter o valor de $P R T_{i, t}$ deve-se calcular a queda bruta média ao longo do intervalo $t$. Essa queda é obtida pela diferença entre o nível d'água do reservatório (nível de montante) e o nível d'água de jusante (ver Figura 4.3). O nível d'água do reservatório é calculado com base na sua curva cotavolume. O nível d'água de jusante é obtido a partir da curva-chave (relação cota-descarga) do canal de fuga da usina. Ambas as relações são representadas por equações não-lineares. O setor elétrico brasileiro adota, para representação dessas funções, polinômios de até quarto grau. $O$ equacionamento a seguir demonstra claramente essas questões.

$$
\begin{aligned}
& P R T_{i, t}=9,81 \cdot 10^{-3} \cdot \eta_{\mathrm{g}} \cdot \eta_{\mathrm{t}} \cdot \eta_{\mathrm{h}} \cdot\left[\left(N A_{i, t}+N A_{i, t-1}\right) / 2-N J_{i, t}\right] \\
& N A_{i, t}=a 0_{i}+a 1_{i} \cdot V F_{i, t}+a 2_{i} \cdot V F_{i, t}^{2}+a 3_{i} \cdot V F_{i, t}^{3}+a 4_{i} \cdot V F_{i, t}^{4} \\
& N J_{i, t}=b 0_{i}+b 1_{i} \cdot Q D_{i, t}+b 2_{i} \cdot Q D_{i, t}^{2}+b 3_{i} \cdot Q D_{i, t}^{3}+b 4_{i} \cdot Q D_{i, t}^{4}
\end{aligned}
$$

onde

$N A_{i, t}=$ nível d'água do reservatório $i$ ao final do intervalo $t$;

$N J_{i, t}=$ nível d'água a jusante do reservatório $i$ ao longo do intervalo $t$;

$a 0_{i} \ldots . . . a 4_{i}=$ coeficientes do polinômio cota-volume do reservatório $i$;

$b 0_{i} \ldots . . . b 4_{i}=$ coeficientes do polinômio cota-vazão defluente do reservatório $i$. 
Segundo Lopes et al. (2002), o equacionamento da relação entre a vazão máxima turbinada $\left(\right.$ QTmáximo $\left._{i}\right)$ e a queda bruta $\left(H B_{i, t}\right)$ pode também ser representada por uma função polinomial análoga às eqs.(25) e (26).

Como visto em 4.1.3, para se obter o volume líquido evaporado mensal $\left(E V_{i, t}\right)$ é necessário calcular a área média do reservatório ao longo do intervalo $t$. O setor elétrico adota a mesma representação polinomial para a relação cota-área dos reservatórios.

$\mathrm{Na}$ resolução das equações do problema em questão, há um processo iterativo que envolve o cálculo da área média e do nível d'água médio do reservatório, ao longo do intervalo de tempo de cálculo. Para cálculo dessas variáveis, o modelo deve conhecer os valores da área e do nível d'água no início do passo de cálculo. A solução global do problema de otimização deve atender a essas condições.

Além da função-objetivo apresentada na eq.(16), que visa a maximização da produção energética, existem outras formas de função-objetivo que podem ser empregadas no caso da otimização de sistemas hidrelétricos. Barros et al. (2003) e Ros (2002) apresentam, além da função já citada, mais cinco formas alternativas para a função-objetivo, como segue:

Minimizar a perda da energia potencial armazenada:

$\operatorname{Min} \cdots \sum_{i=1}^{m} \sum_{t=1}^{n}\left(c t_{i} \cdot Q T_{i, t}+c v_{i} \cdot Q V_{i, t}\right)$

onde $c t_{i}$ e $c v_{i}$ são, respectivamente, os coeficientes de ponderação para a vazão turbinada e a vazão vertida para o reservatório $i$. Para minimizar vertimentos adota-se um valor alto para $c v_{i}$.

Minimizar a soma dos desvios quadráticos dos armazenamentos em relação a volumes-meta:

$$
\operatorname{Min} \cdots \sum_{i=1}^{m} \sum_{t=1}^{n}\left(V F_{i, t}-T_{i, t}\right)^{2}
$$


onde $T_{i, t}$ é o volume-meta para o reservatório $i$ ao final do intervalo $t$.

Minimizar a energia vertida:

$\operatorname{Min} \cdots \sum_{i=1}^{m} \sum_{t=1}^{n}\left(P R T_{i, t} \cdot Q V_{i, t}\right)$

Minimizar a complementação térmica (ou outras fontes de geração mais caras):

$\operatorname{Min} \cdots \sum_{t=1}^{n}\left[D E T-\sum_{i=1}^{m}\left(P R T_{i, t} \cdot Q T_{i, t}\right)\right]^{2}$

onde $D E T$ é a demanda total de energia elétrica a atendida, independente da fonte de geração.

Maximizar os lucros obtidos com a venda de energia secundária:

$\operatorname{Max} \cdots \sum_{t=1}^{n} P E_{t} \cdot\left(\sum_{i=1}^{m} P R T_{i, t} \cdot Q T_{i, t}-E F\right)$

esta função, sugerida por Barros et al. (2003), procura maximizar os lucros provenientes dos contratos de fornecimento de curto prazo (mercado spot). $P E_{t}$ é o preço da energia elétrica no intervalo $t$; e $E F$ é a energia firme do sistema ou o valor da energia que é usado para as contratações de longo prazo com risco de falha baixo. Assim, a diferença entre a energia produzida pelo sistema e a energia firme, que é denominada energia secundária, pode ser oferecida para contratações de curto prazo.

O tipo de função-objetivo, ou combinações destas, deve ser escolhido em função dos aspectos que se pretende analisar com o modelo de otimização. Esses aspectos, em geral, estão relacionados com questões operacionais, como a análise das trajetórias de armazenamento dos reservatórios, ou com questões relativas à potencialidade energética do sistema, como valores máximos, mínimos e médios de geração ao longo do horizonte de estudo. 


\subsection{Tratamento da Questão Estocástica}

O modelo matemático formulado em 4.1.3 tem um caráter estocástico, uma vez que as vazões naturais afluentes aos reservatórios são variáveis aleatórias associadas ao tempo, cujas realizações futuras são desconhecidas.

Portanto, o problema da operação de reservatórios é um processo de tomada de decisão sob incerteza, onde o decisor deve utilizar ferramentas adequadas de análise estatística para orientá-lo nesse processo.

Uma das formas de tratar o problema é explicitar a variável aleatória no modelo através de sua distribuição de probabilidades. Geralmente, essas distribuições são definidas "a priori” com base em dados históricos. Esse é o chamado método explícito. Este método é de difícil aplicação prática para sistemas com vários reservatórios, pois essas distribuições de probabilidades são multidimensionais, em virtude das correlações temporais e espaciais presentes nas séries de vazões naturais afluentes aos reservatórios.

Uma outra forma de se tratar o problema indiretamente é através do chamado método implícito. A partir de um modelo de geração de séries temporais, são geradas diversas seqüências de afluências naturais sintéticas, que são então utilizadas como dados de entrada para solução do problema de otimização. Os resultados obtidos são analisados estatisticamente e, a partir daí, são definidas as regras de operação do sistema, os níveis de garantia para atendimento das demandas, etc.

A seguir, são apresentados os modelos mais comumente utilizados para a análise de séries temporais e geração de séries sintéticas. 


\subsubsection{Modelos para Geração de Séries Sintéticas}

A principal hipótese para geração de séries sintéticas de vazão é que os eventos são gerados por um processo estocástico estacionário. Ou seja, os parâmetros estatísticos que caracterizam a população não devem variar ao longo do tempo.

Além disso, a teoria estatística desenvolvida para a análise de séries temporais assume a hipótese de que os resíduos aleatórios dessas séries sejam normalmente distribuídos. Para a normalização das séries, pode-se aplicar a transformação logarítmica ou a transformação de Box-Cox.

A literatura sobre a modelagem e o tratamento de séries temporais é muito vasta. Uma das referências mais importantes sobre o tema é devida a Box et Jenkins (1976). Nessa obra, os autores apresentam uma série de modelos estocásticos e definem os principais métodos e análises utilizadas para a seleção de modelos, estimação de parâmetros, transformações, testes de hipótese, etc.

Outra referência importante em hidrologia estocástica é de autoria de Salas (1993). Nessas duas referências, são descritos os modelos AR (autoregressivo) e ARMA (auto-regressivo e de médias móveis), que são os mais utilizados em hidrologia e em muitas outras áreas, com algumas adaptações, dependendo do tipo da série temporal e da aplicação da modelagem. Também existem os modelos MA (médias móveis) e ARIMA (auto-regressivo e de médias móveis, integrado).

O modelo $A R$ de ordem $p$, que normalmente é designado por $A R(p)$, é apresentado em Salas (1993) como segue:

$y_{t}=\mu+\sum_{j=1}^{p} \phi_{j}\left(y_{t-j}-\mu\right)+\varepsilon_{t}$

onde 
$y_{t}=$ variável aleatória modelada, ou seja, a série temporal em estudo;

$p=$ "lag" ou ordem do modelo, indica o grau de autocorrelação temporal;

$\varepsilon_{t}=$ ruído sem correlação - variável aleatória normalmente distribuída com média zero e desvio padrão $\sigma_{\varepsilon}$.

Uma vez que $\varepsilon_{t}$ é normalmente distribuído, $y_{t}$ também o é. Os parâmetros do modelo são $\mu, \phi_{1}, \phi_{2}$, $\phi_{p}$ e $\sigma_{\varepsilon .}$. O parâmetro $\mu$ pode ser estimado pela média da série $y_{t}$ e os demais parâmetros do modelo são estimados pelas chamadas equações de Yule-Walker. Todas essas equações são apresentadas em detalhe nas referências citadas.

Segundo Salas, os modelos AR de baixa ordem como o $A R(1)$ são largamente utilizados para modelagem de séries de hidrológicas anuais, e até mesmo sazonais, após a retirada da sazonalidade das séries originais.

Os modelos ARMA com p parâmetros auto-regressivos e q parâmetros de médias móveis, conhecidos como ARMA $(p, q)$, são apresentados pelo autor, conforme o seguinte equacionamento:

$y_{t}=\mu+\sum_{j=1}^{p} \phi\left(y_{t-1}-\mu\right)+\varepsilon_{t}-\sum_{j=1}^{q} \theta_{j} \varepsilon_{t-j}$

O último termo à direita na eq.(33) é o termo de médias móveis. Os demais termos correspondem à parcela auto-regressiva do modelo, conforme indicado na eq.(32). Os parâmetros de médias móveis são $\theta_{1}, \theta_{2}, \ldots \ldots \ldots . ., \theta_{q}$. Um modelo apenas de médias móveis MA(q) apresenta apenas os termos correspondentes, ou seja, o último termo da eq.(33).

Da mesma forma como ocorre com os modelos AR de baixa ordem, os modelos ARMA também são freqüentemente utilizados para modelagem de séries hidrológicas anuais e sazonais. No caso das séries sazonais (mensais ou semanais) deve-se retirar os efeitos da sazonalidade, que é uma das formas de não estacionariedade. 
As equações para estimativas dos parâmetros dos modelos ARMA são também apresentadas em Salas (1993).

Como já visto, a hipótese básica e fundamental para a aplicação de modelos estocásticos é que os processos modelados sejam estacionários. As séries hidrológicas são estacionárias caso não apresentem tendência, shifts (alterações bruscas nos parâmetros estatísticos) ou periodicidade. As séries de vazões médias anuais, desde que não apresentem tendência ou shifts, são, em geral, estacionárias. Por outro lado, as séries de vazões médias mensais, devido ao caráter sazonal do ciclo hidrológico, são periódicas e, portanto, não estacionárias por natureza.

A técnica para a remoção da sazonalidade na média e na variância das séries, conhecida como padronização, é dada por:

$$
z_{M}=\frac{y_{M}-\overline{y_{M}}}{s_{M}}
$$

onde

$M=$ indica um dado mês do ano: janeiro, fevereiro, março, etc.;

$z_{M}=$ variável aleatória padronizada sazonal;

$y_{M}=$ vazões no mês $M$;

$\overline{y_{M}}=$ média das vazões no mês $M$;

$s_{M}=$ desvio padrão das vazões no mês $M$.

Uma forma de se tratar com séries sazonais é aplicar os chamados modelos periódicos PAR e PARMA, descritos também em Salas (1993), onde são consideradas as estruturas de correlação mês a mês e não seqüencialmente, como nos modelos AR e ARMA.

Outra forma é a aplicação de modelos com base em séries anuais e posterior desagregação a nível mensal. O autor descreve, entre outros 
métodos, o de Valencia et Schaake (1973), também aplicado por Barros (1984). Esse método permite a desagregação de um vetor de $n$ séries anuais correspondentes a $n$ locais diferentes, em séries mensais. Dessa forma, é um método adequado para a geração multivairada de vazões, ou seja, quando a vazão num determinado ponto exibe algum nível de correlação com vazões em outros pontos de uma bacia ou de um sistema. É um modelo baseado na preservação das correlações temporais e cruzadas.

Os modelos AR e ARMA mutivariados são muito similares aos utilizados para séries isoladas. Eles seguem os mesmos princípios e estão apoiados nas mesmas hipóteses de normalidade e estacionariedade. A notação escalar é substituída por vetores e matrizes, referentes a médias, variâncias e covariâncias.

A seleção de um determinado tipo de modelo para geração de séries sintéticas ou para a previsão de vazões depende das características das séries a serem modeladas. Em geral, devem ser analisadas as questões de estacionariedade e normalidade, as estruturas de autocorrelação temporal, as correlações espaciais, etc. A partir daí, são estimados os parâmetros do modelo e, então, são geradas as séries em número e extensão adequadas ao estudo.

Conforme definido em 4.1.2, o período de análise adotado neste estudo é de seis anos.

Para se definir o número de séries a serem geradas, Peng et Buras (2000) propõem que sejam gerados dois conjuntos de dados com o mesmo número de séries em cada um deles. Após o processamento do modelo de otimização considerando cada conjunto de dados, são calculadas as distribuições de probabilidades das variáveis de decisão resultantes da aplicação de cada conjunto e comparadas as suas formas. Na medida em que as formas dessas duas distribuições não são significantemente diferentes, não há benefício em se aumentar o número de séries geradas. 
Salas (1993) indica um critério baseado no teorema de Kolmogorov. Nesse caso, o interesse na geração das séries sintéticas é representar com precisão a distribuição de probabilidades de alguma variável aleatória, que no caso da modelagem de reservatórios são as variáveis de decisão resultantes do modelo de otimização. Segundo esse critério, $P(\max |\hat{F}-F|<1,36 / \sqrt{m})=0,95$ indica que a diferença máxima absoluta entre as distribuições amostral $(\hat{F})$ e populacional $(F)$ é menor que 1,36/ $\sqrt{m}$ com probabilidade igual a 95\%. Para o caso de se utilizar 1000 séries sintéticas $(m=1000)$, o erro na estimativa da distribuição de probabilidades é menor que 0,043 com probabilidade igual a 0,95.

Conover (1980) apresenta uma formulação para o teste de KolmogorovSmirnov para testar se duas amostras independentes e com tamanhos $m$ e $n$ seguem a mesma distribuição cumulativa de probabilidades. Nesse caso, é calculada a estatística $D=\max |F(x)-G(x)|$ e comparada com os valores críticos do teste que, para os níveis de significância de 95\% e 90\%, são dados por:

$w_{95 \%}=1,36 \sqrt{\frac{(m+n)}{m n}}$

$w_{90 \%}=1,22 \sqrt{\frac{(m+n)}{m n}}$

Os cálculos que envolvem a análise de séries temporais e todas as estimativas associadas são muitas vezes complexos e de difícil execução. Atualmente, dispõe-se de diversos pacotes computacionais que são ferramentais fundamentais e imprescindíveis para se aplicar a modelagem estocástica. Entre esses programas pode-se mencionar o SAMS (Stochastic Analysis, Modeling and Simulation) de Salas et al. (2000), desenvolvido pela Colorado State University em conjunto com o Bureau of Reclamation dos EUA, o LAST (LANE et FREVERT, 1990) também desenvolvido pelo Bureau of Reclamation e o GESS, desenvolvido pela Kelman Consultoria (2001a). 
Para realização deste estudo foi utilizado o pacote GESS (Gerador Estocástico de Séries Sintéticas), cuja licença é de propriedade do Laboratório de Sistemas de Suporte à Decisão da Escola Politécnica da USP, com anuência da Kelman Consultoria. Na seqüência, apresenta-se um resumo da metodologia utilizada por esse software, naquilo em que atende à geração de séries sintéticas para utilização neste estudo.

\subsubsection{Metodologia do Software GESS}

Os modelos estocásticos foram desenvolvidos com base na preservação das características estatísticas das séries históricas, assumindo que o valor atual de uma dada variável é a soma de um termo determinístico, que depende dos valores verificados no passado, e de uma variável aleatória $a_{t}$, independente do tempo, conhecida como ruído. Esses modelos procuram preservar tanto médias como variâncias, bem como correlações, tanto temporais como espaciais.

Uma questão importante, quando a geração de séries de vazões visa estudos de modelagem de reservatórios com regularização plurianual, é a preservação da variância e dos coeficientes de autocorrelação anuais. Segundo os autores do GESS, Maceira (1989 apud Kelman Consultoria, 2001b) demonstrou que séries geradas por modelos auto-regressivos periódicos (PAR) atendem essa exigência.

O GESS produz séries sintéticas com base no modelo tipo PAR, com periodicidade semanal ou mensal. Para este estudo foi utilizado o intervalo temporal mensal, pois é o passo de cálculo do modelo de otimização e o intervalo temporal das séries históricas.

A questão da não normalidade das séries não é tratada no GESS por meio das transformações clássicas (logarítmica ou Box-Cox), pois o uso de tais transformações resulta em funções não lineares entre a vazão atual e as vazões passadas. A linearidade dessas funções é uma hipótese básica para 
a utilização do algoritmo de Programação Dinâmica Dual Estocástica (PDDE) que foi desenvolvido pelos mesmos autores, e que é uma técnica que visa atenuar os problemas de dimensionalidade da PD.

Segundo os autores do GESS, o uso das transformações (log e Box-Cox) evita a geração de vazões negativas, contudo a geração de valores não negativos pode ser garantida fazendo-se com que o limite inferior da distribuição de probabilidades de $a_{t}$, para cada $t$, seja dependente das condições passadas.

Assumindo-se que $a_{t}$ tem um limite inferior, o GESS adota para $a_{t}$ uma distribuição Log-Normal de três parâmetros com média zero, variância $\sigma_{a}^{2} \mathrm{e}$ limite inferior $\Psi_{t}$.

Para selecionar a ordem p dos modelos PAR (é adotado um modelo para cada mês do ano, no caso de geração mensal), o GESS adota o seguinte critério:

a) Admite p entre 1 a 6, ou seja, a ordem máxima do modelo é 6 .

b) Estima as variâncias residuais $\varphi(1), \varphi(2), \ldots \ldots ., \varphi(6)$.

c) Aceita $p=6$ caso a diminuição da variância residual, quando se passa de $p=5$ para $p=6$, seja significativa. Ou mais especificamente, adota $\mathrm{p}=6$ quando $\varphi(6) / \varphi(5)<0,975$, caso contrário, $o$ teste continua entre $p=5$ e $p=4$, e assim sucessivamente.

Para estimativa dos parâmetros amostrais, médias e variâncias, o GESS adota o método dos momentos.

Com relação à estimativa dos parâmetros dos modelos PAR, é utilizado o Método dos Mínimos Quadrados Ordinários referenciado pelos autores do GESS através da publicação devida a Johnston (1963 apud Kelman Consultoria, 2001b). 
O GESS executa automaticamente uma série de testes para o usuário avaliar a validade das diversas hipóteses assumidas ao longo do processo de modelagem estocástica. Esses testes, descritos em detalhe no Manual do software, são os seguintes:

- Teste de Anderson e Teste de Porte-Manteau: para verificação da independência dos resíduos transformados da série integral.

- Teste de Ljung-Box: para verificação da independência dos resíduos transformados das séries sazonais.

- Teste de correlação de Filliben: para verificação da normalidade dos resíduos transformados.

- Teste de Mann-Kendall e Teste de Smirnov: para verificação da homogeneidade da série histórica.

- Teste de Grubbs e Beck: para verificação de outliers na série histórica.

Para tratamento da geração multivariada, o software busca preservar a matriz de correlação contemporânea das vazões anuais entre os diversos locais considerados para geração estocástica.

Segundo os autores, ....apenas se observa um relacionamento contemporâneo, ou seja, os gráficos da correlações cruzadas indicam valores significativos apenas para lag 0 .

A modelagem espacial é feita da seguinte forma:

$V_{t}=A \cdot W_{t}$

onde

$V_{t}=\left[V_{t}(1), \quad V_{t}(2), \ldots \ldots \ldots, V_{t}(k)\right] \quad$ é o conjunto de ruídos serialmente independentes, onde os índices $1,2, \ldots \ldots, k$ correspondem aos locais do sistema onde serão geradas as séries sintéticas. 
$W_{t}$ é um vetor com $k$ componentes, distribuídos normalmente e independentes entre si.

Pode-se demonstrar que a matriz $A$ deve satisfazer a seguinte condição:

$A \cdot A^{t}=\operatorname{Cov}\left(V_{t}\right)$

onde

$\operatorname{Cov}\left(V_{t}\right)$ é a matriz de covariância de $V_{t}$, que é estimada a partir das observações simultâneas de $V_{t}(1), V_{t}(2), \ldots \ldots \ldots . ., V_{t}(k)$.

O manual do software apresenta em detalhe o processo de cálculo para solução do problema em questão. 


\section{ESTUDO DE CASO}

Conforme indicado no capítulo 2, a metodologia proposta foi aplicada ao sistema de reservatórios do rio São Francisco. Esse sistema foi implantado fundamentalmente para geração de energia elétrica visando o abastecimento da região Nordeste. Contudo, ao longo das últimas décadas, as demandas de água para irrigação vêm aumentando significativamente. Caso as projeções de demanda de irrigação para o futuro se concretizem, haverá uma intensificação no conflito entre esses usos da água na bacia.

Além desse dois usos, as águas do São Francisco são utilizadas para navegação, abastecimento público, diluição de esgotos, recreação e conservação ambiental. Os reservatórios da bacia são também usados para promover o controle de cheias e evitar prejuízos às cidades ribeirinhas.

\subsection{O Sistema São Francisco}

\subsubsection{Características Gerais}

A bacia do rio São Francisco, com cerca de $640.000 \mathrm{~km}^{2}$, conta com seis reservatórios no seu curso principal, dos quais dois são de grande capacidade de acumulação, a saber: Três Marias e Sobradinho. Esses dois reservatórios permitem regularização plurianual de vazões, isto é, possuem ciclos de enchimento e esvaziamento superiores a um ano. O reservatório de Itaparica, situado a jusante de Sobradinho, apresenta capacidade de regularização anual, os demais possuem pequena capacidade de acumulação de água. A jusante de Itaparica, estão localizadas as usinas do complexo Moxotó-Paulo Afonso e a UHE Xingó.

Esses aproveitamentos foram construídos com a finalidade principal de produção de energia elétrica, mas, devido à sua importância estratégica na 
regularização do rio, podem considerar outros usos para a água nos seus procedimentos operativos, tais como, irrigação, navegação e controle de cheias. As principais características desses reservatórios/usinas são mostradas na Tabela 5.1.

Tabela 5.1 - Reservatórios/Usinas no Rio São Francisco

\begin{tabular}{|c|c|c|c|c|c|c|c|}
\hline APROVEITAMENTO & $\begin{array}{l}\text { EMPRESA } \\
\text { OPERADORA }\end{array}$ & $\begin{array}{c}\text { DIST. ATÉ } \\
\text { A FOZ } \\
(\mathrm{Km})\end{array}$ & $\begin{array}{c}\text { ÁREA DE } \\
\text { DRENAGEM } \\
\left(\mathrm{Km}^{2}\right)\end{array}$ & $\begin{array}{c}\text { VOLUME } \\
\text { ÚTIL } \\
\left(\mathrm{Hm}^{3}\right)\end{array}$ & $\begin{array}{c}\text { NÍVEL } \\
\text { D'ÁGUA } \\
\text { MÁX. } \\
\text { NORMAL } \\
(\mathrm{m})\end{array}$ & $\begin{array}{c}\text { NÍVEL } \\
\text { D'ÁGUA } \\
\text { MÍN. } \\
\text { NORMAL } \\
(\mathrm{m})\end{array}$ & $\begin{array}{c}\text { POTÊNCIA } \\
\text { INSTALADA } \\
\text { (MW) }\end{array}$ \\
\hline TRÊS MARIAS & CEMIG & 2220 & 50560 & 15278 & 572,50 & 549,20 & 396 \\
\hline SOBRADINHO & CHESF & 800 & 498425 & 28669 & 392,45 & 380,50 & 1050 \\
\hline ITAPARICA & CHESF & 310 & 587000 & 3548 & 304,00 & 299,00 & 1500 \\
\hline MOXOTÓ & CHESF & 270 & 599200 & - & 251,50 & 251,50 & 400 \\
\hline P.AFONSO1,2 e 3 & CHESF & 270 & 599200 & - & 251,50 & 251,50 & 1423 \\
\hline P.AFONSO4 & CHESF & 270 & 599200 & - & 251,50 & 251,50 & 2460 \\
\hline XINGÓ & CHESF & 210 & 608700 & - & 138,00 & 138,00 & 3000 \\
\hline
\end{tabular}

Na Figura 5.1 é mostrado um mapa da bacia do rio São Francisco, onde são destacadas as várias denominações dos seus diversos trechos.

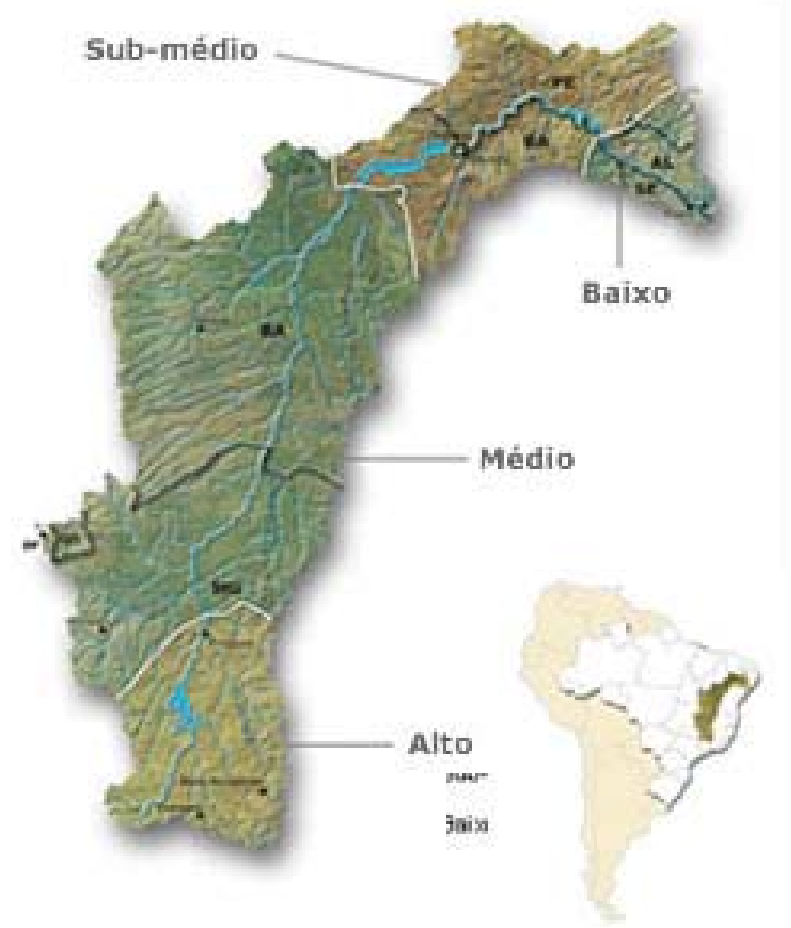

Fonte: Comitê da Bacia do São Francisco (www.cbhsaofrancisco.org.br)

Figura 5.1 - Bacia do Rio São Francisco 
A Figura 5.2 apresenta o esquema topológico com os reservatórios/usinas desse sistema.

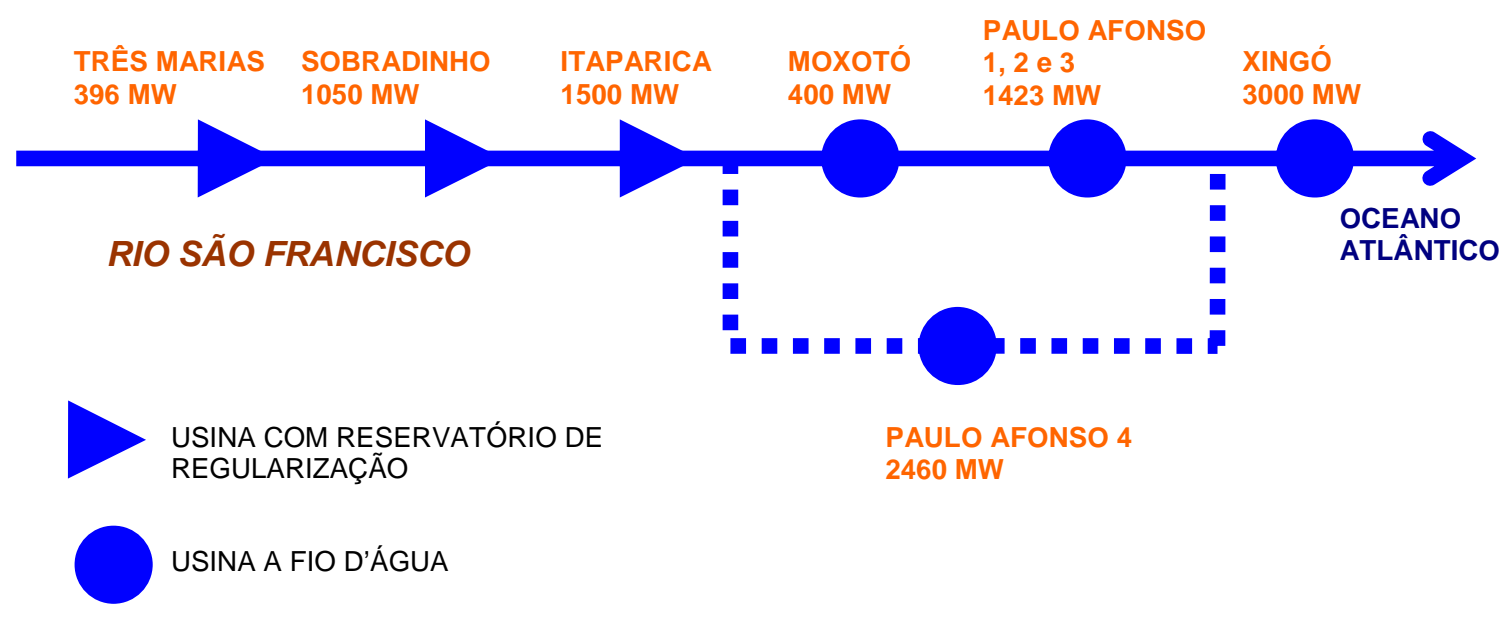

Figura 5.2 - Esquema Topológico do São Francisco

As usinas do São Francisco pertencem ao subsistema nordeste, exceto Três Marias, que pertence ao subsistema sudeste.

\subsubsection{Dados Básicos}

Os dados cadastrais e hidrometeorológicos dos reservatórios/usinas foram coletados junto às fontes do setor elétrico, como o sítio do ONS (www.ons.org.br), o SIPOT (Sistema de Informações do Potencial Hidrelétrico Brasileiro - versão 4.0) da Eletrobrás. Na publicação devida a Lopes et al. (2002), cujo resumo executivo está disponível em www.ana.gov.br/gefsf/4ProgGerenc/4-4.asp, também é possível encontrar os dados cadastrais das usinas do São Francisco e as relações entre queda e turbinamento máximo para cada uma delas. Esses dados são reproduzidos nas três tabelas a seguir. Nos casos das curvas cota-volume, cota-vazão (curva chave do canal de fuga) e cota-área, o setor elétrico utiliza polinômios de quarto grau que seguem a seguinte formatação: $Y=C 0+C 1 . X+C 2 . X^{2}+$ 
C3. $X^{3}+C 4 . X^{4}$. Portanto, nas tabelas referentes a essas curvas são indicados tais coeficientes.

Tabela 5.2 - Dados Físicos das Usinas

\begin{tabular}{|l|c|c|c|c|c|}
\hline \multicolumn{1}{|c|}{ USINA } & $\begin{array}{c}\text { POTÊNCIA } \\
\text { INSTALADA } \\
\text { (MW) }\end{array}$ & $\begin{array}{c}\text { ÍNDICE DE } \\
\text { DISPONIBILIDADE }\end{array}$ & RENDIMENTOS* & $\begin{array}{c}\text { VOLUME } \\
\text { MÁXIMO } \\
\text { (hm3) }\end{array}$ & $\begin{array}{c}\text { VOLUME } \\
\text { MíNIMO } \\
\text { (hm3) }\end{array}$ \\
\hline Três Marias & 396 & 0,894 & 0,851 & 19528 & 4250 \\
\hline Sobradinho & 1050 & 0,894 & 0,840 & 34116 & 5447 \\
\hline Itaparica & 1500 & 0,849 & 0,850 & 10782 & 7234 \\
\hline $\begin{array}{l}\text { P.Afonso - } \\
\text { Moxotó }\end{array}$ & 4285 & 0,860 & 0,830 & 1373 & 1373 \\
\hline Xingó & 3000 & 0,860 & 0,890 & 3800 & 3800 \\
\hline
\end{tabular}

(*) Produto dos rendimentos da turbina, do gerador e hidráulico.

Tabela 5.3 - Evaporação Líquida Mensal (mm)

\begin{tabular}{|c|c|c|c|c|c|}
\hline Meses & Três Marias & Sobradinho & Itaparica & $\begin{array}{c}\text { Paulo Afonso } \\
\text { Moxotó }\end{array}$ & Xingó \\
\hline Jan & 2 & 118 & 140 & 140 & 140 \\
\hline Fev & 0 & 106 & 109 & 109 & 109 \\
\hline Mar & 22 & 81 & 81 & 81 & 81 \\
\hline Abr & 40 & 132 & 105 & 105 & 105 \\
\hline Maio & 51 & 153 & 109 & 109 & 109 \\
\hline Jun & 55 & 142 & 101 & 101 & 101 \\
\hline Jul & 50 & 158 & 123 & 123 & 123 \\
\hline Ago & 42 & 181 & 158 & 158 & 158 \\
\hline Set & 57 & 197 & 180 & 180 & 180 \\
\hline Out & 48 & 189 & 195 & 195 & 195 \\
\hline Nov & 23 & 114 & 158 & 158 & 158 \\
\hline Dez & 29 & 98 & 152 & 152 & 152 \\
\hline
\end{tabular}


Tabela 5.4 - Polinômios Característicos das Usinas

\begin{tabular}{|c|c|c|c|c|c|}
\hline \multirow[t]{2}{*}{ USINA } & \multicolumn{5}{|c|}{ Polinômio cota-volume } \\
\hline & $\mathrm{CO}$ & C1 & $\mathrm{C} 2$ & $\mathrm{C} 3$ & $\mathrm{C} 4$ \\
\hline Três Marias & $5,30 E+02$ & 6,08E-03 & $-4,84 \mathrm{E}-07$ & $2,20 \mathrm{E}-11$ & $-3,85 E-16$ \\
\hline Sobradinho & $3,74 \mathrm{E}+02$ & $1,40 \mathrm{E}-03$ & $-5,35 E-08$ & $1,16 \mathrm{E}-12$ & $-9,55 \mathrm{E}-18$ \\
\hline Itaparica & $2,76 \mathrm{E}+02$ & $6,76 \mathrm{E}-03$ & $-8,87 \mathrm{E}-07$ & 7,07E-11 & $-2,24 \mathrm{E}-15$ \\
\hline P.Afonso-Moxotó & $2,52 \mathrm{E}+02$ & & & & \\
\hline Xingó & $1,38 \mathrm{E}+02$ & & & & \\
\hline \multirow[t]{2}{*}{ USINA } & \multicolumn{5}{|c|}{ Polinômio turbinamento máximo-queda } \\
\hline & $\mathrm{CO}$ & C1 & $\mathrm{C} 2$ & C3 & $\mathrm{C} 4$ \\
\hline Três Marias & $3,74 \mathrm{E}+02$ & $9,12 \mathrm{E}+00$ & & & \\
\hline Sobradinho & $1,73 \mathrm{E}+03$ & $7,81 \mathrm{E}+01$ & & & \\
\hline Itaparica & $1,46 E+03$ & $2,98 \mathrm{E}+01$ & & & \\
\hline P.Afonso-Moxotó & $1,96 \mathrm{E}+03$ & $1,80 \mathrm{E}+01$ & & & \\
\hline Xingó & $1,28 \mathrm{E}+03$ & $1,11 \mathrm{E}+01$ & & & \\
\hline \multirow[t]{2}{*}{ USINA } & \multicolumn{5}{|c|}{ Polinômio cota de jusante-vazao defluente } \\
\hline & $\mathrm{CO}$ & C1 & $\mathrm{C} 2$ & C3 & C4 \\
\hline Três Marias & $5,15 E+02$ & 1,61E-03 & $-2,55 \mathrm{E}-07$ & 2,89E-11 & $-1,18 \mathrm{E}-15$ \\
\hline Sobradinho & $3,60 \mathrm{E}+02$ & 1,96E-03 & $-2,97 \mathrm{E}-07$ & 2,51E-11 & $-7,70 \mathrm{E}-16$ \\
\hline Itaparica & $2,52 E+02$ & & & & \\
\hline P.Afonso-Moxotó & $1,29 E+02$ & 2,08E-03 & $-5,27 E-08$ & $6,66 \mathrm{E}-13$ & $2,23 \mathrm{E}-17$ \\
\hline Xingó & $1,95 E+01$ & & & & \\
\hline \multirow[t]{2}{*}{ USINA } & \multicolumn{5}{|c|}{ Polinômio área-cota } \\
\hline & $\mathrm{CO}$ & $\mathrm{C} 1$ & $\mathrm{C} 2$ & $\mathrm{C} 3$ & $\mathrm{C} 4$ \\
\hline Três Marias & $1,21 E+07$ & $-8,93 E+04$ & $2,48 \mathrm{E}+02$ & $-3,06 \mathrm{E}-01$ & $1,42 \mathrm{E}-04$ \\
\hline Sobradinho & $-5,04 \mathrm{E}+05$ & $4,91 \mathrm{E}+03$ & $-8,97 \mathrm{E}+00$ & $-1,89 \mathrm{E}-02$ & $4,65 \mathrm{E}-05$ \\
\hline Itaparica & $-2,00 \mathrm{E}+05$ & $1,82 E+03$ & $-4,44 \mathrm{E}+00$ & $-1,92 \mathrm{E}-03$ & 1,29E-05 \\
\hline P.Afonso-Moxotó & $2,13 E+02$ & & & & \\
\hline Xingó & $6,00 \mathrm{E}+01$ & & & & \\
\hline
\end{tabular}

Quanto às vazões naturais médias mensais nos aproveitamentos, foram utilizadas as séries referentes ao período janeiro de 1931 a dezembro de 2001 utilizadas pelo ONS, disponíveis em www.ons.org.br/ons/planejamento/index.htm, que são reproduzidas no Anexo A. 


\subsubsection{Restrições Operativas}

Segundo documentos do ONS (2002a), as principais restrições operativas para esses reservatórios são mostradas na Tabela 5.5.

Tabela 5.5- Restrições Operativas no Sistema São Francisco

\begin{tabular}{|c|c|c|c|c|}
\hline Aproveitamento & $\begin{array}{l}\text { Vazão Mínima } \\
\qquad\left(\mathrm{m}^{3} / \mathrm{s}\right)\end{array}$ & $\begin{array}{l}\text { Taxa de variação } \\
\text { da defluência } \\
\text { (m3/s/dia) }\end{array}$ & $\begin{array}{l}\text { Nível d'Água } \\
\text { Montante (m) }\end{array}$ & $\begin{array}{c}\text { Vazão Máxima a } \\
\text { Jusante }\left(\mathrm{m}^{3} / \mathrm{s}\right)\end{array}$ \\
\hline TRÊS MARIAS & 500 & 500 a 700 & - & 2500 \\
\hline SOBRADINHO & 1300 & 1000 & - & 8000 \\
\hline ITAPARICA & 1300 & - & - & - \\
\hline MOXOTÓ & - & - & - & - \\
\hline P.AFONSO1/3 & - & - & - & - \\
\hline P.AFONSO4 & - & - & - & - \\
\hline XINGÓ & 1300 & - & - & 8000 \\
\hline
\end{tabular}

As restrições de vazão mínima são necessárias para garantir calado para as embarcações que trafegam no rio. As de vazão máxima foram fixadas para conter inundações nas cidades ribeirinhas.

Para evitar a não superação dessas vazões máximas, o ONS estabelece volumes de espera em Três Marias e Sobradinho de forma a garantir o controle de cheias na bacia (ONS, 2002b). O período de retorno associado aos volumes de espera em Três Marias é de 20 anos e o de Sobradinho, de 10 anos. Em Itaparica, é necessário rebaixar o nível d'água máximo normal do lago durante os meses de cheias para evitar inundações na cidade de Belém do São Francisco, que se situa na extremidade de montante do reservatório. Os volumes de espera para esses reservatórios são reproduzidos na Tabela $\mathbf{5 . 6}$. 
Tabela 5.6 - Volumes de Espera no Rio São Francisco - Ciclo 2002/2003

\begin{tabular}{|c|c|c|c|c|c|c|c|c|}
\hline \multirow{3}{*}{\multicolumn{3}{|c|}{ PERÍODO }} & \multirow{2}{*}{\multicolumn{2}{|c|}{$\begin{array}{c}\text { TRÊS MARIAS } \\
\mathrm{Tr}=20 \text { anos } \\
\end{array}$}} & \multirow{2}{*}{\multicolumn{2}{|c|}{$\begin{array}{c}\text { SOBRADINHO } \\
\operatorname{Tr}=10 \text { anos } \\
\end{array}$}} & \multirow{2}{*}{\multicolumn{2}{|c|}{ ITAPARICA }} \\
\hline & & & & & & & & \\
\hline & & & Cota (m) & $\% \mathrm{VU}$ & Cota (m) & $\%$ VU & Cota (m) & $\% V U$ \\
\hline $26 / 10 / 02$ & $a$ & $01 / 11 / 02$ & 569,61 & 81,80 & 392,48 & 99,69 & 303,80 & 95,52 \\
\hline 02/11/02 & $\mathrm{a}$ & $08 / 11 / 02$ & 568,19 & 73,88 & 391,68 & 88,52 & 303,57 & 90,36 \\
\hline $09 / 11 / 02$ & $a$ & $15 / 12 / 02$ & 567,49 & 70,02 & 391,10 & 81,06 & 303,33 & 85,06 \\
\hline $16 / 11 / 02$ & $a$ & $22 / 11 / 02$ & 567,83 & 71,92 & 390,91 & 78,64 & 303,11 & 79,82 \\
\hline $23 / 11 / 02$ & $\mathrm{a}$ & $29 / 11 / 02$ & 568,39 & 75,00 & 390,82 & 77,61 & 302,87 & 74,86 \\
\hline $30 / 11 / 02$ & $\mathrm{a}$ & $06 / 12 / 02$ & 568,47 & 75,45 & 390,82 & 77,61 & 302,65 & 70,12 \\
\hline $07 / 12 / 02$ & $a$ & $13 / 12 / 02$ & 568,47 & 75,45 & 390,82 & 77,61 & 302,43 & 65,33 \\
\hline $14 / 12 / 02$ & $\mathrm{a}$ & $20 / 12 / 02$ & 568,47 & 75,45 & 390,82 & 77,61 & 302,20 & 60,60 \\
\hline $21 / 12 / 02$ & $\mathrm{a}$ & $27 / 12 / 02$ & 568,50 & 75,59 & 390,82 & 77,64 & 302,00 & 56,51 \\
\hline $28 / 12 / 02$ & $\mathrm{a}$ & 03/01/03 & 568,61 & 76,20 & 390,85 & 77,95 & 302,00 & 56,51 \\
\hline 04/01/03 & $\mathrm{a}$ & 10/01/03 & 568,61 & 76,20 & 390,87 & 78,20 & 302,00 & 56,51 \\
\hline 11/01/03 & $\mathrm{a}$ & $17 / 01 / 03$ & 568,61 & 76,20 & 390,88 & 78,31 & 302,00 & 56,51 \\
\hline $18 / 01 / 03$ & $a$ & $24 / 01 / 03$ & 568,61 & 76,20 & 390,89 & 78,43 & 302,00 & 56,51 \\
\hline $25 / 01 / 03$ & $a$ & $30 / 01 / 03$ & 568,87 & 77,69 & 390,91 & 78,72 & 302,00 & 56,51 \\
\hline 01/02/03 & $\mathrm{a}$ & $07 / 02 / 03$ & 569,34 & 80,29 & 390,97 & 79,33 & 302,00 & 56,51 \\
\hline $08 / 02 / 03$ & $\mathrm{a}$ & $14 / 02 / 03$ & 569,80 & 82,90 & 391,11 & 81,17 & 302,00 & 56,51 \\
\hline $15 / 02 / 03$ & $\mathrm{a}$ & $21 / 02 / 03$ & 570,25 & 85,50 & 391,28 & 83,25 & 302,00 & 56,51 \\
\hline $22 / 02 / 03$ & $\mathrm{a}$ & $28 / 02 / 03$ & 570,65 & 87,96 & 391,61 & 87,60 & 302,00 & 56,51 \\
\hline 01/03/03 & $a$ & $07 / 03 / 03$ & 570,95 & 89,79 & 391,85 & 90,93 & 302,00 & 56,51 \\
\hline $08 / 03 / 03$ & $a$ & $14 / 03 / 03$ & 571,15 & 91,10 & 391,85 & 90,76 & 302,00 & 56,51 \\
\hline $15 / 03 / 03$ & $a$ & $21 / 03 / 03$ & 571,36 & 92,41 & 392,13 & 94,73 & 302,00 & 56,51 \\
\hline $22 / 03 / 03$ & $a$ & $28 / 03 / 03$ & 571,75 & 94,89 & 392,18 & 95,36 & 302,00 & 56,51 \\
\hline $29 / 03 / 03$ & $a$ & $04 / 04 / 03$ & 571,89 & 95,81 & 392,18 & 95,36 & 302,52 & 67,38 \\
\hline 05/04/03 & $a$ & $11 / 04 / 03$ & 571,98 & 96,40 & 392,23 & 96,09 & 303,02 & 78,26 \\
\hline $12 / 04 / 03$ & $a$ & $18 / 04 / 03$ & 572,25 & 98,23 & 392,34 & 97,73 & 303,52 & 89,13 \\
\hline $19 / 04 / 03$ & $a$ & $25 / 04 / 03$ & 572,37 & 99,08 & 392,40 & 98,54 & 304,00 & 100,00 \\
\hline $26 / 04 / 03$ & $a$ & $02 / 05 / 03$ & 572,50 & 100,00 & 392,45 & 99,34 & 304,00 & 100,00 \\
\hline
\end{tabular}

\subsubsection{Demandas para Irrigação}

Com relação às demandas para irrigação, a Agência Nacional das Águas (ANA), em atendimento às solicitações do setor elétrico quanto aos valores de demandas atuais e futuras para irrigação na bacia do rio São Francisco, emitiu a Resolução 145 de 22 de julho de 2002 (ANA, 2002), cujos principais dados são mostrados na Tabela 5.7 e na Tabela 5.8. 
Tabela 5.7 - Estimativas para Área Irrigada na Bacia do Rio São Francisco (ha)

\begin{tabular}{|r|c|c|c|c|c|c|c|c|c|}
\hline Ano & 1999 & 2000 & 2001 & 2002 & 2003 & $\mathbf{2 0 0 4}$ & $\mathbf{2 0 0 5}$ & $\mathbf{2 0 0 6}$ & $\mathbf{2 0 0 7}$ \\
\hline $\begin{array}{r}\text { Montante de } \\
\text { Sobradinho }\end{array}$ & 162.407 & 166.305 & 170.203 & 174.101 & 177.999 & 181.897 & 185.795 & 189.693 & 193.591 \\
\hline $\begin{array}{r}\text { Entre } \\
\text { Sobradinho } \\
\text { e Itaparica }\end{array}$ & 149.619 & 153.210 & 156.801 & 160.392 & 163.983 & 167.575 & 171.166 & 174.757 & 178.348 \\
\hline $\begin{array}{r}\text { Entre } \\
\text { Itaparica e } \\
\text { Xingó }\end{array}$ & 6.885 & 7.050 & 7.216 & 7.381 & 7.546 & 7.711 & 7.877 & 8.042 & 8.207 \\
\hline $\begin{array}{r}\text { Jusante de } \\
\text { Xingó }\end{array}$ & 14.399 & 14.745 & 15.090 & 15.436 & 15.781 & 16.127 & 16.473 & 16.818 & 17.164 \\
\hline TOTAL & 333.310 & 341.310 & 349.310 & 357.310 & 365.310 & 373.310 & 381.310 & 389.310 & 397.310 \\
\hline
\end{tabular}

Tabela 5.8 - Estimativa da Vazão Média Anual Retirada para Irrigação na Bacia do Rio São Francisco $\left(\mathrm{m}^{3} / \mathrm{s}\right)$

\begin{tabular}{|r|r|r|r|r|r|r|r|r|r|}
\hline Ano & 1999 & $\mathbf{2 0 0 0}$ & $\mathbf{2 0 0 1}$ & $\mathbf{2 0 0 2}$ & $\mathbf{2 0 0 3}$ & $\mathbf{2 0 0 4}$ & $\mathbf{2 0 0 5}$ & $\mathbf{2 0 0 6}$ & $\mathbf{2 0 0 7}$ \\
\hline $\begin{array}{r}\text { Montante de } \\
\text { Sobradinho }\end{array}$ & 94,2 & 96,5 & 98,7 & 101,0 & 103,2 & 105,5 & 107,8 & 110,0 & 112,3 \\
\hline $\begin{array}{r}\text { Entre Sobradinho e } \\
\text { Itaparica }\end{array}$ & 86,8 & 88,9 & 90,9 & 93,0 & 95,1 & 97,2 & 99,3 & 101,4 & 103,4 \\
\hline $\begin{array}{r}\text { Entre Itaparica e } \\
\text { Xingó }\end{array}$ & 4,0 & 4,1 & 4,2 & 4,3 & 4,4 & 4,5 & 4,6 & 4,7 & 4,8 \\
\hline $\begin{array}{r}\text { Jusante de Xingó } \\
\text { TOTAL }\end{array}$ & 193,4 & 8,6 & 8,8 & 9,0 & 9,2 & 9,4 & 9,6 & 9,8 & 10,0 \\
\hline 198,0 & 202,6 & 207,2 & 211,9 & 216,5 & 221,2 & 225,8 & 230,4 \\
\hline
\end{tabular}

Com base no fator de sazonalidade médio para as demandas na bacia do rio São Francisco, avaliados pela ANA conforme Lopes et al. (2002), mostrados na Tabela 5.9, podem ser estimadas as vazões médias mensais retiradas para a irrigação. Não foram admitidas taxas de retorno da água da irrigação, dado que se trata de região semi-árida. 
Tabela 5.9 - Fator de Sazonalidade Médio para as Demandas na Bacia do Rio São Francisco

\begin{tabular}{|c|c|c|c|c|c|c|c|c|c|c|c|}
\hline JAN & FEV & MAR & ABR & MAI & JUN & JUL & AGO & SET & OUT & NOV & DEZ \\
\hline 1,144 & 0,877 & 0,839 & 0,815 & 0,912 & 0,839 & 0,884 & 1,001 & 1,113 & 1,286 & 1,189 & 1,101 \\
\hline \multicolumn{10}{|c|}{ Fonte: Lopes et al. (2002) }
\end{tabular}

\subsection{Desenvolvimento do Modelo SFPLUS}

Com base nos equacionamentos dos problemas de otimização da operação de reservatórios tratados no capítulo 4, foi criado o modelo SFPLUS para resolver os problemas de otimização para o sistema da bacia do rio São Francisco. Esse modelo foi criado para dar o suporte necessário para o estudo de caso em análise. Contudo, a sua metodologia é genérica e pode ser empregada para modelagem de qualquer sistema de reservatórios. Para que a aplicação do modelo SFPLUS a outros sistemas seja amigável, será necessário desenvolver estruturas genéricas de entrada de dados e saída de resultados e introduzir no programa uma rotina que permita a análise de sistemas com topologias diversas.

O modelo SFPLUS foi elaborado com base na linguagem estruturada para solução de problemas de programação matemática GAMS (BROOKE et al., 1998), cujos princípios são mostrados em 5.3. Esse tipo de linguagem facilita a formulação de problemas de otimização baseados em programação matemática (linear, não-linear, inteira e mista) para serem resolvidos por determinados pacotes de otimização, como o MINOS, o CPLEX, o CONOPT e outros.

O pacote utilizado foi o MINOS que permite a solução de problemas de programação linear e não-linear, conforme relatado em 5.4. Esse software tem sido aplicado para solução de problemas semelhantes, como visto no capítulo 3. 
A utilização do GAMS e do MINOS neste trabalho foi possível através da parceria de pesquisa entre o Departamento de Engenharia Hidráulica e Sanitária da EPUSP e a Faculdade de Engenharia Civil da UNICAMP (projeto CT-HIDRO: Modelo de Adução de Água 2003/2004).

Os usos enfocados no estudo de caso foram a geração de energia elétrica e a irrigação, pois são os principais usos conflitantes na bacia do São Francisco.

As demandas para irrigação na bacia foram representadas por valores selecionados da Tabela 5.8, distribuídos mensalmente com base nos fatores de sazonalidade indicados na Tabela 5.9. O cenário básico da irrigação foi o correspondente às vazões previstas para o ano 2007. Os demais cenários foram definidos a partir de múltiplos desse valor, a saber: 0; 0,5; 1,0;1,5 e 2,0 .

Quanto à geração de energia, foram feitas análises da produção energética resultante da modelagem. Foi considerada como variável de análise a média de seis anos da energia total do sistema correspondente a cada seqüência temporal otimizada.

O problema de otimização também levou em conta as demais restrições operacionais para cada reservatório/usina descritas em 5.1.3.

Para facilitar o equacionamento do problema, as curvas cota-volume e cotaárea, cujos parâmetros são mostrados na Tabela 5.4, foram combinadas de forma a se obter curvas área-volume.

De acordo com o exposto em 4.1.2, o intervalo de tempo de cálculo adotado é mensal e o horizonte do período de análise é igual a 6 anos (72 meses).

O modelo foi desenvolvido em dois módulos. O primeiro módulo trata o problema segundo o método das restrições. Nesse caso, a função-objetivo busca maximizar a energia média gerada pelo sistema ao longo do período de análise. O segundo módulo enfoca o problema de acordo com o método 
das ponderações. Nesse equacionamento se inclui uma função-objetivo que busca maximizar uma ponderação entre a energia média gerada pelo sistema e a vazão média total extraída do sistema para irrigação. Os equacionamentos desses dois módulos são apresentados na seqüência. $A$ notação matemática adotada é similar à empregada no programa desenvolvido com a linguagem GAMS.

\section{- Formulação do Modelo SFPLUS - Método das Restriç̃̃es}

Função-objetivo:

Maximizar em (maximizar a energia média do sistema)

Equações auxiliares:

$$
\begin{aligned}
& \operatorname{incr}(t, u)=\operatorname{afl}(t, u)-a f l(t, u-1) \\
& q d f l(t t, u)=q t u r(t t, u)+q v e r(t t, u) \\
& q m o n(t t, u)=q d f l(t t, u-1) \\
& \operatorname{named}(t t, u)=\left[a 0(u)+a 1(u) * v f i m(t t, u)+a 2(u) * v f i m(t t, u)^{2}+\right. \\
& a 3(u) * v f i m(t t, u)^{3}+a 4(u) * v f i m(t t, u)^{4} a 0(u)+a 1(u) * v f i m(t t-1, u)+ \\
& \left.a 2(u) * v f i m(t t-1, u)^{2}+a 3(u) * v f i m(t t-1, u)^{3}+a 4(u) * v f i m(t t-1, u)^{4}\right] / 2 \\
& \operatorname{amed}(t t, u)=[s 0(u)+s 1(u) * v f i m(t t, u)+s 0(u)+s 1(u) * v f i m(t t-1, u)] / 2 \\
& n a j(t, u)=b 0(u)+b 1(u) * q d f l(t, u)+b 2(u) * q d f l(t, u)^{2}+b 3(u) * q d f l(t, u)^{3} \\
& +b 4(u) * q d f l(t, u)^{4} \\
& h(t, u)=\operatorname{named}(t, u)-n a j(t, u) \\
& \operatorname{ener}(t, u)=q \operatorname{tur}(t, u) * h(t, u) * k(u) \\
& \operatorname{enertot}(t)=\sum_{u} \operatorname{ener}(t, u) \\
& \text { em }=\left[\sum_{t} \operatorname{enertot}(t)\right] / 72
\end{aligned}
$$




\section{Restrições:}

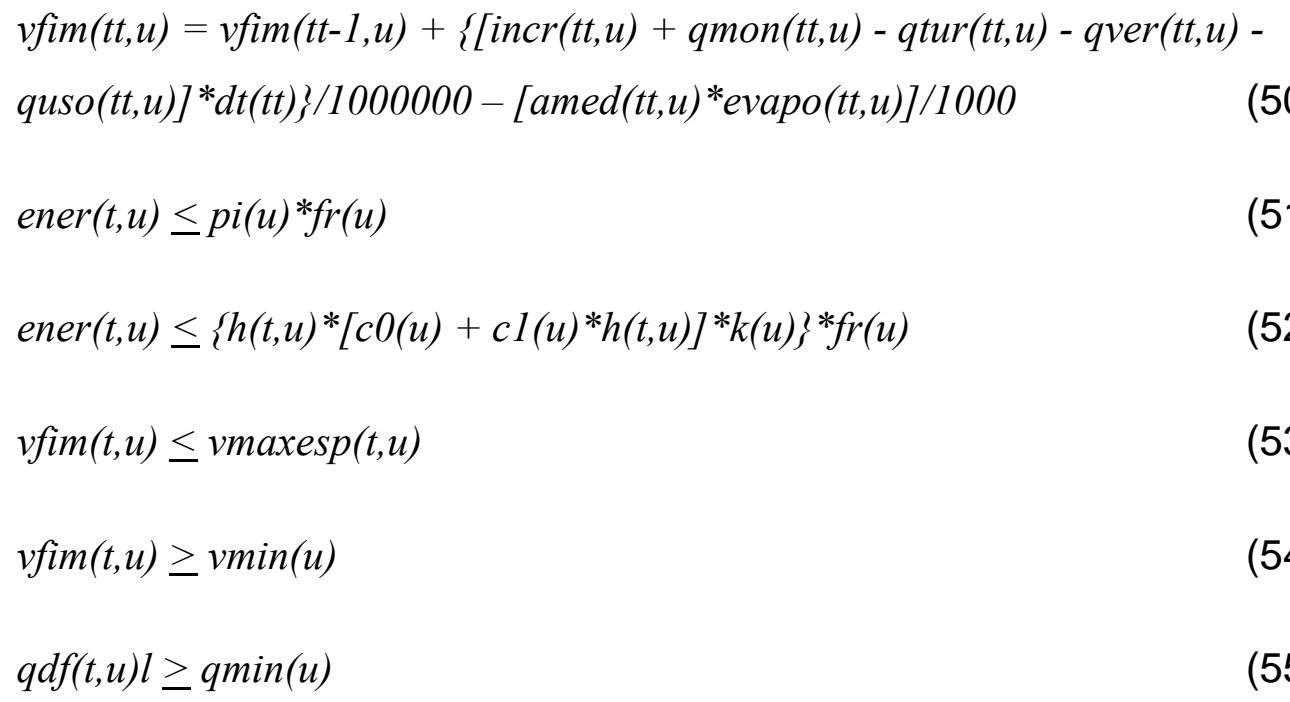

\section{Condições de contorno:}

se $t t=0 \rightarrow v f i m(t t, u)=v 0(u) ; \operatorname{evapo}(t t, u)=0 ; q u s o(t t, u)=0$

se $t t=72 \rightarrow v f i m(t t, u)=v 0(u)$

se $u=\operatorname{tma} \rightarrow$ qmon $(t t, u)=0 ; \operatorname{incr}(t, u)=a f l(t, u)$

onde

$u=$ índice de usina: tma (Três Marias), sob (Sobradinho), itp (Itaparica), pam (Paulo Afonso-Moxotó), xin (Xingó);

$t=$ índice de tempo: $1,2, \ldots \ldots \ldots, 72$;

$t t=$ índice auxiliar de tempo: $0,1, \ldots \ldots \ldots . .72$

em = energia média do sistema ao longo do período de análise;

$a f l(t, u)^{*}=$ vazão natural afluente ao reservatório $u$ no intervalo de tempo $t$; $\operatorname{incr}(t, u)=$ vazão incremental natural ao reservatório $u$ no intervalo de tempo $t$; 
$q t u r(t t, u)=$ vazão turbinada pela usina $u$ no intervalo de tempo $t t$;

qver $(t t, u)=$ vazão vertida pela usina $u$ no intervalo de tempo $t t$;

$q d f l(t t, u)=$ vazão defluente total da usina $u$ no intervalo de tempo $t t$;

$q m o n(t t, u)=$ vazão defluente da usina imediatamente a montante da usina $u$ no intervalo de tempo $t t$;

$q u s o(t t, u)^{*}=$ vazão do uso consuntivo (irrigação) extraída do reservatório da usina $u$ no intervalo de tempo $t t$;

$v f i m(t t, u)=$ volume do reservatório da usina $u$ no final do intervalo de tempo $t$;

named $(t t, u)=$ nível d'água médio do reservatório da usina $u$ ao longo do intervalo de tempo $t t$;

$\operatorname{amed}(t t, u)=$ área média do reservatório da usina $u$ ao longo do intervalo de tempo $t t$;

$n a j(t, u)=$ nível d'água no canal de fuga da usina $u$ ao longo do intervalo de tempo $t$;

$a 0(u) * \ldots . . a 4(u) *=$ parâmetros da curva cota-volume da usina $u$;

$s 0(u)^{*}, s 1(u)^{*}=$ parâmetros da curva área-volume da usina $u$;

$b 0(u)^{*} \ldots . . . b 4(u)^{*}=$ parâmetros da curva-chave do canal de fuga da usina $u$;

$h(t, u)=$ queda bruta da usina $u$ no intervalo de tempo $t$;

$k(u)^{*}=9,81 \cdot 10^{-3} \cdot \eta_{g} \cdot \eta_{t} \cdot \eta_{h}:$ produtibilidade específica da usina $u$

ener $(t, u)=$ energia gerada pela usina $u$ no intervalo de tempo $t$;

enertot $(t)=$ energia total gerada pelo sistema no intervalo de tempo $t$; 
evapo $(t t, u)^{*}=$ evaporação líquida do reservatório da usina $u$ no intervalo de tempo $t t$;

$d t(t t)^{*}=$ número de segundos do intervalo de tempo $t t ;$

$p i(u)^{*}=$ potência instalada da usina $u$;

$f r(u)^{*}=$ fator de reserva ou índice de disponibilidade de máquinas da usina $u$;

$c 0(u)^{*}, c 1(u)^{*}=$ parâmetros da equação da vazão turbinada máxima em função da queda da usina $u$;

vmaxesp $(t, u)^{*}=$ volume máximo do reservatório da usina u no final do intervalo de tempo $t$, considerando volumes de espera;

$v \min (u) *=$ volume mínimo do reservatório da usina $u$;

$v 0(u)^{*}=$ volume de inicial do reservatório da usina $u$.

Observaç̃̃es: volumes em milhões de $\mathrm{m}^{3}$, vazões em $\mathrm{m}^{3} / \mathrm{s}$, áreas em $\mathrm{Km}^{2}$, evaporação em mm, níveis d'água em metros, queda em metros, energia em MW-médios, potência em MW. As grandezas assinaladas com (*) são dados de entrada do modelo.

- Formulação do Modelo SFPLUS - Método das Ponderações

Função-objetivo:

Maximizar $\underline{\alpha . e m}+\beta . u m$ (max. a ponderação entre energia e irrigação)

Equações auxiliares:

$\operatorname{qirtot}(t t)=\sum_{u} \operatorname{qir}(t t, u)$

$u m=\left[\sum_{t t} \operatorname{qirtot}(t t)\right] / 72$ 


\section{Restrições:}

$v f i m(t t, u)=v f i m(t t-1, u)+\{[\operatorname{incr}(t t, u)+q m o n(t t, u)-q t u r(t t, u)-q v e r(t t, u)-$

$\operatorname{qir}(t t, u)] * d t(t t)\} / 1000000-[$ amed $(t t, u) *$ evapo $(t t, u)] / 1000$

$0 \leq q i r(t t, u) \leq q u s o(t t, u)$

onde

$\alpha=$ parâmetro de ponderação da energia;

$\beta=$ parâmetro de ponderação da irrigação;

qir $(t t, u)=$ vazão extraída para irrigação do reservatório da usina $u$ no intervalo de tempo $t t$;

qirtot $(t t)=$ vazão total extraída do sistema para irrigação no intervalo de tempo $t t$;

um = vazão média extraída do sistema para irrigação ao longo do período de análise.

As demais equações, restrições e condições de contorno são as mesmas do equacionamento segundo o método das restrições.

Os programas formulados com a linguagem GAMS referentes a esses dois módulos são apresentados no Anexo B.

A seguir apresentam-se os resumos com as principais características do GAMS e do MINOS.

\subsection{A Ferramenta GAMS}

Nas últimas décadas houve um grande avanço no desenvolvimento de programas e pacotes computacionais voltados para a solução de problemas de otimização, como o MINOS, o LINDO, o CPLEX, o CONOPT, etc. Esses 
pacotes foram criados com base no desenvolvimento de diversos algoritmos e técnicas para a solução de problemas de programação linear e não-linear e programação inteira e mista. Com o advento das linguagens de modelação, como o GAMS (BROOKE et al.,1998) e o AMPL (FOURER et al.,2003), os processos de formulação dos problemas e de processamento desses pacotes computacionais tornaram-se extremamente facilitados. Além disso, o desenvolvimento vertiginoso dos computadores propiciou a solução de problemas cada vez maiores com tempos de processamento cada vez mais reduzidos.

Normalmente, a interação dos usuários com um determinado pacote de otimização pode ser feita através de arquivos de entrada de dados, listas de argumentos de sub-rotinas, sub-rotinas escritas pelo usuário, planilhas eletrônicas, arquivos texto no formato padrão MPS, ou arquivos texto que descrevem o problema num dado formato específico. Essas formas de interação, via de regra, são trabalhosas, herméticas e pouco flexíveis, o que se reflete no tempo e no esforço gastos para formulação do problema e sua solução. Uma análise interessante sobre esses aspectos é apresentada por Wright (1999).

Há cerca de dez anos, foram criadas as linguagens voltadas para a programação matemática e a formulação de problemas de otimização. Essa é uma forma muito prática e direta de se criar interfaces entre o usuário e o pacote de otimização, na medida em que permite definir o modelo e a entrada de dados de uma maneira muito intuitiva e seguindo basicamente a notação matemática utilizada na descrição desses problemas.

Uma dessas linguagens é o GAMS (General Algebric Modeling System), cujas informações podem ser obtidas em www.gams.com e o material bibliográfico está referenciado em Brooke et al. (1998). O GAMS foi especificamente idealizado para modelagem de problemas de programação linear, não-linear e programação inteira e mista. A ferramenta é útil na solução de problemas complexos e de grande porte, e pode ser utilizada em microcomputadores, estações de trabalho e computadores de grande porte. 
A linguagem foi desenvolvida com o propósito de atender aos seguintes requisitos:

- Produzir uma linguagem de alto nível voltada para a representação compacta e adequada de modelos complexos e de grande porte.

- Permitir que as mudanças no modelo sejam feitas de forma simples e segura.

- Não permitir declarações ambíguas das relações algébricas.

- Permitir que o processo de elaboração de modelos possa ser independente dos pacotes de otimização a serem utilizados.

O desenvolvimento do GAMS incorporou as idéias derivadas da teoria de banco de dados relacionais e da programação matemática, com o objetivo de mesclar essas idéias de forma a atender as necessidades estratégicas dos modeladores. A teoria sobre banco de dados forneceu o arcabouço necessário para desenvolvimento das estruturas de organização, armazenamento e transformação dos dados em geral. A programação matemática deu o suporte necessário aos processos de formulação e descrição do problema e contribuiu com uma variedade de métodos para sua solução. Os seguintes princípios foram utilizados na elaboração da linguagem:

- Possíveis alterações nos algoritmos dos pacotes de otimização não devem exigir alterações em modelos existentes elaborados com 0 GAMS.

- O problema de otimização deve poder ser equacionado independentemente dos dados utilizados. Esta separação entre lógica e dados permite que o problema possa aumentar de tamanho sem aumentar a complexidade de sua representação. 
- O uso da modelagem relacional de dados faz com que os recursos computacionais sejam alocados de forma automática. Isto resulta que o usuário não precisa se preocupar com detalhes sobre armazenamento de dados, como tamanho de matrizes e vetores, etc.

Por essas razões, o GAMS facilita e agiliza a elaboração e manipulação de modelos de otimização. Os modelos podem ser escritos e alterados facilmente. Os dados podem ser armazenados em arquivos texto e/ou em estruturas de bancos de dados ou planilhas eletrônicas. Os resultados podem ser visualizados e/ou exportados para editores de texto ou planilhas. Além disso, de acordo com as características de cada problema, podem ser utilizados diversos pacotes de otimização para solução de um mesmo modelo.

\subsection{Metodologia para Solução de PNL: MINOS}

O modelo SFPLUS, desenvolvido neste estudo, utiliza o pacote computacional MINOS (MURTAGH et SAUNDERS, 1995) para resolver os problemas de otimização propostos. Esse programa, escrito em FORTRAN, é destinado a resolver problemas de otimização de grande escala. O software foi desenvolvido pelo Laboratório de Otimização de Sistemas da Universidade de Stanford, Califórnia, e permite a solução de problemas de programação linear e não-linear segundo a seguinte formulação básica:

$\operatorname{Minimizar}_{\mathrm{x}, \mathrm{y}}: F(x)+c^{T} x+d^{T} y$

Sujeito a:

$$
\begin{aligned}
& f(x)+A_{1} y=b_{1} \\
& A_{2} x+A_{3} y=b_{2} \\
& l \leq\left(_{y}^{x}\right) \leq u
\end{aligned}
$$


onde os vetores $c, d, b_{1}, b_{2}, l, u$ e as matrizes $A_{1}, A_{2}, e$ A3 são constantes, $F(x)$ é uma função escalar contínua e $f(x)$ é um vetor de funções contínuas.

Os $\mathrm{n}_{1}$ componentes de $x$ são as variáveis não-lineares e os $\mathrm{n}_{2}$ componentes de $y$ são as variáveis lineares. Analogamente, as $m_{1}$ equações (65) são as chamadas restrições não-lineares e as $m_{2}$ equações (66) são as restrições lineares. As eqs.(65) e (66) representam a totalidade das restrições do problema. As restrições representadas por (67) indicam os limites superiores e inferiores de todas as variáveis.

Nos casos em que as funções $F(x)$ e $f(x)$ não existam, o problema se resume a uma aplicação de Programação Linear (PL). Nesse caso, o MINOS utiliza o método Simplex para solução do problema. Quando os aspectos nãolineares estão confinados à função $F(x)$ da função-objetivo, tem-se um problema de Programação Não-Linear (PNL) com restrições lineares. O MINOS resolve este tipo de problema utilizando o método do gradiente reduzido em combinação com o método quasi-Newton. Quando o problema contém restrições não-lineares, o MINOS usa o método Lagrangiano aumentado. Todos esses métodos são descritos em Mays (1996) e Hillier et Lieberman (1995).

Dessa forma, o MINOS é um programa apto a resolver uma grande variedade de problemas de otimização linear e não-linear. Essa flexibilidade é muito importante na procura de soluções de problemas de operação de reservatórios, onde os aspectos não-lineares podem aparecer tanto na função-objetivo como nas restrições.

\subsubsection{Solução Ótima Global ou Local}

Os algoritmos de PNL encerram o processo de busca da solução ótima quando não há aumento significativo (no caso de maximização) do valor da função-objetivo, dentro da precisão desejada. Essa é considerada uma solução ótima local, ou seja, uma solução que é a melhor naquela 
vizinhança. Contudo, o ótimo local pode não ser a melhor solução global para o problema. Um outro ótimo local pode ser a melhor solução para o problema numa outra área da região viável de soluções. Esse tipo de comportamento é ilustrado no gráfico da Figura 5.3, que foi elaborado a partir dos conceitos descritos por Ragsdale (2001).

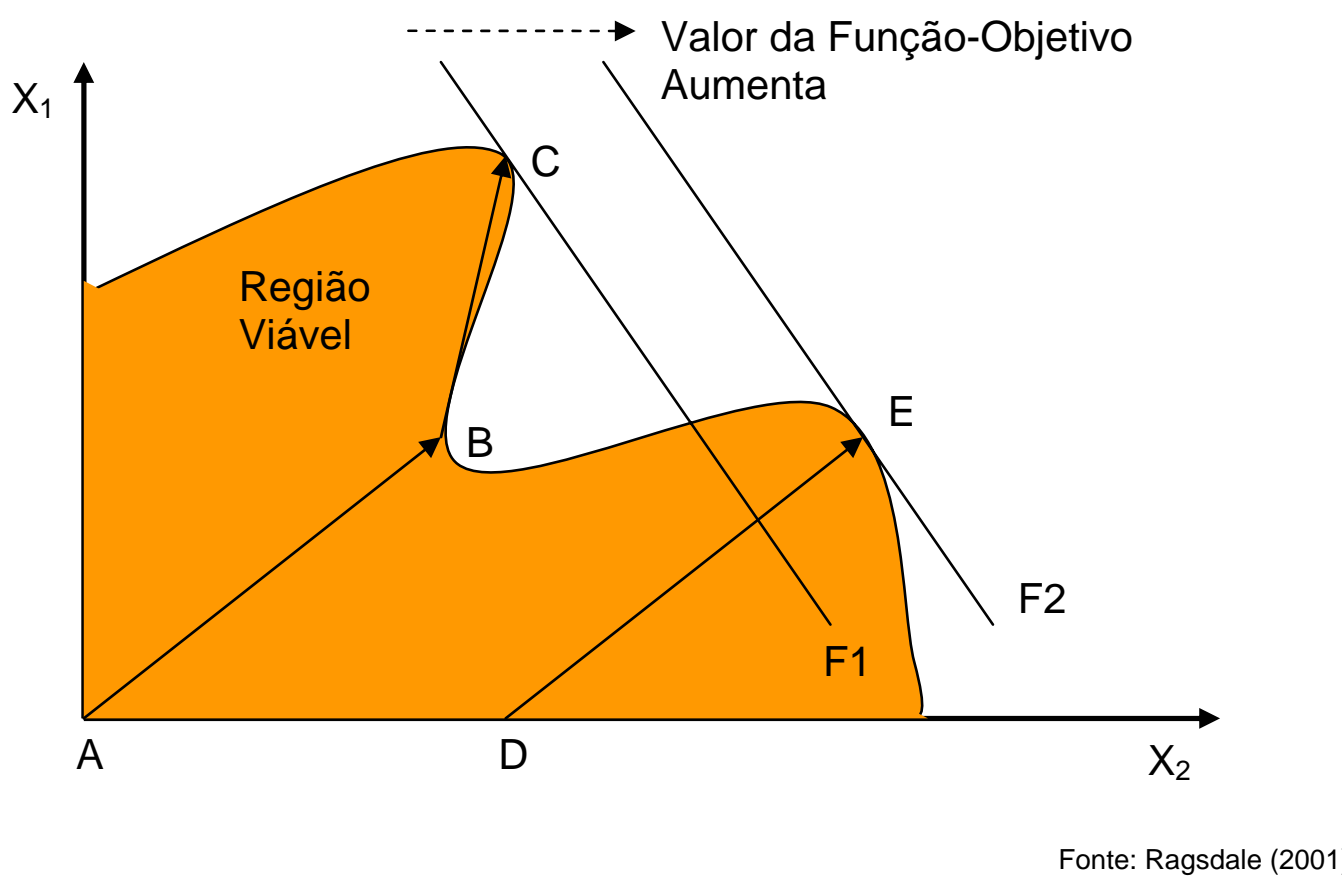

Figura 5.3 - Ótimo Local versus Ótimo Global

De acordo com o gráfico da Figura 5.3, $X_{1}$ e $X_{2}$ são variáveis de decisão. Se o algoritmo de PNL inicia no ponto $A$, no passo seguinte ele encontra 0 ponto B e evolui para o ponto $C$. Dado que não há nenhuma outra solução viável melhor próximo de $\mathrm{C}$, ele encerra o problema nesse ponto. Se ao invés disso, o algoritmo iniciar o processamento em $D$, ele passa para 0 ponto $E$, que nesse caso é também um ótimo local uma vez que não há solução viável que melhore a função-objetivo nas suas imediações.

Ainda conforme o problema ilustrado na Figura 5.3, F1 e F2 são retas sobre as quais a função-objetivo apresenta o mesmo valor. Nesse caso, o valor de 
F2 é superior ao de F1. Assim, a solução ótima global para esse problema está no ponto $E$, e não no ponto $C$.

Esses argumentos servem para exemplificar que, no caso da otimização não-linear, a solução ótima de um algoritmo de PNL pode não levar à solução ótima global e que a solução encontrada depende do ponto de partida do problema. Nesse caso, é recomendável realizar alguns testes de sensibilidade para avaliar se a solução do problema é afetada significativamente pelos valores iniciais adotados.

Esse tipo de abordagem fica bastante facilitado na medida em que se conhece o problema de otimização em questão. No caso da solução de problemas de otimização de reservatórios, uma solução inicial que tem sido utilizada e que têm apresentado resultados satisfatórios é aquela que considera a operação dos reservatórios a fio d'água (volume útil igual a zero). Essa técnica é apresentada por Lopes et al. (2002). 


\section{ANÁLISE DA OPERAÇÃO PARA USOS MÚLTIPLOS}

Nesta etapa foram analisados os problemas formulados segundo os métodos das restrições e das ponderações utilizando-se como ferramenta o modelo SFPLUS, apresentado em 5.2. Além disso, foi analisada uma alternativa de solução do problema com base na otimização econômica.

Nesta fase foram utilizadas seqüências temporais de vazões médias mensais com extensão de seis anos, referentes a cenários hidrológicos prédefinidos. Esses estudos são mostrados na seqüência.

\subsection{Seleção de Cenários Hidrológicos}

As principais séries de vazões médias mensais ao longo do São Francisco são Três Marias e Sobradinho. Três Marias drena uma área de $50.560 \mathrm{~km}^{2} \mathrm{e}$ situa-se na Região Sudeste. A área incremental entre essa usina e a de Sobradinho é de $447.865 \mathrm{~km}^{2}$ e entre Itaparica e Sobradinho, $88.574 \mathrm{~km}^{2}$. Apesar da expressiva área incremental entre Itaparica e Sobradinho, por se tratar de região semi-árida, as vazões incrementais são bastante reduzidas, com média multianual em torno de $50 \mathrm{~m}^{3} / \mathrm{s}$. As áreas incrementais entre as demais usinas são de menor magnitude (da ordem de $10.000 \mathrm{Km}^{2}$ ) e também estão localizadas em região semi-árida, tanto que o setor elétrico atribui vazão incremental "zero" entre Paulo Afonso/Moxotó e Itaparica e incremental constante no tempo igual a $10 \mathrm{~m}^{3} / \mathrm{s}$ para a área entre Xingó e Paulo Afonso/Moxotó.

Dessa forma, os estudos de seleção de cenários hidrológicos foram desenvolvidos a partir das séries de vazão de Três Marias e Sobradinho. $\mathrm{O}$ gráfico da Figura 6.1 apresenta as médias mês a mês para essas duas séries e também para a série incremental entre elas, no período 1931 a 2001. 


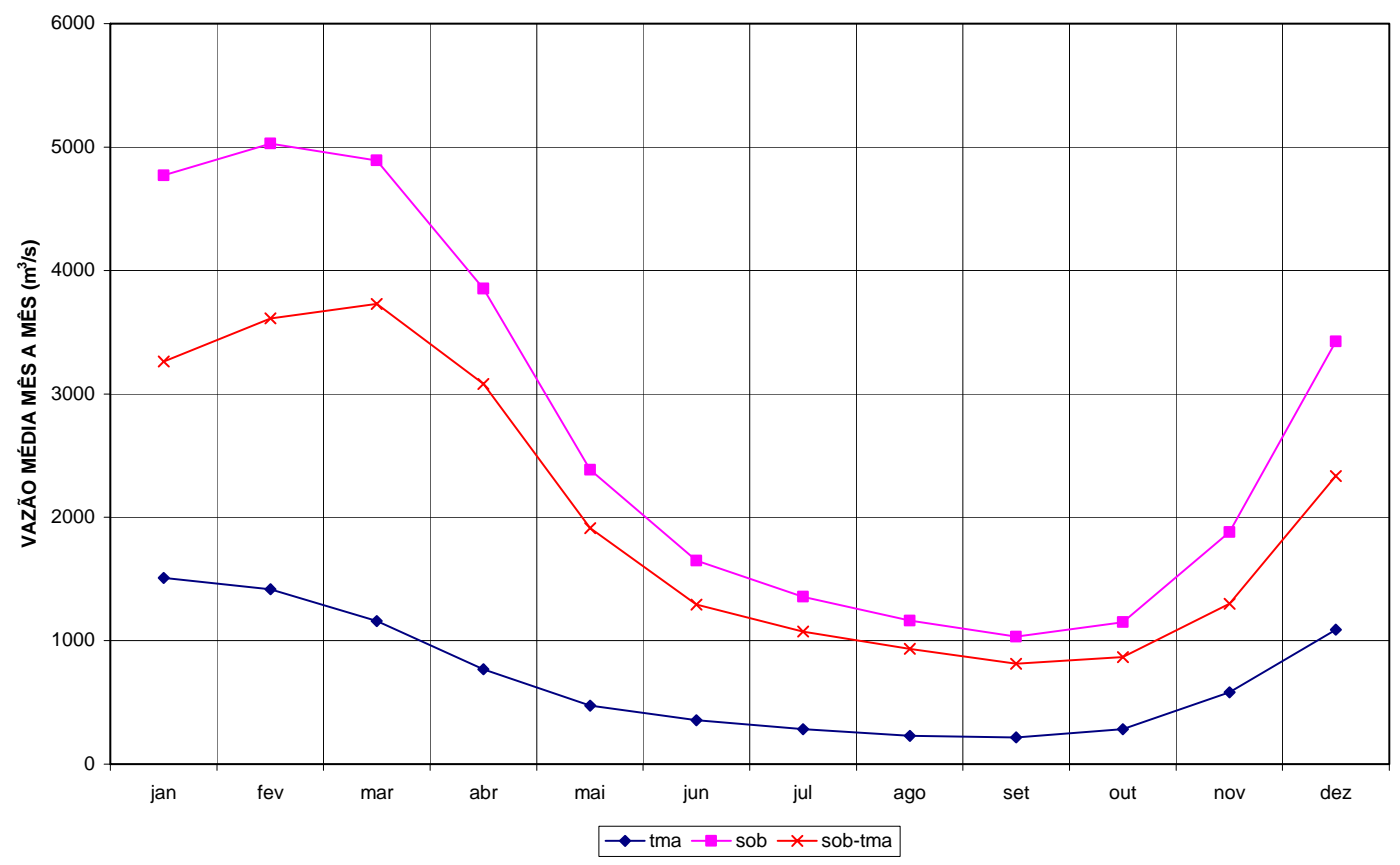

Figura 6.1 - Vazões Médias Mês a Mês no Período 1931 a 2001

A partir do gráfico anterior, nota-se que a sazonalidade dessa bacia indica que os períodos de cheia se iniciam em outubro. Dessa forma, para efeito de cálculo das séries de médias anuais, foi admito o ano hidrológico com início em outubro e término em setembro. O gráfico com as médias anuais para Três Marias e a Incremental de Sobradinho é mostrado na Figura 6.2. 


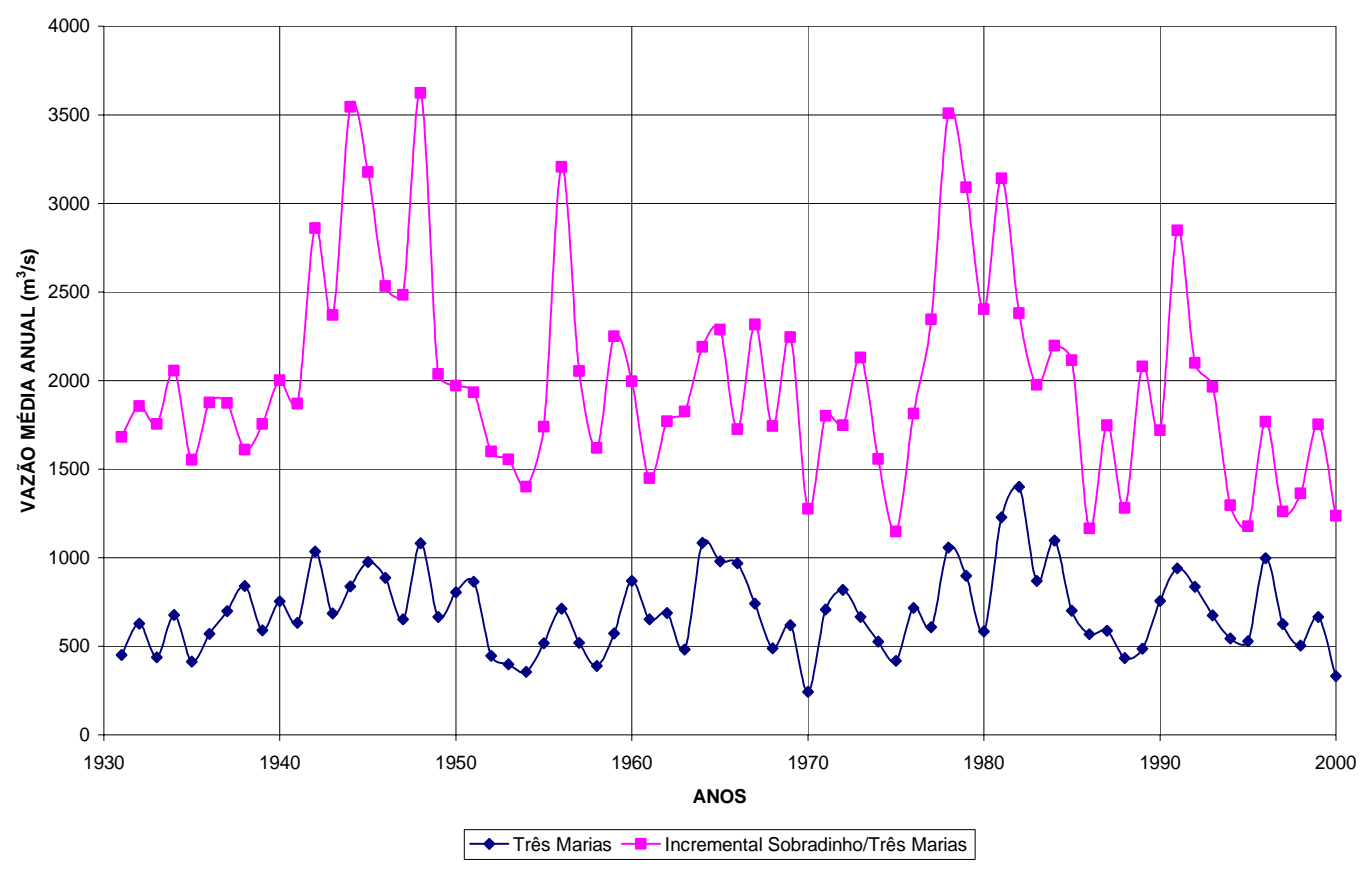

Figura 6.2 - Vazões Médias Anuais no Período 1931 a 2000 - Ano Hidrológico Out/Set

Os valores dos coeficientes de correlação entre as séries de Três Marias e a Incremental de Sobradinho são da ordem de 0,65, tanto para as séries anuais como para as séries mensais. Esse número indica que há uma considerável correlação espacial entre essas duas séries de vazão que deve ser levada em conta na formulação dos cenários hidrológicos.

Para seleção dos cenários, foram calculadas as médias móveis de 6 anos consecutivos para essas duas séries de vazão. A partir da distribuição conjunta dessas duas variáveis, foram selecionados os casos que correspondem aproximadamente ao $1^{\circ}, 2^{\circ}$ e $3^{\circ}$ quartil, ou seja, períodos de 6 anos consecutivos cujas médias móveis estão associadas a probabilidades acumuladas conjuntas, respectivamente, iguais a 25\%, 50\% e 75\%. Esses cenários foram denominados: "seco", "mediano" e "úmido", respectivamente. O gráfico da Figura 6.3 representa a distribuição conjunta das médias móveis de Três Marias e a incremental de Sobradinho. Os pontos 1, 2 e 3 desse gráfico referem-se aos valores que correspondem, aproximadamente, ao $1^{\circ}, 2^{\circ}$ e $3^{\circ}$ quartil dessa distribuição conjunta. 
Com base nesses resultados, os cenários hidrológicos foram caracterizados da seguinte forma:

- Cenário seco: ponto 1 da Figura 6.3, correspondente aproximadamente a uma probabilidade acumulada igual a $25 \%$, cujas vazões médias referem-se ao período outubro de 1966 a setembro de 1972.

- Cenário mediano: ponto 2 da Figura 6.3, correspondente aproximadamente a uma probabilidade acumulada igual a 50\%, cujas vazões médias referem-se ao período outubro de 1974 a setembro de 1980.

- Cenário úmido: ponto 3 da Figura 6.3, correspondente aproximadamente a uma probabilidade acumulada igual a 75\%, cujas vazões médias referem-se ao período outubro de 1940 a setembro de 1946.

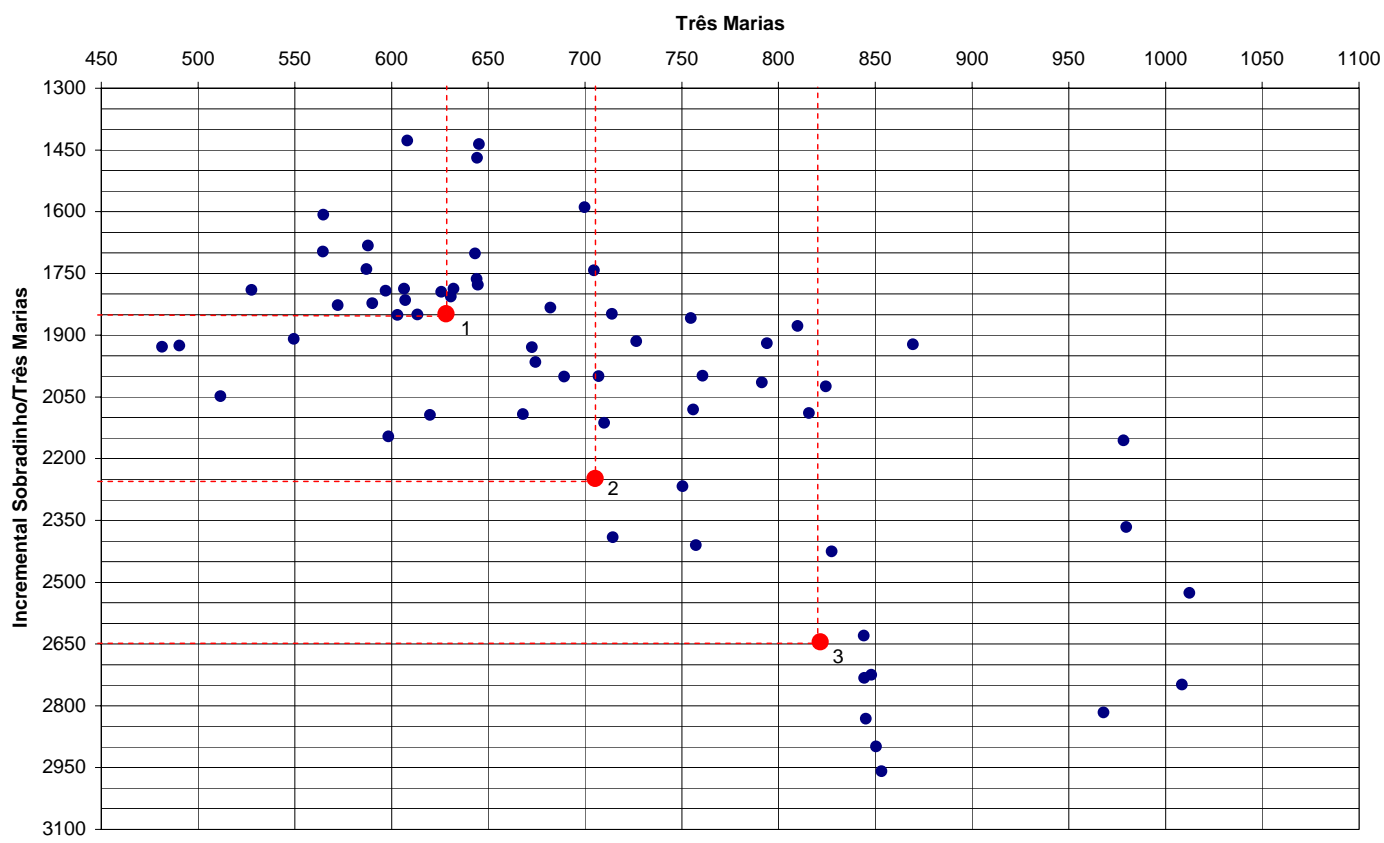

Figura 6.3 - Distribuição Conjunta das Médias Móveis de 6 Anos de Vazões Médias Anuais $\left(\mathrm{m}^{3} / \mathrm{s}\right)$ 


\subsection{Análise do Armazenamento Inicial dos Reservatórios}

Na seqüência dos trabalhos houve a necessidade de se definir o mês mais adequado para início do processo de otimização.

De forma a evitar que esse aspecto influa significativamente nos resultados, é aconselhável iniciar a modelagem em meses que os reservatórios estejam cheios. Para tanto, buscou-se definir esse mês a partir da otimização do sistema considerando toda a série histórica (1931 a 2001) e calcular os valores dos armazenamentos médios para cada mês do ano. Os resultados indicaram que as médias mais elevadas referem-se aos armazenamentos no final do mês de abril. Os valores resultantes foram os seguintes:

- $\quad$ Três Marias, armazenamento inicial $=83 \%$.

- Sobradinho, armazenamento inicial $=70 \%$.

- $\quad$ Itaparica, armazenamento inicial $=100 \%$.

As demais usinas são operadas a fio d'água.

Dessa forma, todos os processos de otimização foram realizados considerando como armazenamento inicial os valores retro-citados com início sempre no mês de maio e fim no mês de abril.

Com o objetivo de permitir a comparação entre os resultados dos diversos casos analisados, foi também estabelecido que o armazenamento final fosse igual ao inicial.

Assim, para efeito de processamento do modelo, os cenários hidrológicos definidos no item anterior foram estabelecidos, iniciando no mês de maio do ano seguinte ao definido por aqueles estudos, mantendo-se a extensão de 6 anos (72 meses).

Uma vez definidos os armazenamentos iniciais já citados, foi feita uma análise de sensibilidade desses parâmetros de forma a se avaliar a sua 
influência nos resultados do modelo de otimização. Para tanto, foram considerados valores de armazenamento inicial 20\% acima e 20\% abaixo dos valores adotados. Foram considerados os reservatórios de maior volume útil da bacia (Três Marias e Sobradinho). Os resultados obtidos indicaram diferenças percentuais na energia média gerada de menos de $1 \%$, o que reflete que a influência dos armazenamentos iniciais é pouco relevante nos resultados energéticos do sistema modelado, considerando que o período de análise é igual a seis anos. Para períodos de análise inferiores, esse efeito tende a se tornar mais significativo.

\subsection{Análise de Usos Múltiplos: Método das Restrições}

Os processamentos para análise do método das restrições foram feitos com base na maximização da energia média gerada em cada seqüência temporal considerada. As vazões derivadas para irrigação foram tratadas como restrições.

Foram considerados os três cenários hidrológicos selecionados, conforme descrito em 6.1, e mais o cenário correspondente ao período crítico dos sistemas interligados, que ocorreu na primeira metade da década de 1950. No processamento, esse cenário foi definido com base no período maio de 1951 a abril de 1957.

Os cenários da vazão de irrigação foram definidos a partir do valor das demandas indicadas para o ano 2007, conforme indicado em 5.1.4, respeitando-se as quantidades retiradas em cada trecho da bacia do rio São Francisco e os fatores de sazonalidade mostrados na Tabela 5.9. Esse cenário corresponde a uma vazão média anual derivada para irrigação na bacia igual a $230,5 \mathrm{~m}^{3} / \mathrm{s}$. Os demais cenários foram compostos a partir de múltiplos desse valor, entre zero e dois.

Com relação à questão da influência da solução inicial, foram feitos testes sem indicar valor para o ponto de partida, uma vez que o MINOS, segundo 
Murtagh et Saunders (1995), conta com procedimentos próprios para tanto. Esses resultados foram iguais aos produzido pela solução a fio d'água. Dessa forma, em todo o estudo não foi especificado nenhum valor como ponto de partida para as variáveis de decisão.

Na Tabela 6.1, são mostrados os resultados obtidos para os três cenários hidrológicos considerados e para o período crítico do setor elétrico. Esses resultados estão reproduzidos no gráfico da Figura 6.4, onde é possível visualizar a relação de troca, ou seja, o trade-off entre a irrigação e a geração hidrelétrica no sistema São Francisco. As curvas apresentadas nessa figura são as chamadas curvas de Pareto.

A título de ilustração, são mostrados no Anexo C os resultados completos da saída do modelo SFPLUS para o caso do cenário hidrológico mediano e vazões para irrigação referentes ao cenário $2007\left(230,5 \mathrm{~m}^{3} / \mathrm{s}\right)$.

Deve-se ressaltar que, no caso da otimização no período crítico, houve necessidade de se reduzir a restrição de vazão mínima a jusante de Três Marias de $500 \mathrm{~m}^{3} / \mathrm{s}$ para $400 \mathrm{~m}^{3} / \mathrm{s}$, dado que sem isso o problema de otimização se torna matematicamente inviável, devido à baixa disponibilidade hídrica do período. O valor da redução dessa vazão foi definido a partir de um processo de tentativa e erro.

Na Tabela 6.1, pode-se visualizar também o gradiente das curvas de Pareto da Figura 6.4. Esse parâmetro indica o valor do trade-off entre esses dois usos. No caso do cenário seco e do período crítico, esse gradiente é da ordem de $-2 \mathrm{MW}$-médios de geração por $\mathrm{m}^{3} / \mathrm{s}$ derivado para irrigação. Ou seja, para cada $\mathrm{m}^{3} / \mathrm{s}$ utilizado na irrigação, perde-se cerca de $2 \mathrm{MW}$-médios, que ao longo de um ano totalizam 17,5 GWh de energia.

Nos casos dos cenários mediano e seco, esse gradientes são respectivamente da ordem -1,3 e -0,8, conseqüência de uma maior disponibilidade hídrica contida nesses cenários. Com base nesses resultados, é possível notar a influência dos cenários hidrológicos nos trade- 
offs entre esses dois usos. Neste caso, como a vazão para irrigação é uma restrição a ser atendida sempre, a disponibilidade hídrica condiciona o quanto pode ser gerado pelas usinas hidrelétricas.

Tabela 6.1 - Relação de Troca entre Usos da Água no Sistema São Francisco - IrrigaçãoxEnergia

\begin{tabular}{|c|c|c|c|}
\hline \multicolumn{4}{|c|}{ Cenário Seco } \\
\hline Fator Irrigação & $\begin{array}{c}\text { Vazão Irrigação } \\
\left(\mathrm{m}^{3} / \mathrm{s}\right)\end{array}$ & $\begin{array}{c}\text { Energia Média } \\
\text { (MW-médio) }\end{array}$ & $\begin{array}{c}\text { Gradiente } \\
\left.\text { (MW-médio } / \mathrm{m}^{3} / \mathrm{s}\right)\end{array}$ \\
\hline 0,0 & 0,00 & 6169 & \\
\hline 0,5 & 115,25 & 5964 & $-1,779$ \\
\hline 1,0 & 230,50 & 5749 & $-1,866$ \\
\hline 1,5 & 345,75 & 5508 & $-2,091$ \\
\hline 2,0 & 461,00 & 5252 & $-2,221$ \\
\hline & & média ---> & $-1,989$ \\
\hline \multicolumn{4}{|c|}{ Cenário Mediano } \\
\hline Fator Irrigação & $\begin{array}{c}\text { Vazão Irrigação } \\
\left(\mathrm{m}^{3} / \mathrm{s}\right)\end{array}$ & $\begin{array}{c}\text { Energia Média } \\
\text { (MW-médio) }\end{array}$ & $\begin{array}{c}\text { Gradiente } \\
\left.\text { (MW-médio/m } / \mathrm{m}^{3} / \mathrm{s}\right)\end{array}$ \\
\hline 0,0 & 0,00 & 6708 & \\
\hline 0,5 & 115,25 & 6565 & $-1,241$ \\
\hline 1,0 & 230,50 & 6410 & $-1,345$ \\
\hline 1,5 & 345,75 & 6252 & $-1,371$ \\
\hline 2,0 & 461,00 & 6090 & $-1,406$ \\
\hline & & média ---> & $-1,341$ \\
\hline \multicolumn{4}{|c|}{ Cenário Úmido } \\
\hline Fator Irrigação & $\begin{array}{c}\text { Vazão Irrigação } \\
\left(\mathrm{m}^{3} / \mathrm{s}\right)\end{array}$ & $\begin{array}{l}\text { Energia Média } \\
\text { (MW-médio) }\end{array}$ & $\begin{array}{c}\text { Gradiente } \\
\left(\mathrm{MW}-\mathrm{mé}^{3} / \mathrm{m}^{3} / \mathrm{s}\right)\end{array}$ \\
\hline 0,0 & 0,00 & 7347 & \\
\hline 0,5 & 115,25 & 7278 & $-0,599$ \\
\hline 1,0 & 230,50 & 7191 & $-0,755$ \\
\hline 1,5 & 345,75 & 7096 & $-0,824$ \\
\hline 2,0 & 461,00 & 6998 & $-0,850$ \\
\hline & & média ---> & $-0,757$ \\
\hline \multicolumn{4}{|c|}{ Período Crítico } \\
\hline Fator Irrigação & $\begin{array}{c}\text { Vazão Irrigação } \\
\left(\mathrm{m}^{3} / \mathrm{s}\right)\end{array}$ & $\begin{array}{c}\text { Energia Média } \\
\text { (MW-médio) }\end{array}$ & $\begin{array}{c}\text { Gradiente } \\
\left(\mathrm{MW}-\text { médio }^{3} \mathrm{~m}^{3} \mathrm{~s}\right)\end{array}$ \\
\hline 0,0 & 0,00 & 5854 & \\
\hline 0,5 & 115,25 & 5616 & $-2,065$ \\
\hline 1,0 & 230,50 & 5372 & $-2,117$ \\
\hline 1,5 & 345,75 & 5123 & $-2,161$ \\
\hline \multirow[t]{2}{*}{2,0} & 461,00 & 4869 & $-2,204$ \\
\hline & & média ---> & $-2,137$ \\
\hline
\end{tabular}




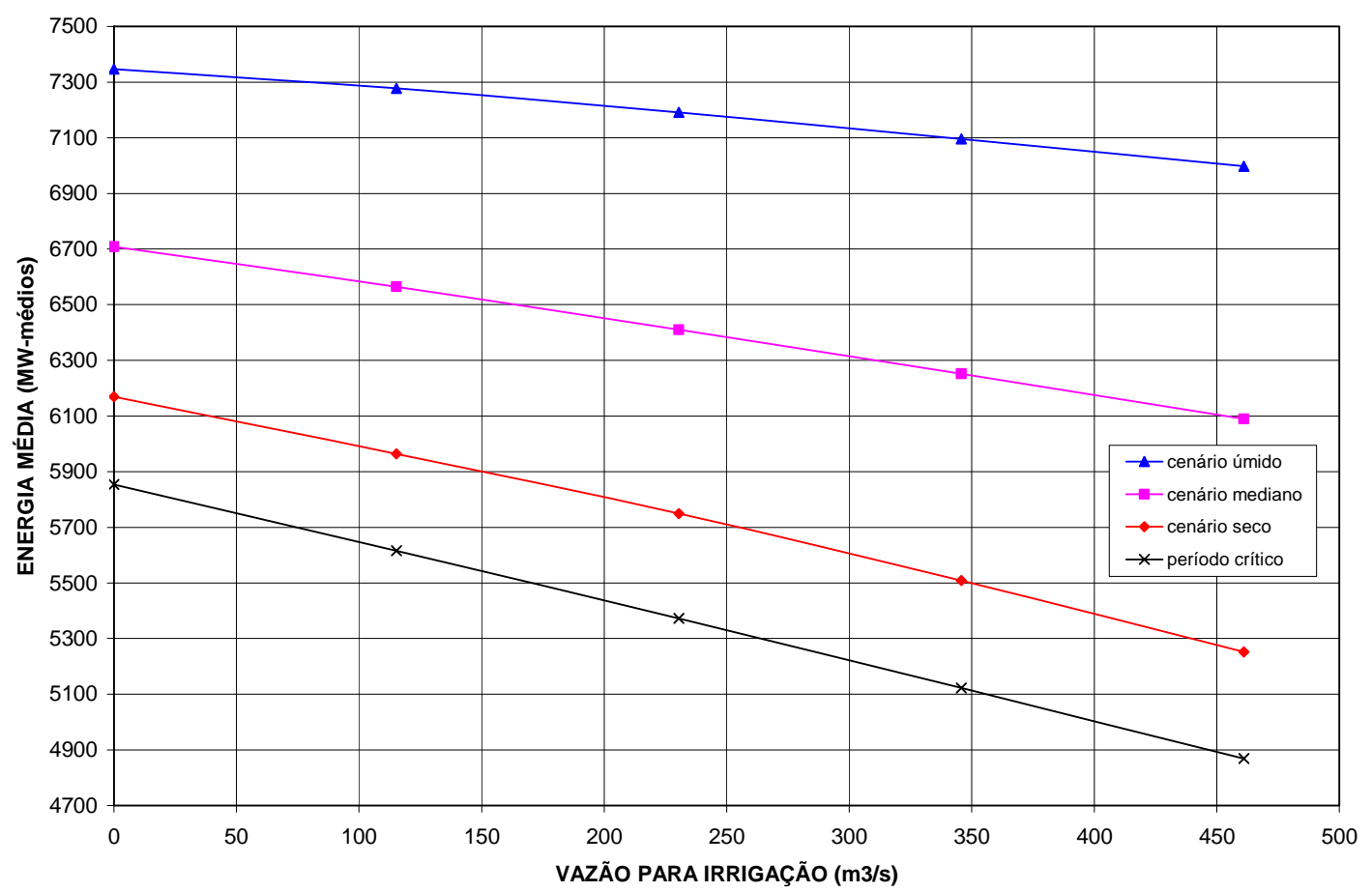

Figura 6.4 - Relação de Troca entre Usos da Água no Sistema São Francisco - IrrigaçãoxEnergia - Curvas de Pareto

\subsubsection{Análise da Influência da Transposição para o Nordeste Setentrional}

$\mathrm{Na}$ seqüência dos trabalhos, foi feita uma avaliação da influência das possíveis retiradas de água da bacia do São Francisco, via transposição, para outras regiões do Nordeste. Segundo estudos recentes (PORTO et MELLO, 2003) as vazões atualmente cogitadas a serem transpostas são da ordem de $48 \mathrm{~m}^{3} / \mathrm{s}$ a partir de Cabrobó, situada a jusante de Sobradinho, e 16 $\mathrm{m}^{3} / \mathrm{s}$ a partir do lago de Itaparica. Neste estudo, essas vazões foram consideradas constantes no tempo. Contudo, estudos ainda não conclusivos no âmbito da ANA indicam a possibilidade de retiradas sazonais da bacia em função do valor da água armazenada em Sobradinho.

Os resultados da redução da energia média com a transposição são mostrados na Tabela 6.2. Os valores chegam a atingir 3\% da produção 
energética nos casos mais críticos de cenários hidrológicos e de demandas de água para irrigação. Mesmo sem considerar as demandas para a irrigação na própria bacia, no cenário seco e no período crítico, a transposição causa uma perda energética de cerca de $2 \%$.

Tabela 6.2 - Avaliação da Redução Energética com a Transposição do São Francisco

\begin{tabular}{|c|c|c|c|}
\hline \multicolumn{2}{|c|}{ Cenário Seco } & \multicolumn{2}{|c|}{ Redução da Energia Média } \\
\hline Fator Irrigação & $\begin{array}{c}\text { Vazão Irrigação } \\
\left(\mathrm{m}^{3} / \mathrm{s}\right)\end{array}$ & MW-médios & Percentual \\
\hline 0,0 & 0,00 & -113 & $-1,83 \%$ \\
\hline 0,5 & 115,25 & -119 & $-2,00 \%$ \\
\hline 1,0 & 230,50 & -134 & $-2,33 \%$ \\
\hline 1,5 & 345,75 & -142 & $-2,58 \%$ \\
\hline 2,0 & 461,00 & -150 & $-2,86 \%$ \\
\hline \multicolumn{2}{|c|}{ Cenário Mediano } & \multicolumn{2}{|c|}{ Redução da Energia Média } \\
\hline Fator Irrigação & $\begin{array}{c}\text { Vazão Irrigação } \\
\left(\mathrm{m}^{3} / \mathrm{s}\right)\end{array}$ & MW-médios & Percentual \\
\hline 0,0 & 0,00 & -77 & $-1,15 \%$ \\
\hline 0,5 & 115,25 & -86 & $-1,31 \%$ \\
\hline 1,0 & 230,50 & -88 & $-1,37 \%$ \\
\hline 1,5 & 345,75 & -90 & $-1,44 \%$ \\
\hline 2,0 & 461,00 & -95 & $-1,56 \%$ \\
\hline \multicolumn{2}{|c|}{ Cenário Úmido } & \multicolumn{2}{|c|}{ Redução da Energia Média } \\
\hline Fator Irrigação & $\begin{array}{c}\text { Vazão Irrigação } \\
\left(\mathrm{m}^{3} / \mathrm{s}\right)\end{array}$ & MW-médios & Percentual \\
\hline 0,0 & 0,00 & -38 & $-0,52 \%$ \\
\hline 0,5 & 115,25 & -47 & $-0,65 \%$ \\
\hline 1,0 & 230,50 & -52 & $-0,72 \%$ \\
\hline 1,5 & 345,75 & -54 & $-0,76 \%$ \\
\hline 2,0 & 461,00 & -57 & $-0,81 \%$ \\
\hline \multicolumn{2}{|c|}{ Período Crítico } & \multicolumn{2}{|c|}{ Redução da Energia Média } \\
\hline Fator Irrigação & $\begin{array}{c}\text { Vazão Irrigação } \\
\left(\mathrm{m}^{3} / \mathrm{s}\right)\end{array}$ & MW-médios & Percentual \\
\hline 0,0 & 0,00 & -133 & $-2,27 \%$ \\
\hline 0,5 & 115,25 & -136 & $-2,42 \%$ \\
\hline 1,0 & 230,50 & -139 & $-2,59 \%$ \\
\hline 1,5 & 345,75 & -142 & $-2,77 \%$ \\
\hline 2,0 & 461,00 & -148 & $-3,04 \%$ \\
\hline
\end{tabular}

$\mathrm{Na}$ Figura 6.5, podem ser visualizadas as curvas de Pareto com a transposição do São Francisco. Os valores dos gradientes dessas curvas, ou 
seja, os valores dos trade-offs, são da mesma ordem de grandeza dos valores referentes à situação sem transposição.

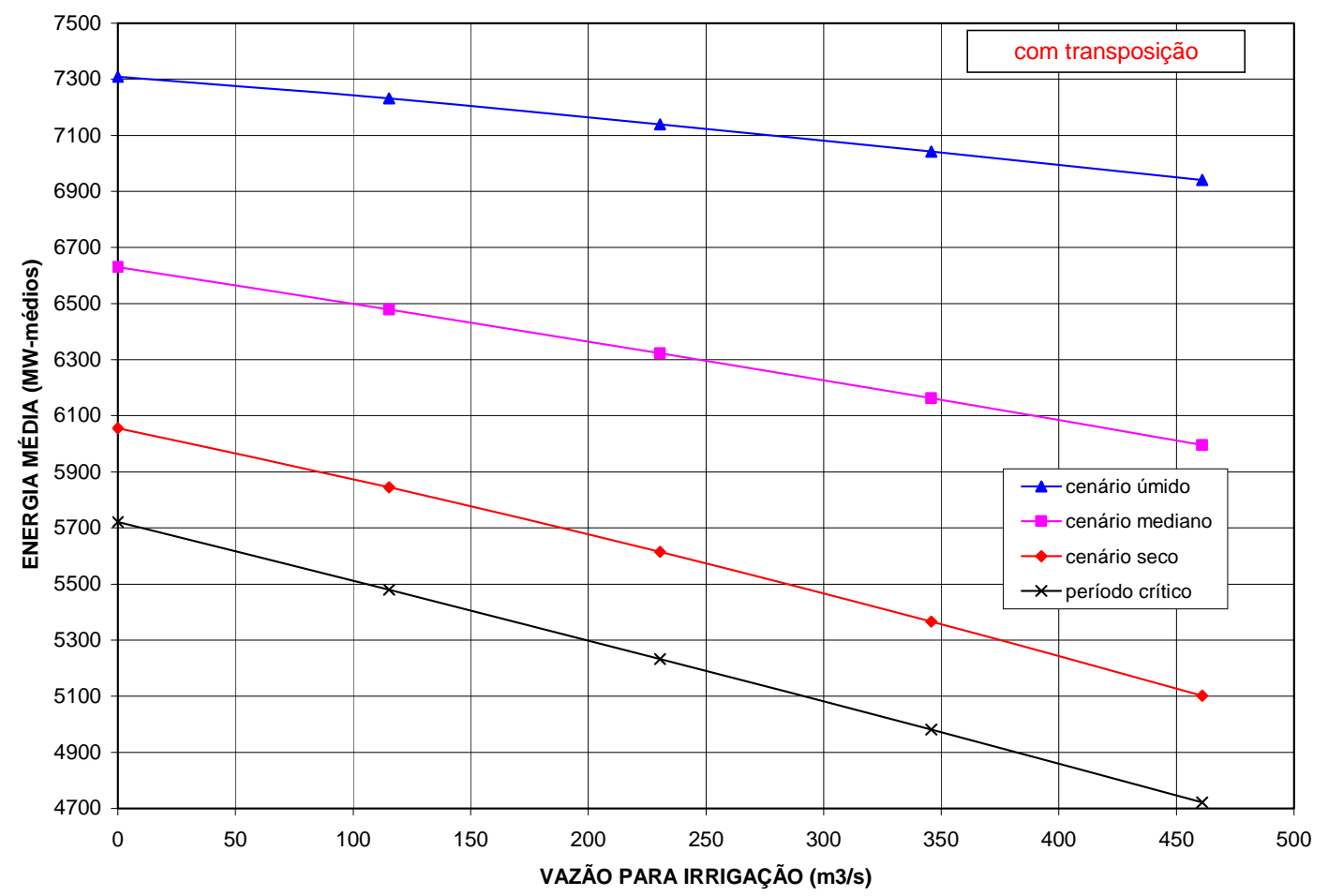

Figura 6.5 - Relação de Troca entre Usos da Água no Sistema São Francisco - IrrigaçãoxEnergia - Curvas de Pareto - com Transposição

Os resultados obtidos por esta análise indicam que a transposição do São Francisco, da forma como foi considerada neste estudo, não afeta significativamente a questão do uso múltiplo na bacia. 


\subsubsection{Análise dos Armazenamentos dos Reservatórios}

Esta análise enfoca as questões sobre os efeitos da utilização da água para geração de energia e irrigação nas trajetórias dos armazenamentos dos reservatórios. Dado que os volumes úteis expressivos da bacia do São Francisco estão alocados em Três Marias e Sobradinho, esta análise foi feita com base nesses dois reservatórios. Foram traçadas curvas de trajetórias de armazenamentos para cada usina, considerando as situações com e sem irrigação, para os três cenários hidrológicos em estudo. Essas curvas aparecem nas três figuras a seguir. As demandas para irrigação correspondem ao cenário para o ano 2007.

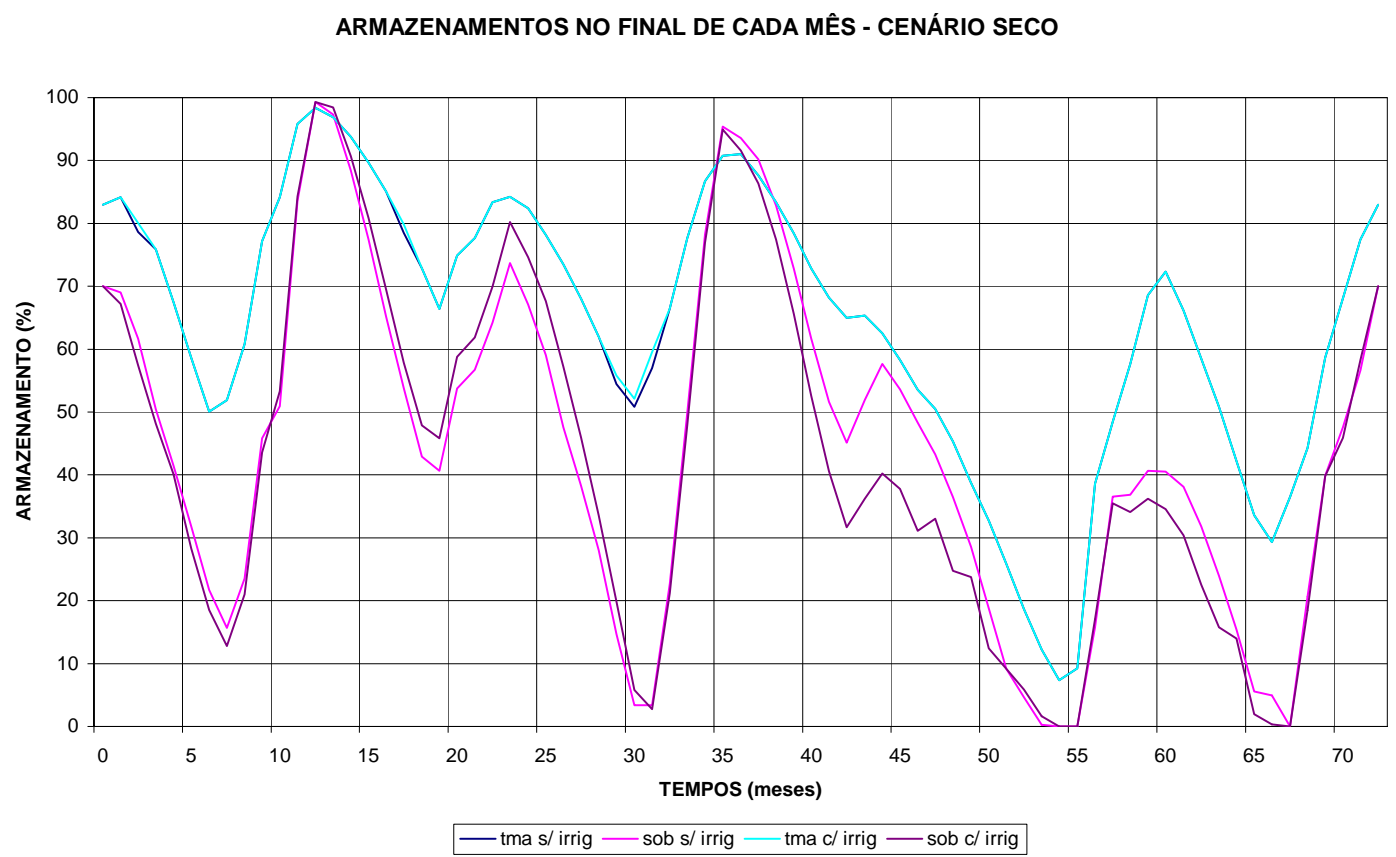

Figura 6.6 - Trajetória de Armazenamentos - Cenário Seco 
ARMAZENAMENTOS NO FINAL DE CADA MÊS - CENÁRIO MEDIANO

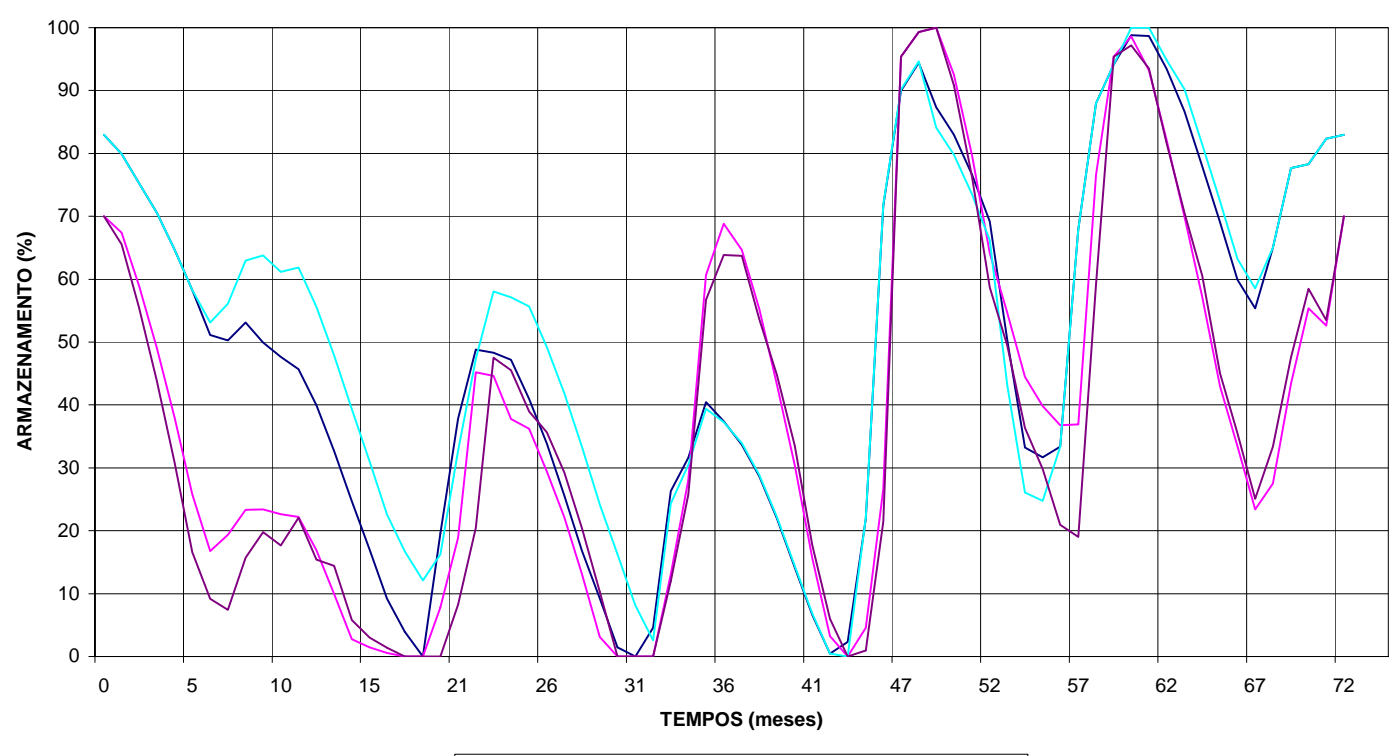

— tma s/irrig — sob s/ irrig — tma c/ irrig — sob c/ irrig

Figura 6.7 - Trajetória de Armazenamentos - Cenário Mediano

ARMAZENAMENTOS NO FINAL DE CADA MÊS - CENÁRIO ÚMIDO

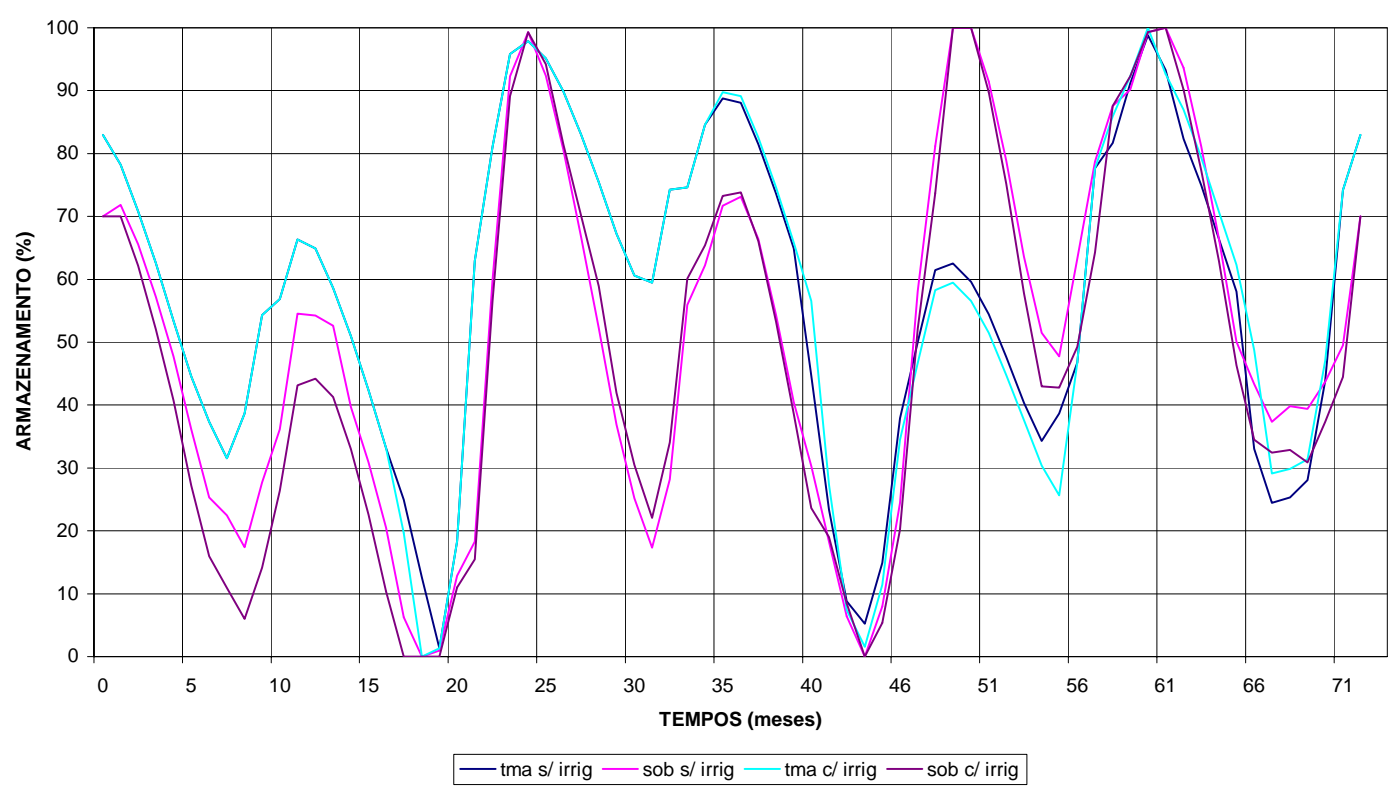

Figura 6.8 - Trajetória de Armazenamentos - Cenário Úmido 
Os resultados dessas trajetórias indicam que os dois reservatórios tendem a operar em fase, com ou sem irrigação, independente do cenário hidrológico.

Além disso, nota-que que as trajetórias de Três Marias praticamente não são afetadas pela irrigação. Isso é uma conseqüência do fato de não haver demandas para irrigação a montante desse reservatório, segundo a fonte de dados utilizada (ANA, 2002). No caso de Sobradinho, no cenário seco há uma utilização mais intensa dos volumes desse reservatório. Essa intensidade é um pouco mais pronunciada na situação com irrigação. 0 modelo tende a reservar um pouco mais de água em Três Marias para utilizá-la pouco antes do fim do período, quando ocorre o maior deplecionamento dos reservatórios.

No caso dos cenários mediano e úmido, nota-que a irrigação pouco afeta a operação dos reservatórios, cujas trajetórias de volumes apresentam a oscilação natural decorrente da sazonalidade hidrológica.

\subsection{Análise de Usos Múltiplos: Método das Ponderações}

Para avaliação do método das ponderações foi também utilizado o módulo do modelo SFPLUS, voltado para esse tipo de formulação, conforme exposto em 5.2.

Apenas para efeito de facilitar a análise, foram selecionados parâmetros de ponderação $\alpha$ e $\beta$ complementares, ou seja, valores cuja soma é igual à unidade. Não há, contudo, necessidade que esses parâmetros sejam complementares, apenas que expressem uma ordem de preferência entre um uso frente aos demais.

No caso em estudo, $\alpha$ e $\beta$ expressam a preferência relativa entre $1 \mathrm{MW}$ médio de energia gerada e $1 \mathrm{~m}^{3} / \mathrm{s}$ de água utilizada na irrigação.

Foram selecionados valores de $\alpha$ entre 0 e 1, e os correspondentes valores de $\beta$ foram calculados a partir da diferença entre a unidade e $\alpha$. Nas três 
figuras a seguir, são mostrados os resultados obtidos. Nessas figuras, podese visualizar, para cada par $\alpha$ e $\beta$, os valores correspondentes da vazão média para irrigação e da energia média gerada, através da curva referente a cada uso.

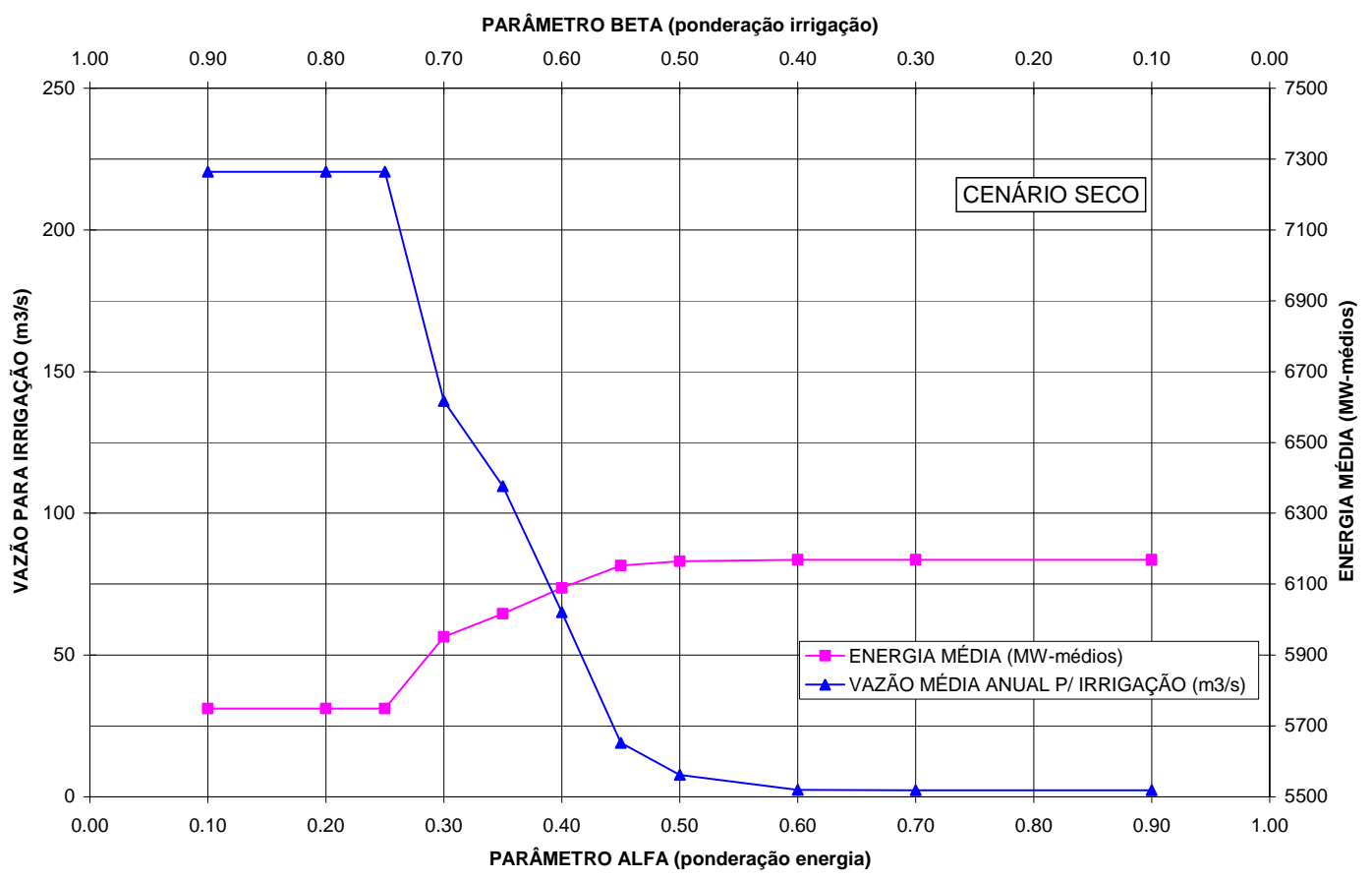

Figura 6.9 - Relação de Troca entre Usos da Água no Sistema São Francisco - Método das Ponderações - Cenário Seco 


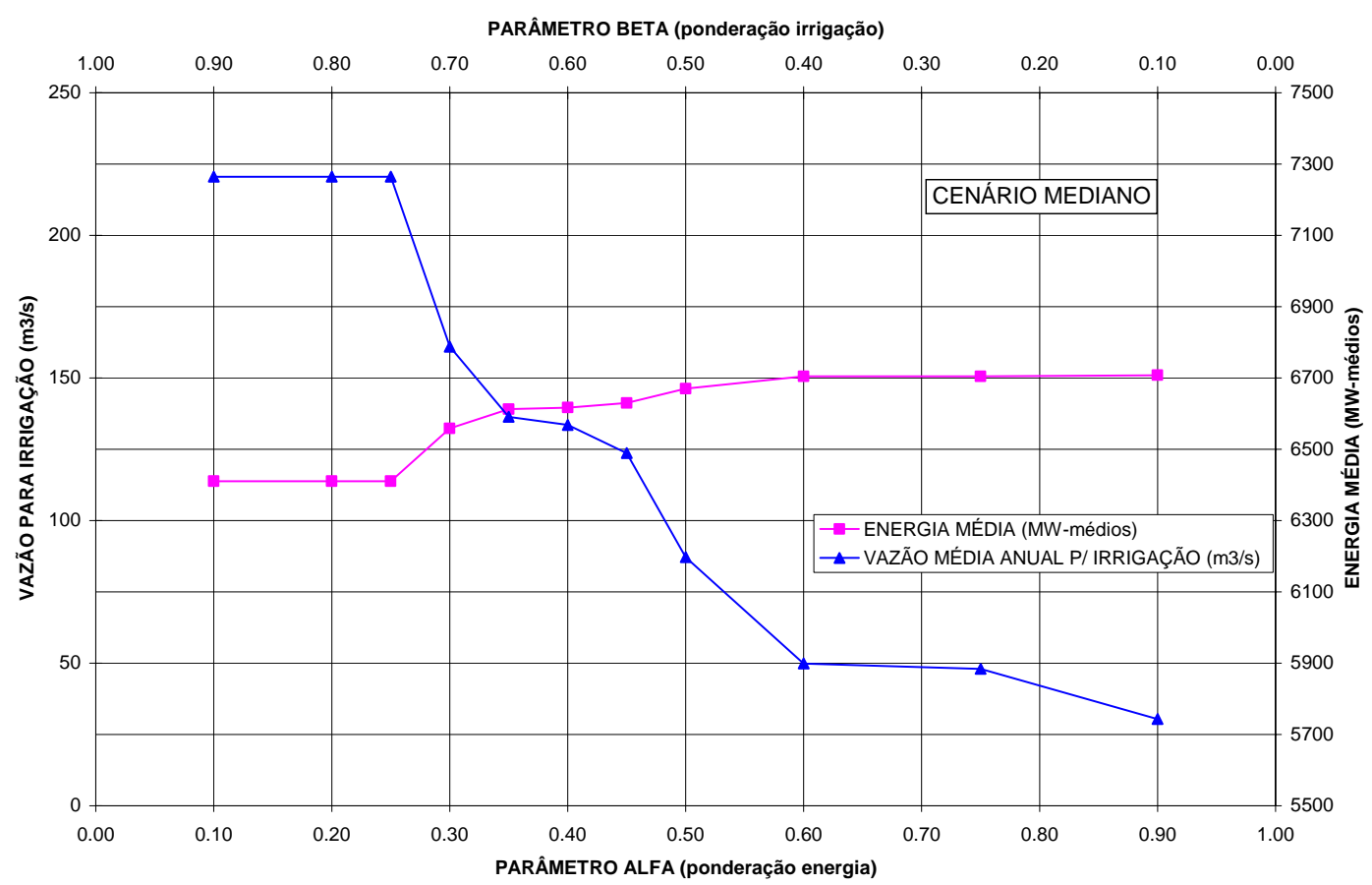

Figura 6.10 - Relação de Troca entre Usos da Água no Sistema São Francisco - Método das Ponderações - Cenário Mediano

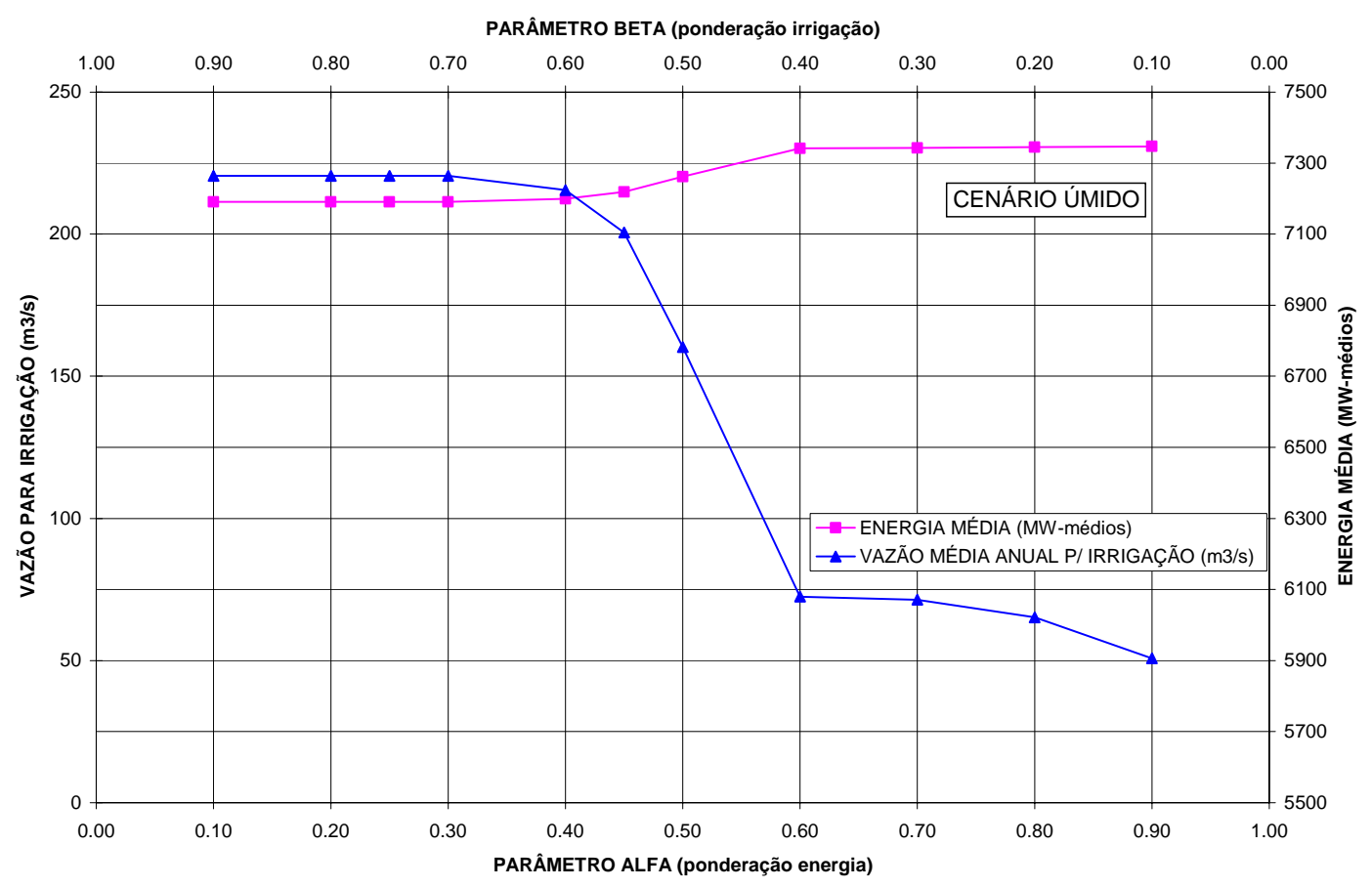

Figura 6.11 - Relação de Troca entre Usos da Água no Sistema São Francisco - Método das Ponderações - Cenário Úmido 
Segundo esses resultados, nota-se que, para os três cenários hidrológicos estudados, há uma região onde o trade-off entre a irrigação e a energia se dá de uma forma mais intensa. Essa região corresponde aproximadamente a valores de $\alpha$ entre $0,25(\beta=0,75)$ e $0,60(\beta=0,40)$. Fora dessa região encontram-se os limites máximo e mínimo para utilização dos dois usos. Ou seja, para valores de $\alpha$ abaixo de 0,25 ( $\beta$ acima de 0,75 ), encontra-se 0 limite superior da vazão para irrigação que é de $220,5 \mathrm{~m}^{3} / \mathrm{s}$ (demanda prevista para $2007 \mathrm{sem} 10 \mathrm{~m}^{3} / \mathrm{s}$ que é a demanda a jusante de Xingó e que não entra no trade-off, por esta ser a usina mais a jusante do sistema). Nesse caso, os valores da energia são mínimos em cada cenário hidrológico, e correspondem a cerca de 5750 MW-médios no cenário seco, 6400 MW-médios, no mediano e 7200 MW-medios, no úmido.

Para $\alpha$ acima de 0,60 ( $\beta$ abaixo de 0,40 ), encontram-se os valores mínimos para a irrigação, que são iguais a zero no cenário seco, e da ordem de 25 a $50 \mathrm{~m}^{3} / \mathrm{s}$, no mediano e entre 50 a $75 \mathrm{~m}^{3} / \mathrm{s}$, no úmido. Em contraposição, esses casos resultam nos valores máximos de energia para cada cenário hidrológico, ou seja, 6170 MW-médios no cenário seco, 6700 MW-médios, no mediano e 7350 MW-médios, no úmido.

Dessa forma, para valores de $\alpha$ entre $0,25(\beta=0,75)$ e $0,60(\beta=0,40)$ é que se pode pesquisar efetivamente o trade-off entre esses dois usos, pois, nesse caso, uma redução num dado uso provoca um aumento proporcional no outro. A fixação desses parâmetros é uma tarefa árdua e carregada de subjetividade. No caso de um sistema público, como é a maioria dos sistemas de recursos hídricos, numa situação extremamente idealizada, esses parâmetros devem refletir o valor que a sociedade atribui a cada uso. Porém, essa atividade extrapola a instância técnica e passa para a esfera política, que muitas vezes não reflete, de forma adequada, os anseios da sociedade. Além disso, muitas vezes fica muito difícil quantificar o reflexo de uma decisão no âmbito regional e mesmo nacional, devido à abrangência e à magnitude desses reflexos para a sociedade. 
Uma forma de introduzir um pouco mais de objetividade nesse tipo de análise, porém perdendo um pouco em abrangência, é através da aplicação do conceito de otimização econômica, que é apresentado na seqüência.

\subsubsection{Análise Econômica}

Uma forma de se resolver um problema de otimização com objetivo econômico é considerar na função-objetivo os benefícios econômicos produzidos pelo sistema em análise. Essa é na realidade uma forma particular do método das ponderações, onde os parâmetros de ponderação são explicitados a partir de valores econômicos.

No caso da irrigação e da geração hidrelétrica no vale do São Francisco, foram levantados dados para se calcular a receita bruta anual decorrente desses dois usos da água.

Para a quantificação da receita proveniente da irrigação, foi utilizada a vazão específica média de 0,58 l/s/ha, conforme ANA (2002). Para o valor da produção bruta anual por hectare irrigado, foi utilizado o índice de $\mathrm{R} \$$ 2.500,00/ha, levantado a partir de dados da produção de campos irrigados existentes na bacia (CODEVASF, sem data) referentes ao ano 2000.

Quanto ao valor da energia gerada, foi estimado o índice de $\mathrm{R} \$ 43,75 / \mathrm{MWh}$ obtido com base na produção e na receita da CHESF referentes à geração no ano de 2002 (CHESF, 2002).

A partir desses dados foi possível estabelecer uma função-objetivo com a finalidade de maximizar a receita bruta anual possível de ser auferida no sistema de reservatórios do São Francisco, considerando a irrigação e a geração de energia hidrelétrica.

Sabe-se que esses valores unitários são apenas indicadores do real valor econômico de cada um desses usos. Além disso, seria mais adequado analisar o problema do ponto de vista do benefício líquido, ou seja, haveria 
que se descontar desses índices os correspondentes valores dos custos operacionais. Como esses dados são de difícil avaliação, especificamente no que se refere à irrigação, optou-se pela análise com base na receita bruta.

Com o objetivo de contornar esses problemas, as análises foram feitas alterando-se os valores unitários adotados e verificado a sua influência nos resultados obtidos. Foram admitidas as seguintes alternativas para os valores unitários do hectare irrigado e da energia gerada:

- Alternativa 1: $1,0 * \mathrm{R} \$ 2500,00 /$ ha e $1,0 * \mathrm{R} \$ 43,75 / \mathrm{MWh}$.

- Alternativa 2: $1,0 * \mathrm{R} \$ 2500,00 /$ ha e $2,0 * \mathrm{R} \$ 43,75 / \mathrm{MWh}$.

- Alternativa 3: $\mathbf{0 , 5}{ }^{\star} \mathrm{R} \$ 2500,00 /$ ha e $\mathbf{2 , 0} \mathbf{0}^{\star} \mathrm{R} \$ 43,75 / \mathrm{MWh}$.

- Alternativa 4: $\mathbf{0 , 5}{ }^{\star} \mathrm{R} \$ 2500,00 /$ ha e $3,0 * \mathrm{R} \$ 43,75 / \mathrm{MWh}$.

Tabela 6.3 - Resultados da Análise Econômica

\begin{tabular}{|c|c|c|c|c|c|c|}
\hline \multirow{2}{*}{$\begin{array}{c}\text { ALTERNATIVAS } \\
\text { DE } \\
\text { COMPOSIÇÃO } \\
\text { DE VALORES } \\
\text { UNITÁRIOS } \\
\end{array}$} & \multicolumn{2}{|c|}{ CENÁRIO SECO } & \multicolumn{2}{|c|}{$\begin{array}{l}\text { CENÁRIO } \\
\text { MEDIANO }\end{array}$} & \multicolumn{2}{|c|}{ CENÁRIO ÚMIDO } \\
\hline & $\begin{array}{c}\text { VAZÃ̃O } \\
\text { IRRIGAČñO } \\
\left(\mathrm{m}^{3} / \mathrm{s}\right) \\
\end{array}$ & $\begin{array}{c}\text { ENERGIA } \\
\text { MÉDIAA } \\
\text { (MW-médios) }\end{array}$ & $\begin{array}{c}\text { VAZÃ̃O } \\
\text { IRRIGAČñO } \\
\left(\mathrm{m}^{3} / \mathrm{s}\right) \\
\end{array}$ & $\begin{array}{c}\text { ENERGIA } \\
\text { MÉDIA } \\
\text { (MW-médios) }\end{array}$ & $\begin{array}{c}\text { VAZÃ̃O } \\
\text { IRRIGAČ̃̃O } \\
\left(\mathrm{m}^{3} / \mathrm{s}\right) \\
\end{array}$ & $\begin{array}{c}\text { ENERGIA } \\
\text { MÉDIA } \\
\text { (MW-médios) }\end{array}$ \\
\hline 1 & 220,50 & 5749 & 220,50 & 6410 & 220,50 & 7191 \\
\hline 2 & 220,50 & 5749 & 220,50 & 6410 & 220,50 & 7191 \\
\hline 3 & 220,50 & 5749 & 220,50 & 6410 & 220,50 & 7191 \\
\hline 4 & 109,59 & 6017 & 6612 & 6612 & 220,50 & 7191 \\
\hline
\end{tabular}

Observando-se os resultados da Tabela 6.3, verifica-se que para a quase totalidade das situações analisadas, a otimização econômica implica em se adotar como vazão para irrigação, o valor máximo admitido para esse uso neste estudo (demanda prevista para 2007). Apenas nos caso dos cenários 
seco e mediano, e valorizando a irrigação em $\mathrm{R} \$ 1250,00 /$ ha e a energia em $\mathrm{R} \$$ 131,25/MWh, é que há algum trade-off entre esses dois usos, caso contrário, do ponto de vista macroeconômico, vale a pena atender as demandas para irrigação na bacia, mesmo que haja algum prejuízo para a geração hidrelétrica.

Essa é uma outra forma de se explicitar o trade-off entre dois usos conflitantes. A otimização econômica é menos abrangente que a análise multi-objetivo, enfocada neste estudo através do método das ponderações, porém o processo é menos subjetivo, desde que os índices unitários de avaliação econômica dos benefícios sejam definidos de forma realista. 


\section{ANÁLISE ESTOCÁSTICA DA OPERAÇÃO DE RESERVATÓRIOS}

Na seqüência do trabalho, foi feita uma avaliação do tratamento da questão estocástica relacionada com a natureza aleatória das vazões naturais afluentes aos reservatórios. Essas avaliações foram desenvolvidas a partir da formulação do problema de otimização segundo o método das restrições, com a imposição das demandas para irrigação para o ano 2007, como restrição a ser atendida pelo sistema. A função-objetivo adotada foi a maximização da energia média anual. Optou-se por esse tipo de abordagem nesta fase, em função dos resultados obtidos em 6.4.1, que, segundo a análise do ponto de vista econômico, indicam ser vantajoso o atendimento integral das demandas para irrigação na bacia do rio São Francisco.

O tratamento da questão estocástica foi baseado no esquema implícito. Para tanto, foram geradas séries sintéticas, que foram inseridas no modelo de otimização. Com base nos resultados obtidos, foram traçadas curvas de freqüência para as variáveis de interesse para a avaliação de desempenho do sistema.

\subsection{Geração de Séries Sintéticas}

Conforme visto em 4.2.2, o software utilizado nesta fase dos trabalhos foi 0 GESS desenvolvido pela Kelman Consultoria (2001b). Nesse processo foram gerados trechos de série com extensão de seis anos, seguindo os argumentos já apresentados em 5.2. Com o intuito de se avaliar a influência número de séries nos resultados, foram considerados conjuntos com 200, 500 e 1000 anos.

De acordo com o exposto em 6.1, as principais séries do sistema São Francisco são as referentes aos reservatórios de Três Marias e Sobradinho. 
Assim, essas foram consideradas as séries "chave" para a geração estocástica. As séries de Itaparica foram obtidas a partir de regressões lineares, para cada mês do ano, com a vazão de Sobradinho. As séries do complexo Paulo Afonso/Moxotó foram consideradas as mesmas de Itaparica, pois como visto em 6.1, a incremental entre esses dois aproveitamentos é nula. Ainda, conforme o exposto em 6.1, as séries de Xingó foram obtidas somando-se $10 \mathrm{~m}^{3} / \mathrm{s}$ aos valores correspondentes a Itaparica.

O software GESS, além de definir os parâmetros dos modelos estocásticos, faz uma série de análises e testes em relação às séries modeladas. Os resultados dessas análises são apresentados na seqüência.

\subsubsection{Resultados dos Testes de Hipótese sobre as Séries Históricas}

Os testes de hipótese, já apontados em 4.2.2, foram aplicados às séries "chave" do processo de geração, a saber, Três Marias e Sobradinho. Os resultados obtidos a partir do GESS são mostrados a seguir.

- Teste de Anderson - para verificação da independência dos resíduos transformados da série integral:

Três Marias - aceita independência (95\%) para lag's 3 a 30.

Sobradinho - idem anterior, exceto para lag 8, hipótese rejeitada.

- Teste de Porte-Manteau - para verificação da independência dos resíduos transformados da série integral:

Três Marias - aceita independência (90\%) para lag's 3 a 30.

Sobradinho - aceita independência para lag 3 (90\%) e lag 5 (95\%), lag's 8 a 30, independência rejeitada. 
- Teste de Ljung-Box - para verificação da independência dos resíduos transformados das séries sazonais.

Três Marias - aceita independência (90\%, 95\%, 99\%) para todos os meses, para lag's 3 a 30.

Sobradinho - idem anterior.

- Teste de correlação de Filliben - para verificação da normalidade dos resíduos transformados.

Três Marias - aceita normalidade $(90 \%$, ) para todos os meses, exceto abril (99\%). Para toda a série, aceita normalidade (90\%).

Sobradinho - aceita normalidade (90\%) nos meses de fevereiro, abril, junho, outubro e novembro. Aceita normalidade (95\%) nos meses de janeiro e dezembro. Aceita normalidade (99\%) nos meses de julho e setembro. Rejeita normalidade nos meses de maio e agosto. Aceita normalidade (90\%) para toda a série.

- Teste de Mann-Kendall - para verificação da homogeneidade da série histórica.

Três Marias - aceita homogeneidade $(90 \%$,$) para todos os meses$ e para a série anual.

Sobradinho - aceita homogeneidade (90\%) nos meses de outubro, novembro e dezembro. Aceita homogeneidade (95\%) no mês de janeiro. Aceita homogeneidade (99\%) nos meses de fevereiro, março, abril, setembro. Rejeitada homogeneidade nos meses de maio a agosto. Aceita homogeneidade (99\%) para a série anual.

- Teste de Smirnov - para verificação da homogeneidade da série histórica. 
Três Marias - aceita homogeneidade $(90 \%$,$) para todos os meses$ e para a série anual.

Sobradinho - aceita homogeneidade (90\%) nos meses de janeiro, março e abril e de setembro a dezembro. Aceita homogeneidade (95\%) nos meses de fevereiro e de maio a julho. Aceita homogeneidade (99\%) no mês de agosto. Aceita homogeneidade (90\%) para a série anual.

- Teste de Grubbs e Beck - para verificação de outliers na série histórica: Três Marias - 7 outliers, em 3 anos. Sobradinho - 2 outliers, em 2 anos.

\subsubsection{Funções de Autocorrelação das Séries Históricas}

As funções de autocorrelação das séries históricas servem para auxiliar no processo de avaliação do tipo e da ordem dos modelos estocásticos a serem utilizados para geração das séries sintéticas. O programa GESS utiliza modelos estocásticos do tipo PAR, ou seja, modelos auto-regressivos periódicos, e também estima os parâmetros desses modelos.

De qualquer forma, o programa calcula as funções de autocorrelação e autocorrelação parcial para as séries em análise. Essas funções são determinadas para a série contínua e para as séries referentes ao período adotado para a análise, que no caso deste estudo é o mensal. Essas funções, referentes às séries de Três Marias e Sobradinho são mostradas nos gráficos da Figura 7.1 à Figura 7.8. 


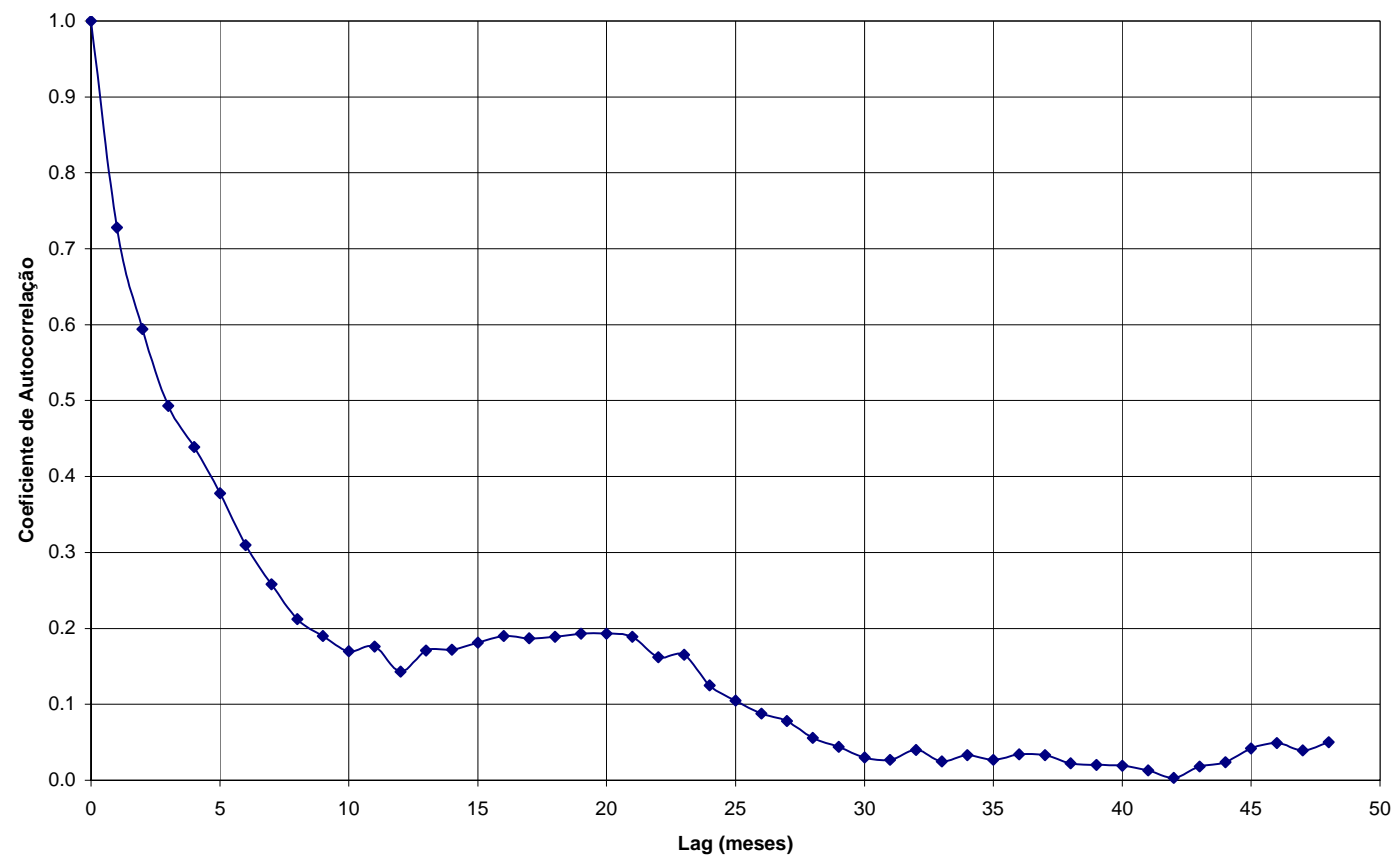

Figura 7.1 - Função de Autocorrelação da Série Contínua - Três Marias

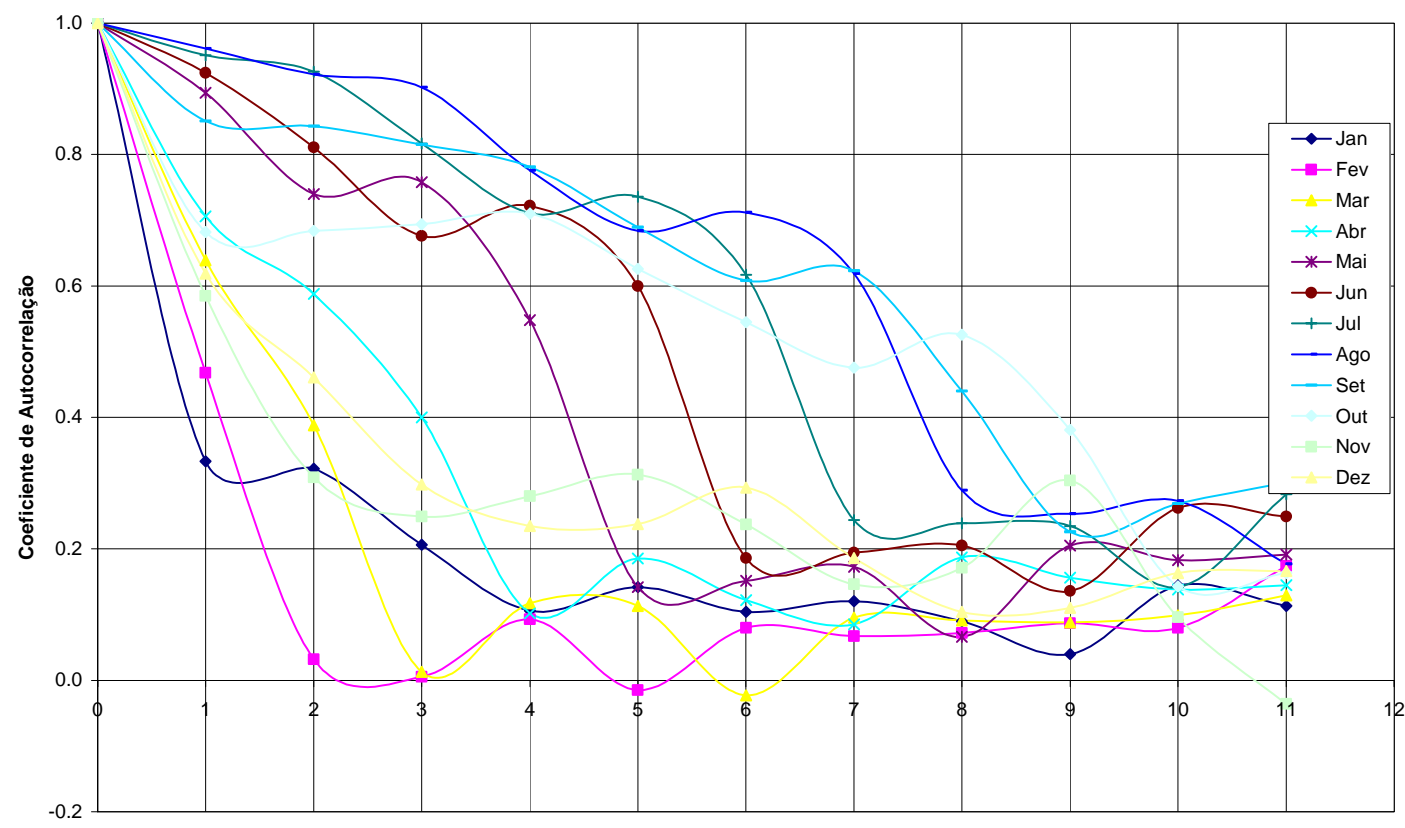

Lag (meses)

Figura 7.2 - Funções de Autocorrelação Periódicas - Três Marias 


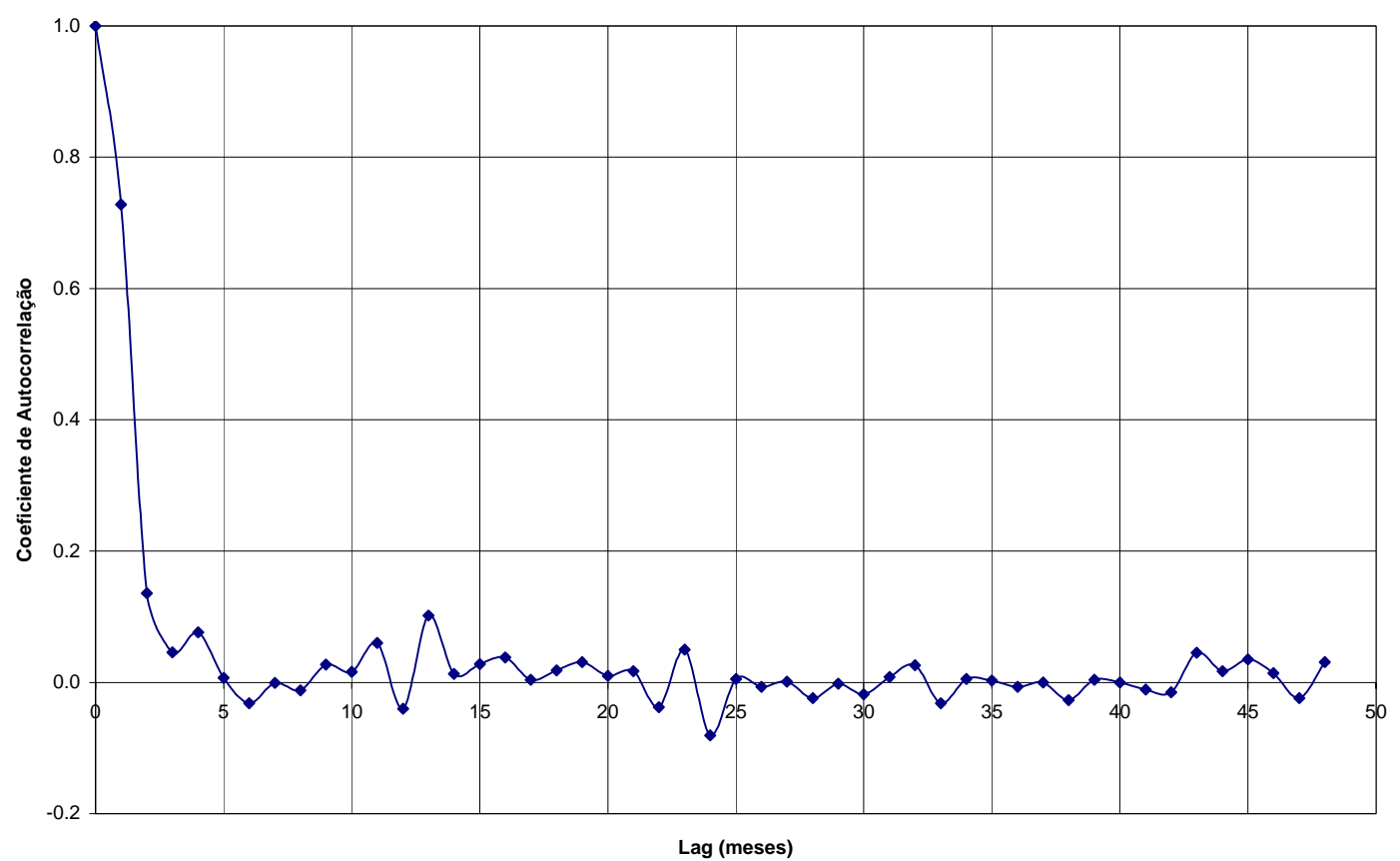

Figura 7.3 - Função de Autocorrelação Parcial da Série Contínua - Três Marias

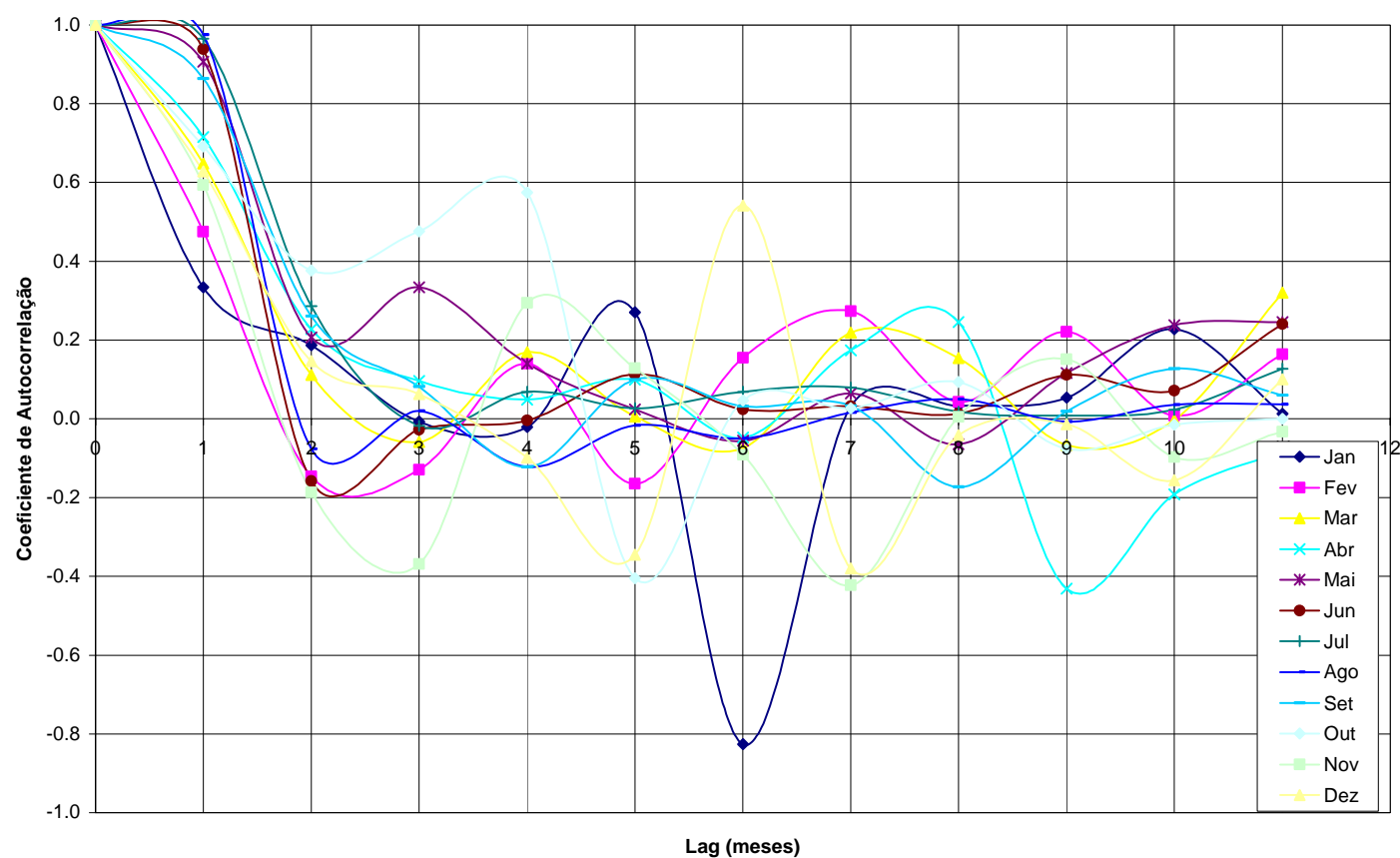

Figura 7.4 - Funções de Autocorrelação Parcial Periódicas - Três Marias 


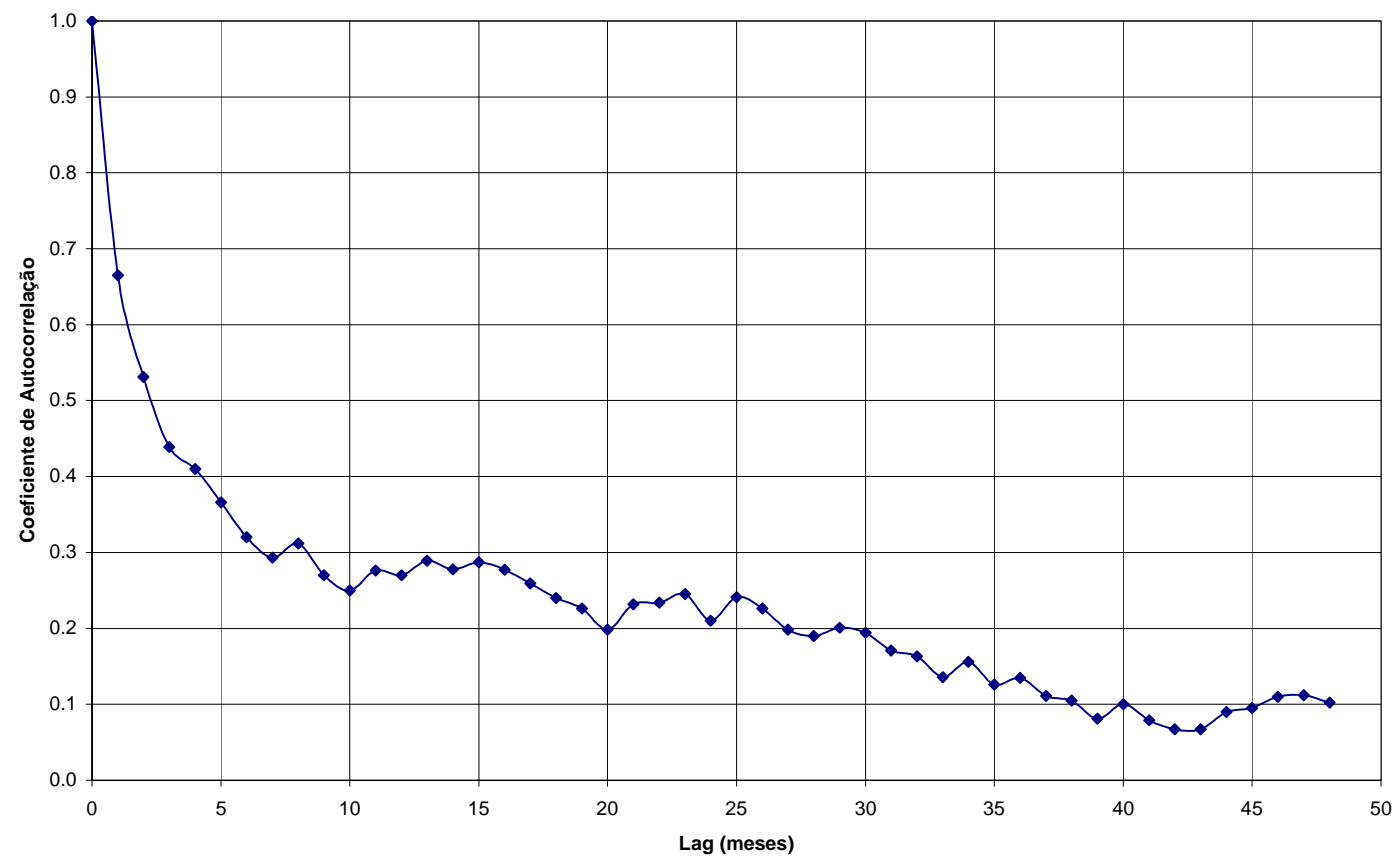

Figura 7.5 - Função de Autocorrelação da Série Contínua - Sobradinho

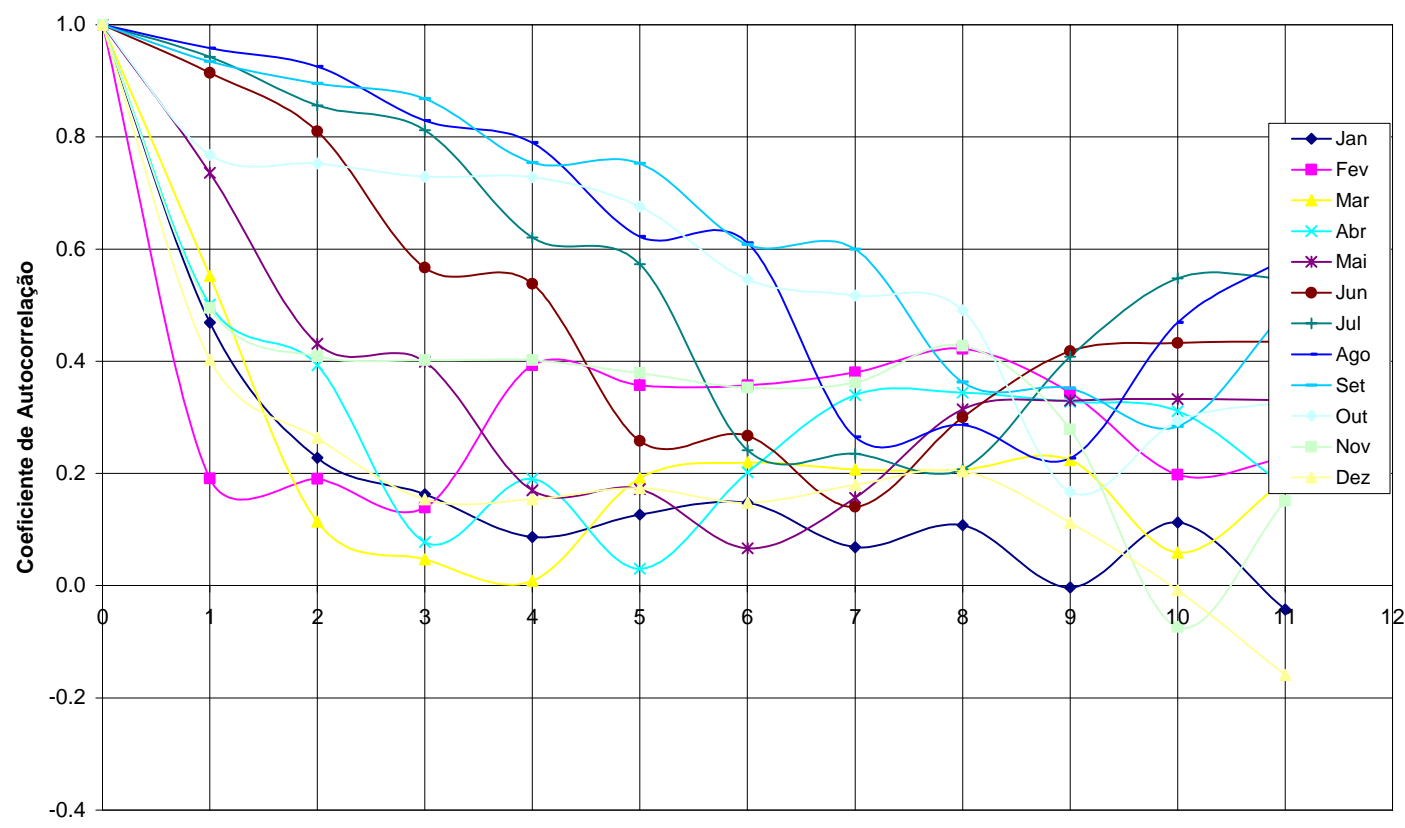

Lag (meses)

Figura 7.6 - Funções de Autocorrelação Periódicas - Sobradinho 


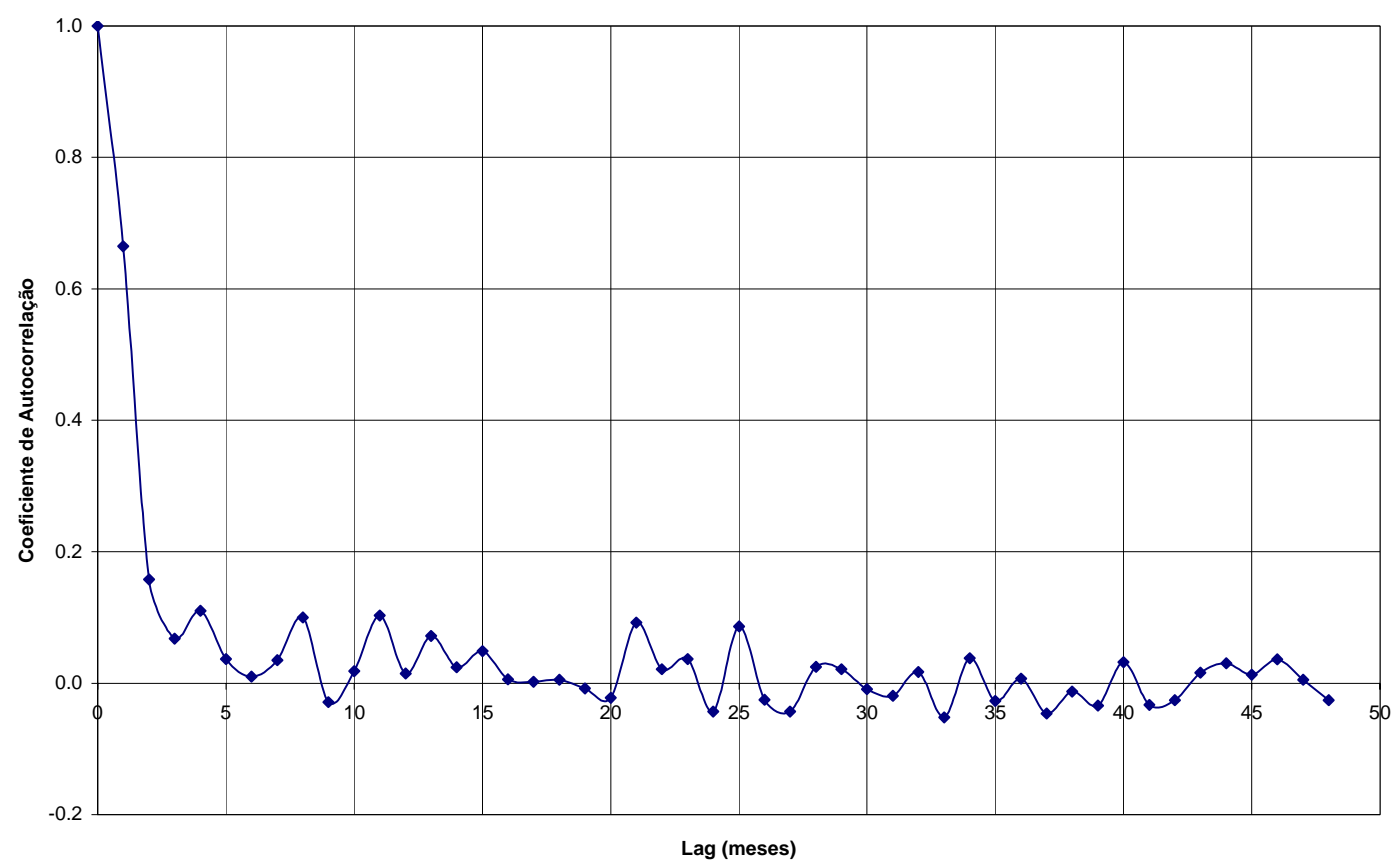

Figura 7.7 - Função de Autocorrelação Parcial da Série Contínua Sobradinho

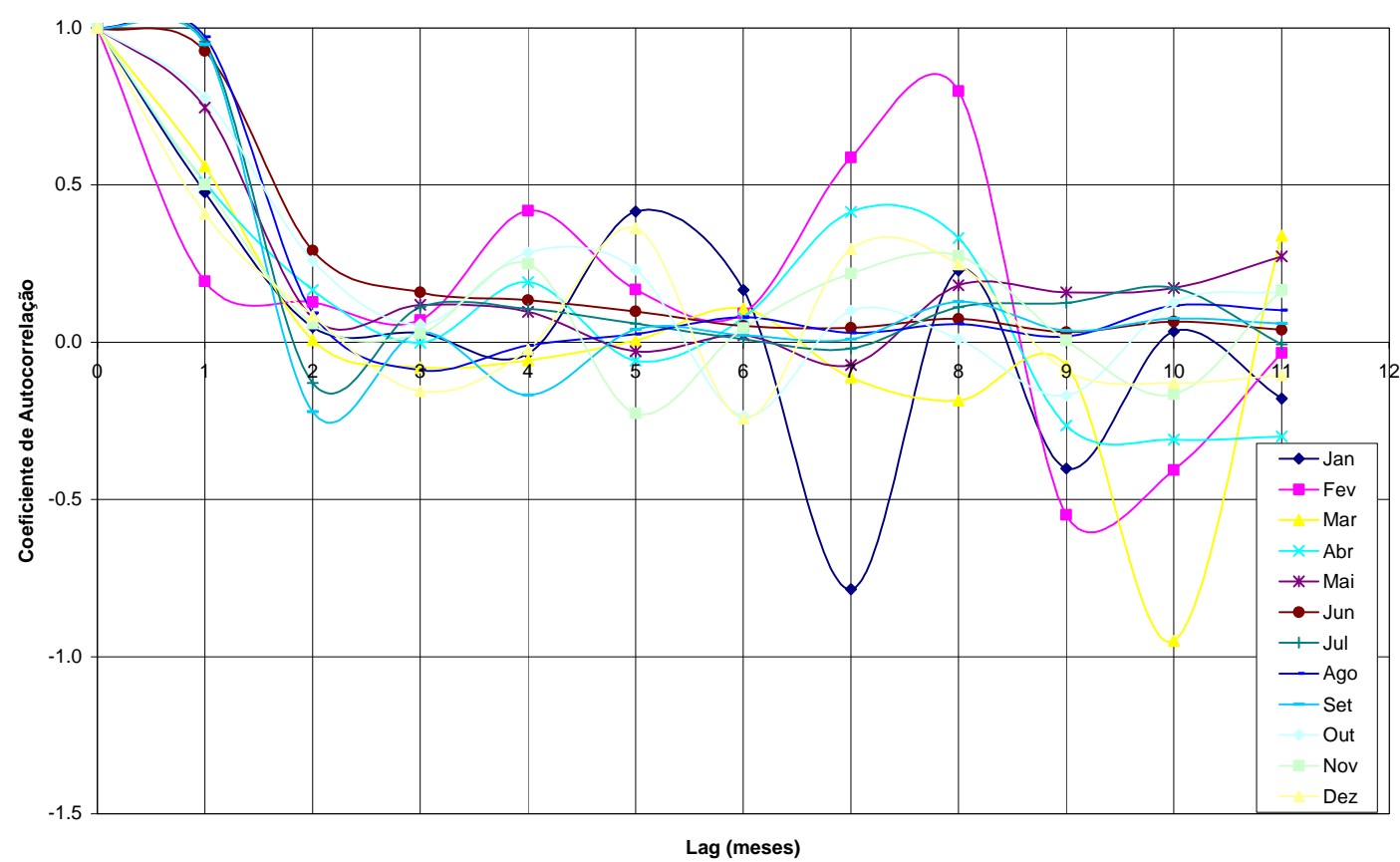

Figura 7.8 - Funções de Autocorrelação Parcial Periódicas Sobradinho 
Os gráficos das funções de autocorrelação e autocorrelação parcial para séries contínuas, tanto de Três Marias como de Sobradinho, sugerem modelos auto-regressivos de baixa ordem ( $p=1$ ou 2). Contudo, esse tipo de modelo não é utilizado pelo GESS.

As funções de autocorrelação periódicas sugerem modelos auto-regressivos de baixa ordem para os períodos referentes a meses de maior disponibilidade hídrica (novembro, dezembro, janeiro, fevereiro, março e abril), tanto em Três Marias como em Sobradinho. Para os demais meses do ano e para as duas séries em análise há uma tendência para modelos autoregressivos de ordem 3,4 ou 5 , havendo até a possibilidade de modelos do tipo PARMA (caso do mês de novembro em Sobradinho).

\subsubsection{Parâmetros dos Modelos Estocásticos}

Os parâmetros dos modelos estocásticos identificados e estimados pelo software GESS são mostrados na Tabela 7.1.

Cabe salientar que o critério adotado pelo GESS para estimativa dos modelos estocásticos, conforme descrito em 4.2.2, é baseado na minimização da variância residual, e, dessa forma, não leva em conta a análise de funções de autocorrelação, como mostrado no item anterior. 
Tabela 7.1 - Modelos PAR(p) Identificados e Parâmetros Estimados

\begin{tabular}{|c|c|c|c|c|c|c|c|c|c|c|c|c|}
\hline \multicolumn{13}{|c|}{ Série: TRÊS MARIAS - Histórico: 1931/2001 } \\
\hline & Jan & Fev & Mar & Abr & Mai & Jun & Jul & Ago & Set & Out & Nov & Dez \\
\hline Media & 1510 & 1416 & 1160 & 770 & 472 & 355 & 283 & 229 & 216 & 284 & 580 & 1089 \\
\hline D. Padrão & 712 & 822 & 566 & 374 & 185 & 146 & 98.9 & 77 & 78.2 & 118 & 292 & 476 \\
\hline Ordem $\mathrm{p}$ & 4 & 5 & 4 & 4 & 4 & 2 & 6 & 1 & 5 & 4 & 3 & 3 \\
\hline Parâmetros & 0.219 & 0.55 & 0.585 & 0.502 & 0.646 & 1.081 & 0.657 & 0.975 & 0.666 & 0.329 & 0.79 & 0.551 \\
\hline & 0.186 & -0.08 & 0.132 & 0.207 & 0.047 & -0.16 & 0.2 & & 0.189 & 0.004 & 0.085 & 0.097 \\
\hline & 0.01 & -0.23 & -0.16 & 0.118 & 0.286 & & 0.018 & & 0.161 & -0.14 & -0.37 & 0.063 \\
\hline & -0.02 & 0.267 & 0.169 & 0.049 & 0.14 & & 0.062 & & -0.24 & 0.575 & & \\
\hline & & -0.17 & & & & & 0.029 & & 0.099 & & & \\
\hline & & & & & & & 0.069 & & & & & \\
\hline $\begin{array}{l}\text { Variância } \\
\text { Residual }\end{array}$ & 0.853 & 0.713 & 0.528 & 0.404 & 0.08 & 0.115 & 0.054 & 0.049 & 0.244 & 0.445 & 0.589 & 0.581 \\
\hline \multicolumn{13}{|c|}{ Série: SOBRADINHO - Histórico: 1931/2001 } \\
\hline & Jan & Fev & Mar & Abr & Mai & Jun & Jul & Ago & Set & Out & Nov & Dez \\
\hline Media & 3262 & 3612 & 3730 & 3081 & 1913 & 1293 & 1074 & 932 & 815 & 866 & 1300 & 2333 \\
\hline D. Padrão & 1234 & 1642 & 2339 & 1458 & 1053 & 450 & 308 & 245 & 210 & 229 & 531 & 853 \\
\hline Ordem p & 6 & 4 & 1 & 4 & 3 & 5 & 5 & 6 & 2 & 6 & 1 & 5 \\
\hline \multirow[t]{6}{*}{ Parâmetros } & 0.452 & 0.12 & 0.56 & 0.412 & 0.689 & 0.642 & 0.793 & 0.809 & 1.162 & 0.614 & 0.502 & 0.365 \\
\hline & 0.034 & 0.076 & & 0.158 & 0.02 & 0.238 & -0.02 & 0.139 & -0.22 & 0.11 & & 0.205 \\
\hline & 0.028 & -0.13 & & -0.1 & 0.119 & 0.096 & 0.116 & -0.03 & & -0.04 & & -0.09 \\
\hline & -0.38 & 0.419 & & 0.191 & & 0.118 & 0.088 & 0.011 & & 0.117 & & -0.41 \\
\hline & 0.236 & & & & & 0.098 & 0.06 & 0.007 & & 0.224 & & 0.362 \\
\hline & 0.166 & & & & & & & 0.079 & & -0.23 & & \\
\hline $\begin{array}{l}\text { Variância } \\
\text { Residual }\end{array}$ & 0.751 & 0.814 & 0.676 & 0.656 & 0.423 & 0.063 & 0.068 & 0.049 & 0.099 & 0.351 & 0.737 & 0.8 \\
\hline
\end{tabular}

\subsubsection{Análise da Correlação Espacial Anual}

$\mathrm{Na}$ Tabela 7.2, são mostrados os resultados das correlações espaciais anuais entre Três Marias e Sobradinho. É mostrado o valor obtido para o coeficiente de correlação entre as séries históricas e os valores característicos decorrentes da série de coeficientes de correlação obtidos a partir da geração de 500 séries em paralelo. 
Tabela 7.2 - Correlações Espaciais Anuais das Séries Históricas e Sintéticas

\begin{tabular}{|c|c|}
\hline \multicolumn{2}{|c|}{ CORRELAÇÕES CRUZADAS DAS SÉRIES } \\
HISTÓRICAS E SINTÉTICAS ANUAIS (Lag 0) \\
\hline \multicolumn{2}{|c|}{ TRÊS MARIAS e SOBRADINHO } \\
\hline Séries Históricas: & 0,796 \\
\hline \multicolumn{2}{|c|}{ Séries Sintéticas: } \\
\hline Quartil 1 & 0,694 \\
\hline Quartil 2 & 0,850 \\
\hline Quartil 3 & 0,927 \\
\hline
\end{tabular}

De acordo com os resultados da tabela anterior, nota-se que o processo de geração de séries sintéticas preservou, de forma aproximada, as correlações cruzadas contemporâneas entre Três Marias e Sobradinho para a maioria das séries geradas.

\subsubsection{Análise da Autocorrelação Anual}

Os resultados da análise do coeficiente de correlação serial anual (lag 1) são mostrados na Tabela 7.3.

Tabela 7.3 - Coeficientes de Autocorrelação Serial Anual (lag 1)

\begin{tabular}{|c|c|c|c|c|c|}
\hline \multicolumn{1}{|c|}{ Local } & $\begin{array}{c}\text { Série } \\
\text { Histórica }\end{array}$ & $\begin{array}{c}1000 \\
\text { Séries } \\
\text { Sintéticas } \\
\text { de } \mathbf{6} \text { anos }\end{array}$ & $\begin{array}{c}\text { 500 Séries } \\
\text { Sintéticas } \\
\text { de 6 anos }\end{array}$ & $\begin{array}{c}\mathbf{2 0 0} \text { Séries } \\
\text { Sintéticas } \\
\text { de } 6 \text { anos }\end{array}$ & $\begin{array}{c}\text { Série } \\
\text { Contínua } \\
\text { com 500 } \\
\text { anos }\end{array}$ \\
\hline Três Marias & 0,4867 & 0,2720 & 0,2645 & 0,2511 & 0,2787 \\
\hline Sobradinho & 0,5426 & 0,3322 & 0,3135 & 0,3241 & 0,3451 \\
\hline
\end{tabular}

Os resultados da Tabela 7.3 mostram que há uma coerência entre os coeficientes de autocorrelação anual das séries geradas em paralelo (em traços de 6 anos) e a série continua de 500 anos. Contudo, comparado os coeficientes das séries sintéticas com os das séries históricas, nota-se que 
estas últimas apresentam uma persistência temporal anual mais elevada que a dos modelos estocásticos. Neste caso, os modelos estocásticos gerados pelo GESS não preservaram os coeficientes de correlação serial anual das séries históricas.

\subsection{Resultados da Análise Estocástica}

A partir do processamento do modelo de otimização com os três conjuntos de séries sintéticas (200, 500 e 1000 séries) foram calculadas as distribuições de probabilidades acumuladas de energia média correspondentes. Essas curvas são mostradas na Figura 7.9.

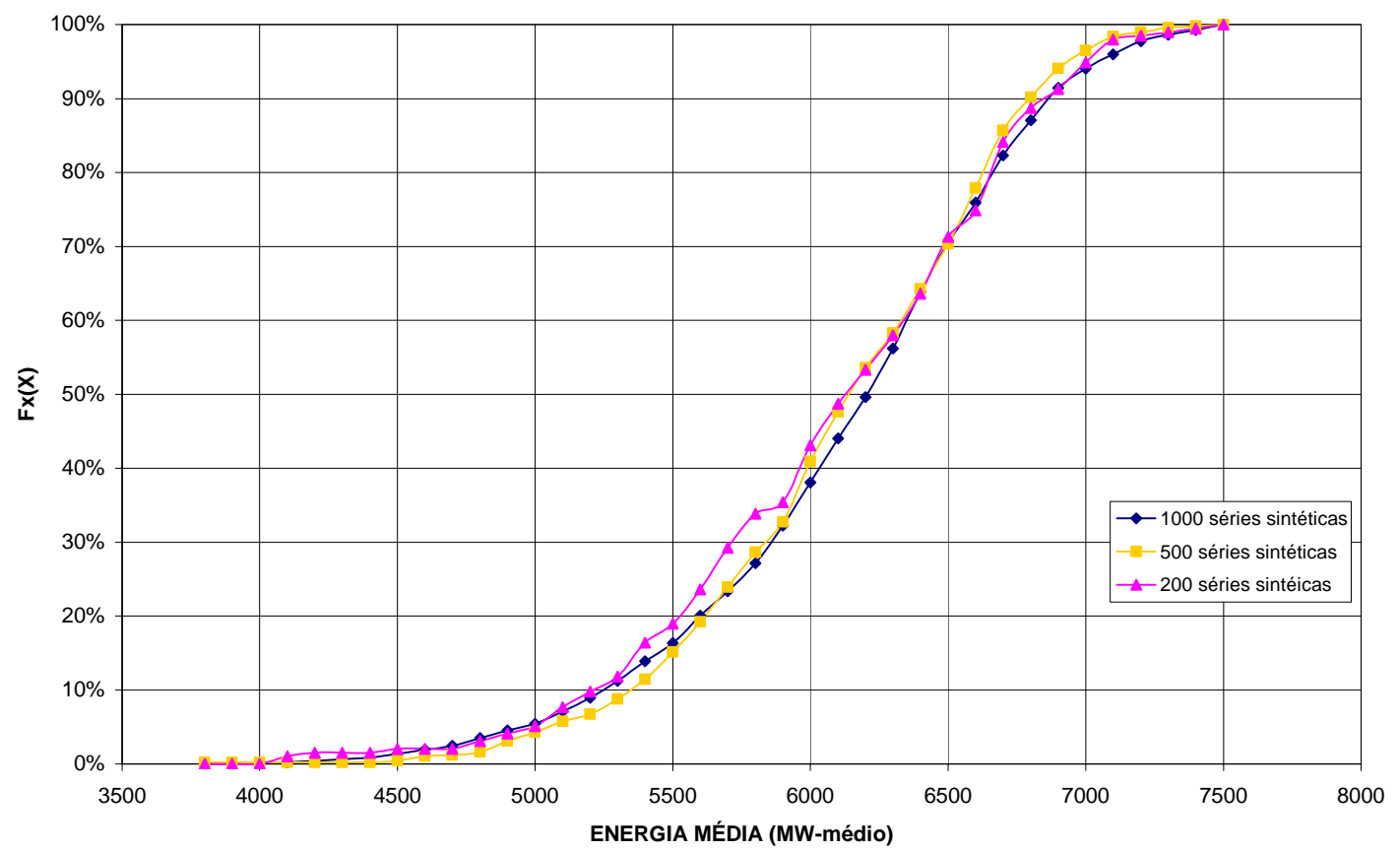

Figura 7.9 - Curvas de Probabilidades Acumuladas de Energia Obtidas com Séries Sintéticas

Observando-se as curvas da Figura 7.9, nota-se pouca diferença entre as distribuições relativas a cada caso. De forma a se avaliar estatisticamente a hipótese de igualdade dessas três distribuições, foi aplicado o teste de 
Kolmogorov-Smirnov, conforme descrito em 4.2.1. Os resultados desse teste são mostrados na Tabela 7.4.

Tabela 7.4 - Teste de Kolmogorov-Smirnov para as Distribuições de Probabilidades de Energia Obtidas com Séries Sintéticas

\begin{tabular}{|l|c|c|c|}
\cline { 2 - 4 } \multicolumn{1}{c|}{} & \multicolumn{3}{c|}{ Teste entre Distribuições de Probabilidades de Energia Média } \\
\cline { 2 - 4 } \multicolumn{1}{c|}{} & 1000 séries e 500 séries & 500 séries e 200 séries & 1000 séries e 200 séries \\
\hline Valor Crítico 90\% & 0,06764 & 0,10333 & 0,09573 \\
\hline Valor Crítico 95\% & 0,07540 & 0,11518 & 0,10671 \\
\hline Estatística "D" & 0,03990 & 0.05304 & 0,06686 \\
\hline
\end{tabular}

Os resultados da Tabela 7.4 mostram que, para os níveis de significância de 90\% e de 95\%, a hipótese nula, ou seja, a igualdade entre as três distribuições, não pode ser descartada. Dessa forma, a partir desses resultados, pode-se admitir que qualquer das distribuições obtidas produz resultados estatisticamente similares. Contudo, analisando-se visualmente as curvas da Figura 7.9, observa-se uma melhor aderência entre as distribuições com 500 e 1000 séries sintéticas.

Dado que para algumas séries sintéticas com pouca disponibilidade hídrica não foi possível atender as restrições de vazões mínimas, tornou-se necessário flexibilizar tais restrições para que o problema resultasse numa solução viável.

O critério adotado foi o seguinte: no caso do problema ser inviável com as restrições originais, a restrição em Três Marias foi reduzida em 80\% (vazão mínima igual a $400 \mathrm{~m}^{3} / \mathrm{s}$ ). Se mesmo assim, o problema ainda continuasse a ser inviável, as restrições em Três Marias, Sobradinho e Xingó foram reduzidas em $50 \%$ (respectivamente, iguais a $250 \mathrm{~m}^{3} / \mathrm{s}, 650 \mathrm{~m}^{3} / \mathrm{s}$ e 
$\left.650 \mathrm{~m}^{3} / \mathrm{s}\right)$. Se mesmo com essa redução o problema ainda continuasse inviável, essas restrições não foram consideradas no problema.

Essas alterações nas vazões mínimas implicam em interrupções para a navegação nos trechos a jusante dos reservatórios. Para se avaliar a magnitude dessas interrupções, foram calculadas as probabilidades de ocorrência dessas vazões mínimas para o caso de modelagem com 500 séries sintéticas. Esses resultados aparecem na Tabela 7.5.

Tabela 7.5 - Probabilidades de Ocorrência de Vazões Mínimas a jusante dos Reservatórios

\begin{tabular}{|c|c|c|c|}
\hline \multicolumn{2}{|c|}{ TRÊS MARIAS } & \multicolumn{2}{|c|}{ SOBRADINHO E XINGÓ } \\
\hline $\begin{array}{c}\text { VAZÃO MÍNIMA } \\
\left(\mathrm{m}^{3} / \mathrm{s}\right)\end{array}$ & $\begin{array}{c}\text { Probabilidade } \\
\text { (\%) }\end{array}$ & $\begin{array}{c}\text { VAZÃO MÍNIMA } \\
\left(\mathrm{m}^{3} / \mathrm{s}\right)\end{array}$ & $\begin{array}{c}\text { Probabilidade } \\
(\%)\end{array}$ \\
\hline menor que 250 & 2,20 & menor que 650 & 2,20 \\
\hline igual a 250 & 9,20 & igual a 650 & 9,20 \\
\hline igual a 400 & 14,80 & igual a 1300 & 88,60 \\
\hline igual a 500 & 73,80 & - & - \\
\hline
\end{tabular}

Os resultados da tabela anterior indicam que para $2,20 \%$ dos casos analisados a solução do problema só é viável com a desconsideração das restrições de vazão mínima. Os demais resultados indicam que a flexibilização dessas restrições não altera significativamente o uso da água para navegação na bacia.

Na seqüência dos trabalhos, foram traçadas as curvas de Pareto para o $1^{\circ}$, $2^{\circ}$ e $3^{\circ}$ quartís para modelagens com 500 séries sintéticas. Essas curvas são mostradas na Figura 7.10, e foram traçadas com base nas mesmas premissas indicadas em 6.3. 


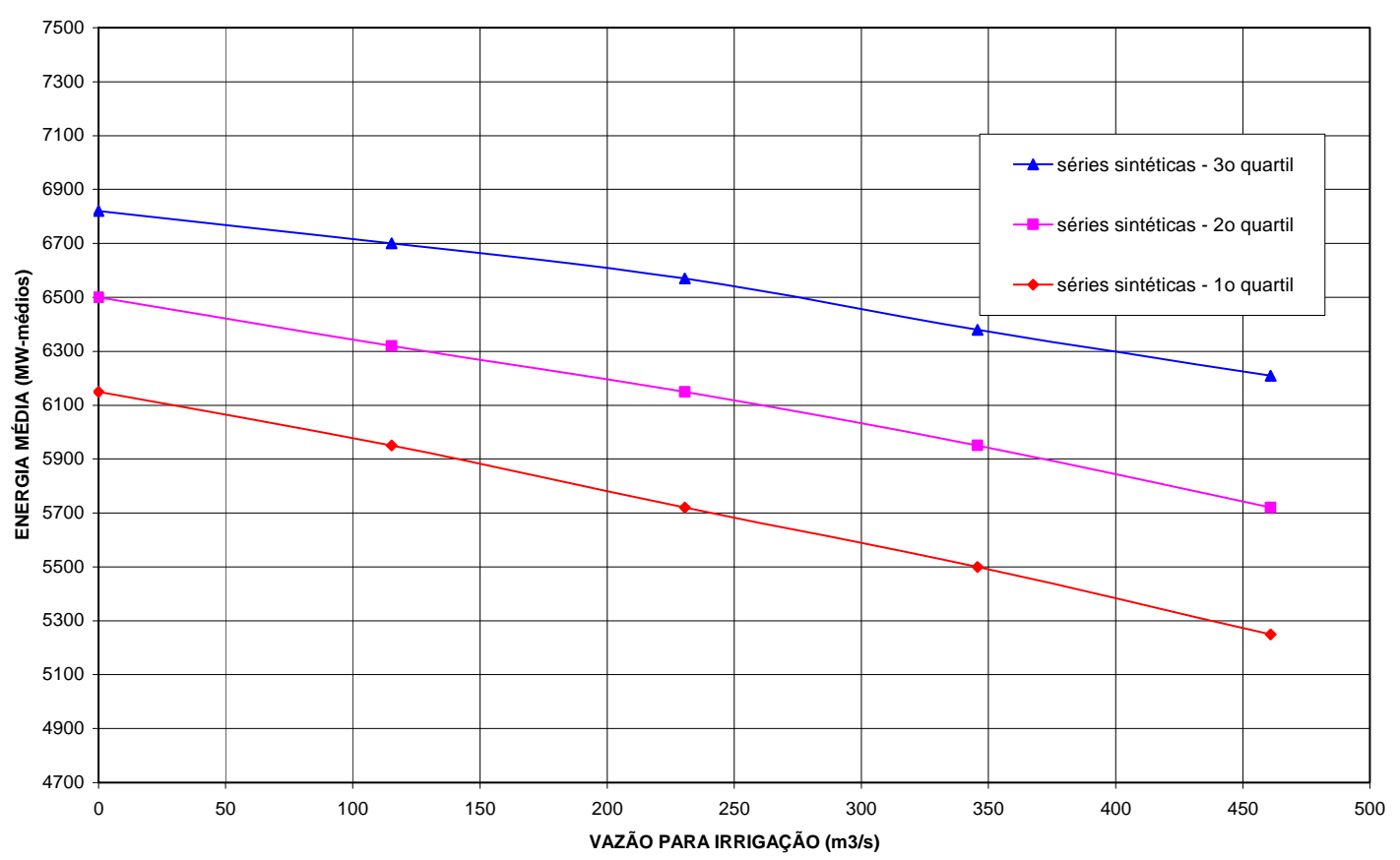

Figura 7.10 - Curvas de Pareto com Séries Sintéticas

Os gradientes dessas curvas são -2,0; $-1,7$ e $-1,3$ MW-médio/m³/s, respectivamente, para $01^{\circ}, 2^{\circ}$ e $3^{\circ}$ quartil. Ou seja, esses números expressam o quanto se perde de energia em MW-médio por $\mathrm{m}^{3} / \mathrm{s}$ derivado para irrigação. Esses valores expressam, de certa forma, o trade-off entre a geração hidrelétrica e a irrigação para cenários com probabilidades acumuladas iguais a 25\%,50\% e 75\%, respectivamente, ou seja, cenários seco, mediano e úmido.

\subsubsection{Comparação com Resultados Obtidos a Partir de Séries Históricas}

Os valores dos gradientes determinados para os cenários extraídos da série histórica, conforme visto em 6.3, são -2,0; -1,3 e -0,8 MW-médio/m³/s, respectivamente, para os cenários seco, mediano e úmido. Comparando-se esses números com os valores apresentados no item anterior, observa-se 
para o cenário seco os mesmos valores do trade-off entre a irrigação e a geração hidrelétrica. Nos caso dos cenários mediano e úmido, os trade-offs obtidos com as séries sintéticas são mais acentuados que os correspondentes às séries históricas.

Nos gráficos das três figuras a seguir, são mostradas as curvas de Pareto obtidas com base na série histórica (vide item 6.3) e as obtidas a partir das séries sintéticas. Essas curvas foram traçadas para os três cenários hidrológicos em análise.

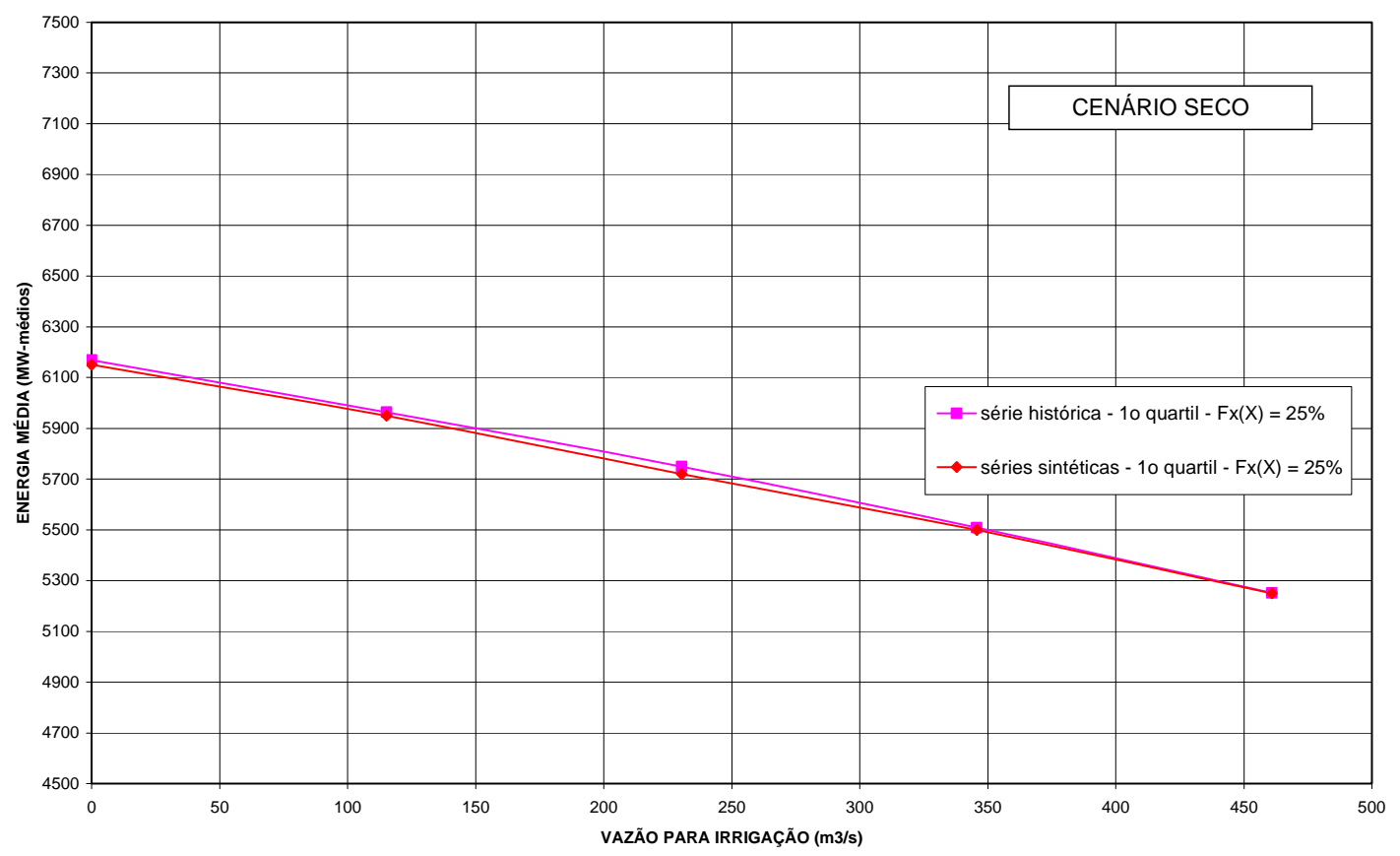

Figura 7.11 - Curvas de Pareto - Comparação entre Séries Sintéticas e Série Histórica - Cenário Seco 


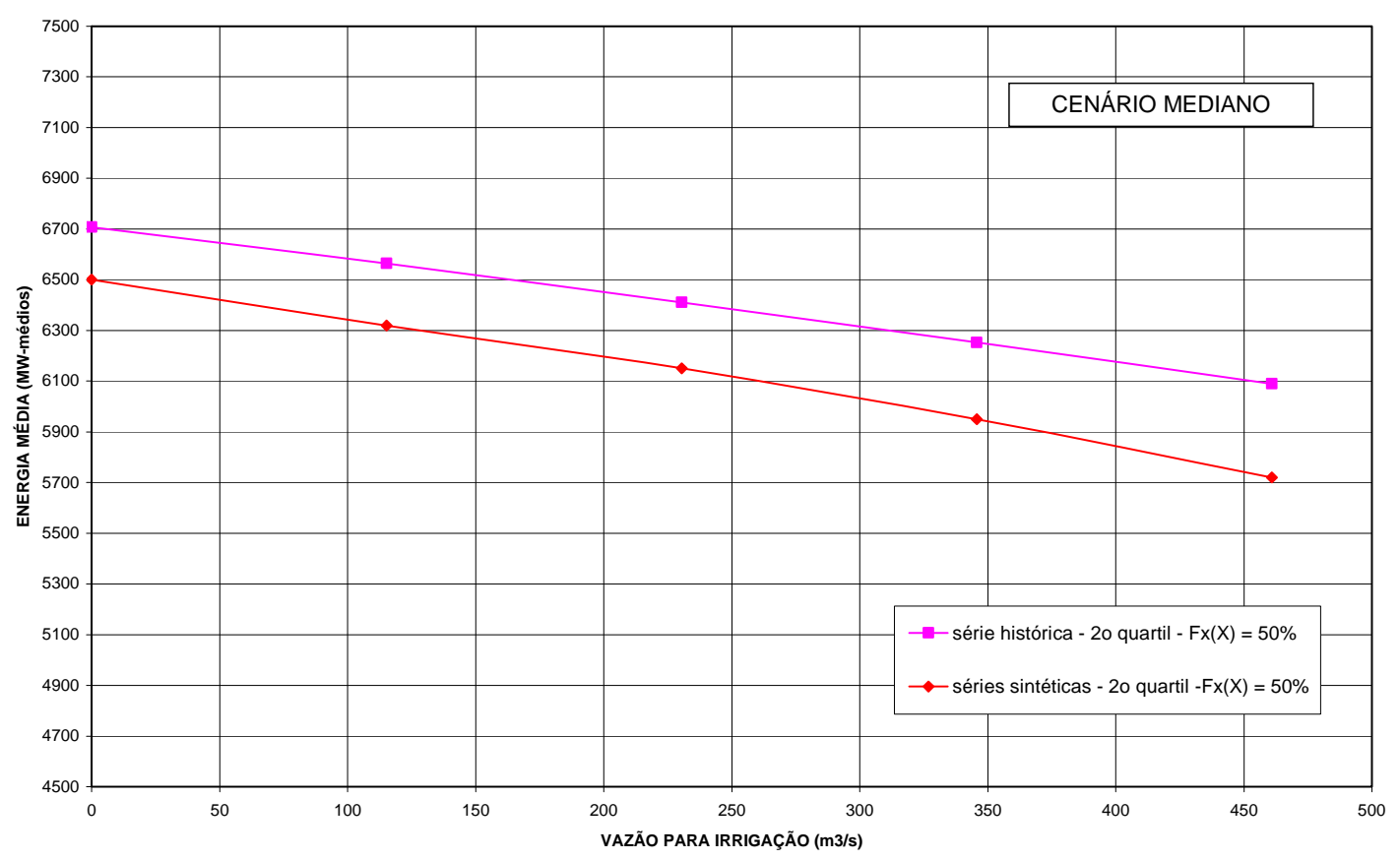

Figura 7.12 - Curvas de Pareto - Comparação entre Séries Sintéticas e Série Histórica - Cenário Mediano

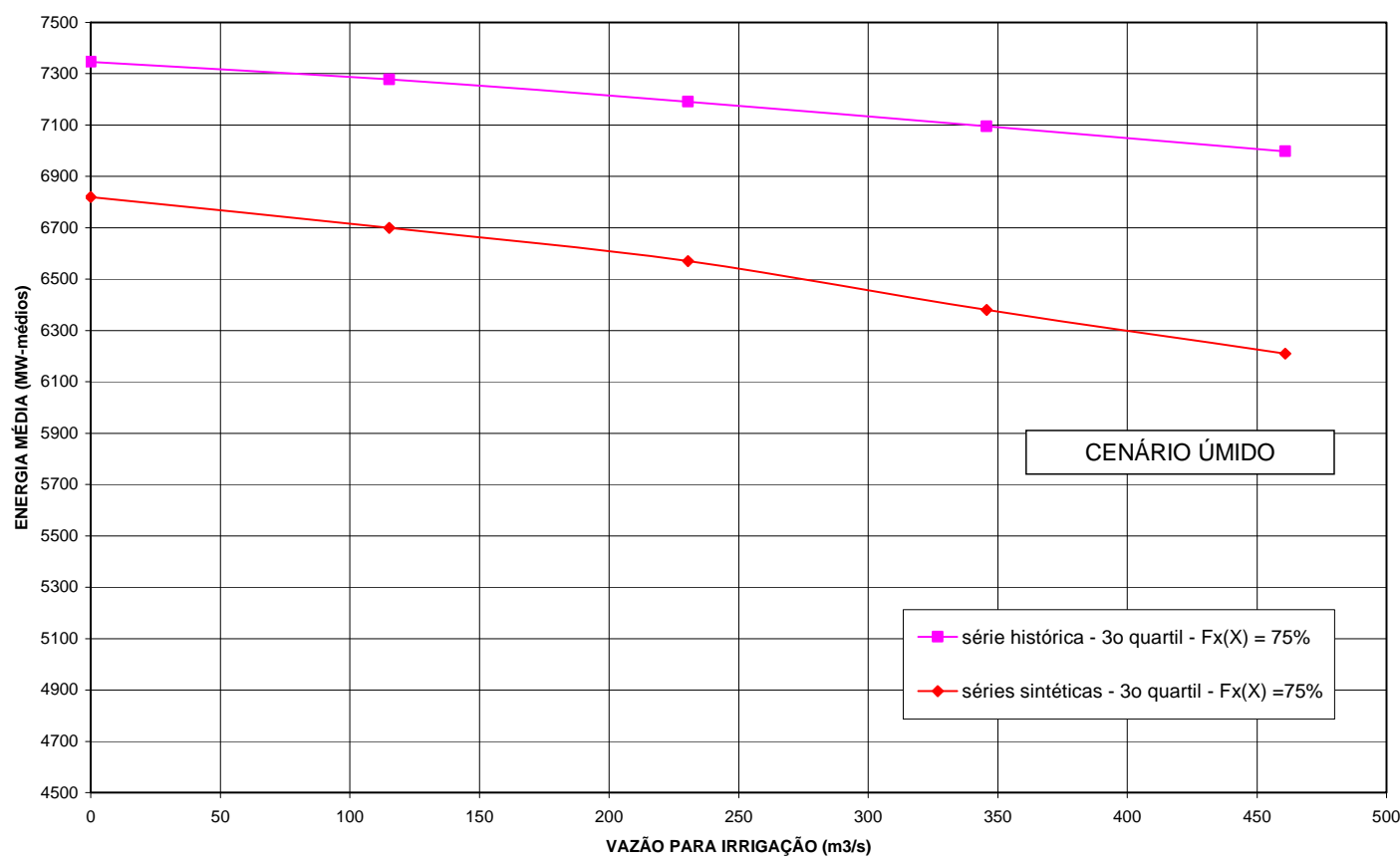

Figura 7.13 - Curvas de Pareto - Comparação entre Séries Sintéticas e Série Histórica - Cenário Úmido 
Os resultados apresentados na Figura 7.11 mostram que, para o cenário seco, as curvas de Pareto, referentes aos dois casos em análise, são praticamente coincidentes. Na Figura 7.12 e na Figura 7.13, que se referem, respectivamente, aos cenários mediano e úmido, nota-se que as curvas obtidas com a série histórica são superiores àquelas obtidas com as séries sintéticas. Com relação ao cenário mediano, verifica-se que o incremento da energia gerada está entre 3\% e 6\%, conforme a vazão utilizada para a irrigação. Para o cenário úmido, esse incremento varia entre $8 \%$ e $13 \%$.

Esses resultados indicam que, para o cenário seco, é indiferente usar cenários hidrológicos extraídos da série histórica ou a geração de séries sintéticas. Para os cenários mediano e úmido, a utilização de séries sintéticas repercute em avaliações mais severas tanto dos trade-offs (gradientes mais acentuados) como dos valores da energia gerada.

Dando continuidade à análise de resultados produzidos pelo uso de séries sintéticas ou série histórica, foram geradas 65 séries com extensão de seis anos cada a partir dos dados das séries históricas de vazões médias mensais, disponíveis para o período 1931 a 2001. Dessa forma, cada série de 6 anos teve seu início no mês de maio de cada ano do traço histórico, até o ano de 1995.

A modelagem dessas 65 séries forneceu os resultados para o traçado da curva de probabilidades acumuladas da energia média gerada, analogamente como feito no caso das séries sintéticas. Essa distribuição de probabilidades é apresentada na Figura 7.14, juntamente com as distribuições já definidas com base nas séries sintéticas. 


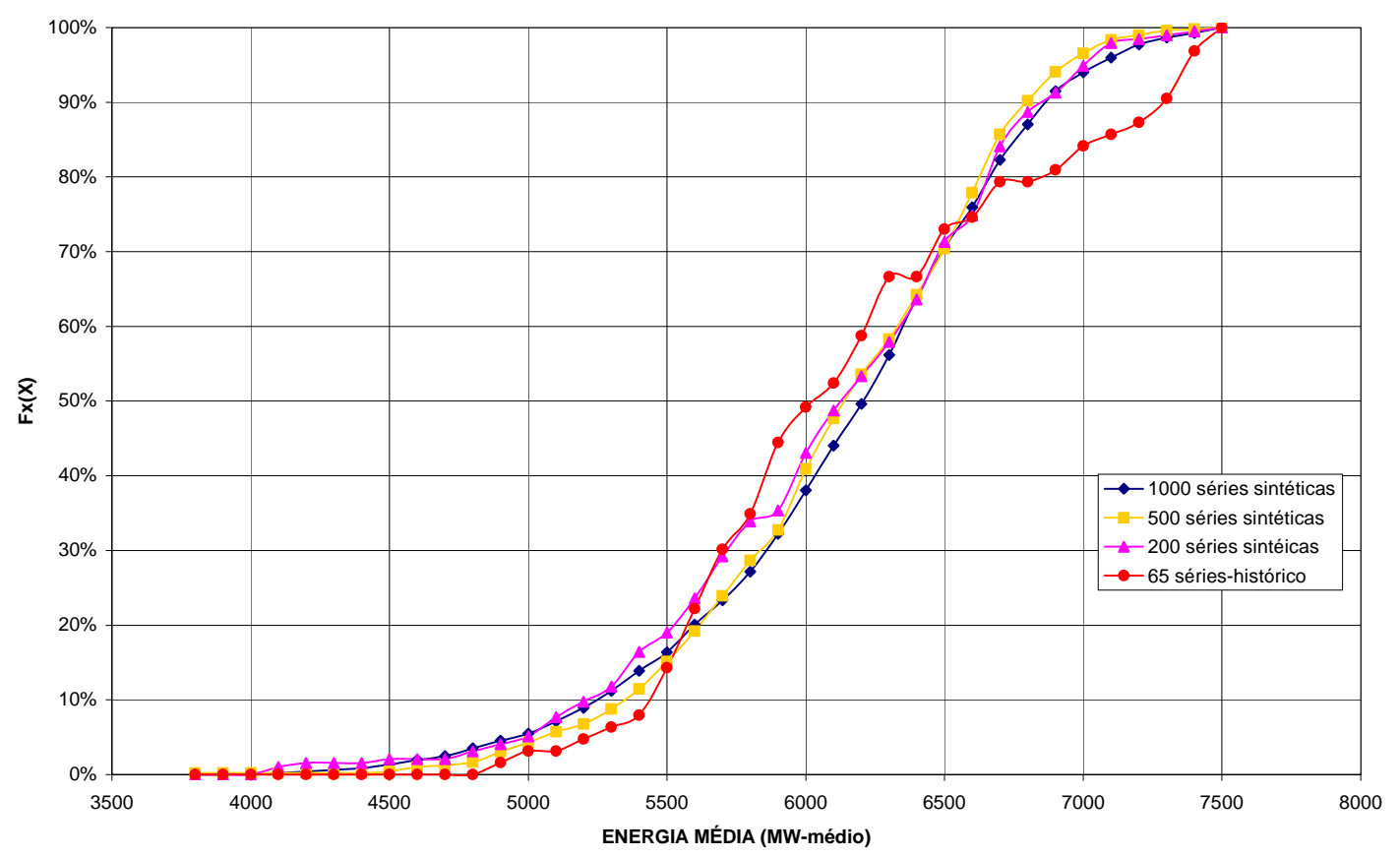

Figura 7.14 - Curvas de Probabilidades Acumuladas de Energia Obtidas com Séries Sintéticas e Série Histórica

A Tabela 7.6 apresenta os resultados do teste de Kolmogorov-Smirnov para verificação da aderência entre a distribuição de energia obtida com a série histórica e as distribuições encontradas com o uso de séries sintéticas. Esses resultados indicam novamente que a hipótese nula do teste não pode ser descartada, aos níveis de significância de 95\% e 90\%. Isso equivale a afirmar que, estatisticamente, a distribuição de probabilidades que resulta do uso dos traços históricos é semelhante às distribuições obtidas com as séries sintéticas. Contudo, a partir da análise visual das curvas da Figura 7.14, nota-se uma maior discrepância entre a distribuição devida aos traços históricos em relação àquelas resultantes da aplicação de séries sintéticas, principalmente nos extremos. 
Tabela 7.6 - Teste de Kolmogorov-Smirnov para as Distribuições de Probabilidades de Energia Obtidas com Séries Sintéticas e Série Histórica

\begin{tabular}{|l|c|c|c|}
\cline { 2 - 4 } \multicolumn{1}{c|}{} & \multicolumn{3}{c|}{ Teste entre Distribuições de Probabilidades de Energia Média } \\
\cline { 2 - 4 } & 1000 séries e histórico & 500 séries e histórico & 200 séries e histórico \\
\hline Valor Crítico 90\% & 0,15861 & 0,16331 & 0,17680 \\
\hline Valor Crítico 95\% & 0,17681 & 0,18205 & 0,19709 \\
\hline Estatística "D" & 0,12243 & 0,13117 & 0,12234 \\
\hline
\end{tabular}




\section{CONCLUSÕES}

O enfoque deste trabalho é a análise da operação e do desempenho dos sistemas de reservatórios segundo a ótica dos usos múltiplos da água. Dado que em muitos sistemas há uma competição pela água entre os diversos usuários, esse tipo de enfoque leva inevitavelmente à determinação de regras para partilha da água. Essas regras são geralmente definidas a partir de métodos e critérios de alocação do recurso hídrico para cada setor usuário. Por sua vez, para uma alocação equilibrada e equânime desses recursos é necessário visualizar o desempenho do sistema de reservatórios de acordo com os critérios e métodos propostos. Assim, esse tipo de análise prospectiva só é possível a partir da utilização das técnicas de modelagem desses sistemas. Os trabalhos de modelagem foram desenvolvidos com base em modelos de otimização através da solução de problemas de Programação Não-Linear. Para tanto, foram utilizadas as ferramentas de programação matemática GAMS, para elaboração dos modelos, e o pacote de otimização MINOS, para solução desses problemas. Essas ferramentas foram utilizadas no desenvolvimento do modelo SFPLUS, que visa a otimização de sistemas de reservatórios com usos múltiplos. Deve-se salientar que a formulação desse modelo envolve uma metodologia que é genérica e que pode ser aplicada em diversos sistemas de reservatórios.

O estudo de caso analisado nesta tese refere-se ao sistema de reservatórios da bacia do rio São Francisco. Foram criados três cenários hidrológicos, com extensão de 6 anos cada um, a partir das séries históricas de vazão. Esses cenários foram denominados seco, mediano e úmido, e foram definidos com base nos critérios descritos no item 6.1. Conforme visto nos capítulos 4 e 5 , que tratam dos aspectos teóricos e metodológicos do trabalho, inicialmente foi analisado o tratamento da otimização segundo os métodos das restrições e das ponderações, cujos resultados são apresentados no capítulo 6. Nessa fase, também foi considerada a análise segundo o enfoque da otimização econômica. Na seqüência, foram consideradas alternativas para tratamento 
dos aspectos estocásticos do problema, a partir da geração de séries sintéticas de vazões afluentes e da utilização das séries históricas de vazões, conforme descrito no capítulo 7.

A análise segundo o método das restrições, quando a função-objetivo inclui apenas um dos usos da água e os demais usos são tratados como restrições, permite explicitar claramente as relações de troca (trade-offs) entre usos competitivos, conforme demonstram os gráficos da Figura 6.4. Nesses gráficos, estão traçadas as chamadas curvas de Pareto para a irrigação e a geração de energia. Para o cenário seco e o período crítico do sistema interligado, o trade-off do sistema São Francisco indica que para cada $\mathrm{m}^{3} / \mathrm{s}$ utilizado na irrigação, perde-se cerca de $2 \mathrm{MW}$-médios, que ao longo de um ano totalizam 17,5 GWh de energia. Contudo, esse método não permite avaliar mais do que três usos.

O outro método analisado foi o método das ponderações, onde os usos competitivos são incluídos na função-objetivo. Nesse caso, cada uso é ponderado segundo um parâmetro que indica uma relação de prioridade no atendimento de um dado uso em relação aos demais. Os gráficos da Figura 6.9 à Figura 6.11 mostram as curvas de alocação entre a irrigação e a geração de energia na bacia do São Francisco. Essas curvas foram obtidas a partir de um critério de ponderação complementar em relação à unidade. Assim, a soma dos parâmetros de ponderação $\alpha$ (energia) e $\beta$ (irrigação) é igual a um. Cada um desses gráficos refere-se a um cenário hidrológico. Contudo, independente dos cenários considerados, nota-se que há uma região onde o trade-off entre a irrigação e a energia se dá de uma forma mais intensa. Essa região, no caso do São Francisco, corresponde aproximadamente a valores de $\alpha$ entre $0,25(\beta=0,75)$ e $0,60(\beta=0,40)$. Fora dessa região encontram-se os limites máximos e mínimos para os dois usos. Neste caso, a análise de sensibilidade desses coeficientes permite avaliar as conseqüências de uma decisão que privilegie um uso em relação ao outro. Portanto, segundo esse tipo de análise, as soluções de compromisso para 
exploração de um sistema depende da ponderação associada a cada uso, e a escolha desses coeficientes está sujeita a implicações de caráter subjetivo.

Uma outra forma de se utilizar o método das ponderações é através do uso de coeficientes que permitam a valorização econômica dos benefícios produzidos pelo sistema. Essa abordagem é apresentada em 6.4.1. Dessa forma, a análise se reduz ao que se chama de avaliação com objetivo único, ou seja, atenua-se o problema da subjetividade, mas em compensação o único objetivo considerado é a produção de benefícios econômicos. No caso estudado, os resultados da otimização econômica, conforme mostrado na Tabela 6.3, indicam uma ampla vantagem para atendimento integral das demandas de irrigação, mesmo havendo uma redução da energia gerada pelo sistema. Essa é uma constatação segundo o ponto de vista macroeconômico, apoiado sobre a tese que os sistemas de reservatórios de recursos hídricos são, em geral, de caráter público e que, via de regra, as conseqüências de seus resultados extrapolam os âmbitos local e regional.

Uma questão complementar analisada nesta fase dos estudos foi a avaliação da influência da cogitada transposição das águas do São Francisco para a região do Nordeste setentrional. As vazões atualmente em consideração são da ordem de $48 \mathrm{~m}^{3} / \mathrm{s}$ a partir de Cabrobó, situada a jusante de Sobradinho, e $16 \mathrm{~m}^{3} / \mathrm{s}$ a partir do lago de Itaparica. Segundo os resultados deste trabalho, essas vazões causam uma perda energética de cerca de 3\% sobre o total da energia gerada no sistema São Francisco, nos períodos de baixa disponibilidade hídrica. Além disso, os valores dos tradeoffs entre irrigação e energia são da mesma ordem de grandeza dos valores referentes à situação sem transposição.

Outro aspecto analisado dentro da ótica da utilização múltipla da água diz respeito à sua influência na operação dos reservatórios. No caso do São Francisco, os reservatórios com volumes úteis expressivos são Três Marias e Sobradinho. Os resultados das trajetórias de armazenamentos para os dois reservatórios, mostrados na Figura 6.6 à Figura 6.8, indicam que eles tendem a operar em fase, com ou sem irrigação, independente do cenário 
hidrológico. No caso de Sobradinho, no cenário seco, há uma utilização mais intensa dos volumes desse reservatório. Essa intensidade é um pouco mais pronunciada na situação com irrigação.

$\mathrm{Na}$ fase seguinte da pesquisa, foram desenvolvidos os estudos com modelos estocásticos voltados para a geração de séries sintéticas de vazões afluentes. Essas atividades foram desenvolvidas com o auxílio do programa GESS, apresentado em 4.2.2. Os resultados desses estudos são mostrados no capítulo 7.

Foram geradas séries com extensão de 6 anos em grupos com 200, 500 e 1000 séries sintéticas. Essas séries foram incluídas no modelo de otimização formulado segundo o método das restrições. A partir dos resultados desses processamentos, foram obtidas as curvas de probabilidades acumuladas das energias médias para cada grupo, que são mostradas na Figura 7.9. Segundo os resultados do teste de KolmogorovSmirnov, apresentados na Tabela 7.4, a hipótese nula do teste, ou seja, a igualdade entre as três distribuições, não pode ser descartada. Dessa forma, a partir desses resultados, pode-se concluir que qualquer das distribuições obtidas produz resultados estatisticamente similares. Analogamente, foi criado um grupo composto por séries com extensão de 6 anos a partir das séries históricas de vazões, cada série iniciando-se num ano do histórico. Isso resultou num grupo com 65 séries. Esse grupo também foi inserido no modelo de otimização resultando numa distribuição de probabilidades acumuladas para a energia média, mostrada na Figura 7.14. Essa distribuição foi também comparada com as distribuições obtidas a partir das séries sintéticas, com base no teste de Kolmogorov-Smirnov. Os resultados da Tabela 7.6, indicaram similaridade estatística entre a distribuição obtida com base no grupo derivado do histórico e aquelas obtidas a partir das séries sintéticas. Contudo, esse tipo de tratamento pode não ser estatisticamente adequado na medida em que essas séries derivadas do histórico não representam processos aleatórios independentes, pois são formadas a partir da superposição de eventos. Ou seja, uma série de 6 anos 
não é totalmente independente da outra. Assim, é preferível adotar o tratamento estocástico com base na geração de séries sintéticas. Nesse caso, segundo os resultados deste estudo, o fato de se utilizar 200, 500 ou 1000 séries é estaticamente indiferente, segundo o teste do KolmogorovSmirnov.

Foram também traçadas e comparadas as curvas de Pareto obtidas com base nos cenários hidrológicos e aquelas obtidas a partir de séries sintéticas (grupo com 500 séries). Essas curvas são mostradas nos gráficos da Figura 7.11 à Figura 7.13. Os resultados obtidos mostram que, para o cenário seco, as curvas de Pareto, referentes aos dois casos em análise, são praticamente coincidentes. Nos cenários mediano e úmido, nota-se que as curvas obtidas com a série histórica são superiores àquelas obtidas com as séries sintéticas. Para o cenário mediano, o aumento da energia gerada está entre 3\% e 6\%, conforme a vazão utilizada para a irrigação. Para o cenário úmido, esse incremento varia entre $8 \%$ e 13\%. Esses resultados indicam que, para o cenário seco, é indiferente usar cenários hidrológicos extraídos da série histórica ou a geração de séries sintéticas. Para os cenários mediano e úmido, a utilização de séries sintéticas repercute em avaliações mais severas tanto dos trade-offs (gradientes mais acentuados) como dos valores da energia gerada (valores menores).

Um aspecto a ser sublinhado na utilização do programa GESS, que utiliza modelos estocásticos auto-regressivos periódicos, é que os coeficientes de autocorrelação serial anual das séries produzidas por esses modelos não conseguiram reproduzir de forma adequada os coeficientes de autocorrelação anual das séries históricas, conforme demonstram os resultados da Tabela 7.3.

Uma questão final a ser abordada nestas conclusões refere-se à utilização da ferramenta GAMS e do programa MINOS. O GAMS permitiu elaborar os diversos tipos de modelos utilizados nesta pesquisa com extrema facilidade, rapidez e flexibilidade. O uso do MINOS foi também extremamente benéfico na medida em que é um pacote de solução de problemas lineares e não 
lineares que mostrou grande adaptabilidade para a solução dos problemas propostos, que envolvem uma série de funções monotônicas crescentes. Isso se refletiu de forma mais clara no processo de busca da solução ótima a partir de uma solução inicial pesquisada pelo próprio programa. Os resultados da análise de sensibilidade das soluções iniciais mostraram que há uma convergência para a solução ótima encontrada a partir da solução inicial definida pelo MINOS. Outro aspecto a ser destacado na integração GAMS/MINOS é o reduzido tempo de processamento dos modelos. Para o sistema da bacia do São Francisco, o tempo de processamento de cada cenário de 6 anos foi de aproximadamente 15 segundos, utilizando um computador equipado com processador Pentium IV-2.0 GHz e memória RAM de 512 Mbytes. No caso das séries sintéticas, o grupo com 1000 séries consumiu cerca de 2 horas e meia de processamento.

$\mathrm{Na}$ seqüência, apresenta-se um resumo dos aspectos conceituais que puderam ser avaliados a partir dos resultados deste trabalho. Deve-se ressaltar que alguns desses aspectos são restritos ao caso estudado e que eventuais extrapolações e generalizações para outros sistemas e outras situações devem ser encaradas com as devidas reservas e precauções.

- O método as restrições é mais fácil e direto de ser aplicado. Explicita claramente os trade-offs entre os usos competitivos. Ou seja, é possível avaliar o leque de opções das soluções de compromisso entre os usos ou usuários da água. Contudo, é um método que se aplica à análise de poucos usos (no máximo 3) devido à nossa limitação física para visualizar representações gráficas multidimensionais.

- O método das ponderações permite analisar um número maior de usos da água. Contudo, é necessário estabelecer a priori os coeficientes de ponderação entre os usos competitivos, o que introduz um certo grau de subjetividade à análise . 
- Uma forma de contornar o problema dos coeficientes de ponderação é a otimização dos benefícios econômicos. Nesse caso, a análise se torna menos subjetiva.

- Considerando a análise estocástica, conclui-se que, para o caso estudado, o número de séries sintéticas não influi significativamente na forma das distribuições de probabilidades da energia gerada pelo modelo de otimização. Contudo, na comparação dos resultados do modelo obtidos com séries sintéticas e com séries históricas, nota-se que o modelo é sensível à utilização de séries sintéticas, principalmente quando se analisa os extremos das distribuições de probabilidades de energia.

- Na comparação entre as curvas de Pareto definidas com base em cenários hidrológicos derivados da série histórica e aquelas definidas com base na geração de séries sintéticas, essas curvas são quase coincidentes no caso dos cenários secos. Para os cenários medianos e úmidos, há uma tendência de subestimação das curvas traçadas com as séries sintéticas em comparação com às traçadas com base nas séries históricas. Ou seja, esses resultados indicam que análise com base na geração de séries sintéticas afeta as avaliações sobre os aspectos de usos múltiplos.

Com este trabalho buscou-se ampliar o foco sobre a questão da modelagem de sistemas de reservatórios com destaque para o uso múltiplo das águas. Essa premissa atende aos princípios da Política Nacional de Recursos Hídricos instituída pela Lei Federal oํ 9.433. Espera-se que os resultados produzidos e as análises decorrentes venham a contribuir para aumentar o grau de entendimento sobre o tema nos meios técnicos e acadêmicos e, dessa forma, permitir que futuros desenvolvimentos nessa área possam incluir os aspectos aqui tratados.

Quanto ao prosseguimento dos estudos relacionados com a linha de pesquisa enfocada nesta tese, pode-se indicar: 
- Estudos sobre a sensibilidade dos resultados do modelo de otimização proposto a outros métodos de geração de séries sintéticas, incluindo modelos estocásticos baseados na desagregação de vazões anuais em mensais que preservem o coeficiente de correlação serial anual.

- Avaliações mais profundas sobre a influência da solução inicial nos resultados da Programação Não-Linear adotada no modelo proposto.

- Tornar o modelo SFPLUS genérico e amigável através do desenvolvimento de estruturas de entrada de dados e geração de resultados e possibilitando a modelagem de sistemas com topologias diversas.

- Aplicações de outros solvers de Programação Não-Linear para solução do modelo de otimização proposto. 


\section{ANEXO A - SÉRIES DE VAZÕES MÉDIAS MENSAIS}

Observação: todos os valores de vazão em $\mathrm{m}^{3} / \mathrm{s}$. 


\begin{tabular}{|c|c|c|c|c|c|c|c|c|c|c|c|c|c|c|c|}
\hline \multicolumn{16}{|c|}{ TRÊS MARIAS } \\
\hline ano & jan & fev & mar & $a b r$ & mai & jun & jul & ago & set & out & nov & dez & mín. & méd. & máx. \\
\hline 1931 & 792 & 1610 & 1890 & 1650 & 748 & 465 & 360 & 286 & 258 & 277 & 383 & 515 & 258 & 769 & 1890 \\
\hline 1932 & 1250 & 832 & 619 & 371 & 262 & 251 & 220 & 169 & 143 & 211 & 524 & 1040 & 143 & 491 & 1250 \\
\hline 1933 & 1830 & 970 & 786 & 592 & 484 & 374 & 309 & 265 & 206 & 267 & 371 & 1330 & 206 & 649 & 1830 \\
\hline 1934 & 1130 & 467 & 411 & 326 & 259 & 174 & 163 & 144 & 151 & 166 & 259 & 459 & 144 & 342 & 1130 \\
\hline 1935 & 1350 & 1920 & 1020 & 1250 & 671 & 371 & 273 & 235 & 224 & 216 & 311 & 765 & 216 & 717 & 1920 \\
\hline 1936 & 526 & 517 & 948 & 561 & 347 & 220 & 176 & 145 & 150 & 171 & 467 & 771 & 145 & 417 & 948 \\
\hline 1937 & 1350 & 1770 & 635 & 473 & 430 & 268 & 206 & 164 & 137 & 229 & 822 & 1730 & 137 & 684 & 1770 \\
\hline 1938 & 1700 & 891 & 926 & 596 & 463 & 350 & 279 & 266 & 240 & 326 & 691 & 1590 & 240 & 693 & 1700 \\
\hline 1939 & 2390 & 1970 & 824 & 648 & 484 & 358 & 307 & 253 & 223 & 370 & 392 & 672 & 223 & 741 & 2390 \\
\hline 1940 & 1110 & 1390 & 1360 & 527 & 366 & 268 & 217 & 183 & 177 & 273 & 1050 & 1330 & 177 & 688 & 1390 \\
\hline 1941 & 1860 & 907 & 926 & 1170 & 512 & 342 & 295 & 219 & 219 & 304 & 361 & 1110 & 219 & 685 & 1860 \\
\hline 1942 & 1610 & 899 & 1290 & 674 & 397 & 296 & 235 & 189 & 211 & 305 & 826 & 1610 & 189 & 712 & 1610 \\
\hline 1943 & 3250 & 1900 & 1620 & 885 & 612 & 471 & 399 & 345 & 293 & 377 & 682 & 1600 & 293 & 1036 & 3250 \\
\hline 1944 & 784 & 1400 & 1140 & 744 & 416 & 317 & 269 & 220 & 181 & 213 & 391 & 918 & 181 & 583 & 1400 \\
\hline 1945 & 1190 & 2130 & 1410 & 1420 & 818 & 581 & 455 & 347 & 297 & 364 & 964 & 2180 & 297 & 1013 & 2180 \\
\hline 1946 & 2510 & 1020 & 1430 & 1220 & 623 & 449 & 356 & 282 & 267 & 327 & 659 & 732 & 267 & 823 & 2510 \\
\hline 1947 & 1420 & 1700 & 2470 & 1300 & 624 & 457 & 382 & 300 & 361 & 380 & 604 & 1330 & 300 & 944 & 2470 \\
\hline 1948 & 1460 & 1090 & 1050 & 572 & 331 & 275 & 212 & 177 & 151 & 217 & 737 & 1740 & 151 & 668 & 1740 \\
\hline 1949 & 2120 & 3470 & 1590 & 970 & 692 & 528 & 430 & 340 & 272 & 392 & 557 & 1040 & 272 & 1033 & 3470 \\
\hline 1950 & 930 & 1510 & 1110 & 785 & 500 & 378 & 290 & 229 & 208 & 277 & 787 & 1220 & 208 & 685 & 1510 \\
\hline 1951 & 1060 & 1470 & 1400 & 1440 & & 479 & 378 & 304 & 251 & 274 & 268 & 000 & 251 & 709 & 1470 \\
\hline 1952 & 992 & 2040 & 2920 & 1240 & & 457 & 406 & 330 & 357 & 268 & 570 & 812 & 268 & 920 & 2920 \\
\hline 1953 & 365 & 529 & 735 & 754 & 364 & 257 & 200 & 162 & 162 & 241 & 536 & 1030 & 162 & 445 & 1030 \\
\hline 1954 & 520 & 700 & 353 & 465 & 299 & 196 & 151 & 122 & 106 & 104 & 388 & 438 & 104 & 320 & 700 \\
\hline 1955 & 952 & 569 & 521 & 560 & 214 & 181 & 134 & 106 & 93 & 211 & 394 & 1360 & 93 & 441 & 1360 \\
\hline 1956 & 1000 & 609 & 985 & 367 & 412 & 347 & 227 & 203 & 185 & 178 & 286 & 1140 & 178 & 495 & 1140 \\
\hline 1957 & 1390 & 1070 & 1290 & 1380 & 646 & 400 & 322 & 268 & 261 & 254 & 611 & 1330 & 254 & 768 & 1390 \\
\hline 1958 & 759 & 817 & 674 & 464 & 345 & 269 & 261 & 189 & 242 & 324 & 325 & 476 & 189 & 429 & 817 \\
\hline 1959 & 833 & 577 & 865 & 388 & 212 & 170 & 138 & 122 & 112 & 218 & 513 & 539 & 112 & 391 & 865 \\
\hline 1960 & 1220 & 1260 & 1510 & 556 & 342 & 251 & 200 & 156 & 126 & 159 & 533 & 1280 & 126 & 633 & 1510 \\
\hline 1961 & 2110 & 2210 & 1550 & 825 & 632 & 420 & 327 & 261 & 202 & 185 & 323 & 630 & 185 & 806 & 2210 \\
\hline 1962 & 1670 & 1730 & 1310 & 597 & 400 & 320 & 248 & 204 & 226 & 337 & 545 & 2290 & 204 & 823 & 2290 \\
\hline 1963 & 1780 & 1240 & 621 & 356 & 265 & 228 & 198 & 169 & 134 & 149 & 235 & 138 & 134 & 459 & 1780 \\
\hline 1964 & 1180 & 1810 & 795 & 430 & 324 & 218 & 213 & 160 & 120 & 277 & 576 & 1030 & 120 & 594 & 1810 \\
\hline 1965 & 2030 & 2990 & 2950 & 1140 & 722 & 480 & 382 & 311 & 243 & 587 & 755 & 1180 & 243 & 1147 & 2990 \\
\hline 1966 & 2780 & 2320 & 1470 & 814 & 577 & 432 & 341 & 274 & 230 & 359 & 906 & 1410 & 230 & 993 & 2780 \\
\hline 1967 & 2360 & 2210 & 1530 & 960 & 580 & 444 & 359 & 287 & 240 & 253 & 842 & 1250 & 240 & 943 & 2360 \\
\hline 1968 & 1690 & 1210 & 1440 & 666 & 429 & 336 & 279 & 253 & 246 & 379 & 379 & 1250 & 246 & 713 & 1690 \\
\hline 1969 & 925 & 859 & 555 & 404 & 273 & 241 & 197 & 167 & 148 & 302 & 1100 & 1140 & 148 & 526 & 1140 \\
\hline
\end{tabular}

continua 
continuação

\begin{tabular}{|c|c|c|c|c|c|c|c|c|c|c|c|c|c|c|c|}
\hline \multicolumn{16}{|c|}{ TRÊS MARIAS } \\
\hline ano & jan & fev & mar & abr & mai & jun & jul & ago & set & out & nov & dez & mín. & média & máx. \\
\hline 1970 & 1400 & 1070 & 737 & 527 & 326 & 260 & 234 & 191 & 242 & 328 & 526 & 348 & 191 & 516 & 1400 \\
\hline 1971 & 260 & 200 & 331 & 202 & 130 & 158 & 116 & 92 & 131 & 224 & 614 & 2180 & 92 & 386 & 2180 \\
\hline 1972 & 1060 & 1080 & 1130 & 802 & 416 & 306 & 308 & 235 & 207 & 453 & 1120 & 1160 & 207 & 690 & 1160 \\
\hline 1973 & 1550 & 1340 & 1300 & 1110 & 580 & 407 & 342 & 253 & 219 & 355 & 729 & 1170 & 219 & 780 & 1550 \\
\hline 1974 & 1640 & 785 & 1070 & 710 & 451 & 352 & 288 & 233 & 174 & 270 & 270 & 881 & 174 & 594 & 1640 \\
\hline 1975 & 1670 & 1060 & 503 & 496 & 340 & 237 & 248 & 174 & 135 & 217 & 681 & 898 & 135 & 555 & 1670 \\
\hline 1976 & 545 & 581 & 613 & 382 & 296 & 223 & 234 & 203 & 328 & 393 & 896 & 1620 & 203 & 526 & 1620 \\
\hline 1977 & 1540 & 1410 & 687 & 663 & 370 & 293 & 225 & 172 & 207 & 186 & 526 & 877 & 172 & 596 & 1540 \\
\hline 1978 & 1740 & 892 & 1010 & 532 & 405 & 401 & 303 & 225 & 200 & 260 & 583 & 1200 & 200 & 646 & 1740 \\
\hline 1979 & 1760 & 3860 & 1820 & 1040 & 675 & 535 & 421 & 349 & 369 & 305 & 606 & 1180 & 305 & 1077 & 3860 \\
\hline 1980 & 2700 & 2030 & 858 & 1040 & 533 & 463 & 392 & 290 & 254 & 237 & 474 & 1120 & 237 & 866 & 2700 \\
\hline 1981 & 1480 & 805 & 739 & 628 & 391 & 372 & 268 & 241 & 185 & 525 & 1520 & 1950 & 185 & 759 & 1950 \\
\hline 1982 & 2760 & 1830 & 2310 & 1500 & 778 & 576 & 448 & 354 & 271 & 379 & 432 & 980 & 271 & 1051 & 2760 \\
\hline 1983 & 2880 & 3900 & 2340 & 2000 & 1220 & 1150 & 722 & 535 & 570 & 900 & 1570 & 2390 & 535 & 1681 & 3900 \\
\hline 1984 & 1500 & 847 & 716 & 623 & 462 & 333 & 277 & 257 & 351 & 301 & 413 & 1360 & 257 & 620 & 1500 \\
\hline 1985 & 2600 & 2640 & 2230 & 1180 & 742 & 557 & 438 & 351 & 330 & 349 & 493 & 742 & 330 & 1054 & 2640 \\
\hline 1986 & 1970 & 1490 & 1010 & 579 & 470 & 351 & 320 & 316 & 222 & 181 & 218 & 866 & 181 & 666 & 1970 \\
\hline 1987 & 1590 & 962 & 722 & 858 & 420 & 329 & 252 & 205 & 223 & 248 & 330 & 1230 & 205 & 614 & 1590 \\
\hline 1988 & 822 & 1610 & 993 & 557 & 370 & 282 & 219 & 178 & 148 & 261 & 353 & 613 & 148 & 534 & 1610 \\
\hline 1989 & 784 & 880 & 883 & 375 & 269 & 243 & 208 & 192 & 175 & 238 & 481 & 1140 & 175 & 489 & 1140 \\
\hline 1990 & 1330 & 562 & 586 & 415 & 318 & 217 & 206 & 179 & 191 & 159 & 212 & 295 & 159 & 389 & 1330 \\
\hline 1991 & 1760 & 1940 & 1420 & 1490 & 661 & 421 & 289 & 244 & 217 & 378 & 318 & 553 & 217 & 808 & 1940 \\
\hline 1992 & 1770 & 3840 & 1440 & 920 & 745 & 470 & 359 & 286 & 309 & 417 & 1360 & 1360 & 286 & 1106 & 3840 \\
\hline 1993 & 1260 & 1580 & 1260 & 927 & 517 & 459 & 326 & 268 & 243 & 304 & 292 & 490 & 243 & 660 & 1580 \\
\hline 1994 & 2380 & 850 & 1300 & 692 & 593 & 402 & 318 & 242 & 185 & 185 & 261 & 736 & 185 & 679 & 2380 \\
\hline 1995 & 578 & 1668 & 1030 & 682 & 469 & 315 & 248 & 185 & 173 & 259 & 402 & 1066 & 173 & 590 & 1668 \\
\hline 1996 & 1710 & 679 & 711 & 429 & 311 & 236 & 189 & 172 & 196 & 176 & 1005 & 1301 & 172 & 593 & 1710 \\
\hline 1997 & 3957 & 1373 & 1367 & 896 & 568 & 524 & 352 & 271 & 243 & 314 & 414 & 1499 & 243 & 981 & 3957 \\
\hline 1998 & 1206 & 1261 & 802 & 500 & 412 & 368 & 253 & 232 & 168 & 207 & 552 & 673 & 168 & 553 & 1261 \\
\hline 1999 & 904 & 596 & 1629 & 521 & 317 & 217 & 178 & 96 & 99 & 126 & 603 & 756 & 96 & 503 & 1629 \\
\hline 2000 & 1194 & 1993 & 1444 & 677 & 406 & 299 & 228 & 155 & 233 & 108 & 563 & 912 & 108 & 684 & 1993 \\
\hline 2001 & 736 & 314 & 436 & 202 & 147 & 128 & 106 & 97 & 114 & 191 & 427 & 849 & 97 & 312 & 849 \\
\hline méd. & 1510 & 1416 & 1160 & 770 & 472 & 355 & 283 & 229 & 216 & 284 & 580 & 1089 & 202 & 697 & 1898 \\
\hline
\end{tabular}




\begin{tabular}{|c|c|c|c|c|c|c|c|c|c|c|c|c|c|c|c|}
\hline \multicolumn{16}{|c|}{ SOBRADINHO } \\
\hline ano & jan & fev & mar & $a b r$ & mai & jun & jul & ago & set & out & nov & dez & mín. & méd. & máx. \\
\hline 1931 & 4674 & 4803 & 6628 & 7331 & 4465 & 2395 & 1867 & 1617 & 1446 & 1373 & 1933 & 2205 & 1373 & 3395 & 7331 \\
\hline 1932 & 4034 & 4529 & 3211 & 1974 & 1422 & 1289 & 1173 & 993 & 902 & 980 & 2104 & 3592 & 902 & 2184 & 4529 \\
\hline 1933 & 5011 & 5513 & 3426 & 2690 & 1902 & 1354 & 1248 & 1070 & 912 & 1192 & 1796 & 3334 & 912 & 2454 & 5513 \\
\hline 1934 & 6107 & 4220 & 2295 & 1613 & 1782 & 1165 & 994 & 894 & 796 & 874 & 902 & 1603 & 796 & 1937 & 6107 \\
\hline 1935 & 4517 & 5439 & 5406 & 4714 & 3737 & 2008 & 1554 & 1234 & 1053 & 1077 & 1175 & 2583 & 1053 & 2875 & 5439 \\
\hline 1936 & 2693 & 2661 & 4171 & 2761 & 2107 & 1297 & 1089 & 931 & 858 & 884 & 1595 & 2721 & 858 & 1981 & 4171 \\
\hline 1937 & 4640 & 5595 & 4239 & 2885 & 2234 & 1452 & 1228 & 1034 & 897 & 917 & 2392 & 4700 & 897 & 2684 & 5595 \\
\hline 1938 & 6305 & 4234 & 3847 & 2369 & 1611 & 1417 & 1155 & 1031 & 954 & 911 & 1536 & 2955 & 911 & 2360 & 6305 \\
\hline 1939 & 5093 & 5895 & 4888 & 2153 & 1625 & 1256 & 1104 & 1033 & 933 & 1282 & 1017 & 1705 & 933 & 2332 & 5895 \\
\hline 1940 & 3101 & 4736 & 5497 & 4295 & 1911 & 1413 & 1185 & 1052 & 858 & 923 & 2135 & 3790 & 858 & 2575 & 5497 \\
\hline 1941 & 5002 & 4420 & 4129 & 4789 & 2718 & 1656 & 1420 & 1257 & 1019 & 1134 & 1667 & 2312 & 1019 & 2627 & 5002 \\
\hline 1942 & 4621 & 4417 & 5274 & 3357 & 2271 & 1544 & 1297 & 1114 & 1021 & 1321 & 2271 & 5167 & 1021 & 2806 & 5274 \\
\hline 1943 & 6183 & 9463 & 7963 & 5094 & 2878 & 2110 & 1771 & 1519 & 1286 & 1391 & 2202 & 5147 & 1286 & 3917 & 9463 \\
\hline 1944 & 6325 & 4860 & 4746 & 3726 & 2515 & 1735 & 1465 & 1275 & 1100 & 959 & 1649 & 3845 & 959 & 2850 & 6325 \\
\hline 1945 & 5629 & 6941 & 7969 & 7147 & 8760 & 3936 & 2588 & 2075 & 1700 & 1975 & 3264 & 5590 & 1700 & 4798 & 8760 \\
\hline 1946 & 7281 & 10073 & 4592 & 5588 & 3578 & 2450 & 2006 & 1722 & 1494 & 1515 & 2168 & 3766 & 1494 & 3853 & 10073 \\
\hline 1947 & 3746 & 5139 & 5702 & 7280 & 4315 & 2350 & 1939 & 1623 & 1610 & 1433 & 3109 & 4245 & 1433 & 3541 & 7280 \\
\hline 1948 & 6340 & 4517 & 5418 & 4013 & 2207 & 1843 & 1578 & 1356 & 1203 & 1321 & 1501 & 5152 & 1203 & 3037 & 6340 \\
\hline 1949 & 7846 & 9216 & 13040 & 7131 & 3496 & 2586 & 2151 & 1817 & 1544 & 1461 & 2925 & 2941 & 1461 & 4679 & 13040 \\
\hline 1950 & 4447 & 4712 & 3457 & 3780 & 2617 & 1739 & 1512 & 1301 & 1072 & 1262 & 2135 & 4124 & 1072 & 2680 & 4712 \\
\hline 1951 & 4175 & 4152 & 4435 & 4851 & 2518 & 1842 & 1483 & 1272 & 1099 & 1023 & 938 & 1638 & 938 & 2452 & 4851 \\
\hline 1952 & 3306 & 4714 & 5788 & 6934 & 3253 & 1967 & 1600 & 1307 & 1188 & 1132 & 1778 & 3389 & 1132 & 3030 & 6934 \\
\hline 1953 & 3559 & 1789 & 2681 & 3736 & 1930 & 1303 & 1103 & 967 & 852 & 1156 & 1407 & 3185 & 852 & 1972 & 3736 \\
\hline 1954 & 4401 & 2775 & 2776 & 2425 & 1439 & 1195 & 974 & 847 & 710 & 640 & 876 & 3540 & 640 & 1883 & 4401 \\
\hline 1955 & 2306 & 4047 & 2161 & 2611 & 1432 & 1067 & 894 & 782 & 671 & 655 & 1973 & 3301 & 655 & 1825 & 4047 \\
\hline 1956 & 5366 & 2211 & 4581 & 2538 & 1768 & 1634 & 1320 & 1061 & 897 & 835 & 1464 & 3683 & 835 & 2280 & 5366 \\
\hline 1957 & 5944 & 7114 & 6899 & 7959 & 5810 & 2762 & 2027 & 1638 & 1366 & 1516 & 1411 & 4338 & 1366 & 4065 & 7959 \\
\hline 1958 & 3619 & 5208 & 3381 & 3099 & 2415 & 1691 & 1406 & 1414 & 1121 & 1512 & 1833 & 1794 & 1121 & 2374 & 5208 \\
\hline 1959 & 3597 & 3655 & 3490 & 2702 & 1357 & 1132 & 1008 & 898 & 813 & 841 & 1595 & 2707 & 813 & 1983 & 3655 \\
\hline 1960 & 3287 & 5725 & 6119 & 6052 & 2461 & 1757 & 1380 & 1143 & 970 & 894 & 1071 & 4167 & 894 & 2919 & 6119 \\
\hline 1961 & 5323 & 6270 & 5593 & 3445 & 2395 & 1745 & 1349 & 1159 & 972 & 880 & 1018 & 1583 & 880 & 2644 & 6270 \\
\hline 1962 & 3183 & 4800 & 3643 & 2829 & 2048 & 1640 & 1526 & 1080 & 841 & 1108 & 1787 & 3241 & 841 & 2310 & 4800 \\
\hline 1963 & 5965 & 6776 & 3580 & 1729 & 1418 & 1133 & 1021 & 903 & 786 & 689 & 924 & 1127 & 689 & 2171 & 6776 \\
\hline 1964 & 3528 & 7716 & 5404 & 2713 & 1648 & 1214 & 1009 & 932 & 746 & 805 & 2829 & 4148 & 746 & 2724 & 7716 \\
\hline 1965 & 5082 & 5655 & 6268 & 6178 & 2910 & 1871 & 1527 & 1269 & 1030 & 1460 & 2630 & 4122 & 1030 & 3333 & 6268 \\
\hline 1966 & 4434 & 6989 & 6760 & 4481 & 2571 & 1917 & 1505 & 1322 & 1059 & 1272 & 1996 & 2782 & 1059 & 3091 & 6989 \\
\hline 1967 & 5106 & 5105 & 4351 & 3775 & 2529 & 1598 & 1421 & 1351 & 1210 & 1136 & 1756 & 3800 & 1136 & 2761 & 5106 \\
\hline 1968 & 5970 & 4441 & 6461 & 5223 & 2343 & 1654 & 1418 & 1277 & 1206 & 1264 & 1718 & 4322 & 1206 & 3108 & 6461 \\
\hline 1969 & 3148 & 3920 & 3842 & 2361 & 1682 & 1212 & 1119 & 1005 & 831 & 940 & 2366 & 4775 & 831 & 2267 & 4775 \\
\hline
\end{tabular}


continuação

\begin{tabular}{|c|c|c|c|c|c|c|c|c|c|c|c|c|c|c|c|}
\hline \multicolumn{16}{|c|}{ SOBRADINHO } \\
\hline ano & jan & fev & mar & abr & mai & jun & jul & ago & set & out & nov & dez & mín. & méd. & máx. \\
\hline 1970 & 5909 & 6559 & 4792 & 2675 & 1959 & 1421 & 1143 & 1002 & 1156 & 1565 & 2830 & 2672 & 1002 & 2807 & 6559 \\
\hline 1971 & 1722 & 1467 & 1693 & 1432 & 1121 & 950 & 894 & 747 & 690 & 1080 & 2182 & 6257 & 690 & 1686 & 6257 \\
\hline 1972 & 5150 & 2981 & 3509 & 3049 & 1809 & 1254 & 1127 & 1010 & 825 & 1268 & 1879 & 4029 & 825 & 2324 & 5150 \\
\hline 1973 & 4800 & 3880 & 3418 & 4611 & 2191 & 1554 & 1311 & 1026 & 888 & 1196 & 3007 & 4377 & 888 & 2688 & 4800 \\
\hline 1974 & 4696 & 3341 & 3284 & 5232 & 2992 & 1830 & 1486 & 1250 & 1058 & 1161 & 1877 & 2349 & 1058 & 2546 & 5232 \\
\hline 1975 & 4230 & 4180 & 2427 & 2468 & 1951 & 1233 & 1132 & 955 & 742 & 1008 & 2252 & 2766 & 742 & 2112 & 4230 \\
\hline 1976 & 2128 & 2001 & 2187 & 1826 & 1092 & 1085 & 851 & 847 & 1031 & 1420 & 2234 & 4825 & 847 & 1794 & 4825 \\
\hline 1977 & 4751 & 6278 & 2358 & 2147 & 1875 & 1355 & 1147 & 933 & 867 & 1188 & 1379 & 2708 & 867 & 2249 & 6278 \\
\hline 1978 & 5561 & 5227 & 6502 & 4274 & 2591 & 2193 & 1615 & 1350 & 1140 & 1326 & 1899 & 3601 & 1140 & 3107 & 6502 \\
\hline 1979 & 5740 & 9301 & 15364 & 6666 & 3349 & 2679 & 2031 & 1700 & 1631 & 1587 & 2748 & 3101 & 1587 & 4658 & 15364 \\
\hline 1980 & 5472 & 9415 & 10501 & 4409 & 3190 & 2200 & 1961 & 1634 & 1426 & 1455 & 1843 & 4164 & 1426 & 3972 & 10501 \\
\hline 1981 & 5706 & 4862 & 2848 & 5484 & 2789 & 2203 & 1639 & 1412 & 1259 & 1698 & 3942 & 6366 & 1259 & 3351 & 6366 \\
\hline 1982 & 6757 & 8455 & 6786 & 7129 & 3593 & 2693 & 2037 & 1732 & 1543 & 1459 & 1600 & 1868 & 1459 & 3804 & 8455 \\
\hline 1983 & 3985 & 7394 & 9868 & 6869 & 4153 & 2600 & 2294 & 1744 & 1579 & 1992 & 3443 & 5970 & 1579 & 4324 & 9868 \\
\hline 1984 & 6468 & 3020 & 2599 & 3382 & 1947 & 1437 & 1239 & 1083 & 1237 & 1347 & 1626 & 3823 & 1083 & 2434 & 6468 \\
\hline 1985 & 5116 & 8340 & 6266 & 4775 & 2465 & 1795 & 1464 & 1278 & 1169 & 1459 & 1957 & 2887 & 1169 & 3248 & 8340 \\
\hline 1986 & 6518 & 7222 & 4724 & 2186 & 1823 & 1413 & 1240 & 1212 & 1149 & 944 & 1147 & 1686 & 944 & 2605 & 7222 \\
\hline 1987 & 3263 & 2745 & 2385 & 2833 & 1635 & 1207 & 982 & 845 & 744 & 911 & 1382 & 3783 & 744 & 1893 & 3783 \\
\hline 1988 & 5485 & 3542 & 4297 & 2840 & 1840 & 1277 & 1026 & 904 & 809 & 899 & 1546 & 2350 & 809 & 2235 & 5485 \\
\hline 1989 & 3707 & 2488 & 3051 & 1738 & 1198 & 976 & 940 & 880 & 858 & 971 & 1702 & 4436 & 858 & 1912 & 4436 \\
\hline 1990 & 9475 & 3325 & 3281 & 2033 & 1470 & 1166 & 1121 & 969 & 967 & 863 & 1234 & 1537 & 863 & 2287 & 9475 \\
\hline 1991 & 3087 & 5456 & 4698 & 5730 & 2375 & 1553 & 1203 & 1013 & 879 & 1273 & 1919 & 2996 & 879 & 2682 & 5730 \\
\hline 1992 & 4059 & 9713 & 13254 & 3689 & 2865 & 1892 & 1585 & 1351 & 1186 & 1679 & 4168 & 4549 & 1186 & 4166 & 13254 \\
\hline 1993 & 5878 & 4531 & 4437 & 2774 & 1992 & 1610 & 1330 & 1097 & 980 & 1199 & 1134 & 1820 & 980 & 2398 & 5878 \\
\hline 1994 & 5681 & 4839 & 4786 & 4992 & 2135 & 1662 & 1365 & 1099 & 939 & 842 & 988 & 3057 & 842 & 2699 & 5681 \\
\hline 1995 & 2950 & 2777 & 2923 & 2742 & 1776 & 1242 & 1010 & 865 & 706 & 797 & 1762 & 2780 & 706 & 1861 & 2950 \\
\hline 1996 & 4811 & 2106 & 2141 & 1642 & 1219 & 988 & 782 & 726 & 781 & 758 & 1488 & 3360 & 726 & 1733 & 4811 \\
\hline 1997 & 6520 & 4858 & 4440 & 4211 & 2512 & 1839 & 1367 & 1076 & 890 & 962 & 1157 & 3333 & 890 & 2764 & 6520 \\
\hline 1998 & 3416 & 3369 & 3536 & 1821 & 1294 & 1161 & 893 & 796 & 674 & 966 & 1969 & 3233 & 674 & 1927 & 3536 \\
\hline 1999 & 3180 & 1697 & 4381 & 2436 & 1290 & 979 & 873 & 743 & 645 & 705 & 1473 & 3289 & 645 & 1808 & 4381 \\
\hline 2000 & 4304 & 5383 & 4518 & 3639 & 1771 & 1283 & 1068 & 918 & 1002 & 815 & 1658 & 3643 & 815 & 2500 & 5383 \\
\hline 2001 & 3374 & 1767 & 1796 & 1396 & 970 & 916 & 781 & 713 & 722 & 894 & 1221 & 2276 & 713 & 1402 & 3374 \\
\hline méd. & 4772 & 5028 & 4890 & 3852 & 2385 & 1648 & 1357 & 1162 & 1031 & 1150 & 1880 & 3423 & 996 & 2715 & 6298 \\
\hline
\end{tabular}




\begin{tabular}{|c|c|c|c|c|c|c|c|c|c|c|c|c|c|c|c|}
\hline \multicolumn{16}{|c|}{ ITAPARICA } \\
\hline ano & jan & fev & mar & $a b r$ & mai & jun & jul & ago & set & out & nov & dez & mín. & méd. & máx. \\
\hline 1931 & 4674 & 4803 & 6628 & 7331 & 4465 & 2395 & 1867 & 1617 & 1446 & 1373 & 1933 & 2205 & 1373 & 3395 & 7331 \\
\hline 1932 & 4034 & 4529 & 3211 & 1974 & 1422 & 1289 & 1173 & 993 & 902 & 980 & 2104 & 3592 & 902 & 2184 & 4529 \\
\hline 1933 & 5011 & 5513 & 3426 & 2690 & 1902 & 1354 & 1248 & 1070 & 912 & 1192 & 1796 & 3334 & 912 & 2454 & 5513 \\
\hline 1934 & 6107 & 4220 & 2295 & 1613 & 1782 & 1165 & 994 & 894 & 796 & 874 & 902 & 1603 & 796 & 1937 & 6107 \\
\hline 1935 & 4517 & 5439 & 5406 & 4714 & 3737 & 2008 & 1554 & 1234 & 1053 & 1077 & 1175 & 2583 & 1053 & 2875 & 5439 \\
\hline 1936 & 2693 & 2661 & 4171 & 2761 & 2107 & 1297 & 1089 & 931 & 858 & 884 & 1595 & 2721 & 858 & 1981 & 4171 \\
\hline 1937 & 4724 & 5872 & 4518 & 3261 & 2522 & 1452 & 1228 & 1034 & 897 & 917 & 2392 & 4858 & 897 & 2806 & 5872 \\
\hline 1938 & 6480 & 4358 & 4042 & 2574 & 1738 & 1417 & 1155 & 1031 & 954 & 911 & 1536 & 2955 & 911 & 2429 & 6480 \\
\hline 1939 & 5093 & 5895 & 4888 & 2153 & 1625 & 1256 & 1104 & 1033 & 933 & 1282 & 1017 & 1705 & 933 & 2332 & 5895 \\
\hline 1940 & 3167 & 5159 & 6296 & 4445 & 2002 & 1413 & 1185 & 1052 & 858 & 923 & 2135 & 3790 & 858 & 2702 & 6296 \\
\hline 1941 & 5002 & 4420 & 4672 & 4829 & 2718 & 1656 & 1420 & 1257 & 1019 & 1134 & 1667 & 2312 & 1019 & 2675 & 5002 \\
\hline 1942 & 4621 & 4417 & 5274 & 3357 & 2271 & 1544 & 1297 & 1114 & 1021 & 1321 & 2271 & 5220 & 1021 & 2811 & 5274 \\
\hline 1943 & 6274 & 9698 & 8081 & 5094 & 2878 & 2110 & 1771 & 1519 & 1286 & 1391 & 2202 & 5147 & 1286 & 3954 & 9698 \\
\hline 1944 & 6325 & 4860 & 4746 & 3726 & 2515 & 1735 & 1465 & 1275 & 1100 & 959 & 1649 & 3900 & 959 & 2855 & 6325 \\
\hline 1945 & 5714 & 7001 & 8026 & 7378 & 8760 & 3936 & 2588 & 2075 & 1700 & 1975 & 3264 & 5590 & 1700 & 4834 & 8760 \\
\hline 1946 & 7281 & 10073 & 4592 & 5588 & 3578 & 2450 & 2006 & 1722 & 1494 & 1515 & 2168 & 3766 & 1494 & 3853 & 10073 \\
\hline 1947 & 3746 & 5139 & 6609 & 7655 & 4315 & 2350 & 1939 & 1623 & 1610 & 1433 & 3109 & 4245 & 1433 & 3648 & 7655 \\
\hline 1948 & 6340 & 4517 & 5418 & 4013 & 2207 & 1843 & 1578 & 1356 & 1203 & 1321 & 1501 & 5152 & 1203 & 3037 & 6340 \\
\hline 1949 & 7846 & 9216 & 13040 & 7131 & 3496 & 2586 & 2151 & 1817 & 1544 & 1461 & 2925 & 2941 & 1461 & 4679 & 13040 \\
\hline 1950 & 4447 & 4712 & 3457 & 3780 & 2617 & 1739 & 1512 & 1301 & 1072 & 1262 & 2135 & 4124 & 1072 & 2680 & 4712 \\
\hline 1951 & 4175 & 4152 & 4435 & 4851 & 2518 & 1842 & 1483 & 1272 & 1099 & 1023 & 938 & 1638 & 938 & 2452 & 4851 \\
\hline 1952 & 3306 & 4714 & 5788 & 6934 & 3253 & 1967 & 1600 & 1307 & 1188 & 1132 & 1778 & 3389 & 1132 & 3030 & 6934 \\
\hline 1953 & 3559 & 1789 & 2681 & 3736 & 1930 & 1303 & 1103 & 967 & 852 & 1156 & 1407 & 3185 & 852 & 1972 & 3736 \\
\hline 1954 & 4401 & 2775 & 2776 & 2425 & 1439 & 1195 & 974 & 847 & 710 & 640 & 876 & 3540 & 640 & 1883 & 4401 \\
\hline 1955 & 2306 & 4047 & 2161 & 2611 & 1432 & 1067 & 894 & 782 & 671 & 655 & 1973 & 3301 & 655 & 1825 & 4047 \\
\hline 1956 & 5366 & 2211 & 4581 & 2538 & 1768 & 1634 & 1320 & 1061 & 897 & 835 & 1464 & 3683 & 835 & 2280 & 5366 \\
\hline 1957 & 5944 & 7114 & 7402 & 8268 & 5810 & 2762 & 2027 & 1638 & 1366 & 1516 & 1411 & 4338 & 1366 & 4133 & 8268 \\
\hline 1958 & 3619 & 5208 & 3381 & 3099 & 2415 & 1691 & 1406 & 1414 & 1121 & 1512 & 1833 & 1794 & 1121 & 2374 & 5208 \\
\hline 1959 & 3597 & 3655 & 3490 & 2702 & 1357 & 1132 & 1008 & 898 & 813 & 841 & 1595 & 2707 & 813 & 1983 & 3655 \\
\hline 1960 & 3362 & 5865 & 9187 & 6525 & 2546 & 1818 & 1380 & 1143 & 970 & 894 & 1071 & 4167 & 894 & 3244 & 9187 \\
\hline 1961 & 5366 & 6375 & 5650 & 3445 & 2395 & 1745 & 1349 & 1159 & 972 & 880 & 1018 & 1583 & 880 & 2661 & 6375 \\
\hline 1962 & 3183 & 4800 & 3643 & 2829 & 2048 & 1640 & 1526 & 1080 & 841 & 1108 & 1787 & 3241 & 841 & 2310 & 4800 \\
\hline 1963 & 5977 & 6915 & 3629 & 1782 & 1418 & 1133 & 1021 & 903 & 786 & 689 & 924 & 1279 & 689 & 2205 & 6915 \\
\hline 1964 & 3842 & 8116 & 5584 & 3166 & 1747 & 1214 & 1009 & 932 & 746 & 805 & 2829 & 4148 & 746 & 2845 & 8116 \\
\hline 1965 & 5082 & 5758 & 6290 & 6307 & 2910 & 1871 & 1527 & 1269 & 1030 & 1460 & 2630 & 4122 & 1030 & 3355 & 6307 \\
\hline 1966 & 4434 & 6989 & 6760 & 4748 & 2604 & 1917 & 1505 & 1322 & 1059 & 1272 & 1996 & 2782 & 1059 & 3116 & 6989 \\
\hline 1967 & 5106 & 5105 & 4634 & 4545 & 2755 & 1632 & 1421 & 1351 & 1210 & 1136 & 1756 & 3800 & 1136 & 2871 & 5106 \\
\hline 1968 & 5970 & 4441 & 6948 & 5223 & 2542 & 1654 & 1418 & 1277 & 1206 & 1264 & 1718 & 4322 & 1206 & 3165 & 6948 \\
\hline 1969 & 3148 & 3920 & 3842 & 2361 & 1682 & 1212 & 1119 & 1005 & 831 & 940 & 2366 & 4775 & 831 & 2267 & 4775 \\
\hline
\end{tabular}


continuação

\begin{tabular}{|c|c|c|c|c|c|c|c|c|c|c|c|c|c|c|c|}
\hline \multicolumn{16}{|c|}{ ITAPARICA } \\
\hline ano & jan & fev & mar & $a b r$ & mai & jun & jul & ago & set & out & nov & dez & mín. & méd. & máx. \\
\hline 1970 & 6130 & 6600 & 4864 & 2748 & 1959 & 1421 & 1143 & 1002 & 1156 & 1565 & 2830 & 2672 & 1002 & 2841 & 6600 \\
\hline 1971 & 1722 & 1467 & 1764 & 1785 & 1170 & 950 & 894 & 747 & 690 & 1080 & 2182 & 6257 & 690 & 1726 & 6257 \\
\hline 1972 & 5150 & 2981 & 3509 & 3049 & 1809 & 1254 & 1127 & 1010 & 825 & 1268 & 1879 & 4029 & 825 & 2324 & 5150 \\
\hline 1973 & 4800 & 3880 & 3601 & 4689 & 2285 & 1554 & 1311 & 1026 & 888 & 1196 & 3007 & 4377 & 888 & 2718 & 4800 \\
\hline 1974 & 4696 & 3985 & 4465 & 6382 & 3092 & 1830 & 1486 & 1250 & 1058 & 1161 & 1877 & 2349 & 1058 & 2803 & 6382 \\
\hline 1975 & 4230 & 4180 & 2689 & 2622 & 2017 & 1233 & 1132 & 955 & 742 & 1008 & 2252 & 2766 & 742 & 2152 & 4230 \\
\hline 1976 & 2150 & 2120 & 2226 & 1883 & 1092 & 1085 & 851 & 847 & 1031 & 1420 & 2234 & 4825 & 847 & 1814 & 4825 \\
\hline 1977 & 4773 & 6446 & 2394 & 2224 & 1886 & 1436 & 1147 & 933 & 867 & 1188 & 1379 & 2708 & 867 & 2282 & 6446 \\
\hline 1978 & 5593 & 5395 & 6756 & 4322 & 2810 & 2193 & 1615 & 1350 & 1140 & 1326 & 1899 & 3707 & 1140 & 3175 & 6756 \\
\hline 1979 & 5937 & 9360 & 15407 & 6763 & 3446 & 2679 & 2031 & 1700 & 1631 & 1587 & 2748 & 3214 & 1587 & 4709 & 15407 \\
\hline 1980 & 5625 & 9991 & 10501 & 4409 & 3190 & 2200 & 1961 & 1634 & 1426 & 1455 & 1843 & 4208 & 1426 & 4037 & 10501 \\
\hline 1981 & 5823 & 4899 & 3869 & 5830 & 2907 & 2203 & 1639 & 1412 & 1259 & 1698 & 3942 & 6366 & 1259 & 3487 & 6366 \\
\hline 1982 & 6757 & 8455 & 6786 & 7129 & 3593 & 2693 & 2037 & 1732 & 1543 & 1459 & 1600 & 1949 & 1459 & 3811 & 8455 \\
\hline 1983 & 4099 & 7692 & 9985 & 6943 & 4153 & 2600 & 2294 & 1744 & 1579 & 1992 & 3443 & 5970 & 1579 & 4374 & 9985 \\
\hline 1984 & 6468 & 3020 & 2649 & 3953 & 2014 & 1437 & 1239 & 1083 & 1237 & 1347 & 1626 & 3823 & 1083 & 2491 & 6468 \\
\hline 1985 & 5308 & 8819 & 7051 & 6944 & 2975 & 1912 & 1464 & 1278 & 1169 & 1459 & 1957 & 3072 & 1169 & 3617 & 8819 \\
\hline 1986 & 6518 & 7618 & 5178 & 2401 & 1884 & 1413 & 1240 & 1212 & 1149 & 944 & 1147 & 1686 & 944 & 2699 & 7618 \\
\hline 1987 & 3263 & 2745 & 2666 & 2924 & 1685 & 1207 & 982 & 845 & 744 & 911 & 1382 & 3783 & 744 & 1928 & 3783 \\
\hline 1988 & 5750 & 3542 & 4804 & 3684 & 2108 & 1376 & 1133 & 966 & 837 & 925 & 1620 & 2350 & 837 & 2425 & 5750 \\
\hline 1989 & 3707 & 2488 & 3051 & 1738 & 1198 & 976 & 940 & 880 & 858 & 971 & 1744 & 5376 & 858 & 1994 & 5376 \\
\hline 1990 & 9676 & 3325 & 3281 & 2033 & 1470 & 1166 & 1121 & 969 & 967 & 863 & 1234 & 1537 & 863 & 2303 & 9676 \\
\hline 1991 & 3092 & 5461 & 4823 & 5735 & 2380 & 1558 & 1208 & 1018 & 884 & 1278 & 1924 & 3001 & 884 & 2697 & 5735 \\
\hline 1992 & 4393 & 10079 & 13257 & 3692 & 2866 & 1895 & 1588 & 1354 & 1189 & 1682 & 4171 & 4552 & 1189 & 4226 & 13257 \\
\hline 1993 & 5885 & 4538 & 4444 & 2781 & 1999 & 1617 & 1337 & 1104 & 987 & 1206 & 1141 & 1827 & 987 & 2405 & 5885 \\
\hline 1994 & 5685 & 4843 & 4790 & 4996 & 2139 & 1666 & 1369 & 1103 & 943 & 846 & 992 & 3061 & 846 & 2703 & 5685 \\
\hline 1995 & 2950 & 2898 & 3051 & 2843 & 1776 & 1264 & 1019 & 865 & 726 & 803 & 1812 & 2908 & 726 & 1910 & 3051 \\
\hline 1996 & 4811 & 2106 & 2197 & 1900 & 1219 & 1046 & 805 & 728 & 781 & 779 & 1572 & 3438 & 728 & 1782 & 4811 \\
\hline 1997 & 6520 & 4858 & 4440 & 4211 & 2512 & 1839 & 1367 & 1076 & 890 & 962 & 1157 & 3333 & 890 & 2764 & 6520 \\
\hline 1998 & 3416 & 3369 & 3536 & 1821 & 1294 & 1161 & 893 & 796 & 674 & 966 & 1969 & 3233 & 674 & 1927 & 3536 \\
\hline 1999 & 3180 & 1697 & 4381 & 2436 & 1323 & 979 & 873 & 743 & 645 & 705 & 1473 & 3289 & 645 & 1810 & 4381 \\
\hline 2000 & 4304 & 5446 & 4660 & 3639 & 1771 & 1283 & 1068 & 918 & 1002 & 815 & 1658 & 3643 & 815 & 2517 & 5446 \\
\hline 2001 & 3374 & 1767 & 1796 & 1396 & 970 & 916 & 781 & 713 & 722 & 894 & 1221 & 2276 & 713 & 1402 & 3374 \\
\hline méd. & 4812 & 5106 & 5078 & 4001 & 2426 & 1654 & 1359 & 1163 & 1032 & 1151 & 1884 & 3452 & 997 & 2760 & 6448 \\
\hline
\end{tabular}




\begin{tabular}{|c|c|c|c|c|c|c|c|c|c|c|c|c|c|c|c|}
\hline \multicolumn{16}{|c|}{ COMPLEXO PAULO AFONSO-MOXOTÓ } \\
\hline ano & jan & fev & mar & $a b r$ & mai & jun & jul & ago & set & out & nov & dez & mín. & méd. & máx. \\
\hline 1931 & 4674 & 4803 & 6628 & 7331 & 4465 & 2395 & 1867 & 1617 & 1446 & 1373 & 1933 & 2205 & 1373 & 3395 & 7331 \\
\hline 1932 & 4034 & 4529 & 3211 & 1974 & 1422 & 1289 & 1173 & 993 & 902 & 980 & 2104 & 3592 & 902 & 2184 & 4529 \\
\hline 1933 & 5011 & 5513 & 3426 & 2690 & 1902 & 1354 & 1248 & 1070 & 912 & 1192 & 1796 & 3334 & 912 & 2454 & 5513 \\
\hline 1934 & 6107 & 4220 & 2295 & 1613 & 1782 & 1165 & 994 & 894 & 796 & 874 & 902 & 1603 & 796 & 1937 & 6107 \\
\hline 1935 & 4517 & 5439 & 5406 & 4714 & 3737 & 2008 & 1554 & 1234 & 1053 & 1077 & 1175 & 2583 & 1053 & 2875 & 5439 \\
\hline 1936 & 2693 & 2661 & 4171 & 2761 & 2107 & 1297 & 1089 & 931 & 858 & 884 & 1595 & 2721 & 858 & 1981 & 4171 \\
\hline 1937 & 4724 & 5872 & 4518 & 3261 & 2522 & 1452 & 1228 & 1034 & 897 & 917 & 2392 & 4858 & 897 & 2806 & 5872 \\
\hline 1938 & 6480 & 4358 & 4042 & 2574 & 1738 & 1417 & 1155 & 1031 & 954 & 911 & 1536 & 2955 & 911 & 2429 & 6480 \\
\hline 1939 & 5093 & 5895 & 4888 & 2153 & 1625 & 1256 & 1104 & 1033 & 933 & 1282 & 1017 & 1705 & 933 & 2332 & 5895 \\
\hline 1940 & 3167 & 5159 & 6296 & 4445 & 2002 & 1413 & 1185 & 1052 & 858 & 923 & 2135 & 3790 & 858 & 2702 & 6296 \\
\hline 1941 & 5002 & 4420 & 4672 & 4829 & 2718 & 1656 & 1420 & 1257 & 1019 & 1134 & 1667 & 2312 & 1019 & 2675 & 5002 \\
\hline 1942 & 4621 & 4417 & 5274 & 3357 & 2271 & 1544 & 1297 & 1114 & 1021 & 1321 & 2271 & 5220 & 1021 & 2811 & 5274 \\
\hline 1943 & 6274 & 9698 & 8081 & 5094 & 2878 & 2110 & 1771 & 1519 & 1286 & 1391 & 2202 & 5147 & 1286 & 3954 & 9698 \\
\hline 1944 & 6325 & 4860 & 4746 & 3726 & 2515 & 1735 & 1465 & 1275 & 1100 & 959 & 1649 & 3900 & 959 & 2855 & 6325 \\
\hline 1945 & 5714 & 7001 & 8026 & 7378 & 8760 & 3936 & 2588 & 2075 & 1700 & 1975 & 3264 & 5590 & 1700 & 4834 & 8760 \\
\hline 1946 & 7281 & 10073 & 4592 & 5588 & 3578 & 2450 & 2006 & 1722 & 1494 & 1515 & 2168 & 3766 & 1494 & 3853 & 10073 \\
\hline 1947 & 3746 & 5139 & 6609 & 7655 & 4315 & 2350 & 1939 & 1623 & 1610 & 1433 & 3109 & 4245 & 1433 & 3648 & 7655 \\
\hline 1948 & 6340 & 4517 & 5418 & 4013 & 2207 & 1843 & 1578 & 1356 & 1203 & 1321 & 1501 & 5152 & 1203 & 3037 & 6340 \\
\hline 1949 & 7846 & 9216 & 13040 & 7131 & 3496 & 2586 & 2151 & 1817 & 1544 & 1461 & 2925 & 2941 & 1461 & 4679 & 13040 \\
\hline 1950 & 4447 & 4712 & 3457 & 3780 & 2617 & 1739 & 1512 & 1301 & 1072 & 1262 & 2135 & 4124 & 1072 & 2680 & 4712 \\
\hline 1951 & 4175 & 4152 & 4435 & 4851 & 2518 & 1842 & 1483 & 1272 & 1099 & 1023 & 938 & 1638 & 938 & 2452 & 4851 \\
\hline 1952 & 3306 & 4714 & 5788 & 6934 & 3253 & 1967 & 1600 & 1307 & 1188 & 1132 & 1778 & 3389 & 1132 & 3030 & 6934 \\
\hline 1953 & 3559 & 1789 & 2681 & 3736 & 1930 & 1303 & 1103 & 967 & 852 & 1156 & 1407 & 3185 & 852 & 1972 & 3736 \\
\hline 1954 & 4401 & 2775 & 2776 & 2425 & 1439 & 1195 & 974 & 847 & 710 & 640 & 876 & 3540 & 640 & 1883 & 4401 \\
\hline 1955 & 2306 & 4047 & 2161 & 2611 & 1432 & 1067 & 894 & 782 & 671 & 655 & 1973 & 3301 & 655 & 1825 & 4047 \\
\hline 1956 & 5366 & 2211 & 4581 & 2538 & 1768 & 1634 & 1320 & 1061 & 897 & 835 & 1464 & 3683 & 835 & 2280 & 5366 \\
\hline 1957 & 5944 & 7114 & 7402 & 8268 & 5810 & 2762 & 2027 & 1638 & 1366 & 1516 & 1411 & 4338 & 1366 & 4133 & 8268 \\
\hline 1958 & 3619 & 5208 & 3381 & 3099 & 2415 & 1691 & 1406 & 1414 & 1121 & 1512 & 1833 & 1794 & 1121 & 2374 & 5208 \\
\hline 1959 & 3597 & 3655 & 3490 & 2702 & 1357 & 1132 & 1008 & 898 & 813 & 841 & 1595 & 2707 & 813 & 1983 & 3655 \\
\hline 1960 & 3362 & 5865 & 9187 & 6525 & 2546 & 1818 & 1380 & 1143 & 970 & 894 & 1071 & 4167 & 894 & 3244 & 9187 \\
\hline 1961 & 5366 & 6375 & 5650 & 3445 & 2395 & 1745 & 1349 & 1159 & 972 & 880 & 1018 & 1583 & 880 & 2661 & 6375 \\
\hline 1962 & 3183 & 4800 & 3643 & 2829 & 2048 & 1640 & 1526 & 1080 & 841 & 1108 & 1787 & 3241 & 841 & 2310 & 4800 \\
\hline 1963 & 5977 & 6915 & 3629 & 1782 & 1418 & 1133 & 1021 & 903 & 786 & 689 & 924 & 1279 & 689 & 2205 & 6915 \\
\hline 1964 & 3842 & 8116 & 5584 & 3166 & 1747 & 1214 & 1009 & 932 & 746 & 805 & 2829 & 4148 & 746 & 2845 & 8116 \\
\hline 1965 & 5082 & 5758 & 6290 & 6307 & 2910 & 1871 & 1527 & 1269 & 1030 & 1460 & 2630 & 4122 & 1030 & 3355 & 6307 \\
\hline 1966 & 4434 & 6989 & 6760 & 4748 & 2604 & 1917 & 1505 & 1322 & 1059 & 1272 & 1996 & 2782 & 1059 & 3116 & 6989 \\
\hline 1967 & 5106 & 5105 & 4634 & 4545 & 2755 & 1632 & 1421 & 1351 & 1210 & 1136 & 1756 & 3800 & 1136 & 2871 & 5106 \\
\hline 1968 & 5970 & 4441 & 6948 & 5223 & 2542 & 1654 & 1418 & 1277 & 1206 & 1264 & 1718 & 4322 & 1206 & 3165 & 6948 \\
\hline 1969 & 3148 & 3920 & 3842 & 2361 & 1682 & 1212 & 1119 & 1005 & 831 & 940 & 2366 & 4775 & 831 & 2267 & 4775 \\
\hline
\end{tabular}


continuação

\begin{tabular}{|c|c|c|c|c|c|c|c|c|c|c|c|c|c|c|c|}
\hline \multicolumn{16}{|c|}{ COMPLEXO PAULO AFONSO-MOXOTÓ } \\
\hline ano & jan & fev & mar & abr & mai & jun & jul & ago & set & out & nov & dez & mín. & méd. & máx. \\
\hline 1970 & 6130 & 6600 & 4864 & 2748 & 1959 & 1421 & 1143 & 1002 & 1156 & 1565 & 2830 & 2672 & 1002 & 2841 & 6600 \\
\hline 1971 & 1722 & 1467 & 1764 & 1785 & 1170 & 950 & 894 & 747 & 690 & 1080 & 2182 & 6257 & 690 & 1726 & 6257 \\
\hline 1972 & 5150 & 2981 & 3509 & 3049 & 1809 & 1254 & 1127 & 1010 & 825 & 1268 & 1879 & 4029 & 825 & 2324 & 5150 \\
\hline 1973 & 4800 & 3880 & 3601 & 4689 & 2285 & 1554 & 1311 & 1026 & 888 & 1196 & 3007 & 4377 & 888 & 2718 & 4800 \\
\hline 1974 & 4696 & 3985 & 4465 & 6382 & 3092 & 1830 & 1486 & 1250 & 1058 & 1161 & 1877 & 2349 & 1058 & 2803 & 6382 \\
\hline 1975 & 4230 & 4180 & 2689 & 2622 & 2017 & 1233 & 1132 & 955 & 742 & 1008 & 2252 & 2766 & 742 & 2152 & 4230 \\
\hline 1976 & 2150 & 2120 & 2226 & 1883 & 1092 & 1085 & 851 & 847 & 1031 & 1420 & 2234 & 4825 & 847 & 1814 & 4825 \\
\hline 1977 & 4773 & 6446 & 2394 & 2224 & 1886 & 1436 & 1147 & 933 & 867 & 1188 & 1379 & 2708 & 867 & 2282 & 6446 \\
\hline 1978 & 5593 & 5395 & 6756 & 4322 & 2810 & 2193 & 1615 & 1350 & 1140 & 1326 & 1899 & 3707 & 1140 & 3175 & 6756 \\
\hline 1979 & 5937 & 9360 & 15407 & 6763 & 3446 & 2679 & 2031 & 1700 & 1631 & 1587 & 2748 & 3214 & 1587 & 4709 & 15407 \\
\hline 1980 & 5625 & 9991 & 10501 & 4409 & 3190 & 2200 & 1961 & 1634 & 1426 & 1455 & 1843 & 4208 & 1426 & 4037 & 10501 \\
\hline 1981 & 5823 & 4899 & 3869 & 5830 & 2907 & 2203 & 1639 & 1412 & 1259 & 1698 & 3942 & 6366 & 1259 & 3487 & 6366 \\
\hline 1982 & 6757 & 8455 & 6786 & 7129 & 3593 & 2693 & 2037 & 1732 & 1543 & 1459 & 1600 & 1949 & 1459 & 3811 & 8455 \\
\hline 1983 & 4099 & 7692 & 9985 & 6943 & 4153 & 2600 & 2294 & 1744 & 1579 & 1992 & 3443 & 5970 & 1579 & 4374 & 9985 \\
\hline 1984 & 6468 & 3020 & 2649 & 3953 & 2014 & 1437 & 1239 & 1083 & 1237 & 1347 & 1626 & 3823 & 1083 & 2491 & 6468 \\
\hline 1985 & 5308 & 8819 & 7051 & 6944 & 2975 & 1912 & 1464 & 1278 & 1169 & 1459 & 1957 & 3072 & 1169 & 3617 & 8819 \\
\hline 1986 & 6518 & 7618 & 5178 & 2401 & 1884 & 1413 & 1240 & 1212 & 1149 & 944 & 1147 & 1686 & 944 & 699 & 7618 \\
\hline 1987 & 3263 & 2745 & 2666 & 2924 & 1685 & 1207 & 902 & 045 & 744 & 911 & 1382 & 3783 & 744 & 1928 & 3783 \\
\hline 1988 & 5750 & 3542 & 4804 & 3684 & 2108 & 1376 & 1133 & 966 & 837 & 925 & 1620 & 2350 & 837 & 2425 & 5750 \\
\hline 1989 & 3707 & 2488 & 3051 & 1738 & 1198 & 976 & 940 & 880 & 858 & 971 & 1744 & 5376 & 858 & 1994 & 5376 \\
\hline 1990 & 9676 & 3325 & 3281 & 2033 & 1470 & 1166 & 1121 & 969 & 967 & 863 & 1234 & 1537 & 863 & 2303 & 9676 \\
\hline 1991 & 3092 & 5461 & 4823 & 5735 & 2380 & 1558 & 1208 & 1018 & 884 & 1278 & 1924 & 3001 & 884 & 2697 & 5735 \\
\hline 1992 & 4393 & 10079 & 13257 & 3692 & 2866 & 1895 & 1588 & 1354 & 1189 & 1682 & 4171 & 4552 & 1189 & 4226 & 13257 \\
\hline 1993 & 5885 & 4538 & 4444 & 2781 & 1999 & 1617 & 1337 & 1104 & 987 & 1206 & 1141 & 1827 & 987 & 2405 & 5885 \\
\hline 1994 & 5685 & 4843 & 4790 & 4996 & 2139 & 1666 & 1369 & 1103 & 943 & 846 & 992 & 3061 & 846 & 2703 & 5685 \\
\hline 1995 & 2950 & 2898 & 3051 & 2843 & 1776 & 1264 & 1019 & 865 & 726 & 803 & 1812 & 2908 & 726 & 1910 & 3051 \\
\hline 1996 & 4811 & 2106 & 2197 & 1900 & 1219 & 1046 & 805 & 728 & 781 & 779 & 1572 & 3438 & 728 & 1782 & 4811 \\
\hline 1997 & 6520 & 4858 & 4440 & 4211 & 2512 & 1839 & 1367 & 1076 & 890 & 962 & 1157 & 3333 & 890 & 2764 & 6520 \\
\hline 1998 & 3416 & 3369 & 3536 & 1821 & 1294 & 1161 & 893 & 796 & 674 & 966 & 1969 & 3233 & 674 & 1927 & 3536 \\
\hline 1999 & 3180 & 1697 & 4381 & 2436 & 1323 & 979 & 873 & 743 & 645 & 705 & 1473 & 3289 & 645 & 1810 & 4381 \\
\hline 2000 & 4304 & 5446 & 4660 & 3639 & 1771 & 1283 & 1068 & 918 & 1002 & 815 & 1658 & 3643 & 815 & 2517 & 5446 \\
\hline 2001 & 3374 & 1767 & 1796 & 1396 & 970 & 916 & 781 & 713 & 722 & 894 & 1221 & 2276 & 713 & 1402 & 3374 \\
\hline méd. & 4812 & 5106 & 5078 & 4001 & 2426 & 1654 & 1359 & 1163 & 1032 & 1151 & 1884 & 3452 & 997 & 2760 & 6448 \\
\hline
\end{tabular}




\begin{tabular}{|c|c|c|c|c|c|c|c|c|c|c|c|c|c|c|c|}
\hline \multicolumn{16}{|c|}{ XINGÓ } \\
\hline ano & jan & fev & mar & $a b r$ & mai & jun & jul & ago & set & out & nov & dez & mín. & méd. & máx. \\
\hline 1931 & 4684 & 4813 & 6638 & 7341 & 4475 & 2405 & 1877 & 1627 & 1456 & 1383 & 1943 & 2215 & 1383 & 3405 & 7341 \\
\hline 1932 & 4044 & 4539 & 3221 & 1984 & 1432 & 1299 & 1183 & 1003 & 912 & 990 & 2114 & 3602 & 912 & 2194 & 4539 \\
\hline 1933 & 5021 & 5523 & 3436 & 2700 & 1912 & 1364 & 1258 & 1080 & 922 & 1202 & 1806 & 3344 & 922 & 2464 & 5523 \\
\hline 1934 & 6117 & 4230 & 2305 & 1623 & 1792 & 1175 & 1004 & 904 & 806 & 884 & 912 & 1613 & 806 & 1947 & 6117 \\
\hline 1935 & 4527 & 5449 & 5416 & 4724 & 3747 & 2018 & 1564 & 1244 & 1063 & 1087 & 1185 & 2593 & 1063 & 2885 & 5449 \\
\hline 1936 & 2703 & 2671 & 4181 & 2771 & 2117 & 1307 & 1099 & 941 & 868 & 894 & 1605 & 2731 & 868 & 1991 & 4181 \\
\hline 1937 & 4734 & 5882 & 4528 & 3271 & 2532 & 1462 & 1238 & 1044 & 907 & 927 & 2402 & 4868 & 907 & 2816 & 5882 \\
\hline 1938 & 6490 & 4368 & 4052 & 2584 & 1748 & 1427 & 1165 & 1041 & 964 & 921 & 1546 & 2965 & 921 & 2439 & 6490 \\
\hline 1939 & 5103 & 5905 & 4898 & 2163 & 1635 & 1266 & 1114 & 1043 & 943 & 1292 & 1027 & 1715 & 943 & 2342 & 5905 \\
\hline 1940 & 3177 & 5169 & 6306 & 4455 & 2012 & 1423 & 1195 & 1062 & 868 & 933 & 2145 & 3800 & 868 & 2712 & 6306 \\
\hline 1941 & 5012 & 4430 & 4682 & 4839 & 2728 & 1666 & 1430 & 1267 & 1029 & 1144 & 1677 & 2322 & 1029 & 2685 & 5012 \\
\hline 1942 & 4631 & 4427 & 5284 & 3367 & 2281 & 1554 & 1307 & 1124 & 1031 & 1331 & 2281 & 5230 & 1031 & 2821 & 5284 \\
\hline 1943 & 6284 & 9708 & 8091 & 5104 & 2888 & 2120 & 1781 & 1529 & 1296 & 1401 & 2212 & 5157 & 1296 & 3964 & 9708 \\
\hline 1944 & 6335 & 4870 & 4756 & 3736 & 2525 & 1745 & 1475 & 1285 & 1110 & 969 & 1659 & 3910 & 969 & 2865 & 6335 \\
\hline 1945 & 5724 & 7011 & 8036 & 7388 & 8770 & 3946 & 2598 & 2085 & 1710 & 1985 & 3274 & 5600 & 1710 & 4844 & 8770 \\
\hline 1946 & 7291 & 10083 & 4602 & 5598 & 3588 & 2460 & 2016 & 1732 & 1504 & 1525 & 2178 & 3776 & 1504 & 3863 & 10083 \\
\hline 1947 & 3756 & 5149 & 6619 & 7665 & 4325 & 2360 & 1949 & 1633 & 1620 & 1443 & 3119 & 4255 & 1443 & 3658 & 7665 \\
\hline 1948 & 6350 & 4527 & 5428 & 4023 & 2217 & 1853 & 1588 & 1366 & 1213 & 1331 & 1511 & 5162 & 1213 & 3047 & 6350 \\
\hline 1949 & 7856 & 9226 & 13050 & 7141 & 3506 & 2596 & 2161 & 1827 & 1554 & 1471 & 2935 & 2951 & 1471 & 4689 & 13050 \\
\hline 1950 & 4457 & 4722 & 3467 & 3790 & 2627 & 1749 & 1522 & 1311 & 1082 & 1272 & 2145 & 4134 & 1082 & 2690 & 4722 \\
\hline 1951 & 4185 & 4162 & 4445 & 4861 & 2528 & 1852 & 1493 & 1282 & 1109 & 1033 & 948 & 1648 & 948 & 2462 & 4861 \\
\hline 1952 & 3316 & 4724 & 5798 & 6944 & 3263 & 1977 & 1610 & 1317 & 1198 & 1142 & 1788 & 3399 & 1142 & 3040 & 6944 \\
\hline 1953 & 3569 & 1799 & 2691 & 3746 & 1940 & 1313 & 1113 & 977 & 862 & 1166 & 1417 & 3195 & 862 & 1982 & 3746 \\
\hline 1954 & 4411 & 2785 & 2786 & 2435 & 1449 & 1205 & 984 & 857 & 720 & 650 & 886 & 3550 & 650 & 1893 & 4411 \\
\hline 1955 & 2316 & 4057 & 2171 & 2621 & 1442 & 1077 & 904 & 792 & 681 & 665 & 1983 & 3311 & 665 & 1835 & 4057 \\
\hline 1956 & 5376 & 2221 & 4591 & 2548 & 1778 & 1644 & 1330 & 1071 & 907 & 845 & 1474 & 3693 & 845 & 2290 & 5376 \\
\hline 1957 & 5954 & 7124 & 7412 & 8278 & 5820 & 2772 & 2037 & 1648 & 1376 & 1526 & 1421 & 4348 & 1376 & 4143 & 8278 \\
\hline 1958 & 3629 & 5218 & 3391 & 3109 & 2425 & 1701 & 1416 & 1424 & 1131 & 1522 & 1843 & 1804 & 1131 & 2384 & 5218 \\
\hline 1959 & 3607 & 3665 & 3500 & 2712 & 1367 & 1142 & 1018 & 908 & 823 & 851 & 1605 & 2717 & 823 & 1993 & 3665 \\
\hline 1960 & 3372 & 5875 & 9197 & 6535 & 2556 & 1828 & 1390 & 1153 & 980 & 904 & 1081 & 4177 & 904 & 3254 & 9197 \\
\hline 1961 & 5376 & 6385 & 5660 & 3455 & 2405 & 1755 & 1359 & 1169 & 982 & 890 & 1028 & 1593 & 890 & 2671 & 6385 \\
\hline 1962 & 3193 & 4810 & 3653 & 2839 & 2058 & 1650 & 1536 & 1090 & 851 & 1118 & 1797 & 3251 & 851 & 2320 & 4810 \\
\hline 1963 & 5987 & 6925 & 3639 & 1792 & 1428 & 1143 & 1031 & 913 & 796 & 699 & 934 & 1289 & 699 & 2215 & 6925 \\
\hline 1964 & 3852 & 8126 & 5594 & 3176 & 1757 & 1224 & 1019 & 942 & 756 & 815 & 2839 & 4158 & 756 & 2855 & 8126 \\
\hline 1965 & 5092 & 5768 & 6300 & 6317 & 2920 & 1881 & 1537 & 1279 & 1040 & 1470 & 2640 & 4132 & 1040 & 3365 & 6317 \\
\hline 1966 & 4444 & 6999 & 6770 & 4758 & 2614 & 1927 & 1515 & 1332 & 1069 & 1282 & 2006 & 2792 & 1069 & 3126 & 6999 \\
\hline 1967 & 5116 & 5115 & 4644 & 4555 & 2765 & 1642 & 1431 & 1361 & 1220 & 1146 & 1766 & 3810 & 1146 & 2881 & 5116 \\
\hline 1968 & 5980 & 4451 & 6958 & 5233 & 2552 & 1664 & 1428 & 1287 & 1216 & 1274 & 1728 & 4332 & 1216 & 3175 & 6958 \\
\hline 1969 & 3158 & 3930 & 3852 & 2371 & 1692 & 1222 & 1129 & 1015 & 841 & 950 & 2376 & 4785 & 841 & 2277 & 4785 \\
\hline
\end{tabular}




\begin{tabular}{|c|c|c|c|c|c|c|c|c|c|c|c|c|c|c|c|}
\hline \\
\hline ano & jan & fev & mar & $a b r$ & mai & & jul & ago & & out & nov & dez & mín. & méd. & máx. \\
\hline 1970 & & 6610 & & & 969 & & 1153 & & 166 & 575 & 840 & 2682 & 012 & & 6610 \\
\hline 1971 & 732 & 1477 & & & 180 & 960 & ת010 & & 700 & 090 & & & 700 & 736 & 6267 \\
\hline 1972 & 160 & 2991 & 351 & & 1819 & 1264 & 1137 & חבר & 835 & 1278 & 1889 & 4030 & 835 & 334 & 5160 \\
\hline 1973 & 810 & 3890 & 3611 & 699 & 2295 & 1564 & 1321 & 1036 & 398 & 1206 & 3017 & 1387 & 898 & 728 & 4810 \\
\hline 1974 & 706 & 3995 & 4475 & 392 & 3102 & 1840 & 1496 & 260 & 068 & L171 & 1887 & 2359 & 1068 & 813 & 6392 \\
\hline 1975 & 240 & 4190 & 2699 & 2632 & 2027 & 1243 & 1142 & 965 & 752 & 1018 & 2262 & 2776 & 752 & 162 & 4240 \\
\hline 1976 & 160 & 2130 & 2236 & 393 & 1102 & 109 & 861 & 857 & 041 & 1430 & 2244 & 483 & 857 & 324 & 4835 \\
\hline 1977 & 783 & 6456 & 2404 & 234 & 1896 & 1446 & 1157 & 943 & 877 & 1198 & 1389 & 2110 & 877 & 292 & 6456 \\
\hline 1978 & 5603 & 5405 & 6766 & 4002 & 2820 & 2203 & 1625 & 0 & 1150 & & 1909 & TI & 150 & & 0 \\
\hline 1979 & 947 & & 15417 & & 3456 & & & & & & & & & & \\
\hline 1980 & 5635 & 10001 & 10511 & 110 & 3200 & 2210 & 1071 & & 436 & & 853 & & & & 0511 \\
\hline 1981 & 5833 & 4909 & 3879 & 5840 & 2917 & 2213 & 1649 & 1422 & 1269 & 1708 & 3952 & 5376 & L269 & 3497 & 6376 \\
\hline 1982 & 6767 & 8465 & 6796 & 7139 & 3603 & 2703 & 2047 & 1742 & 1553 & 1469 & 1610 & 1959 & 469 & 821 & 8465 \\
\hline 1983 & 4109 & 7702 & 9995 & 6953 & 4163 & 2610 & 2304 & 1754 & 1589 & 2002 & 3453 & 5980 & 589 & 1384 & 9995 \\
\hline 1984 & 6478 & 3030 & 2659 & 3963 & 2024 & 1447 & 1249 & 1093 & 1247 & 1357 & 1636 & 3833 & 1093 & 2501 & 6478 \\
\hline 1985 & 318 & 829 & 7061 & 954 & 2985 & 1922 & 1474 & 1288 & 179 & 1469 & 967 & 3082 & 179 & 627 & 8829 \\
\hline 1986 & 6528 & 7628 & 5188 & & 1894 & 1423 & 1250 & 1222 & 1159 & 954 & 157 & 000 & 954 & & 628 \\
\hline 1987 & 3273 & 2755 & 2676 & 2934 & 1695 & 1217 & 992 & 855 & 754 & 921 & 1392 & 0 & 754 & 000 & 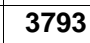 \\
\hline 1988 & 5760 & 3552 & 4814 & 3694 & 2118 & 1386 & 1143 & & 847 & 935 & 1630 & 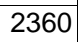 & 847 & 1435 & 5760 \\
\hline 1989 & 3717 & 2498 & 3061 & 1748 & 1208 & 986 & 950 & 890 & 868 & 981 & 1754 & 538 & 868 & 2004 & 5286 \\
\hline 1990 & 9686 & 3335 & 3291 & 2043 & 1480 & 1176 & 1131 & $97 \mathrm{C}$ & 977 & 873 & 1244 & 1547 & 873 & 313 & 9686 \\
\hline 1991 & 3102 & 5471 & 4833 & 5745 & 2390 & 1568 & 1218 & 028 & 894 & 1288 & 1934 & 3011 & 894 & 2707 & 5745 \\
\hline 1992 & 4403 & 10089 & 13267 & 3702 & 2876 & 1905 & 1598 & 1364 & 1199 & 1692 & 4181 & 4562 & 199 & 1236 & 13267 \\
\hline 1993 & 5895 & 4548 & 4454 & 2791 & 2009 & 1627 & 1347 & 1114 & 997 & 1216 & 1151 & 1837 & 997 & 415 & 5895 \\
\hline 1994 & 5695 & 4853 & 4800 & 5006 & 2149 & 1676 & 1379 & 1113 & 953 & 856 & 1002 & 3071 & 856 & 2713 & 5695 \\
\hline 1995 & 2960 & 2908 & 3061 & 2853 & 1786 & 1274 & 1029 & 875 & 736 & 813 & 1822 & 2918 & 736 & 1920 & 3061 \\
\hline 1996 & 4821 & 2116 & 2207 & 1910 & 1229 & 1056 & 815 & 738 & 791 & 789 & 1582 & 3448 & 738 & 1792 & 4821 \\
\hline 1997 & 6530 & & & 4221 & 2522 & 1849 & 1377 & 1086 & 000 & 972 & 1167 & & 000 & 2774 & 00 \\
\hline 1998 & 3426 & 3379 & 3546 & 1831 & 1304 & 1171 & 903 & 806 & 684 & 976 & 1979 & 324 & 684 & 1937 & \\
\hline 1999 & 3190 & 1707 & 4391 & 2446 & 1333 & 989 & 883 & 753 & 655 & 715 & 1483 & 2000 & 655 & 1820 & 391 \\
\hline 2000 & 4314 & 5456 & 4670 & 3649 & 1781 & 1293 & 1078 & 928 & 1012 & 825 & 1668 & 3653 & 825 & 2527 & 5456 \\
\hline 2001 & 3384 & 1777 & 1806 & 1406 & 980 & 926 & 791 & 723 & 732 & 904 & 1231 & 2286 & 723 & 1412 & 3384 \\
\hline méd. & 4822 & 5116 & 5088 & 4011 & 2436 & 1664 & 1369 & 1173 & 1042 & 1161 & 1894 & 3462 & 1007 & 2770 & 6458 \\
\hline
\end{tabular}




\section{ANEXO B - CÓDIGOS DE PROGRAMAÇÃO DO MODELO SFPLUS}




$\begin{array}{ll}8 & 1.001 \\ 9 & 1.113 \\ 10 & 1.286 \\ 11 & 1.189 \\ 12 & 1.101 \quad / ;\end{array}$

Parameter irrigano(u) demanda anual de irrigacao

/

\$ondelim

\$include 'irrig2007.csv'

\$offdelim

/;

Parameter uso $(m, u)$ demanda mensal de irrigacao; uso $(m, u)=\operatorname{firrig}{ }^{*} \operatorname{sazon}(m)$ *irrigano $(u)$;

Table afl $(t, u)$ vazoes afluentes naturais

\$ondelim

\$include 'mediano.csv'

\$offdelim;

Table evp(m, u) evaporacao

$\begin{array}{lcrrrr} & \text { tma } & \text { sob } & \text { itp } & \text { pam } & \text { xin } \\ 1 & 2 & 118 & 140 & 140 & 140 \\ 2 & 0 & 106 & 109 & 109 & 109 \\ 3 & 22 & 81 & 81 & 81 & 81 \\ 4 & 40 & 132 & 105 & 105 & 105 \\ 5 & 51 & 153 & 109 & 109 & 109 \\ 6 & 55 & 142 & 101 & 101 & 101 \\ 7 & 50 & 158 & 123 & 123 & 123 \\ 8 & 42 & 181 & 158 & 158 & 158 \\ 9 & 57 & 197 & 180 & 180 & 180 \\ 10 & 48 & 189 & 195 & 195 & 195 \\ 11 & 23 & 114 & 158 & 158 & 158 \\ 12 & 29 & 98 & 152 & 152 & 152 ;\end{array}$

Table ve $(m, u)$ volumes de espera ciclo 20022003

$1 \quad 77.69$

$2 \quad 87.96$

$3 \quad 95.81$

$4 \quad 100.0$

$5 \quad 100.0$

$6 \quad 100.0$

$7 \quad 100.0$

$8 \quad 100.0$

$9 \quad 100.0$

$10 \quad 81.80$

$11 \quad 75.45$

$12 \quad 76.20$ sob

78.72

87.60

95.36

99.34

100.0

100.0

100.0

100.0

100.0

99.69

77.61

77.95 itp

56.51

56.51

67.38

100.0

100.0

100.0

100.0

100.0

100.0

95.52

70.12

56.51 pam

100.0

100.0

100.0

100.0

100.0

100.0

100.0

100.0

100.0

100.0

100.0

100.0 xin 100.0 100.0 100.0 100.0 100.0 100.0 100.0 100.0 100.0 100.0 100.0 100.0 ;

Parameters

$\begin{array}{cc} & \text { pi }(\text { u }) \text { potencia instalada } \\ \text { tma } & 396 \\ \text { sob } & 1050 \\ \text { itp } & 1500 \\ \text { pam } & 4285\end{array}$




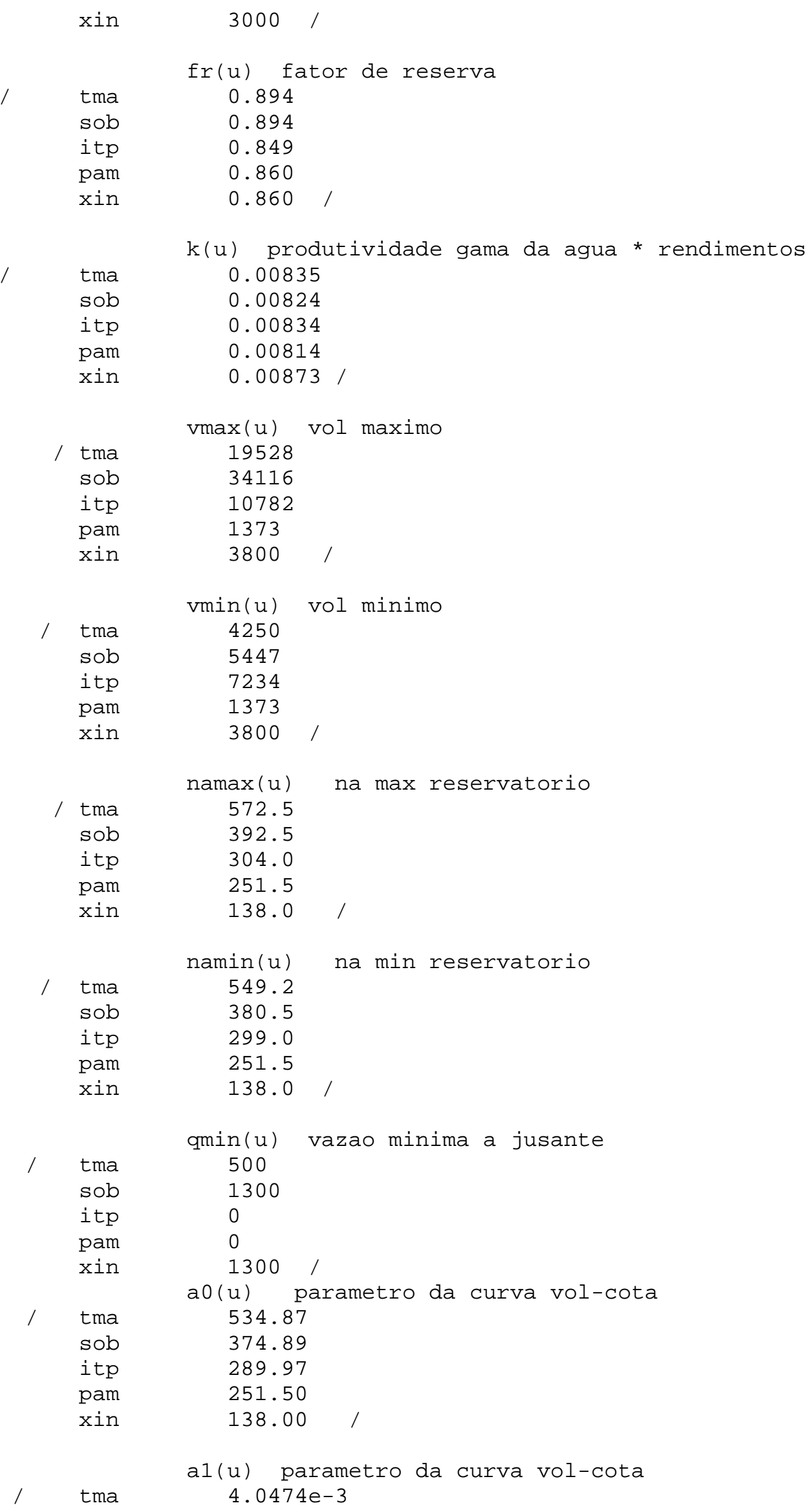




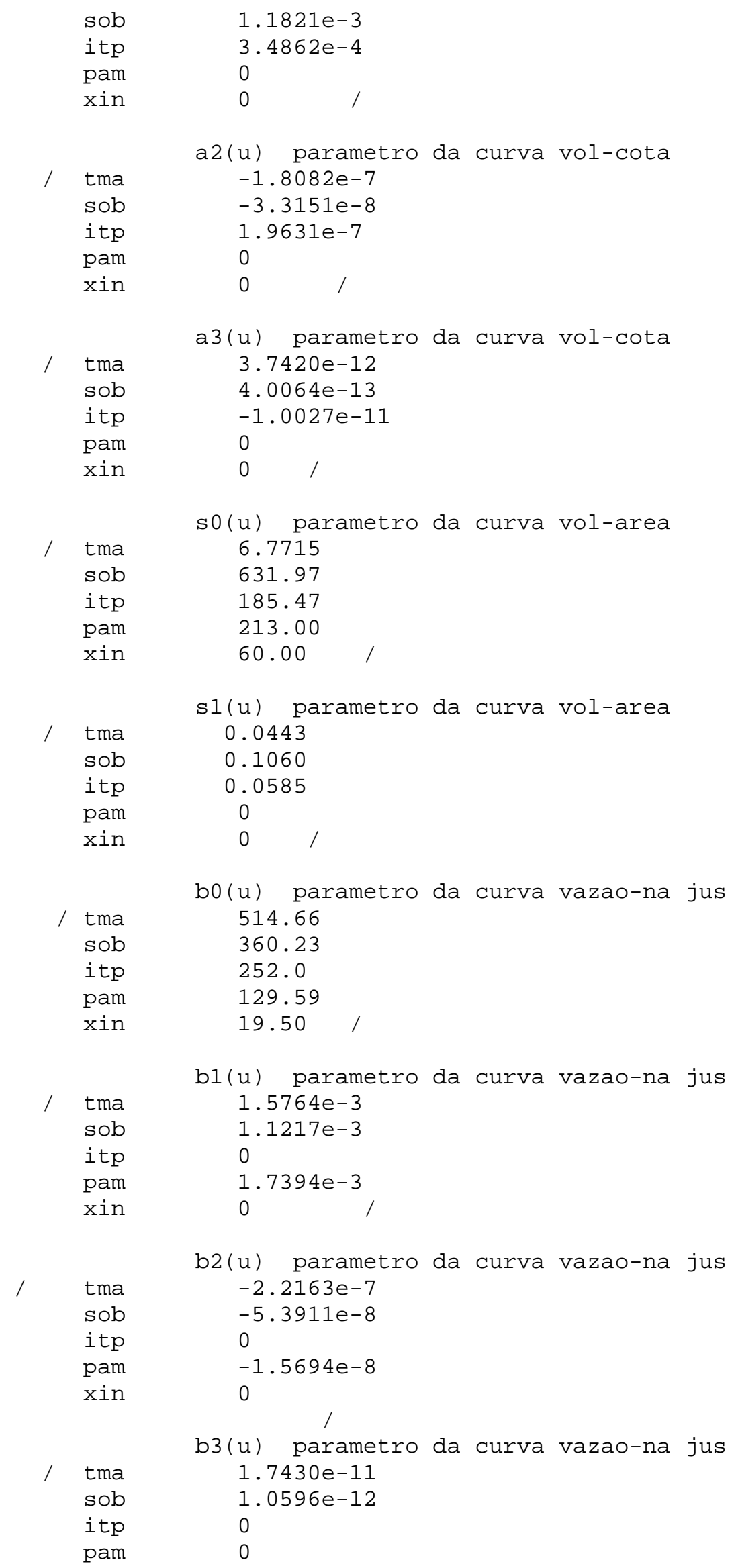




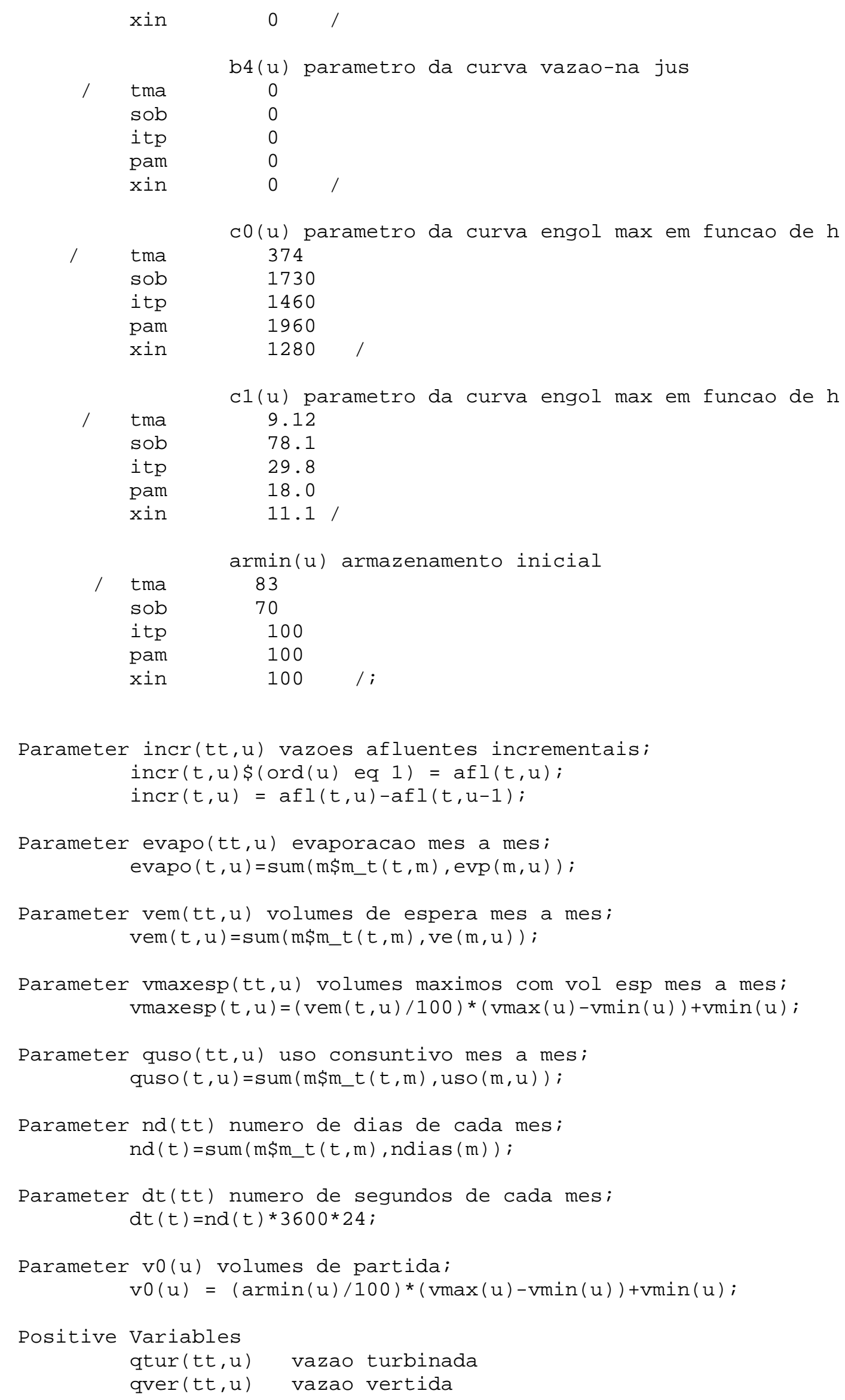




$\begin{array}{ll}\text { qverm } & \text { vazao media vertida total } \\ \text { vfim }(t t, u) & \text { volume no final do intervalo } \\ \text { qdfl }(t, u) & \text { vazao defluente total } \\ \text { qmon }(t, u) & \text { vazao defluente a montante } \\ \text { named }(t t, u) & \text { nivel d'agua medio } \\ \text { amed }(t t, u) & \text { area media } \\ \text { naj(t, } u) & \text { nivel d'agua de jusante } \\ h(t, u) & \text { queda bruta } \\ \text { armusi }(t t, u) & \text { armazenamento por usina } \\ \text { armsis }(t)) & \text { armazenamento do sistema } \\ \text { enertot }(t) & \text { energia do sistema } \\ \text { ener }(t, u) & \text { energia por usina; }\end{array}$

Variables

em

energia media total;

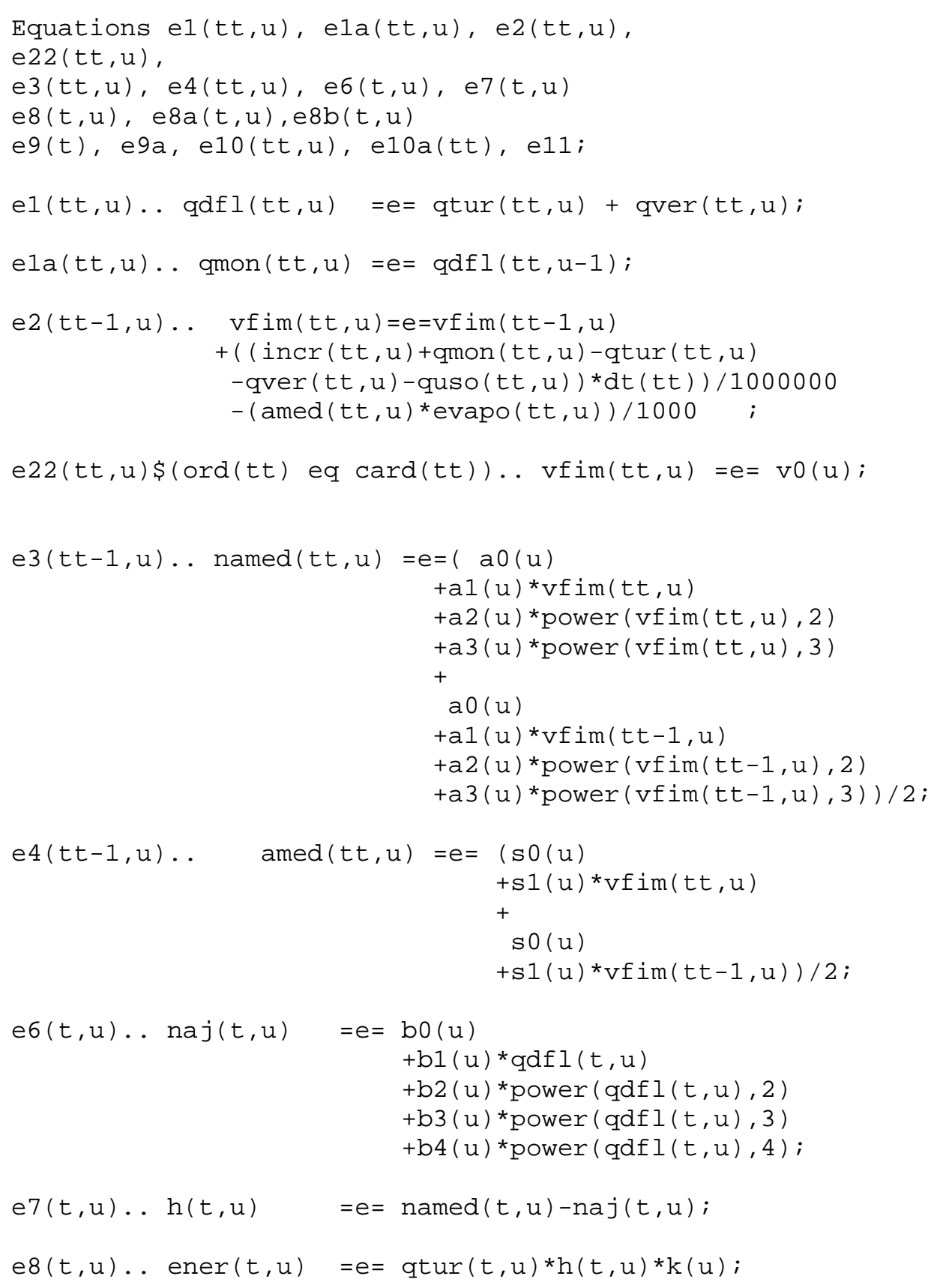




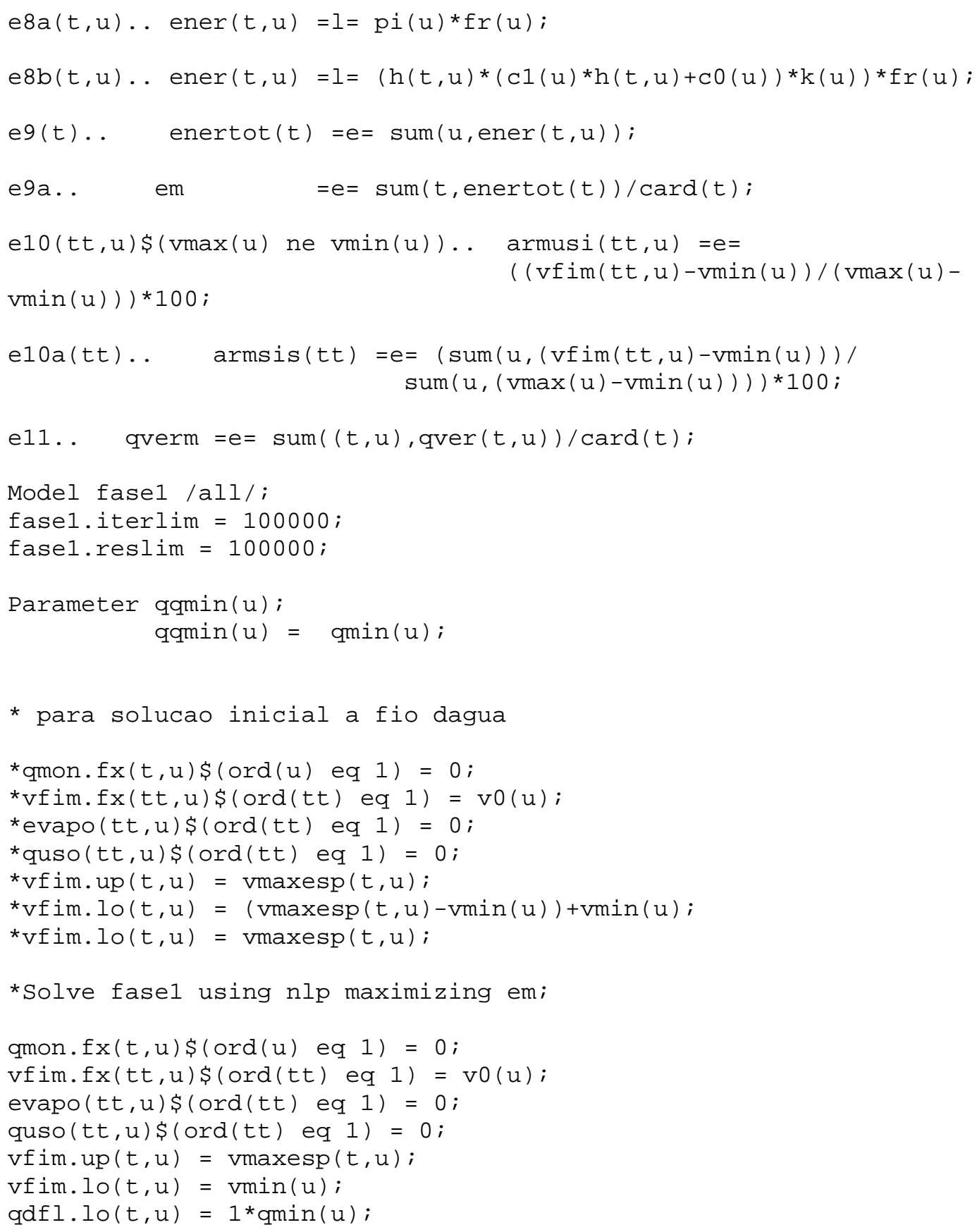

Solve fase1 using nlp maximizing em;

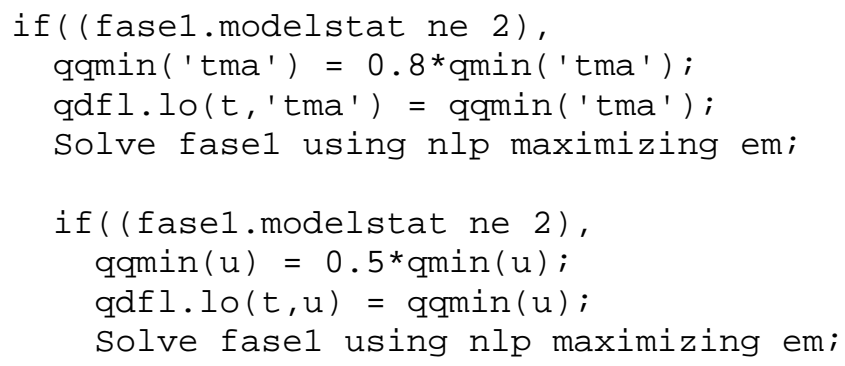


) ;

Display qdfl.l, qver.l, qtur.l, armusi.l, ener.l, em.l, qverm.l, qqmin, fase1. modelstat; 


\section{Módulo 2: MÉTODO DAS PONDERAÇÕES}

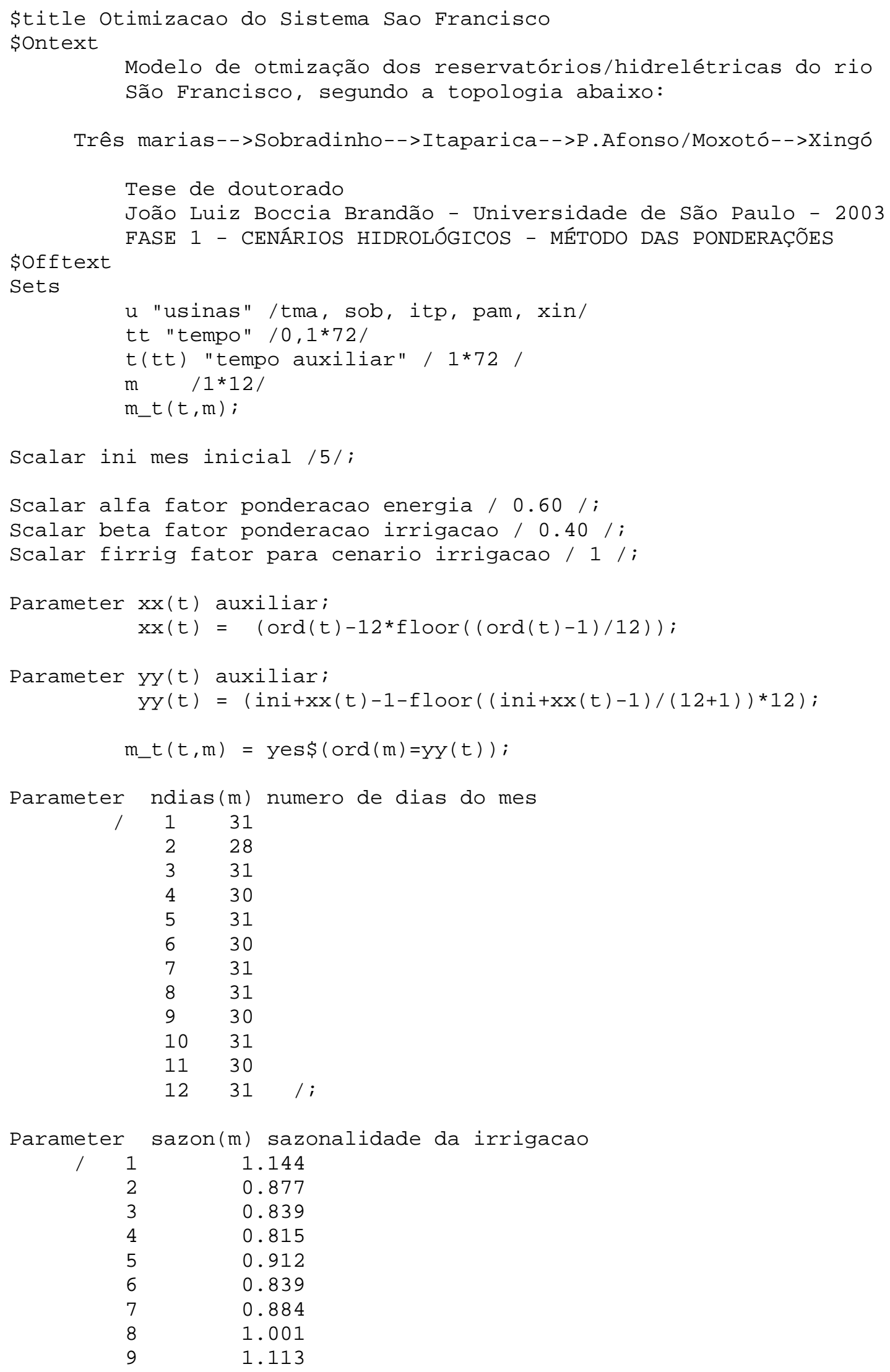




$\begin{array}{ll}10 & 1.286 \\ 11 & 1.189 \\ 12 & 1.101 \quad / ;\end{array}$

Parameter irrigano(u) demanda anual de irrigacao

/

\$ondelim

\$include 'irrig2007.csv'

\$offdelim

/;

Parameter uso $(\mathrm{m}, \mathrm{u})$ demanda maxima mensal de irrigacao; uso $(m, u)=\operatorname{firrig*} \operatorname{sazon}(m) * \operatorname{irrigano}(u)$;

Table afl $(t, u)$ vazoes afluentes naturais

\$ondelim

\$include 'mediano.csv'

\$offdelim;

Table $\operatorname{evp}(m, u)$ evaporacao

$\begin{array}{lcrrrr} & \text { tma } & \text { sob } & \text { itp } & \text { pam } & \text { xin } \\ 1 & 2 & 118 & 14 \odot & 14 \odot & 140 \\ 2 & 0 & 106 & 109 & 109 & 109 \\ 3 & 22 & 81 & 81 & 81 & 81 \\ 4 & 4 \odot & 132 & 105 & 105 & 105 \\ 5 & 51 & 153 & 109 & 109 & 109 \\ 6 & 55 & 142 & 101 & 101 & 101 \\ 7 & 5 \odot & 158 & 123 & 123 & 123 \\ 8 & 42 & 181 & 158 & 158 & 158 \\ 9 & 57 & 197 & 180 & 180 & 180 \\ 10 & 48 & 189 & 195 & 195 & 195 \\ 11 & 23 & 114 & 158 & 158 & 158 \\ 12 & 29 & 98 & 152 & 152 & 152 ;\end{array}$

Table ve(m, u) volumes de espera ciclo 20022003

$\begin{array}{lccccc} & \text { tma } & \text { sob } & \text { itp } & \text { pam } & \text { xin } \\ 1 & 77.69 & 78.72 & 56.51 & 100.0 & 100.0 \\ 2 & 87.96 & 87.60 & 56.51 & 100.0 & 100.0 \\ 3 & 95.81 & 95.36 & 67.38 & 100.0 & 100.0 \\ 4 & 100.0 & 99.34 & 100.0 & 100.0 & 100.0 \\ 5 & 100.0 & 100.0 & 100.0 & 100.0 & 100.0 \\ 6 & 100.0 & 100.0 & 100.0 & 100.0 & 100.0 \\ 7 & 100.0 & 100.0 & 100.0 & 100.0 & 100.0 \\ 8 & 100.0 & 100.0 & 100.0 & 100.0 & 100.0 \\ 9 & 100.0 & 100.0 & 100.0 & 100.0 & 100.0 \\ 10 & 81.80 & 99.69 & 95.52 & 100.0 & 100.0 \\ 11 & 75.45 & 77.61 & 70.12 & 100.0 & 100.0 \\ 12 & 76.20 & 77.95 & 56.51 & 100.0 & 100.0 ;\end{array}$

Parameters

reservatorio

/ tma

sob $\quad 0.51$

itp $\quad 0.47$

pam $\odot$

xin $0.02 /$ 


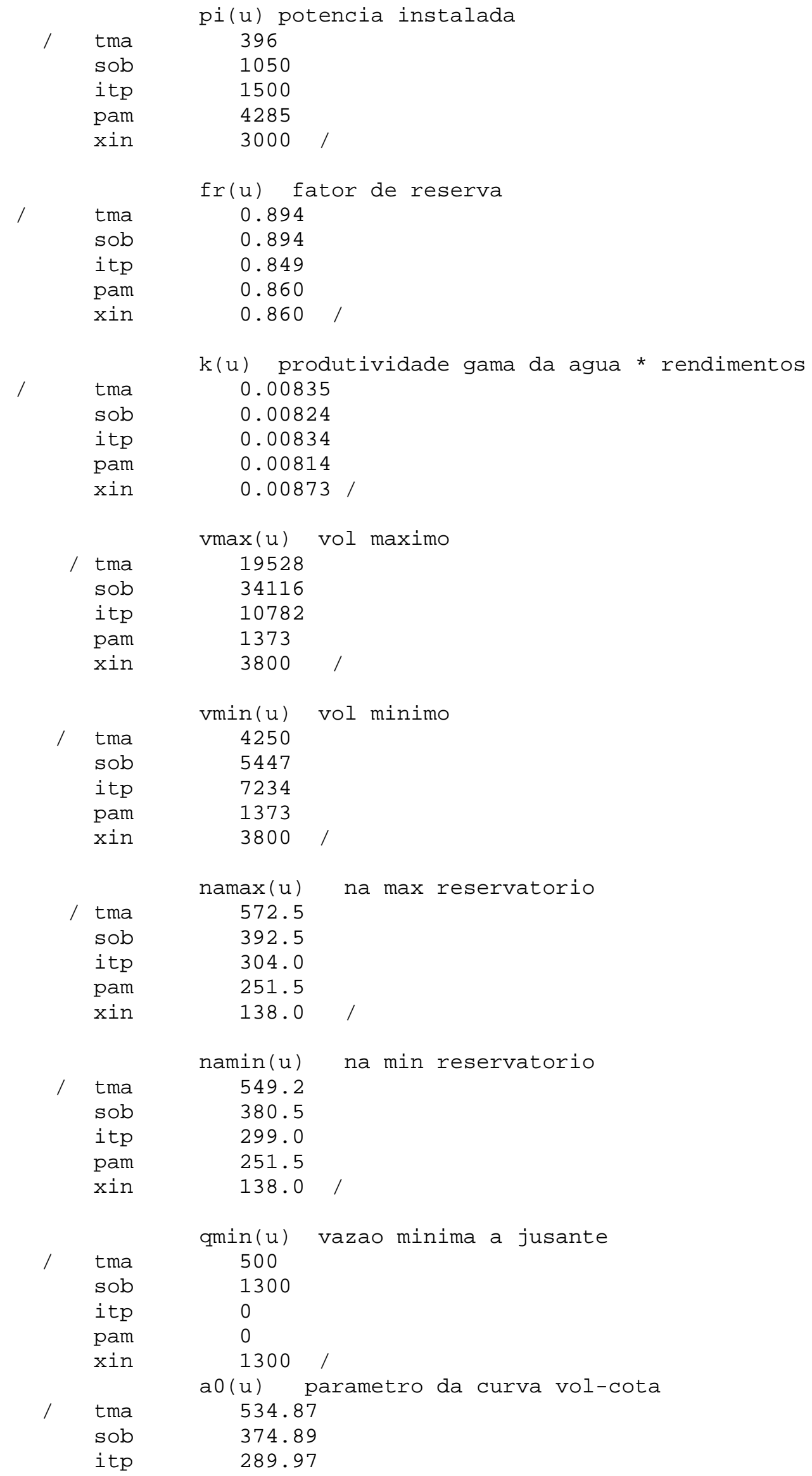




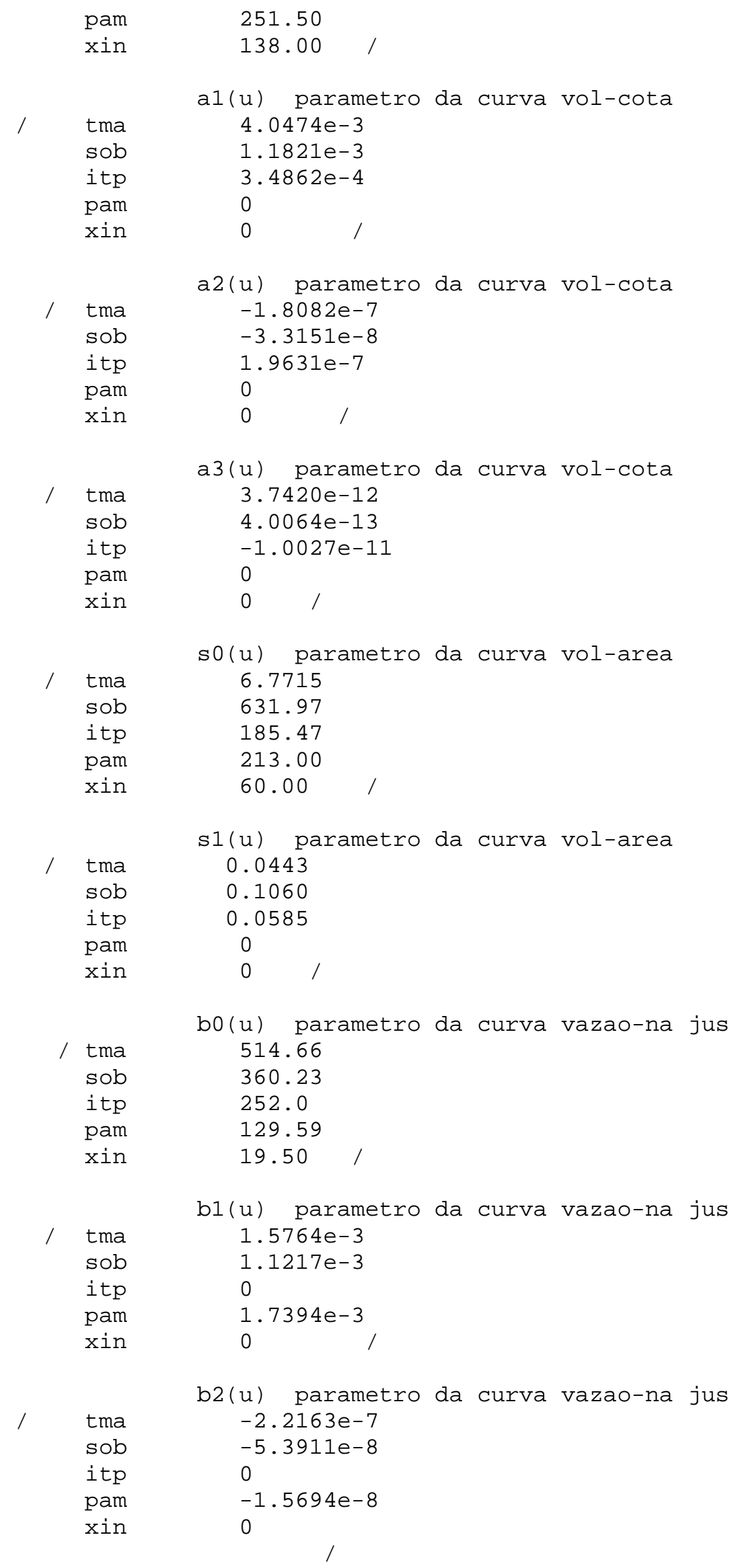




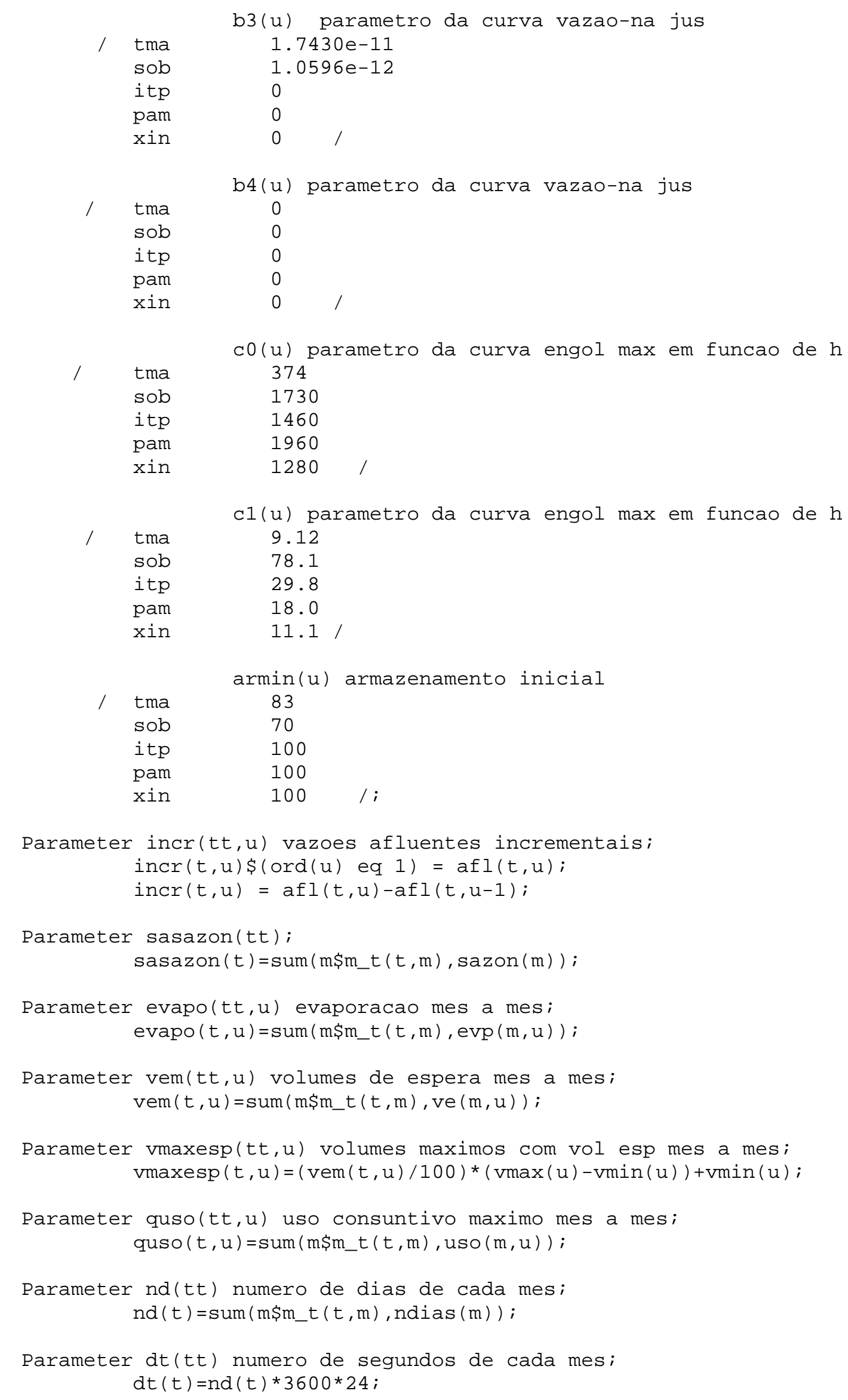




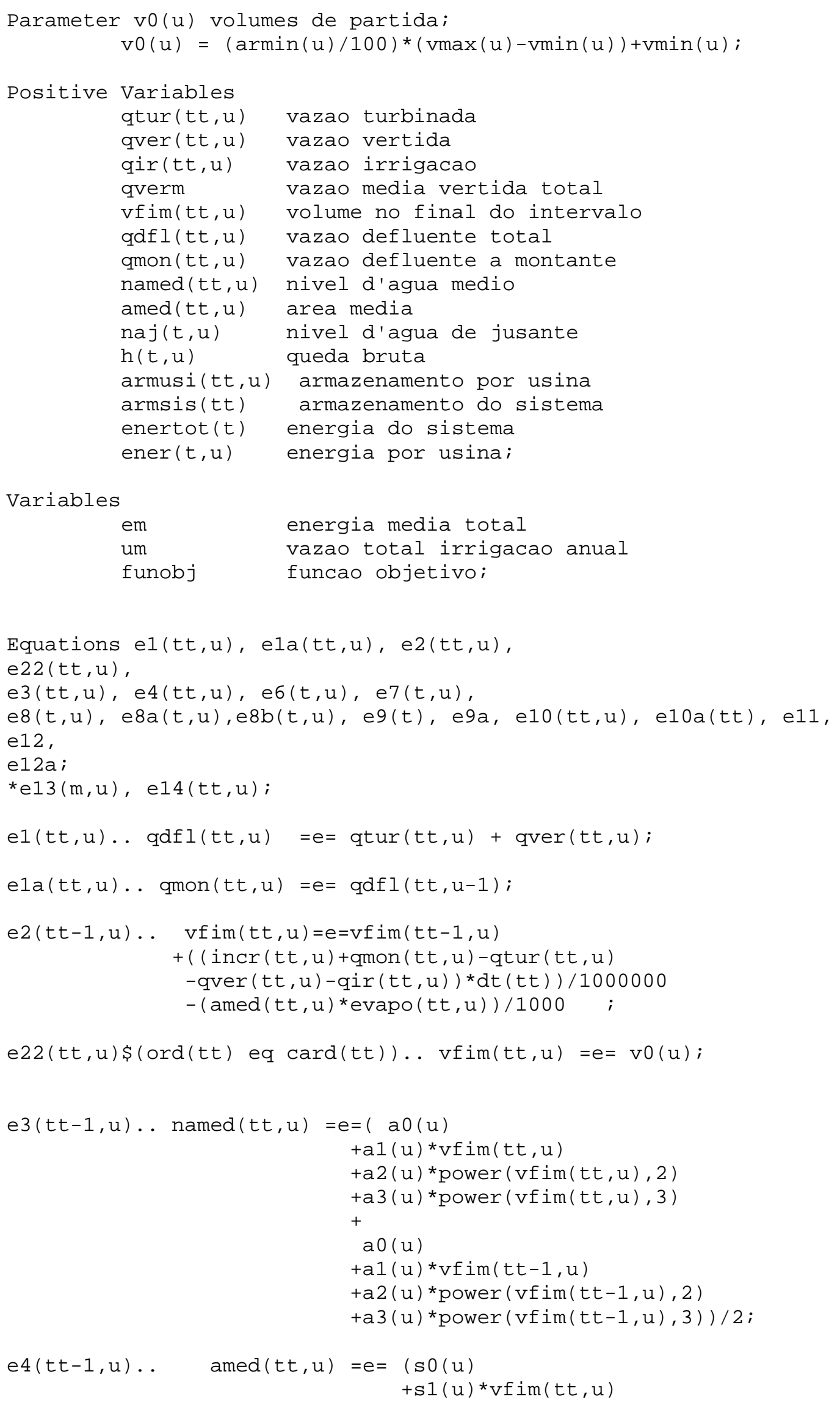




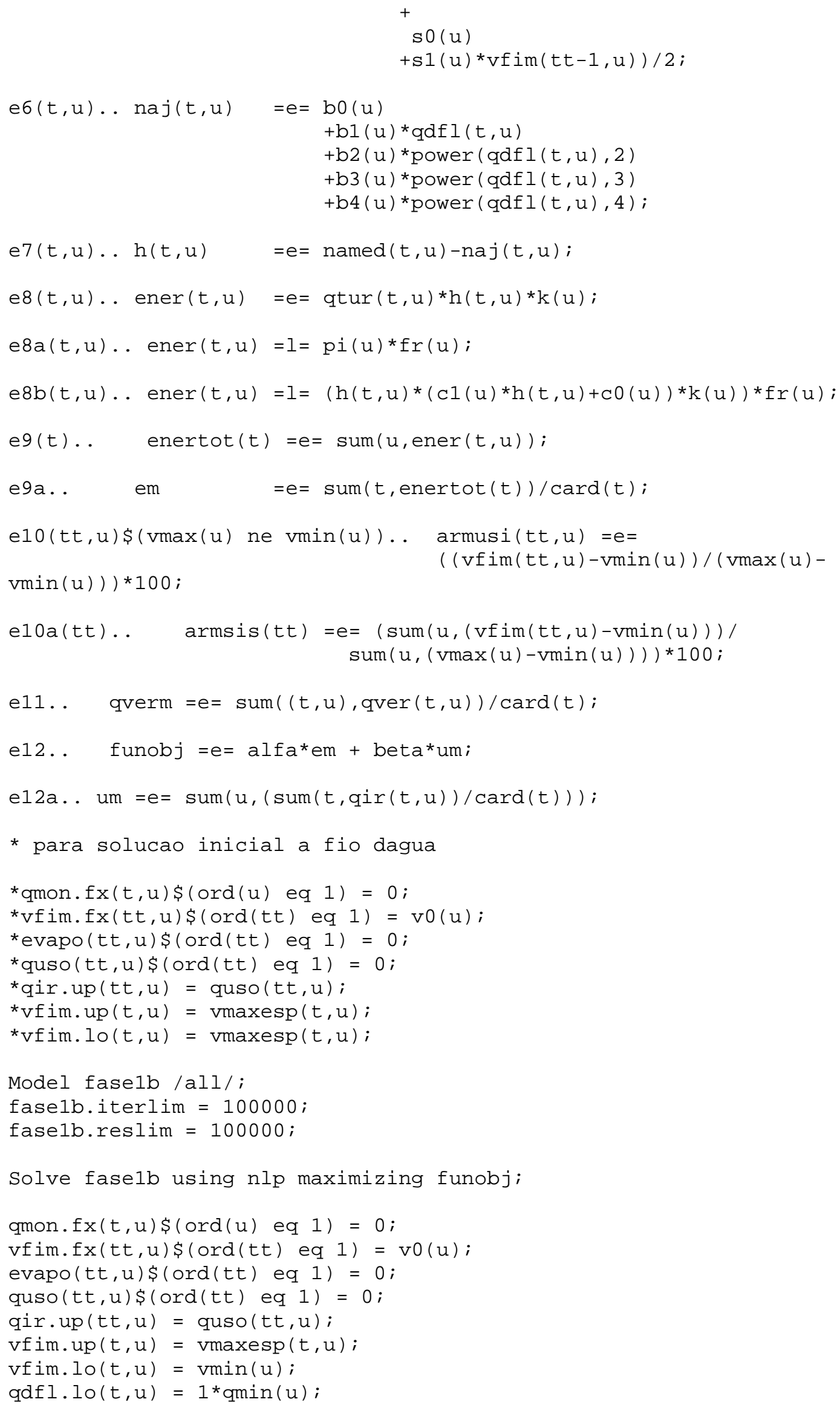


Solve fase1b using nlp maximizing funobj;

Display qdfl.1, qver.l, qtur.l, armusi.l, ener.l, qir.l, um.l, em.l, qverm. 1; 


\section{ANEXO C - RELATÓRIO DE SAÍDA DO MODELO SFPLUS}

Caso:

Cenário hidrológico mediano 
GAMS Rev 121 Windows NT/95/98

$01 / 24 / 04 \quad 14: 25: 39$

PAGE 192

Otimizacao do Sistema Sao Francisco

$\mathrm{E} \times$ e c u t i o $\mathrm{n}$

-..- 571 VARIABLE qdfl.L vazao defluente total

\begin{tabular}{|c|c|c|c|c|c|}
\hline & tma & sob & itp & pam & xin \\
\hline 1 & 500.000 & 2299.006 & 2237.489 & 2228.820 & 2232.001 \\
\hline 2 & $500.00 \odot$ & 2355.223 & 2236.666 & 2228.366 & 2232.001 \\
\hline 3 & $500.00 \odot$ & 2367.670 & 2238.781 & $2229.00 \odot$ & 2232.001 \\
\hline 4 & $500.00 \odot$ & 2394.563 & 2242.910 & 2230.345 & 2232.001 \\
\hline 5 & $500.00 \odot$ & 2418.068 & 2246.302 & 2231.510 & 2232.001 \\
\hline 6 & $500.00 \odot$ & 1821.451 & 1688.738 & 1673.230 & 1672.689 \\
\hline 7 & $500.00 \odot$ & 2067.190 & 2244.349 & 2231.366 & 2232.001 \\
\hline 8 & 500.000 & 1300.000 & 1324.445 & 1312.357 & 1313.667 \\
\hline 9 & 500.000 & 1443.996 & 1309.761 & 1298.627 & 1300.000 \\
\hline 10 & 745.228 & 2242.901 & 2238.511 & 2228.914 & 2232.001 \\
\hline 11 & 568.884 & 1516.323 & 1302.283 & 1295.842 & 1300.000 \\
\hline 12 & 739.614 & 2742.447 & 2236.972 & 2228.344 & 2232.001 \\
\hline 13 & 728.621 & 1433.005 & 1305.488 & 1296.819 & 1300.000 \\
\hline 14 & 714.782 & 2355.223 & 2236.666 & 2228.366 & 2232.001 \\
\hline 15 & 699.002 & 1435.669 & 1306.780 & 1296.999 & 1300.000 \\
\hline 16 & 681.297 & 1300.000 & 1310.909 & 1298.344 & 1300.000 \\
\hline 17 & 664.564 & 1300.000 & 1635.532 & 1620.740 & 1621.231 \\
\hline 18 & 651.108 & 1448.353 & 1316.048 & 1300.541 & 1300.000 \\
\hline 19 & 650.464 & 1801.750 & 2244.349 & 2231.366 & 2232.001 \\
\hline 20 & 675.146 & 2828.047 & 1999.480 & 1987.392 & 1988.702 \\
\hline 21 & 707.839 & 2410.055 & 2241.762 & 2230.628 & 2232.001 \\
\hline 22 & 730.040 & 2193.901 & 2238.511 & 2228.914 & 2232.001 \\
\hline 23 & 737.922 & 2451.324 & 2234.284 & 2227.843 & 2232.001 \\
\hline 24 & 736.101 & 2722.447 & 2236.972 & 2228.344 & 2232.001 \\
\hline 25 & 729.818 & 2354.006 & 2237.489 & 2228.820 & 2232.001 \\
\hline 26 & 718.201 & 2274.223 & 2236.666 & 2228.366 & 2232.001 \\
\hline 27 & 703.599 & 2367.670 & 2238.781 & 2229.000 & 2232.001 \\
\hline 28 & 685.508 & 2290.435 & 2138.782 & 2126.217 & 2127.873 \\
\hline 29 & 665.864 & 2237.190 & 2246.302 & 2231.510 & 2232.001 \\
\hline 30 & 644.807 & 1417.052 & 1665.049 & 1649.542 & 1649.001 \\
\hline 31 & 1003.075 & 1669.362 & 2244.349 & 2231.366 & 2232.001 \\
\hline 32 & 728.055 & 2391.164 & 2242.779 & 2230.691 & 2232.001 \\
\hline 33 & $500.00 \odot$ & 2853.140 & 2443.529 & 2432.395 & 2433.768 \\
\hline 34 & $50 \odot . \odot \odot \odot$ & 3019.370 & 2558.245 & 2548.648 & 2551.735 \\
\hline 35 & $500.00 \odot$ & 2511.314 & 2512.274 & 2505.833 & 2509.991 \\
\hline 36 & 648.942 & 3355.238 & 2840.762 & 2832.134 & 2835.791 \\
\hline 37 & 589.075 & 2505.111 & 2596.593 & 2587.925 & 2591.105 \\
\hline 38 & 691.403 & 3345.620 & 3227.063 & 3218.763 & 3222.398 \\
\hline 39 & 678.469 & 2683.586 & 2554.697 & 2544.915 & 2547.917 \\
\hline 40 & 661.027 & 2706.349 & 2554.697 & 2542.132 & 2543.788 \\
\hline 41 & 640.431 & 3058.497 & 2886.731 & 2871.940 & 2872.431 \\
\hline 42 & 619.556 & 2685.188 & 2552.475 & 2536.968 & 2536.427 \\
\hline 43 & 608.693 & 2394.161 & 3425.637 & 3412.653 & 3413.289 \\
\hline 44 & 1197.888 & 3430.997 & 3494.045 & 3481.957 & 3483.268 \\
\hline 45 & $50 \odot .00 \odot$ & 4197.832 & 3493.091 & 3481.957 & 3483.330 \\
\hline 46 & 714.744 & 3555.945 & 3491.554 & 3481.957 & 3485.044 \\
\hline 47 & 771.689 & 6221.803 & 6011.763 & 6005.321 & 6009.480 \\
\hline 48 & 761.726 & 5643.745 & 5178.269 & 5169.641 & 5173.29 \\
\hline 49 & 1262.309 & 3521.143 & 3490.626 & 3481.957 & 3485.13 \\
\hline
\end{tabular}




$\begin{array}{llllll}50 & 772.903 & 3608.814 & 3490.257 & 3481.957 & 3485.592 \\ 51 & 765.484 & 3620.628 & 3491.739 & 3481.957 & 3484.959\end{array}$

GAMS ReV 121 Windows NT/95/98

$01 / 24 / \odot 414: 25: 39$

PAGE 193

Otimizacao do Sistema Sao Francisco

$\mathrm{E} x \mathrm{e}$ c u $\mathrm{t}$ i o $\mathrm{n}$

571 VARIABLE qdfl.L vazao defluente total

tma sob itp pam xin

$\begin{array}{rrrrrr}52 & 755.896 & 3646.175 & 3494.522 & 3481.957 & 3483.613 \\ 53 & 1716.186 & 3668.515 & 3496.749 & 3481.957 & 3482.448 \\ 54 & 1272.722 & 3630.178 & 3497.465 & 3481.957 & 3481.416 \\ 55 & 678.437 & 3317.782 & 3494.941 & 3481.957 & 3482.593 \\ 56 & 686.253 & 3356.600 & 3494.045 & 3481.957 & 3483.268 \\ 57 & 724.377 & 3496.326 & 3493.091 & 3481.957 & 3483.330 \\ 58 & 767.320 & 3187.677 & 3640.287 & 3630.690 & 3633.777 \\ 59 & 500.000 & 6067.427 & 5814.387 & 5807.946 & 5812.104 \\ 60 & 680.228 & 3545.848 & 2983.373 & 2974.744 & 2978.402 \\ 61 & 516.399 & 3227.920 & 3100.402 & 3091.734 & 3094.914 \\ 62 & 748.982 & 3498.607 & 3380.049 & 3371.750 & 3375.384 \\ 63 & 641.292 & 3086.748 & 2957.860 & 2948.078 & 2951.079 \\ 64 & 778.404 & 2864.857 & 2713.205 & 2700.640 & 2702.296 \\ 65 & 765.887 & 3308.903 & 3137.137 & 3122.345 & 3122.836 \\ 66 & 752.989 & 2685.188 & 2552.475 & 2536.968 & 2536.427 \\ 67 & 742.897 & 3033.058 & 3210.217 & 3197.233 & 3197.868 \\ 68 & 744.223 & 2701.343 & 2769.788 & 2757.700 & 2759.010 \\ 69 & 757.971 & 3223.676 & 3184.441 & 3173.308 & 3174.681 \\ 70 & 767.344 & 3311.721 & 3491.554 & 3481.957 & 3485.044 \\ 71 & 500.00 \odot & 2959.566 & 3488.399 & 3481.957 & 3486.116 \\ 72 & 579.209 & 3361.854 & 3145.379 & 3136.750 & 3140.408\end{array}$

-..- 571 VARIABLE qver.L vazao vertida

tma sob itp pam xin

$31 \quad 386.271$

$32 \quad 117.150$

33

34

35

36

37

38

39

40

41

42

43

117.150

$\begin{array}{rr} & \\ & \\ & \\ & \\ & \\ & \\ 595.841 & 702.765 \\ & 1502.195 \\ & 674.499 \\ & 3064.259 \\ 2192.898 \\ 484.822 \quad\end{array}$

75.868

303.922

41.896

672.366

332.034

930.807

1060.407

1026.374

985.990

3499.488

2641.428

935.929
201.767

319.734

277.990

603.790

359.104

990.397

315.916

311.787

640.430

304.426

1181.288

1251.267

1251.329

1253.043

$2585.492 \quad 3777.479$

$1729.578 \quad 2941.297$

1253.137 


$\begin{array}{rrrr}50 & & 70.747 & 935.560 \\ 51 & & 150.793 & 937.042 \\ 52 & & 266.688 & 939.825 \\ 53 & 992.70 \odot & 369.179 & 942.052 \\ 54 & 581.277 & 409.155 & 944.990\end{array}$

1253.591

1252.958

1251.612

1250.447

1249.415

$01 / 24 / \odot 4 \quad 14: 25: 39$

\section{PAGE 194}

Otimizacao do Sistema Sao Francisco

$\mathrm{E} \times \mathrm{e} \mathrm{c} \mathrm{u} \mathrm{t} \mathrm{i} \mathrm{o} \mathrm{n}$

571 VARIABLE qver.L vazao vertida

tma

sob

itp

pam

xin

55

56

57

58

59

60

61

62

63

64

65

66

67

68

69

70

71

72

$\begin{array}{rr}160.344 & 958.684 \\ 278.880 & 980.133 \\ 485.040 & 987.527 \\ & 1134.722 \\ 2747.463 & 3302.113 \\ & 446.532 \\ & 545.705 \\ & 825.352 \\ 403.163 \\ 158.508 \\ 582.440 \\ \\ \\ 673.960 \\ 255.875 \\ 678.877 \\ 997.820 \\ 987.954 \\ 608.538\end{array}$

1250.592

1251.267

1251.329

$\begin{array}{rr}152.480 & 1401.776 \\ 2383.368 & 3580.103\end{array}$

746.401

862.913

1143.383

719.078

470.295

890.835

304.426

965.867

527.009

942.680

1253.043

1254.115

908.407

-..- 571 VARIABLE qtur.L vazao turbinada

\begin{tabular}{|c|c|c|c|c|c|}
\hline & tma & sob & itp & pam & xin \\
\hline 1 & 500.000 & 2299.006 & 2237.489 & 2228.820 & 2232.001 \\
\hline 2 & $5 \odot \odot . \odot \odot \odot$ & 2355.223 & 2236.666 & 2228.366 & 2232.001 \\
\hline 3 & 500.000 & 2367.670 & 2238.781 & $2229.00 \odot$ & 2232.001 \\
\hline 4 & 500.000 & 2394.563 & 2242.910 & 2230.345 & 2232.001 \\
\hline 5 & $5 \odot \odot . \odot \odot \odot$ & 2418.068 & 2246.302 & 2231.510 & 2232.001 \\
\hline 6 & 500.000 & 1821.451 & 1688.738 & 1673.230 & 1672.689 \\
\hline 7 & 500.000 & 2067.190 & 2244.349 & 2231.366 & 2232.001 \\
\hline 8 & 500.000 & 1300.000 & 1324.445 & 1312.357 & 1313.667 \\
\hline 9 & 500.000 & 1443.996 & 1309.761 & 1298.627 & 1300.000 \\
\hline 10 & 745.228 & 2242.901 & 2238.511 & 2228.914 & 2232.001 \\
\hline 11 & 568.884 & 1516.323 & 1302.283 & 1295.842 & 1300.000 \\
\hline 12 & 739.614 & 2742.447 & 2236.972 & 2228.344 & 2232.001 \\
\hline 13 & 728.621 & 1433.005 & 1305.488 & 1296.819 & 1300.000 \\
\hline 14 & 714.782 & 2355.223 & 2236.666 & 2228.366 & 2232.001 \\
\hline 15 & 699.002 & 1435.669 & 1306.780 & 1296.999 & 1300.000 \\
\hline 16 & 681.297 & $130 \odot . \odot \odot \odot$ & 1310.909 & 1298.344 & 1300.000 \\
\hline 17 & 664.564 & 1300.000 & 1635.532 & 1620.740 & 1621.231 \\
\hline 18 & 651.108 & 1448.353 & 1316.048 & 1300.541 & 1300.000 \\
\hline 19 & 650.464 & 1801.750 & 2244.349 & 2231.366 & 2232.001 \\
\hline
\end{tabular}




$\begin{array}{llllll}20 & 675.146 & 2828.047 & 1999.480 & 1987.392 & 1988.702 \\ 21 & 707.839 & 2410.055 & 2241.762 & 2230.628 & 2232.001 \\ 22 & 730.040 & 2193.901 & 2238.511 & 2228.914 & 2232.001 \\ 23 & 737.922 & 2451.324 & 2234.284 & 2227.843 & 2232.001 \\ 24 & 736.101 & 2722.447 & 2236.972 & 2228.344 & 2232.001 \\ 25 & 729.818 & 2354.006 & 2237.489 & 2228.820 & 2232.001 \\ 26 & 718.201 & 2274.223 & 2236.666 & 2228.366 & 2232.001 \\ 27 & 703.599 & 2367.670 & 2238.781 & 2229.000 & 2232.001\end{array}$

GAMS Rev 121 Windows NT/95/98

$01 / 24 / 04 \quad 14: 25: 39$

PAGE 195

Otimizacao do Sistema Sao Francisco

$E \times$ e c u $t$ i o n

571 VARIABLE qtur.L vazao turbinada

\begin{tabular}{|c|c|c|c|c|c|}
\hline & tma & sob & itp & pam & xin \\
\hline 28 & 685.508 & 2290.435 & 2138.782 & 2126.217 & 2127.873 \\
\hline 29 & 665.864 & 2237.190 & 2246.302 & 2231.510 & 2232.001 \\
\hline 30 & 644.807 & 1417.052 & 1665.049 & 1649.542 & 1649.001 \\
\hline 31 & 616.804 & 1669.362 & 2244.349 & 2231.366 & 2232.001 \\
\hline 32 & 610.905 & 2391.164 & 2242.779 & 2230.691 & 2232.001 \\
\hline 33 & 500.000 & 2853.140 & 2443.529 & 2432.395 & 2232.001 \\
\hline 34 & 500.000 & 3019.370 & 2482.377 & 2548.648 & 2232.001 \\
\hline 35 & 500.000 & 2511.314 & 2512.274 & 2505.833 & 2232.001 \\
\hline 36 & 648.942 & 3355.238 & 2536.841 & 2832.134 & 2232.001 \\
\hline 37 & 589.075 & 2505.111 & 2554.697 & 2587.925 & 2232.001 \\
\hline 38 & 691.403 & 3345.620 & 2554.697 & 3218.763 & 2232.001 \\
\hline 39 & 678.469 & 2683.586 & 2554.697 & 2544.915 & 2232.001 \\
\hline 40 & 661.027 & 2706.349 & 2554.697 & 2542.132 & 2232.001 \\
\hline 41 & 640.431 & 3058.497 & 2554.697 & 2871.940 & 2232.001 \\
\hline 42 & 619.556 & 2685.188 & 2552.475 & 2536.968 & 2232.001 \\
\hline 43 & 608.693 & 2394.161 & 2494.830 & 3412.653 & 2232.001 \\
\hline 44 & 602.047 & 2728.232 & 2433.638 & 3481.957 & 2232.001 \\
\hline 45 & 500.000 & 2695.637 & 2466.716 & 3481.957 & 2232.001 \\
\hline 46 & 714.744 & 2881.445 & 2505.564 & 3481.957 & 2232.001 \\
\hline 47 & 771.689 & 3157.543 & 2512.274 & 3419.830 & 2232.001 \\
\hline 48 & 761.726 & 3450.847 & 2536.841 & 3440.062 & 2232.001 \\
\hline 49 & 777.487 & 3521.143 & 2554.697 & 3481.957 & 2232.001 \\
\hline 50 & 772.903 & 3538.068 & 2554.697 & 3481.957 & 2232.001 \\
\hline 51 & 765.484 & 3469.835 & 2554.697 & 3481.957 & 2232.001 \\
\hline 52 & 755.896 & 3379.486 & 2554.697 & 3481.957 & 2232.001 \\
\hline 53 & 723.486 & 3299.336 & 2554.697 & 3481.957 & 2232.001 \\
\hline 54 & 691.444 & 3221.023 & 2552.475 & 3481.957 & 2232.001 \\
\hline 55 & 678.437 & 3157.438 & 2536.257 & 3481.957 & 2232.001 \\
\hline 56 & 686.253 & 3077.720 & 2513.912 & 3481.957 & 2232.001 \\
\hline 57 & 724.377 & 3011.286 & 2505.564 & 3481.957 & 2232.001 \\
\hline 58 & 767.320 & 3187.677 & 2505.564 & 3478.210 & 2232.001 \\
\hline 59 & 500.000 & 3319.964 & 2512.274 & 3424.578 & 2232.001 \\
\hline 60 & 680.228 & 3545.848 & 2536.841 & 2974.744 & 2232.001 \\
\hline 61 & 516.399 & 3227.920 & 2554.697 & 3091.734 & 2232.001 \\
\hline 62 & 748.982 & 3498.607 & 2554.697 & 3371.750 & 2232.001 \\
\hline 63 & 641.292 & 3086.748 & 2554.697 & 2948.078 & 2232.001 \\
\hline 64 & 778.404 & 2864.857 & 2554.697 & 2700.640 & 2232.001 \\
\hline 65 & 765.887 & 3308.903 & 2554.697 & 3122.345 & 2232.001 \\
\hline 66 & 752.989 & 2685.188 & 2552.475 & 2536.968 & 2232.001 \\
\hline 67 & 742.897 & 3033.058 & 2536.257 & 3197.233 & 2232.001 \\
\hline
\end{tabular}




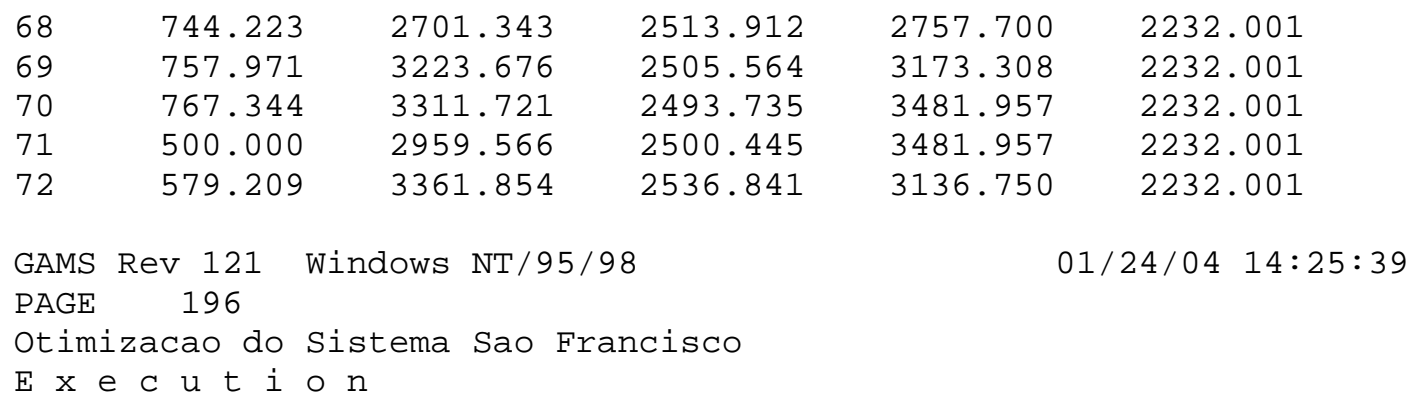

571 VARIABLE armusi. ... 5 armazenamento por usina

\begin{tabular}{|c|c|c|c|}
\hline & tma & sob & itp \\
\hline$\odot$ & $83.0 \odot \odot$ & $7 \odot . \odot \odot \odot$ & $10 \odot . \odot \odot \odot$ \\
\hline 1 & 79.946 & 65.542 & 100.000 \\
\hline 2 & 75.225 & 55.413 & 100.000 \\
\hline 3 & 70.581 & 43.798 & 100.000 \\
\hline 4 & 64.687 & 30.865 & 100.000 \\
\hline 5 & 58.266 & 16.555 & 100.000 \\
\hline 6 & 53.125 & 9.195 & 95.520 \\
\hline 7 & 56.111 & 7.441 & 70.120 \\
\hline 8 & 62.975 & 15.729 & 56.510 \\
\hline 9 & 63.756 & 19.779 & 56.510 \\
\hline 10 & 61.155 & 17.635 & 56.510 \\
\hline 11 & 61.841 & 22.097 & 67.380 \\
\hline 12 & 55.618 & 15.398 & $10 \odot .00 \odot$ \\
\hline 13 & 47.852 & 14.409 & 100.000 \\
\hline 14 & 39.332 & 5.769 & 100.000 \\
\hline 15 & 31.039 & 2.984 & $10 \odot .00 \odot$ \\
\hline 16 & 22.550 & 1.364 & 87.785 \\
\hline 17 & 16.718 & & 51.046 \\
\hline 18 & 12.101 & & 47.091 \\
\hline 19 & 16.223 & & 2.834 \\
\hline 20 & 32.719 & 8.218 & 53.928 \\
\hline 21 & 47.301 & 20.437 & 56.510 \\
\hline 22 & 58.068 & 47.502 & 56.510 \\
\hline 23 & 57.091 & 45.485 & 67.380 \\
\hline 24 & 55.700 & 38.968 & $10 \odot . \odot \odot \odot$ \\
\hline 25 & 49.208 & 35.647 & 100.000 \\
\hline 26 & 41.813 & 29.241 & 100.000 \\
\hline 27 & 33.276 & 20.300 & $10 \odot .0 \odot \odot$ \\
\hline 28 & 24.167 & 10.308 & 100.000 \\
\hline 29 & 16.258 & & 86.855 \\
\hline 30 & 8.127 & & 53.947 \\
\hline 32 & 2.572 & & \\
\hline 33 & 24.307 & 11.941 & 21.916 \\
\hline 34 & 30.514 & 25.772 & 56.510 \\
\hline 35 & 39.393 & 56.714 & 67.380 \\
\hline 36 & 37.290 & 63.850 & 100.000 \\
\hline 37 & 33.918 & 63.735 & 100.000 \\
\hline 38 & 28.844 & 53.606 & 100.000 \\
\hline 39 & 22.141 & 44.713 & 100.000 \\
\hline 40 & 14.410 & 33.551 & 100.000 \\
\hline 41 & 6.838 & 17.691 & 100.000 \\
\hline 42 & 0.465 & 5.969 & 95.520 \\
\hline 43 & & & 7.995 \\
\hline
\end{tabular}




$\begin{array}{rrrr}45 & 22.086 & 0.932 & 56.510 \\ 46 & 71.889 & 21.466 & 56.510 \\ 47 & 90.160 & 95.360 & 67.380 \\ 48 & 94.667 & 99.340 & 100.000 \\ 49 & 84.103 & 100.000 & 100.000 \\ 50 & 79.797 & 90.857 & 100.00 \odot \\ 51 & 73.524 & 76.231 & 100.00 \odot \\ 52 & 66.208 & 58.742 & 100.00 \odot\end{array}$

GAMS Rev 121 Windows NT/95/98

$01 / 24 / 04 \quad 14: 25: 39$

PAGE 197

Otimizacao do Sistema Sao Francisco

$\mathrm{E} \times \mathrm{e} \mathrm{c} \mathrm{u} \mathrm{t}$ i o $\mathrm{n}$

571 VARIABLE armusi.L armazenamento por usina

\begin{tabular}{|c|c|c|c|}
\hline & tma & sob & itp \\
\hline 53 & 43.141 & 49.410 & 100.000 \\
\hline 54 & 26.041 & 36.357 & 95.520 \\
\hline 55 & 24.757 & 29.773 & 70.120 \\
\hline 56 & 33.338 & 20.940 & 56.510 \\
\hline 57 & 67.966 & 18.993 & 56.510 \\
\hline 58 & 87.960 & 59.169 & 56.510 \\
\hline 59 & 94.119 & 95.360 & 67.380 \\
\hline 60 & 100.000 & 97.180 & $10 \odot . \odot \odot \odot$ \\
\hline 61 & 100.000 & 93.522 & 100.000 \\
\hline 62 & 94.841 & 81.598 & 100.000 \\
\hline 63 & 90.201 & 70.541 & $10 \odot .00 \odot$ \\
\hline 64 & 81.426 & 60.534 & 100.000 \\
\hline 65 & 72.474 & 45.075 & 100.000 \\
\hline 66 & 63.223 & 35.449 & 95.520 \\
\hline 67 & 58.570 & 25.067 & 70.120 \\
\hline 68 & 65.041 & 33.349 & 56.510 \\
\hline 69 & 77.690 & 47.591 & 56.510 \\
\hline 70 & 78.286 & 58.481 & 38.415 \\
\hline 71 & 82.370 & 53.503 & 67.380 \\
\hline 72 & 83.000 & 70.000 & 100.000 \\
\hline
\end{tabular}

-..- 571 VARIABLE ener.L energia por usina

tma sob itp pam xin

$\begin{array}{lllll}225.715 & 519.267 & 970.020 & 2142.843 & 2309.016 \\ 222.896 & 519.217 & 969.663 & 2142.420 & 2309.016 \\ 219.496 & 502.177 & 970.580 & 2143.010 & 2309.016 \\ 215.622 & 480.517 & 972.370 & 2144.263 & 2309.016 \\ 210.973 & 446.511 & 973.840 & 2145.348 & 2309.016 \\ 206.440 & 316.748 & 730.883 & 1621.384 & 1730.406 \\ 205.584 & 340.292 & 959.351 & 2145.213 & 2309.016 \\ 209.471 & 228.648 & 556.381 & 1278.218 & 1358.995 \\ 212.441 & 266.365 & 546.608 & 1265.092 & 1344.856 \\ 313.581 & 403.124 & 934.208 & 2142.930 & 2309.016 \\ 239.645 & 283.390 & 546.368 & 1262.428 & 1344.856 \\ 306.967 & 482.836 & 956.629 & 2142.399 & 2309.016 \\ 294.201 & 258.422 & 565.969 & 1263.363 & 1344.856 \\ 278.482 & 389.165 & 969.663 & 2142.420 & 2309.016\end{array}$




$\begin{array}{llllll}15 & 261.038 & 233.135 & 566.529 & 1263.534 & 1344.856 \\ 16 & 242.073 & 207.094 & 565.622 & 1264.821 & 1344.856 \\ 17 & 224.739 & 203.273 & 690.560 & 1571.689 & 1677.172 \\ 18 & 211.216 & 222.760 & 545.086 & 1266.921 & 1344.856 \\ 19 & 210.577 & 272.103 & 904.934 & 2145.213 & 2309.016 \\ 20 & 235.635 & 427.680 & 809.117 & 1917.263 & 2057.323 \\ 21 & 270.744 & 413.183 & 934.352 & 2144.527 & 2309.016 \\ 22 & 295.834 & 432.643 & 934.208 & 2142.930 & 2309.016 \\ 23 & 304.986 & 512.607 & 937.386 & 2141.933 & 2309.016 \\ 24 & 302.860 & 553.554 & 956.629 & 2142.399 & 2309.016 \\ 25 & 295.579 & 473.873 & 970.020 & 2142.843 & 2309.016\end{array}$

GAMS Rev 121 Windows NT/95/98

$01 / 24 / 04 \quad 14: 25: 39$

PAGE 198

Otimizacao do Sistema Sao Francisco

$\mathrm{E} \times \mathrm{e}$ c u $\mathrm{t}$ i o $\mathrm{n}$

571 VARIABLE ener.L energia por usina

tma sob itp pam xin

\begin{tabular}{|c|c|c|c|c|c|}
\hline 26 & 282.329 & 447.331 & 969.663 & 2142.420 & 2309.016 \\
\hline 27 & 266.067 & 442.239 & 970.580 & 2143.010 & 2309.016 \\
\hline 28 & 246.525 & 398.551 & 927.227 & 2047.165 & 2201.295 \\
\hline 29 & 226.065 & 351.790 & 968.850 & 2145.348 & 2309.016 \\
\hline 30 & 205.011 & 218.302 & 703.773 & 1598.966 & 1705.899 \\
\hline 31 & 178.418 & 253.829 & 906.699 & 2145.213 & 2309.016 \\
\hline 32 & 173.021 & 350.552 & 878.547 & 2144.585 & 2309.016 \\
\hline 33 & 160.473 & 439.924 & 969.800 & 2331.849 & 2309.016 \\
\hline 34 & 179.446 & 524.788 & 1017.007 & 2439.290 & 2309.016 \\
\hline 35 & 187.570 & 507.273 & 1054.015 & 2399.761 & 2309.016 \\
\hline 36 & 246.953 & 716.158 & 1084.866 & 2699.796 & 2309.016 \\
\hline 37 & 221.320 & 555.488 & 1107.539 & 2475.509 & 2309.016 \\
\hline 38 & 252.819 & 710.308 & 1107.539 & 3051.701 & 2309.016 \\
\hline 39 & 239.103 & 562.369 & 1107.539 & 2435.845 & 2309.016 \\
\hline 40 & 221.149 & 542.166 & 1107.539 & 2433.277 & 2309.016 \\
\hline 41 & 200.749 & 558.147 & 1107.539 & 2736.206 & 2309.016 \\
\hline 42 & 180.961 & 444.455 & 1104.706 & 2428.511 & 2309.016 \\
\hline 43 & 171.016 & 364.650 & 1032.351 & 3226.720 & 2309.016 \\
\hline 44 & 165.051 & 380.447 & 957.939 & 3289.044 & 2309.016 \\
\hline 45 & 156.935 & 365.533 & 997.857 & 3289.044 & 2309.016 \\
\hline 46 & 278.440 & 453.914 & 1045.658 & 3289.044 & 2309.016 \\
\hline 47 & 345.628 & 600.292 & 1054.015 & 3118.635 & 2309.016 \\
\hline 48 & 354.024 & 775.502 & 1084.866 & 3173.685 & 2309.016 \\
\hline 49 & 354.024 & 840.105 & 1107.539 & 3289.044 & 2309.016 \\
\hline 50 & 347.133 & 831.522 & 1107.539 & 3289.044 & 2309.016 \\
\hline 51 & 337.984 & 787.545 & 1107.539 & 3289.044 & 2309.016 \\
\hline 52 & 326.328 & 731.005 & 1107.539 & 3289.044 & 2309.016 \\
\hline 53 & 288.322 & 682.459 & 1107.539 & 3289.044 & 2309.016 \\
\hline 54 & 252.864 & 636.491 & 1104.706 & 3289.044 & 2309.016 \\
\hline 55 & 239.070 & 600.233 & 1084.128 & 3289.044 & 2309.016 \\
\hline 56 & 247.317 & 556.124 & 1056.060 & 3289.044 & 2309.016 \\
\hline 57 & 289.339 & 520.510 & 1045.658 & 3289.044 & 2309.016 \\
\hline 58 & 340.238 & 617.357 & 1045.658 & 3278.649 & 2309.016 \\
\hline 59 & 232.791 & 694.808 & 1054.015 & 3131.515 & 2309.016 \\
\hline 60 & 321.650 & 836.606 & 1084.866 & 2830.051 & 2309.016 \\
\hline 61 & 247.513 & 766.218 & 1107.539 & 2936.509 & 2309.016 \\
\hline 62 & 354.024 & 805.955 & 1107.539 & 3189.878 & 2309.016 \\
\hline
\end{tabular}




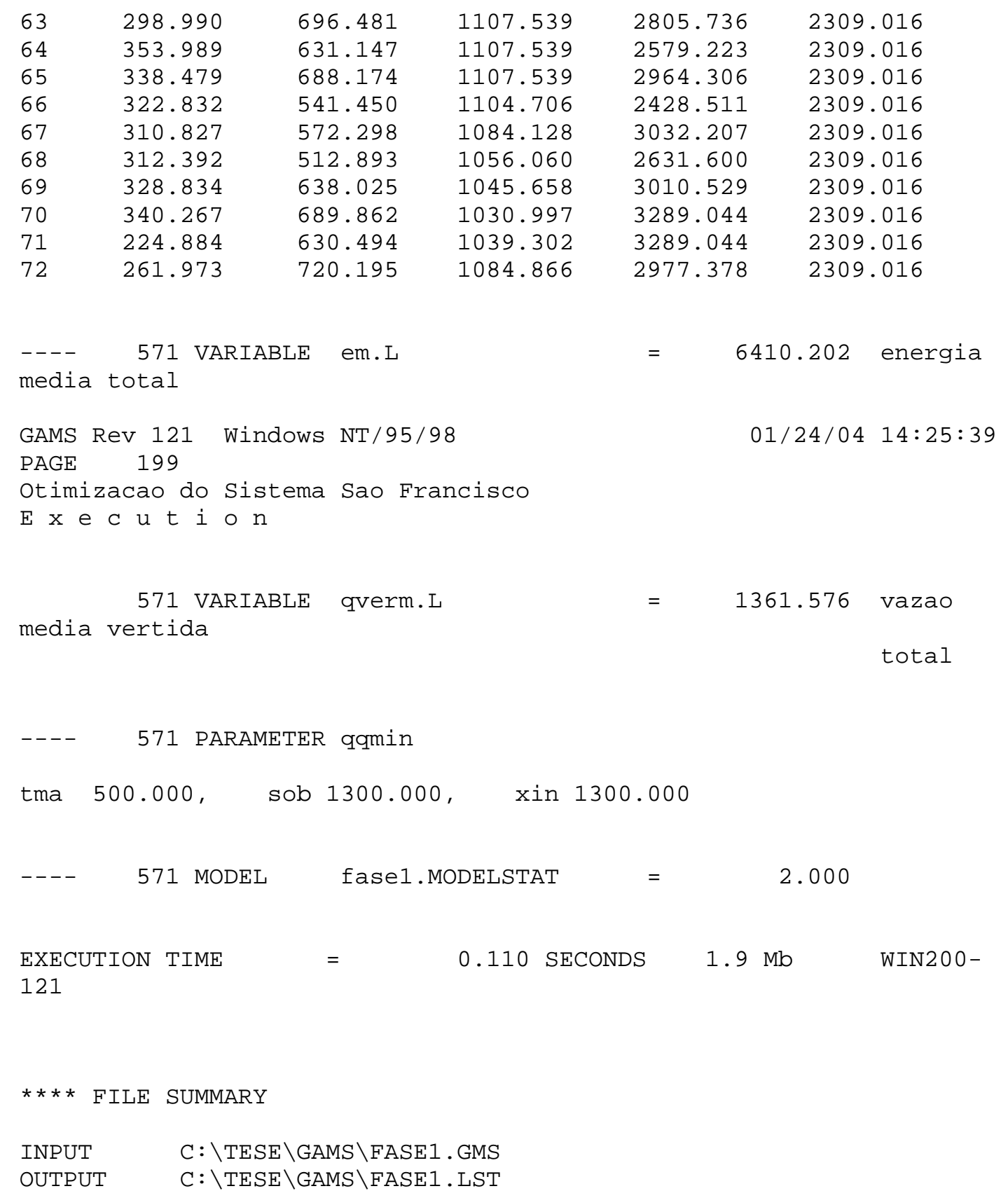




\section{REFERÊNCIAS BIBLIOGRÁFICAS}

ANA, Agência Nacional de Águas. Resolução no. 145, de 22 de Julho de 2002. Brasília: Ana, 2002.

BARROS, M.T.L. Análise de modelos multivariados para geração de séries mensais de vazões. 1984. 207p. Dissertação (Mestrado) - Escola Politécnica, Universidade de São Paulo. São Paulo, 1984.

BARROS, M.T.L. Otimização estocástica implícita de um sistema de reservatórios considerando múltiplos objetivos. 1989. 289p. Tese (Doutorado) - Escola Politécnica, Universidade de São Paulo. São Paulo, 1989.

BARROS, M.T.L. et al. Optimization of large-lcale hydropower systems operations. Journal of Water Resources Planning and Management, v.129, n.3, p178-188, May 2003

BELLMAN, R.; DREYFUS, S. Applied dynamic programming. Princeton: Princeton University Press, 1962.

BOGARDI, J.J.; NACHTNEBEL, H-P. (Ed.). Multicriteria decision analysis in water resources management. Paris: UNESCO, 1994.

BOX, G.E.P.; JENKINS, G. Time series analysis, forecasting and control. San Francisco: Holden-Day, 1976.

BRAGA, B.P.F. et al. Siscom: sistema computadorizado de apoio ao planejamento e operação de sistemas hidroelétricos. Revista Brasileira de Recursos Hídricos, v.3, n.4, p.89-101, 1998.

BRAGA, B.P.F. et al. Stochastic optimization of multiple-reservoir-system operation. Journal of Water Resources Planning and Management, v.117, n.4, p.471-481, Jul.1991.

BROOKE, A. et al. GAMS: A User's Guide. Washington-DC: GAMS Development Corporation, December 1998.

CAMPODÓNICO, N. et al. Modelo SDDP: Manual do Usuário - Versão 7.1. Rio de Janeiro: PSRI, Agosto 2002.

CEPEL, Centro de Pesquisas de Energia Elétrica. Projeto newave - modelo estratégico de geração hidrotérmica a subsistemas equivalentes - manual do usuário - versão 10. Rio de Janeiro: Cepel, Abril 2002a.

CEPEL, Centro de Pesquisas de Energia Elétrica. Determinação da coordenação da operação a curto prazo - manual do usuário - Versão 9.0. Rio de Janeiro: Cepel, Abril 2002b. (Revisão 0) 
CHESF, Cia. Hidro Elétrica do São Francisco. Recife. Demonstrações financeiras de 2002. Disponível em: http://www.chesf.gov.br/financeira. Acesso em: outubro de 2003.

CODEVASF, Cia. de Desenvolvimento dos Vales do São Francisco e do Parnaíba. Brasília. Projetos de irrigação no vale do São Francisco - fonte de desenvolvimento sustentável do nordeste. Disponível em: http://www.codevasf.gov.br/produtos/publicacoes.htm . Acesso em: outubro de 2003

COHON, J.L. Multiobjective programming and planning. New York: Academic Press, 1978.

CONOVER, W.J. Practical nonparametric statistics 2.ed. New York: John Wiley \& Sons, 1980.

CZYZYK, J. et al. PCx user guide (Version 1.1). Optimization Technology Center, November 1997. (Technical Report OTC 96/01)

DAEE, Departamento de Águas e Energia Elétrica, Governo do Estado de São Paulo, Secretaria de Recursos Hídricos, Saneamento e Obras, Conselho Estadual de Recursos Hídricos. Legislação sobre recursos hídricos - outorga e fiscalização. São Paulo: Daee, Julho 2000.

DANDY, G.C.; HASSANLI, A.M. Optimum design and operation of multiple subunit drip irrigation systems. Journal of Irrigation and Drainage Engineering, v.122, n.5, p.265-275, sep./Oct. 1996.

FOURER, R., GAY, D.M., KERNIGHAN, B.W. AMPL: a modeling language for mathematical programming. 2.ed. Pacific Grove: Thomson Brooks/Cole, 2003.

FRANCATO, A.L.; BARBOSA, P.S.F. Fatores determinantes das propriedades operativas ótimas de um sistema hidroelétrico. In: SIMPÓSIO BRASILEIRO DE RECURSOS HÍDRICOS, 12., Vitória, 1997. Anais. Porto Alegre: ABRH, 1997. 1 CD-ROM.

GEORGAKAKOS, A.P.; YAO, H.; YU, Y. A control model for dependable hydropower capacity optimization. Water Resources Research, v.33, n.10, p.2349-2365, Oct. 1997(a).

GEORGAKAKOS, A. P.; YAO, H.; YU, Y. Control models of hydroelectric energy optimization. Water Resources Research, v.33, n.10, p.2367-2379, Oct. 1997(b).

HAIMES, Y.Y.; ALLEE, D.J. (Ed.) Multiobjective analysis in water resources. New York: ASCE, 1982.

HILLIER, F.S.; LIEBERMAN, G.J. Introduction to operations research. New York: McGraw-Hill, 1995. 
JOHNSTON, J. Econometrics methods. New York: McGraw-Hill, 1963.

KARAMOUZ M.; HOUCK, M.H.; DELLEUR J.W. Optimization and simulation of multiple reservoir system. Journal of Water Resources Planning and Management, v.118, n.1, p.71-81, Jan./Feb. 1992.

KELMAN,J. et al. Sampling stochastic dynamic programming applied to reservoir operation. Water Resources Research, v.26, n.3, p.447-454, Mar. 1990.

KELMAN CONSULTORIA. GESS 2001 - generador estocástico de series sintéticas - manual del usuário. Kelman Consultoria Ltda.: Rio de Janeiro, Maio 2001a.

KELMAN CONSULTORIA. GESS 2001 - generador estocástico de series sintéticas - manual de metodología. Kelman Consultoria Ltda.: Rio de Janeiro, Maio 2001b.

KHALIQUZZAMAN; CHANDER, S. Network flow programming model for multireservoir sizing. Journal of Water Resources Planning and Management, v.123, n.1, p.15-22, Jan./Feb. 1997.

LABADIE, J. Combining simulation and optimization in river basin management. In: MARCO, J. et al. (Ed.) Stochastic hydrology and its uses in water resources systems simulation and optimization. Dordrecht: Kluwer Academic Publishers, 1993. p.345-371.

LABADIE, J. Dynamic programming with the microcomputer. In: KENT, A.; WILLIAMS, J. (Ed.) Encyclopedia of microcomputer. New York: Marcel Dekker Inc., 1990. v.5, p.275-337.

LABADIE, J. Reservoir system optimization models. Water Resources Update Journal, Universities Council on Water Resources (UCOWR), Issue107, p83-110, 1998.

LANE, W.L.; FREVERT, D.K. Applied stochastic techniques - LAST personal package computer version 5.2 - user manual. Denver: Bureau of Reclamation/U.S. Department of Interior, October 1990.

LOPES, J.E.G. Otimização de sistemas hidroenergéticos. 2001. 85p. Dissertação (Mestrado) - Escola Politécnica, Universidade de São Paulo. São Paulo, 2001.

LOPES, J.E.G.; BARROS, M.T.L.; BRANDÃO, J.L.B. Projeto de gerenciamento integrado das atividades desenvolvidas em terra na bacia do São Francisco - subprojeto 4.4: determinação de subsídios para procedimentos operacionais dos principais reservatórios da bacia do São Francisco. Brasília: ANA/GEF/PNUMA/OEA, Novembro 2002. 
LOUCKS, D.P.; STEDINGER, J.R.; HAITH, D.A. Water resources planning and analysis. Englewood Cliffs: Prentice-Hall Inc., 1981.

LUND, J.R.; FERREIRA, I. Operating rule optimization for Missouri river reservoir system. Journal of Water Resources Planning and Management, v.122, n.4, p.287-295, Jul./Aug. 1996.

LUND, J.R.; GUZMAN, J. Derived operating rules for reservoir in series or in parallel. Journal of Water Resources Planning and Management, v.125, n.3, p.143-153, May/Jun. 1999.

MAASS, A. et al. Design of water-resource systems. Cambridge: Harvard University Press, 1962.

MACEIRA, M.E.P. Operação ótima de reservatórios com previsão de afluências. 1989. Dissertação (Mestrado) - Coordenação dos Programas de Pós-graduação de Engenharia, Universidade Federal do Rio de Janeiro. Rio de Janeiro, 1989.

MARTIN, Q.W. Optimal reservoir control for hydropower on Colorado river, Texas. Journal of Water Resources Planning and Management, v.121, n.6, p.438-446, Nov./Dec. 1995.

MAYS, L.W. Water resources handbook. New York: McGraw-Hill, 1996.

MURTAGH, B.A.; SAUNDERS, M.A. Minos 5.4 user's guide. Stanford: Systems Optimization Laboratory, Stanford University, February 1995. (Technical Report SOL 83-20R).

OLIVEIRA, R.; LOUCKS, D.P. Operating rules for multireservoir systems. Water Resources Research, v.33, n.4, p.839-852, Apr. 1997.

ONS, Operador Nacional do Sistema Elétrico. Inventário das restrições operativas hidráulicas dos aproveitamentos hidrelétricos. Rio de Janeiro: Ons, Novembro 2002a. (RE 3/332/2002).

ONS, Operador Nacional do Sistema Elétrico. Diretrizes para as regras de operação de controle de cheias: ciclo 2002/2003. Rio de Janeiro: Ons Outubro 2002b. (RE 3/229/2002).

PENG, C-S.; BURAS, N. Dynamic operation of a surface water resources system. Water Resources Research, v. 36, n. 9, p.2701-2709, Sep. 2000.

PEREIRA, M.; CAMPODÓNICO, N.; KELMAN, R. Long term hydro scheduling based on stochastic models. International conference on electrical power systems operation and management - EPSOM'98. Zurich, 1998. Disponível em: http://www.psrinc.com/psr/download/pereira epsom98.pdf. Acesso em: novembro de 2003. 
PHILBRICK Jr., C.R.; KITANIDIS, P.K. Limitations of deterministic optimization applied to reservoir operations. Journal of Water Resources Planning and Management, v.125, n.3, p.135-142, May/Jun. 1999.

PONNAMBALAM, K.; ADAMS, B.J. Stochastic optimization of multireservoir systems using a heuristic algorithm: case study from India. Water Resources Research, v.32, n.3, p.733-741, Mar. 1996.

PORTO, R.L.L.; MELLO, A.V. Sistema generalizado para simulação da transposição da bacia do rio São Francisco para o nordeste setentrional. Brasília: ANA, Setembro 2003.

RAGSDALE, C.T. Spreadsheet modeling and decision analysis. Cincinnati: South-Western College Publishing, 2001.

REIS, L.F.R.; CHAUDHRY, F.H. Caracterização estocástica da resposta ótima de um sistema hidrelétrico via programação dinâmica. In: SIMPÓSIO BRASILEIRO DE RECURSOS HÍDRICOS, 9., Rio de Janeiro, 1991. Anais. São Paulo: ABRH, 1991. v.2., p.357-367.

ROS, D.A. Análise de funções objetivo para otimização da operação de sistemas hidroenergéticos. 2002. 138p. Dissertação (Mestrado) - Escola Politécnica, Universidade de São Paulo. São Paulo, 2002.

SALAS, J.D. Analysis and modeling of hydrologic time series. In: MAIDMENT, D.R. Handbook of hydrology. New York: McGraw-Hill Inc., 1993. p.19.1-19.72

SALAS, J.D. et al. Stochastic analysis, modeling and simulation (SAMS) version 2000, user's manual. Fort Collins: Colorado State University, October 2000. (Technical Report n. 10).

SEIFI, A.; HIPEL, K.W. Interior-point method for reservoir operation with stochastic inflows. Journal of Water Resources Planning and Management, v.127, n.1, p.48-57, Jan./Feb. 2001.

TEJADA-GUILBERT, J.A.; STEDINGER, J.R.; STASCHUS, K. Optimization of value of cvp's hydropower production. Journal of Water Resources Planning and Management, v.116, n.1, p.52-70, Jan. 1990.

VALENCIA, R.D.; SCHAAKE Jr., J.C. Disaggregation processes in stochastic hydrology. Water Resources Research, v.9, n.3, p.580-585, 1973.

VEDULA, S.; KUMAR, D.N. An integrated model for optimal reservoir operation for irrigation of multiple crops. Water Resources Research, v.32, n.4, p.1101-1108, Apr. 1996.

WRIGHT, S. J. Algorithms and software for linear and nonlinear programming. Foundations of Computer-Aided Process Design, CACHE Publications, 1999. 
WURBS, R.A. Reservoir-system simulation and optimization models. Journal of Water Resources Planning and Management, v.119, n.4, p.455-472, Jul./Aug. 1993.

WURBS, R.A. Modeling and analysis of reservoir system operations. Upper Saddle River: Prentice Hall PTR, 1996.

YEH, W.W-G. Reservoir management and operations models: a state-of-the-art review. Water Resources Research, v.21, n.12, p.1797-1818, Dec. 1985. 